January 2002 • NREL/TP-550-31240

\title{
Modular Trough Power Plant Cycle and Systems Analysis
}

Hank Price and Vahab Hassani

Including subcontract reports from:

Barber-Nichols

Exergy, Inc.

Reflective Energies

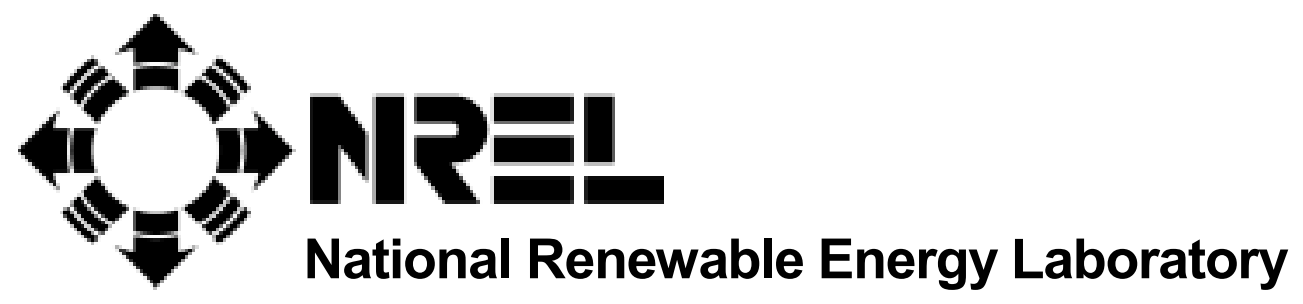

1617 Cole Boulevard

Golden, Colorado 80401-3393

NREL is a U.S. Department of Energy Laboratory

Operated by Midwest Research Institute $\bullet$ Battelle $\bullet$ Bechtel

Contract No. DE-AC36-99-G010337 


\section{Modular Trough Power Plant Cycle and Systems Analysis}

Hank Price and Vahab Hassani

Including subcontract reports from:

Barber-Nichols

Exergy, Inc.

Reflective Energies

Prepared under Task No. CP11.2000

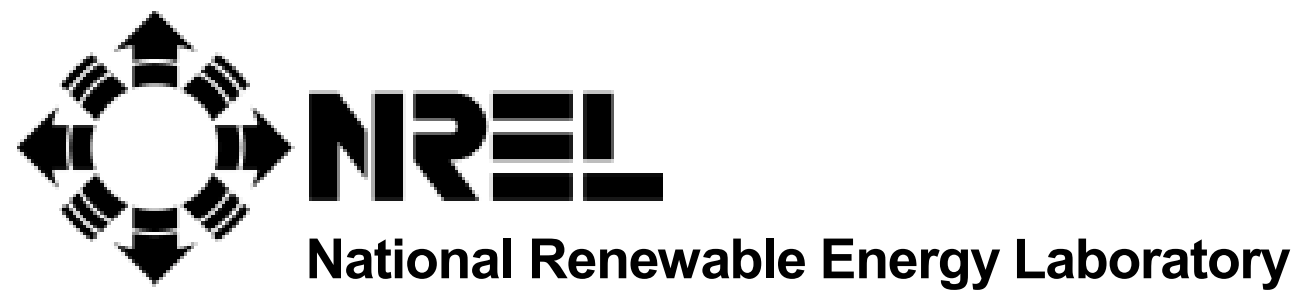

1617 Cole Boulevard

Golden, Colorado 80401-3393

NREL is a U.S. Department of Energy Laboratory

Operated by Midwest Research Institute $\bullet$ Battelle $\bullet$ Bechtel

Contract No. DE-AC36-99-G010337 


\section{NOTICE}

This report was prepared as an account of work sponsored by an agency of the United States government. Neither the United States government nor any agency thereof, nor any of their employees, makes any warranty, express or implied, or assumes any legal liability or responsibility for the accuracy, completeness, or usefulness of any information, apparatus, product, or process disclosed, or represents that its use would not infringe privately owned rights. Reference herein to any specific commercial product, process, or service by trade name, trademark, manufacturer, or otherwise does not necessarily constitute or imply its endorsement, recommendation, or favoring by the United States government or any agency thereof. The views and opinions of authors expressed herein do not necessarily state or reflect those of the United States government or any agency thereof.

Available electronically at http://www.osti.gov/bridge

Available for a processing fee to U.S. Department of Energy

and its contractors, in paper, from:

U.S. Department of Energy

Office of Scientific and Technical Information

P.O. Box 62

Oak Ridge, TN 37831-0062

phone: 865.576.8401

fax: 865.576 .5728

email: reports@adonis.osti.gov

Available for sale to the public, in paper, from:

U.S. Department of Commerce

National Technical Information Service

5285 Port Royal Road

Springfield, VA 22161

phone: 800.553 .6847

fax: 703.605.6900

email: orders@ntis.fedworld.gov

online ordering: http://www.ntis.gov/ordering.htm 


\section{Foreword}

It has been more than 10 years since the last parabolic trough power plant was built. Although parabolic trough steam Rankine cycle power plant technology is the lowest-cost commercial solar electric power technology in the world, in the current market environment it is still more expensive than fossil power technologies. On the other hand, photovoltaic power technology, although several times more expensive than parabolic trough technology, has found high value niche market applications where it can compete successfully on an economic basis. Is it possible that niche markets may also exist for parabolic trough power plant technology?

The modular trough power plant concept integrates modern parabolic solar technology with modern organic Rankine cycle (ORC) power plant technology to create a 1-megawatt-scale solar power plant. This size plant has potential use as customer-side "retail" generation; low-cost green "solar" power; or remote-power, mini-grid applications in developing countries.

This match of technologies was initially tested in the late 1970s in the 150-kWe Coolidge Solar Irrigation Project. Although, the Coolidge system performed significantly below expectations, many on the problems were a direct result of the immature state of both the solar and power plant technologies at the time. Advances in technologies addressed many of the problematic areas of the Coolidge project and made a reassessment of this concept worthwhile. This study looks at the feasibility and potential cost of power from a modular trough power plant.

The study described in this report included the following:

- An optimization of ORC power cycle designs for use with parabolic trough solar collector technology,

- Model development to enable integration solar and power cycles to determine annual performance of systems, and

- An economic assessment of plants and cost of power.

This study concluded that integration of troughs with ORC power cycles is technically feasible with current solar and ORC power cycle technologies. These systems are expected to perform substantially better than the earlier Coolidge system. Some development is still required to fully optimize the solar and power cycle technologies. Several cycles have been considered at this point, and each requires some level of further optimization.

Economic feasibility is more difficult to assess. The cost of power from small trough-ORC plants will be 50 to $100 \%$ higher than large trough plants. However, many of the current incentives that exist in the southwestern United States and Spain could allow economic feasibility of the smaller systems even before large trough systems are built. It seems unlikely that these markets would be sustained if these incentives were terminated. However, remote power applications in developing countries could potentially sustain development in the future.

One issue that remains uncertain is the operation and maintenance $(\mathrm{O} \& \mathrm{M})$ cost. Whether O\&M

costs can be reduced to an acceptable level will likely determine the final economic viability of this concept. In our judgment, based on discussions with the ORC and solar industries, this issue can be resolved.

In our judgment, the trough-ORC system is likely to be the lowest risk and most cost-effective solar technology in the $100-\mathrm{kWe}$ to 10 -MWe range for the near-term and potentially the longterm. 


\section{Table of Contents}

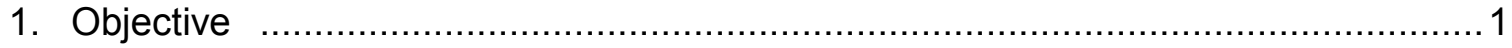

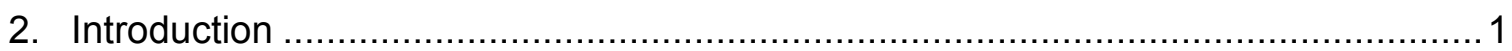

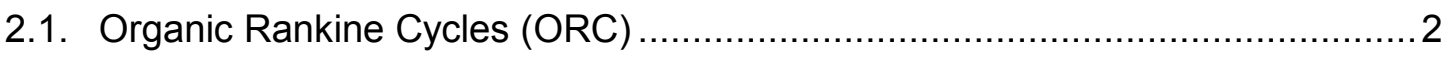

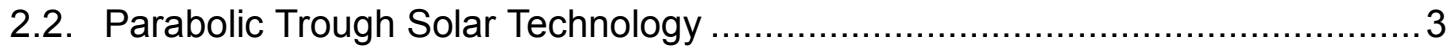

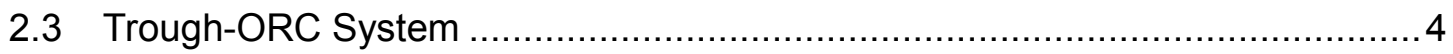

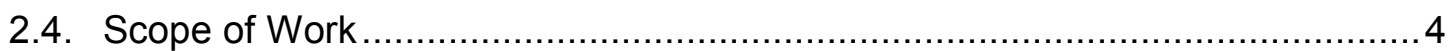

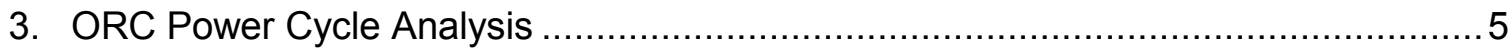

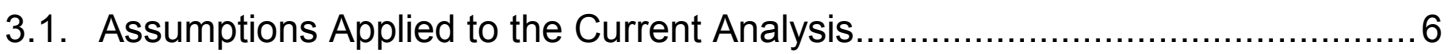

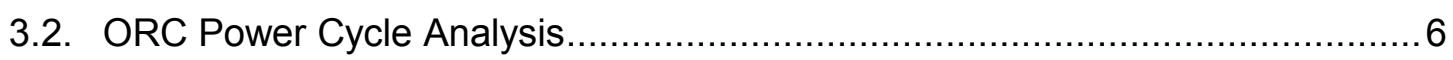

3.2.1 Basic ORC with Pure Hydrocarbons ………….............................

3.2.2 ORC with a Recuperator using Pure Hydrocarbons ............................ 10

3.2.3 ORC with a Recuperator using Mixed Hydrocarbons ...........................13

3.2.4 ORC with Recuperation and Reheat using Pure Hydrocarbons ............. 16

3.2.5 ORC with Recuperation and Reheat using Mixed Hydrocarbons............ 18

3.3 Options for Improving Cycle Efficiency ………...........................................21

3.4 Off-Design (Partial Load) Operation and Its Impact on Performance ..............21

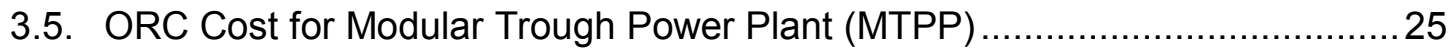

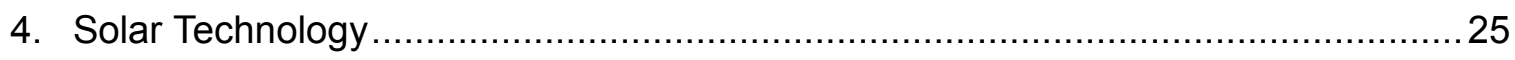

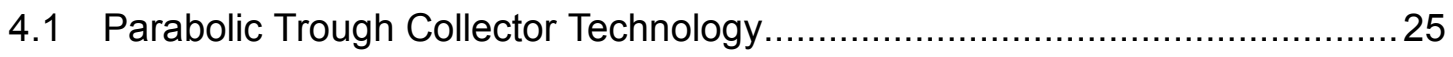

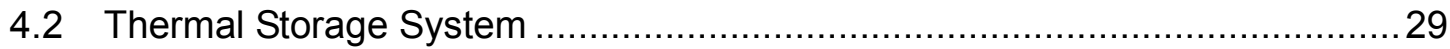

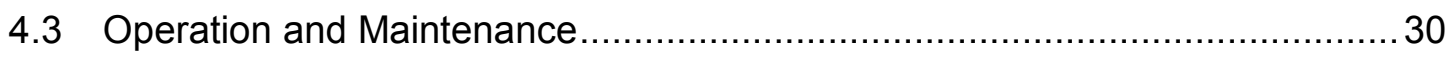

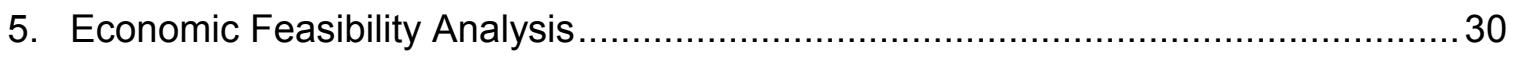

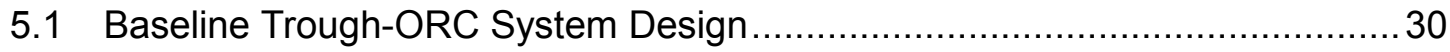

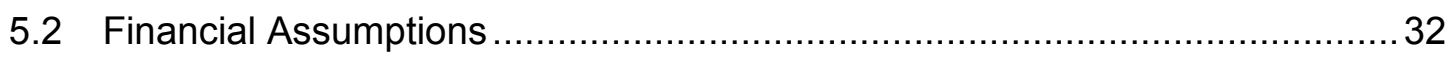

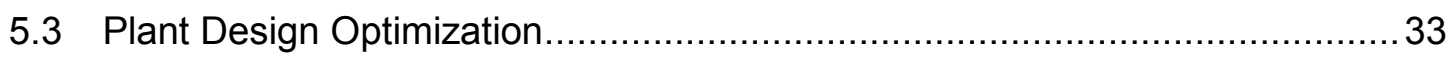

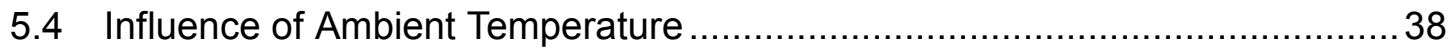

5.5 Influence of Plant Location .................................................................. 40

6. Market Potential for Modular Trough Power Plant Systems ...................................41

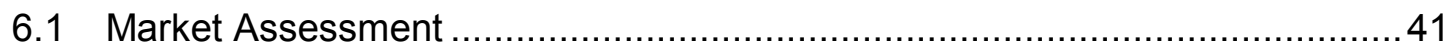

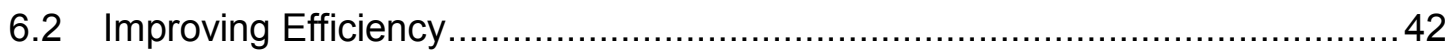

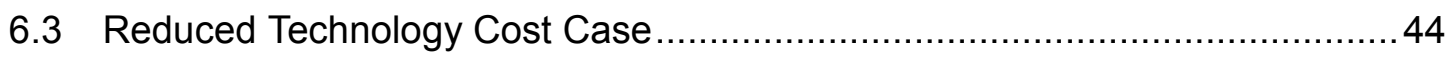

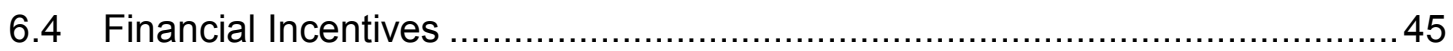

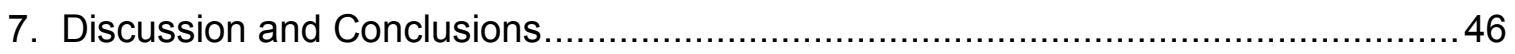

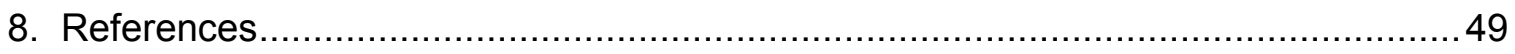

Appendix A. Analysis carried out by Exergy, Inc. ………................................ A-1

Appendix B. Analysis carried out by Reflective Energies ........................................ B-1

Appendix C. Analysis carried out by Barber-Nichols ................................................ C-1 


\section{List of Figures}

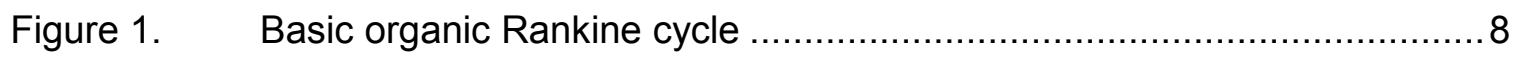

Figure 2. Heating curve for a basic ORC using pure working fluid .......................

Figure 3. Cooling curve for a basic ORC using pure working fluid.........................

Figure 4. Schematic drawing of the basic ORC (software from Aspen Technology, Inc.) ............................................. 10

Figure 5. Organic Rankine cycle with recuperation ........................................ 11

Figure 6. Heating curve for ORC with recuperation with pure fluid ......................12

Figure 7. Cooling curve for ORC with recuperation with pure fluid ......................12

Figure $8 \quad$ Schematic drawing of the ORC with recuperation ..............................13

Figure 9. Heating curve for the mixed working fluid (ic4/c5) ……................... 15

Figure 10. Cooling curve for the mixed working fluid (ic4/c5) ….........................15

Figure 11. Organic Rankine cycle with reheat and recuperation ..........................17

Figure 12. Heating curve for the cycle with reheat and recuperation ...................... 18

Figure 13. Cooling curve for the cycle with reheat and recuperation .....................18

Figure 14. Heating curve for cycle with reheat and recuperation using mixed working fluid ...............................................2 20

Figure 15. Cooling curve for cycle with reheat and recuperation using mixed working fluid .................................................20

Figure 16. Cycle efficiency versus maximum cycle pressure at ambient temperatures of $80^{\circ} \mathrm{F}\left(26.7^{\circ} \mathrm{C}\right)$ and $100^{\circ} \mathrm{F}\left(37.8^{\circ} \mathrm{C}\right)$ for various

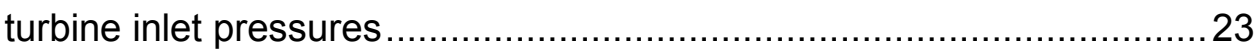

Figure 17. Solar-side fluid outlet temperature versus cycle efficiency …................23

Figure 18. Net cycle power output versus cycle efficiency for $\mathrm{Ta}=80^{\circ} \mathrm{F} \ldots \ldots \ldots \ldots \ldots .24$

Figure 19. Luz System Two (LS-2) parabolic trough collector ..............................26

Figure 20. Sandia parabolic trough collector test results ....................................26

Figure 21. Annual plant capacity factor for 1-MWe trough-ORC plant

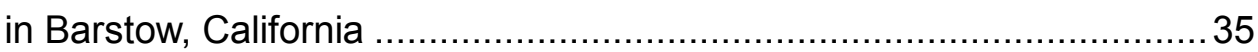

Figure 22. Annual solar to electric efficiency for 1-MWe trough-ORC plant

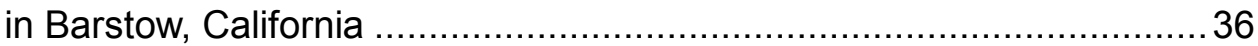

Figure 23. Dumped energy for 1-MWe trough-ORC plant in

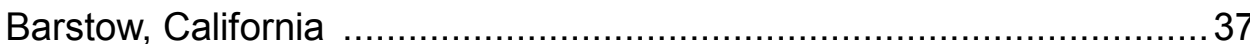

Figure 24. First-year energy price for 1-MWe trough-ORC plant

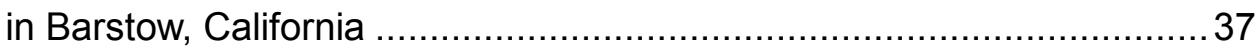

Figure 25. Influence of ambient temperatures on ORC electric output ....................39 


\section{List of Tables}

Table 1. Summary List of Cycles Analyzed in this Report ................................. 6

Table 2. State Points for the Basic ORC with Pure Working Fluid........................ 8

Table 3. State Points for the ORC with Recuperation using Pure

Working Fluid

Table 4. Performance of ORC with Recuperation using Mixed

Working Fluids

Table 5. State Points for the ORC with Recuperation using Mixed

Working Fluid.

Table 6. State Points for the ORC with Reheat and Recuperation

using Pure Working Fluid.....

Table 7. Performance of ORC with Recuperation and Reheat

using Mixed Working Fluids

Table 8. State Points for the ORC with Reheat and Recuperation

using Mixed Working Fluid

Table 9. Cycle Information for Maximum Efficiency Points ...............................22

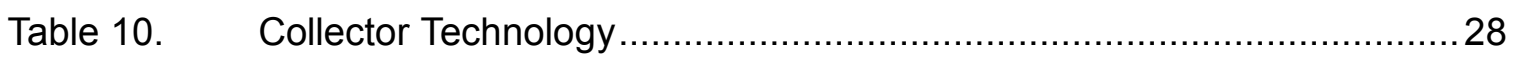

Table 11. Thermal Storage System Cost and Thermal Losses ............................29

Table 12. Design and Cost Assumptions ……………................................... 31

Table 13. Economics and Financing Assumptions ……………........................ 33

Table 14. Solar Field Size for Solar Multiple Cases Evaluated ..............................34

Table 15. Reference Plant Design, Annual Performance, and Economics..............38

Table 16. Influence of Ambient Temperature on Annual Performance ................... 39

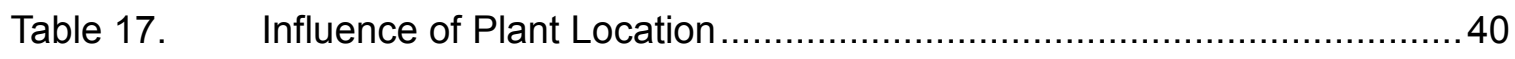

Table 18. Improved Solar Field and Power Plant Efficiency ……..........................4 44

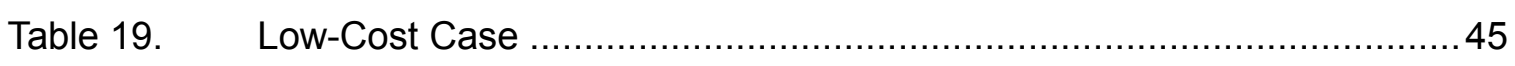

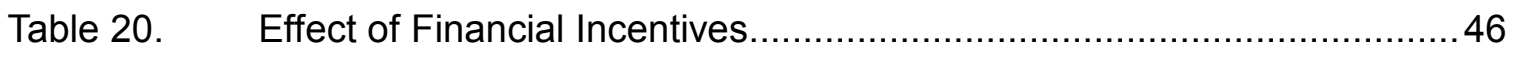




\section{Modular Trough Power Plants Cycle and System Analysis}

\section{Objective}

The objective of this analysis is to reduce the cost of power production from modular concentrating solar power plants through a relatively new and exciting concept that merges two mature technologies to produce distributed modular electric power in the range of 500 to 1,500 $\mathrm{kWe}$. These are the organic Rankine cycle (ORC) power plant and the concentrating solar parabolic (CSP) trough technologies that have been developed independent of each other over many years. Parabolic trough collector technology has been used in large central-station power plants such as the Solar Electric Generating Systems (SEGS) power plants in the California Mojave Desert, which consists of 354 Megawatts (MWe) of installed electric generating capacity. These have been in operation for up to 16 years. ORC air-cooled modular power units have been successfully applied for large- and small-scale geothermal power plants, with more than 600 MWe of capacity, during the same period. The merging of these two technologies to produce distributed modular power plants in the range of 500 to 1500 kilowatt (kWe) offers a new application for both technologies. It is our objective in this report to introduce a modular trough power plant (MTPP) and discuss its performance and the cost of electricity generation from such system.

\section{Introduction}

Several factors are creating an increased market potential for small trough power technology. These include the need for distributed power systems for rural communities worldwide, the need to generate more electricity by non-combustion renewable processes, the need for sustainable power for economic growth in developing countries, and the deregulation and privatization of the electrical generation sector worldwide. Parabolic trough technology has proven to be a very mature solar technology for large-scale power generation. The nine SEGS parabolic trough power plants in the California Mojave Desert consists of 354 MWe of installed electric generating capacity that have been in operation for up to 16 years. The SEGS plants use steam Rankine cycle power plants.

Economic optimization of steam power systems for bulk power applications tends to drive plants to larger and larger sizes. Unfortunately, low energy prices in recent years have slowed the continued development of large-scale trough power plants for bulk power markets. Higher value market opportunities for trough solar power plants include smaller distributed generation and remote power applications. Distributed generation has higher value than centralized power generation because it can eliminate power losses in the transmission and distribution (T\&D) system, improve system reliability, and occasionally offset the need for upgrades to the T\&D system. Distributed generation located at a customer site often offsets energy costs at the customer's retail price rather than the utility's price for bulk generation. Remote power applications are typically of high value because of high fuel prices and low conversion efficiencies.

Diesel generators or photovoltaics are often the competition for remote power applications. In addition, a number of green power markets are developing where customers either choose or are obligated to purchase renewable electric power. Unfortunately, the green power market has not matured to the point where it will support the development of large solar power plants. This 
report looks at the opportunity for developing smaller trough power plants that might be suitable for distributed, remote, or green power markets. Because of the inherent problems (complexity and operational issues) with steam cycle power plants at smaller sizes, this report focuses on systems that integrate troughs into ORC power plants.

The Coolidge Solar Irrigation Project (Larson, 1983) demonstrated a 150-kWe trough-ORC solar power plant. This plant operated successfully for several years, but suffered from a number of problems that at the time precluded further development of this concept. The main problems were low collector performance, high operation and maintenance (O\&M) costs (mainly due to the problems associated with the cooling tower), and a low annual output.

Given the significant improvements in solar and ORC technologies since the 1980s, a reassessment of the technology is warranted.

This report explores the performance of MTPP in the size range of about 1 MWe. The MTPP will use the ORC power plant technology with dry cooling, which has been applied to geothermal power plants over the past 20 years. The MTPP combines the field-proven technologies of the ORC power unit and the CSP troughs with thermal storage systems under development at SunLab (a virtual laboratory collaboration consisting of the National Renewable Energy Laboratory [NREL] and Sandia National Laboratory). The MTPP system will produce costeffective power and have wide applications for distributed power.

The MTPP concept will be the first of its kind to explore small-scale nighttime generation with stored solar energy. This technology will be the first of its kind to produce electricity from trough systems with automated, virtually unattended operation. The MTPP concept will make it possible to produce electricity from solar trough systems in the range of $\$ 0.1$ to $\$ 0.15$ per kilowatt-hour $(\mathrm{kWh})$, as opposed to other solar technologies at $\$ 0.30 / \mathrm{kWh}$.

It is, therefore, NREL's objective to analyze the performance of a base-line MTPP and provide operating, as well as economic, data for a first-of-a-kind MTPP. This report provides such information.

\subsection{Organic Rankine Cycles (ORC)}

ORC power cycles are primarily used for lower temperature heat sources, such as geothermal or waste-heat recovery. The low resource temperature results in low efficiency of the ORCs; however, ORCs can be designed to operate at substantially higher efficiencies for trough systems. Hundreds of megawatts of ORC power systems have been installed around the world. ORCs use organic (hydrocarbon) fluids that can be selected to best match the heat source and heat sink temperatures. They can use air-cooling instead of the evaporative wet cooling typically used at steam Rankine cycle plants. The hydrocarbon working fluids function like steam in the steam Rankine cycles. However, the ORC fluids are generally used at lower pressures. For safety reasons these fluids are condensed at above-atmospheric pressures. These factors greatly reduce the complexity and cost of ORC systems. In addition, smaller ORC systems can generally be run remotely, and they only periodically need on-site operator or maintenance intervention.

The following are the primary advantages of an ORC power cycle for applications with troughs. First, ORCs operate at lower temperatures; thus, we can reduce the trough's operating temperatures from $735^{\circ} \mathrm{F}\left(390^{\circ} \mathrm{C}\right)$ to $580^{\circ} \mathrm{F}\left(304^{\circ} \mathrm{C}\right)$. This means that an inexpensive heat transfer fluid such as Caloria may be used instead of the existing fluid. Since Caloria is inexpensive, it 
can be used in a simple two-tank thermal storage system similar to the thermal storage system at SEGS I. At lower operating temperatures, these plants are ideal for U.S.-supplied non-evacuated receiver tubes. Lower solar field-operating temperatures are likely to translate into lower capital cost and more efficient solar field equipment.

Second, ORCs can be designed to use air-cooling for the power cycle. This, and the fact that the power cycle uses a hydrocarbon for a working fluid (instead of steam), means that the plant needs virtually no water to operate. Mirror washing accounts for about $1.5 \%$ of the water use at the SEGS. Therefore, the plants can be built in desert locations that have limited water availability.

Third, ORC power cycles are simple and generally can be operated remotely, without licensed operators, allowing for increased use of self-diagnostics. This reduces O\&M costs, which has been one of the key reasons for CSP technologies to increase in size. The MTPP technology supports integration of modular systems that use standardized designs and prefabrication. The modular nature of these systems simplifies site requirements, minimizes on-site erection, and provides the possibility of prepackaging collector and cycle hardware. In addition, materials can be shipped to the site in containers.

Finally, it should be pointed out that ORC systems have a number of disadvantages as well. ORC systems generally have lower efficiencies than steam cycles that run at higher temperatures and pressures. However, the efficient steam cycles (approximately at 35\% net) come at the price of more capital investment and the need for higher resource temperatures. The use of air-cooling means that ORC cycles are negatively impacted by high ambient temperatures.

\subsection{Parabolic Trough Solar Technology}

Parabolic trough solar technology is the most-verified solar technology through deployment and construction testing. It is the lowest-cost high-temperature solar collector technology available today. This is primarily due to nine large commercial-scale parabolic trough solar power plants developed by Luz International Limited, which are operating in the California Mojave Desert. These plants, referred to as Solar Electric Generating Systems (SEGS), range in size from 14 MWe to 80 MWe and represent 354 MWE of installed electric generating capacity. By the end of the year 2001, these plants will have accumulated 127 years of operational experience. These plants have more than $2,000,000 \mathrm{~m}^{2}$ of parabolic trough collector technology that have been in daily operation for up to 18 years. The Luz parabolic trough collector technology has demonstrated its ability to operate in a commercial power-plant environment. Although no new plants have been built since 1990, continuing effort by the operators of the SEGS plants, the parabolic trough industry, and solar research laboratories around the world has led to significant advancements in collector and plant design.

Parabolic trough collectors capable of generating temperatures higher than $260^{\circ} \mathrm{C}$ were initially developed for industrial process heat (IPH) applications, but were later adapted for use in power plant applications operating up to temperatures of about $400^{\circ} \mathrm{C}$. Parabolic-trough power plants consist of large fields of parabolic trough collectors, a heat-transfer fluid/steam-generation system, a Rankine steam turbine/generator cycle, and optional thermal storage or fossil-fired backup systems. The collector field consists of a large field of single-axis tracking parabolic trough solar collectors. The solar field is modular in nature and is composed of many parallel rows of solar collectors, normally aligned on a north-south horizontal axis. Each solar collector has a linear parabolic-shaped reflector that focuses the sun's direct beam radiation on a linear 
receiver at the focus of the parabola. The collectors track the sun from east to west during the day to ensure that the sun is continuously focused on the linear receiver. A heat transfer fluid (HTF) is heated as high as $393^{\circ} \mathrm{C}$ as it circulates through the receiver and returns to a series of heat exchangers in the power block, where the fluid is used to generate high-pressure superheated steam $\left(100 \mathrm{bar}, 371^{\circ} \mathrm{C}\right)$. The superheated steam is then fed to a conventional reheat Rankine steam turbine/generator to produce electricity. The spent steam from the turbine is condensed in a standard condenser and returned to the heat exchangers via condensate and feedwater pumps to be transformed back into steam. Condenser cooling is provided by mechanical draft wet cooling towers. After passing through the HTF side of the solar heat exchangers, the cooled HTF is recirculated through the solar field. The existing parabolic trough plants have been designed to use solar energy as the primary energy source to produce electricity. The plants can operate at full rated power using solar energy alone given sufficient solar input. During summer months, the plants typically operate for 10-12 hours a day on solar energy at full-rated electric output.

Thermal storage can also be integrated into the plant design to allow solar energy to be stored and dispatched when power is required. This also allows the solar field to be oversized to allow the plant to generate power for more hours during the day. Thermal storage has been demonstrated commercially for solar field operating temperatures near $300^{\circ} \mathrm{C}$ at SEGS I. Thermal storage has not been demonstrated for plants operating at $393^{\circ} \mathrm{C}$ and is expected to be expensive.

\subsection{Trough-ORC System}

Given the potential advantages that an ORC power plant could offer, we evaluated the performance of a 1-MWe trough power system based on current solar and ORC technologies. General design constraints included the use of dry cooling and the use of Caloria heat-transfer fluid to allow the integration of thermal storage for power generation during periods with no or low solar radiation. Economies-of-scale can be improved through the development of standardized designs and modular systems. Solar technology has the advantage that the solar field can be sized and designed to meet the requirements of the local solar resource while the power plant design remains unchanged. This reduces the initial design cost and allows for mass production of the power cycle components, specifically the turbine.

The goal of the trough-ORC power system will be to create an automated and virtually unattended trough power plant. This concept blends two field-proven technologies into a new solar power system with potential markets in the United States for distributed power, off-grid or grid-connected, and for rural electrification applications in developing countries.

\subsection{Scope of Work}

The current CSP cycle reflects the power-cycle technology that existed in the 1970s. The basic Rankine cycle using high-pressure steam is the cycle used for generating power. Even though the basic Rankine cycle is fundamentally the same, there have been several advances in component design and development that have resulted in more efficient turbines and condensers. During the past decade, some new thermodynamic cycles have been also developed that show a better resource utilization compared to the existing cycles. These new cycles, which use pure or mixed working fluids, have higher second-law efficiency and resource utilization factor. Therefore, it is the objective of this work to analyze the performance of new cycles and consider potential improvements that will result in higher cycle performance or resource utilization and lower cost of electricity generation. 
To achieve the objectives of this work, NREL conducted in-house research using commercially available software from Aspen Technology, Inc. (Cambridge, Massachusetts), while seeking the technical support of three U.S. private companies. These companies-Reflective Energies; Exergy, Inc.; and Barber-Nichols (see Appendices) - assisted in carrying out analysis of potential cycles to be used in conjunction with the CSP Trough system. The focus of this activity was to analyze potential binary cycles (with different working fluids or mixed working fluids) that may out-perform the existing cycle in terms of cost and efficiency.

In this work, the performance of the power cycles with resource temperatures of $735^{\circ} \mathrm{F}$ and $580^{\circ} \mathrm{F}$ were considered. However, this report only presents the results for the $580^{\circ} \mathrm{F}$ resource. The main reason for not including the studies for the $735^{\circ} \mathrm{F}$ resource was that our task was not independently verified by any group of researchers other than NREL. An addendum to this report presenting the results for the $735^{\circ} \mathrm{F}$ resource will be available in the future, following an industry group verification. In the following sections each of the above activities will be described in detail.

\section{ORC Power Cycle Analysis}

Organic Rankine power cycles are typically used for applications with low resource temperatures, such as waste heat recovery or geothermal applications. In these cases, the objective is to get the most specific power possible from a particular thermal resource, while preventing the resource from depleting. These are, in essence, once-through systems where you use the energy or lose it. However, in solar applications the goal is to develop the most efficient solar and power plant systems while trading off the capital and O\&M cost of various components. Since ORC power cycle efficiency tends to be a stronger function of temperature than trough solar fields, the optimum-ORC system will likely have a high average solar resource temperature.

The ORC analysis presented here utilizes a solar resource temperature of $580^{\circ} \mathrm{F}\left(304^{\circ} \mathrm{C}\right)$. This corresponds to the reasonable safe upper operating limit of Caloria. Using this as a boundary condition, an analysis of potential ORC configurations was conducted using commercially available thermal-process modeling software from Aspen Technology, Inc. Three ORC cycles were analyzed in this work: a simple Rankine cycle, a Rankine cycle with recuperation, and a simple Rankine cycle with reheat and recuperation. Pentane and a combination of mixed working fluids were used as the working fluid for these cycles because they provided the best match for the resource temperature, while allowing above-atmospheric pressure in the condenser. These cycles and their corresponding performance information are listed in Table 1.

Some of the above cycles, plus some additional cycles, were also analyzed by Barber-Nichols; Reflective Energies; and Exergy, Inc. (see appendices). Cycles that have been analyzed by these organizations are presented in the appendices. In comparing the performance of the cycles presented in the main body of this report and those in the appendices, it is important to note that all the assumptions such as turbine efficiency, pump efficiency, heat exchanger pinch points, etc., are not necessarily the same. Therefore, when comparing the performance of these cycles, one needs to use his or her judgement in making proper adjustments to the results. The main assumptions used for all the following analysis are the resource and sink temperatures: $580^{\circ} \mathrm{F}$ for the resource (this corresponds to the reasonable safe upper operating limit of Caloria) and $80^{\circ} \mathrm{F}$ for the sink. More specific assumptions used for each analysis are listed in appropriate sections in which those cycles have been described. 
Table 1. Summary List of Cycles Analyzed in this Report

\begin{tabular}{|c|c|c|c|c|c|c|}
\hline Cycle Type & Efficiency & $\begin{array}{c}\text { Gross } \\
\text { Electricity } \\
(\mathbf{k W e})\end{array}$ & $\begin{array}{c}\text { Parasitic } \\
(\mathrm{kWe})\end{array}$ & $\begin{array}{c}\text { HTF } \\
\text { Flow } \\
\text { (lbm/hr) }\end{array}$ & $\begin{array}{c}\text { HTF } \\
\text { Outlet } \\
\text { Temp. } \\
\left({ }^{\circ} \mathrm{F}\right)\end{array}$ & $\begin{array}{l}\text { Working } \\
\text { fluid }\end{array}$ \\
\hline $\begin{array}{l}\text { Basic ORC } \\
\text { /pure working } \\
\text { fluid }\end{array}$ & 12.5 & 1,093 & 116 & 92,141 & 182 & Pentane \\
\hline $\begin{array}{l}\text { ORC } \\
\text { recuperation } \\
\text { with pure } \\
\text { working fluid }\end{array}$ & 20.1 & 1,102 & 120 & 92,018 & 344 & Pentane \\
\hline $\begin{array}{l}\text { ORC } \\
\text { recuperation } \\
\text { with mixed } \\
\text { working fluid }\end{array}$ & 20.4 & 1,134 & 130 & 91,065 & 337 & $\begin{array}{l}\text { Pentane/ } \\
\text { iso- } \\
\text { butane } \\
(90 / 10)\end{array}$ \\
\hline $\begin{array}{l}\text { ORC } \\
\text { recuperation } \\
\text { with reheat } \\
\text { pure working } \\
\text { fluid }\end{array}$ & 20.6 & 1,140 & 120 & 129,829 & 413 & Pentane \\
\hline $\begin{array}{l}\text { ORC } \\
\text { recuperation } \\
\text { with reheat } \\
\text { mixed } \\
\text { working fluid }\end{array}$ & 20.7 & 1,157 & 124 & 129,026 & 410 & $\begin{array}{l}\text { Pentane/ } \\
\text { iso- } \\
\text { butane } \\
(95 / 5)\end{array}$ \\
\hline
\end{tabular}

\subsection{Assumptions Applied to the Current Analysis}

All the cycles were analyzed by NREL staff under the following conditions: solar resource (hot Heat Transfer Fluid $[\mathrm{HTF}])$, temperature $580^{\circ} \mathrm{F}\left(304^{\circ} \mathrm{C}\right)$, boiler pressure 610 psia $(4.2 \mathrm{MPa})$, turbine inlet pressure $600 \mathrm{psia}(4.14 \mathrm{MPa})$, condenser pressure 20 psia $(0.138 \mathrm{MPa})$, ambient temperature of $80^{\circ} \mathrm{F}\left(26.7^{\circ} \mathrm{C}\right)$, turbine efficiency of 0.75 , pump efficiency of 0.67 , generator efficiency 0.94 , and recuperator effectiveness of 0.80 . A pinch point of $17^{\circ} \mathrm{F}\left(9.4^{\circ} \mathrm{C}\right)$ was assumed for the heater/boiler, while the pinch point for the air cooler/condenser was assumed to be $13^{\circ} \mathrm{F}\left(7 \cdot 2^{\circ} \mathrm{C}\right)$.

\subsection{ORC Power Cycle Analysis}

We identified the following potential binary cycles for application to the solar trough systems: the basic ORC using hydrocarbons as working fluid, ORC with recuperation using pure hydrocarbons, ORC with recuperation using mixed hydrocarbons, ORC with recuperation and reheat using pure hydrocarbons, ORC with recuperation and reheat using mixed hydrocarbons, 
Kalina cycle using ammonia/water mixtures as working fluid, and two-tier ORC proposed by Reflective Energies. NREL's analysis of the ORC cycles are presented in the following sections. The analysis of Exergy (Appendix A) for their proposed Kalina cycle and the two-tier cycle proposed by Reflective Energies are presented in the appendices.

Our analysis of potential ORC configurations was conducted using the commercially available thermal-process modeling software (from Aspen Technology, Inc.) These cycles and their corresponding performance information are listed in Table 1.

\subsubsection{Basic ORC with Pure Hydrocarbons}

The basic ORC analyzed in this work is shown in Figure 1. The resource entered the heat exchanger at $580^{\circ} \mathrm{F}\left(304^{\circ} \mathrm{C}\right)$, and its exit temperature was $181^{\circ} \mathrm{F}\left(82.7^{\circ} \mathrm{C}\right)$. The working fluid, Pentane, was pumped from a pressure of $20 \mathrm{psia}(0.138 \mathrm{MPa})$ at $114^{\circ} \mathrm{F}\left(45.6^{\circ} \mathrm{C}\right)$ (saturated liquid conditions) to a pressure of $610 \mathrm{psia}(4.2 \mathrm{MPa})$. The working fluid was then passed through the main heat exchanger, where it was heated and boiled by the oil from the solar field to a temperature of $563^{\circ} \mathrm{F}\left(295^{\circ} \mathrm{C}\right)$. The vapor exiting the boiler at 600 psia $(4.14 \mathrm{MPa})$ (a pressure drop of 10 psia was assumed for the boiler) was then passed through a turbine and was allowed to expand to $24 \mathrm{psia}(0.165 \mathrm{MPa})$. The stream exiting the turbine was sent through an air-cooled condenser, where the working fluid was completely condensed. The efficiency of this cycle, including the fan power for the air cooler and the pump power, is $12.5 \%$. A total pressure drop of 2 psia $(13.8 \mathrm{kPa})$ was assumed for the air-cooled condenser. The heating and cooling curves for this cycle are presented in Figures 2 and 3. Figure 3 shows the source of inefficiency of this cycle. The vapor leaving the turbine is at a very high temperature of $433^{\circ} \mathrm{F}\left(223^{\circ} \mathrm{C}\right)$. In this case, the turbine exhaust is directly sent through a condenser with no attempt to recuperate any heat from this stream. Therefore, a significant amount of heat transferred to the working fluid from solar field is being rejected with no utilization. Our analysis in the next section will take advantage of recuperating heat from the stream exiting the turbine. The schematic of this cycle using software from Aspen Technology, Inc., is shown in Figure 4, and the state points corresponding to this cycle have been listed in Table 2. Note that a conservative condensing pressure of 20 psia was chosen for this analysis. It is possible to condense this working fluid at pressures as low as 15 psia; however, an above-atmospheric condensing pressure is very desirable for this cycle. 


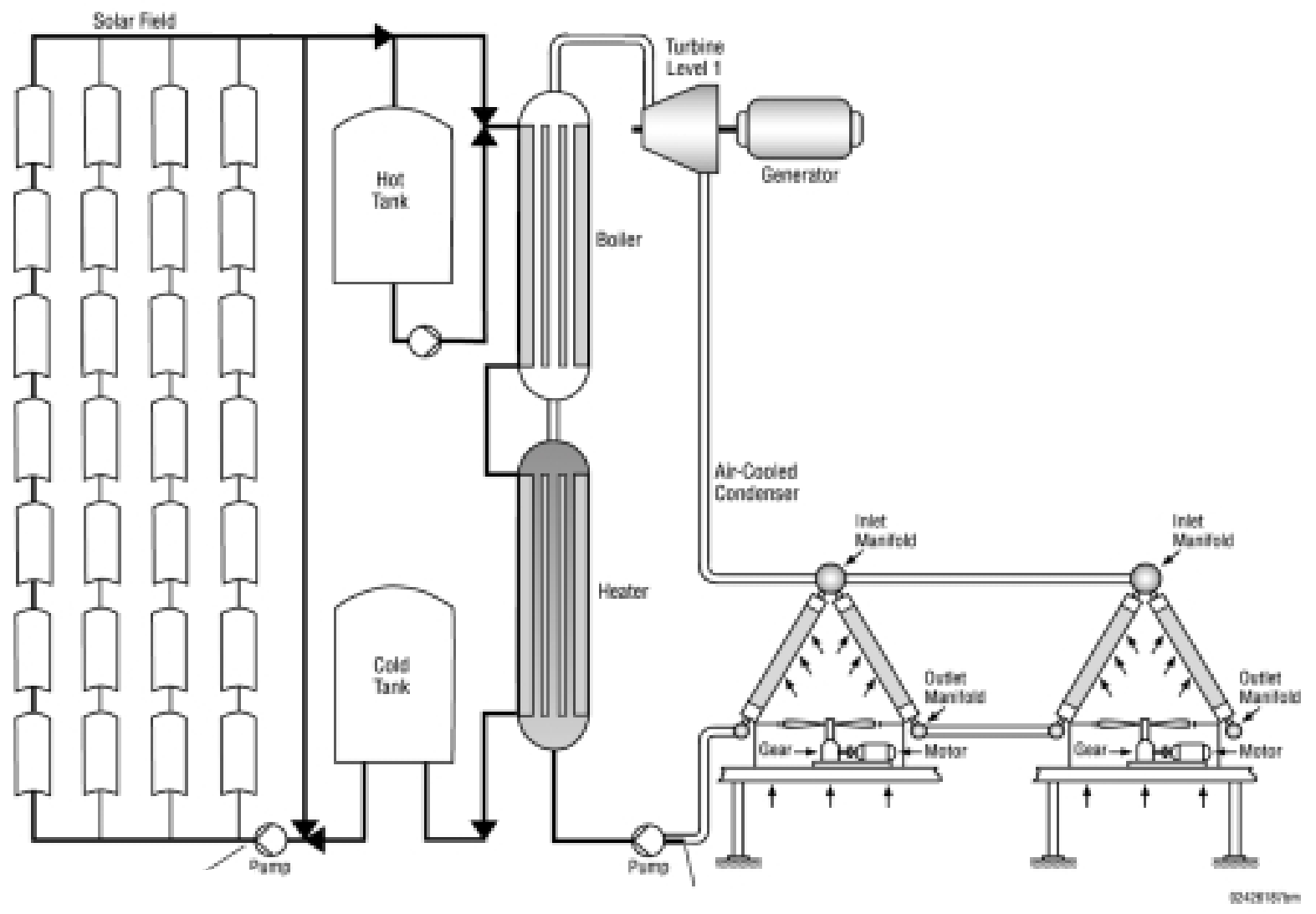

Figure 1. Basic organic Rankine cycle

Table 2. State Points for the Basic ORC with Pure Working Fluid

\begin{tabular}{|c|c|c|c|c|c|c|c|c|c|c|}
\hline & ACC-IN & ACC-OUT & AIR-IN & AIR-IN1 & AIR-OUT & LIQ-1 & LIQ-3 & SF-IN & SF-OUT & VAP-1 \\
\hline Temperature F & $4.33 \mathrm{E}+02$ & $1.14 \mathrm{E}+02$ & $8.00 \mathrm{E}+01$ & $8.03 \mathrm{E}+01$ & $1.34 \mathrm{E}+02$ & $1.14 \mathrm{E}+02$ & $1.20 \mathrm{E}+02$ & $5.80 \mathrm{E}+02$ & $1.82 \mathrm{E}+02$ & $5.63 \mathrm{E}+02$ \\
\hline Pressure psi & $2.40 \mathrm{E}+01$ & $2.00 \mathrm{E}+01$ & $1.47 \mathrm{E}+01$ & $1.47 \mathrm{E}+01$ & $1.47 \mathrm{E}+01$ & $2.00 \mathrm{E}+01$ & $6.10 \mathrm{E}+02$ & $5.00 \mathrm{E}+03$ & $5.00 \mathrm{E}+03$ & $6.00 \mathrm{E}+02$ \\
\hline Vapor Frac & $1.00 \mathrm{E}+00$ & $0.00 \mathrm{E}+00$ & $1.00 \mathrm{E}+00$ & $1.00 \mathrm{E}+00$ & $1.00 \mathrm{E}+00$ & $0.00 \mathrm{E}+00$ & $0.00 \mathrm{E}+00$ & $0.00 \mathrm{E}+00$ & $0.00 \mathrm{E}+00$ & $1.00 \mathrm{E}+00$ \\
\hline Mole Flow $\mathrm{lbmol} / \mathrm{hr}$ & $9.08 \mathrm{E}+02$ & $9.08 \mathrm{E}+02$ & $5.59 \mathrm{E}+04$ & $5.59 \mathrm{E}+04$ & $5.59 \mathrm{E}+04$ & $9.08 \mathrm{E}+02$ & $9.08 \mathrm{E}+02$ & $7.18 \mathrm{E}+02$ & $7.18 \mathrm{E}+02$ & $9.08 \mathrm{E}+02$ \\
\hline Mass Flow $\mathrm{lb} / \mathrm{hr}$ & $6.55 \mathrm{E}+04$ & $6.55 \mathrm{E}+04$ & $1.62 \mathrm{E}+06$ & $1.62 \mathrm{E}+06$ & $1.62 \mathrm{E}+06$ & $6.55 \mathrm{E}+04$ & $6.55 \mathrm{E}+04$ & $9.21 \mathrm{E}+04$ & $9.21 E+04$ & $6.55 \mathrm{E}+04$ \\
\hline Volume Flow cuft/hr & $3.57 \mathrm{E}+05$ & $1.75 \mathrm{E}+03$ & $2.20 \mathrm{E}+07$ & $2.20 \mathrm{E}+07$ & $2.42 \mathrm{E}+07$ & $1.75 \mathrm{E}+03$ & $1.76 \mathrm{E}+03$ & $3.88 \mathrm{E}+03$ & $2.23 \mathrm{E}+03$ & $1.30 \mathrm{E}+04$ \\
\hline $\begin{array}{l}\text { Enthalpy } \mathrm{MMBtu} / \mathrm{hr} \\
\text { Mass Flow } \mathrm{lb} / \mathrm{hr}\end{array}$ & $-4.57 \mathrm{E}+01$ & $-6.65 E+01$ & $1.16 \mathrm{E}+00$ & $1.27 \mathrm{E}+00$ & $2.21 \mathrm{E}+01$ & $-6.65 \mathrm{E}+01$ & $-6.62 \mathrm{E}+01$ & $-5.38 \mathrm{E}+01$ & $-7.81 E+01$ & $-4.19 \mathrm{E}+01$ \\
\hline AIR & $0.00 \mathrm{E}+00$ & $0.00 \mathrm{E}+00$ & $1.62 \mathrm{E}+06$ & $1.62 \mathrm{E}+06$ & $1.62 \mathrm{E}+06$ & $0.00 \mathrm{E}+00$ & $0.00 \mathrm{E}+00$ & $0.00 \mathrm{E}+00$ & $0.00 \mathrm{E}+00$ & $0.00 \mathrm{E}+00$ \\
\hline OIL & $0.00 \mathrm{E}+00$ & $0.00 \mathrm{E}+00$ & $0.00 \mathrm{E}+00$ & $0.00 \mathrm{E}+00$ & $0.00 \mathrm{E}+00$ & $0.00 \mathrm{E}+00$ & $0.00 \mathrm{E}+00$ & $9.21 \mathrm{E}+04$ & $9.21 \mathrm{E}+04$ & $0.00 \mathrm{E}+00$ \\
\hline N-PEN-01 & $6.55 \mathrm{E}+04$ & $6.55 \mathrm{E}+04$ & $0.00 \mathrm{E}+00$ & $0.00 \mathrm{E}+00$ & $0.00 \mathrm{E}+00$ & $6.55 \mathrm{E}+04$ & $6.55 \mathrm{E}+04$ & $0.00 \mathrm{E}+00$ & $0.00 \mathrm{E}+00$ & $6.55 \mathrm{E}+04$ \\
\hline
\end{tabular}




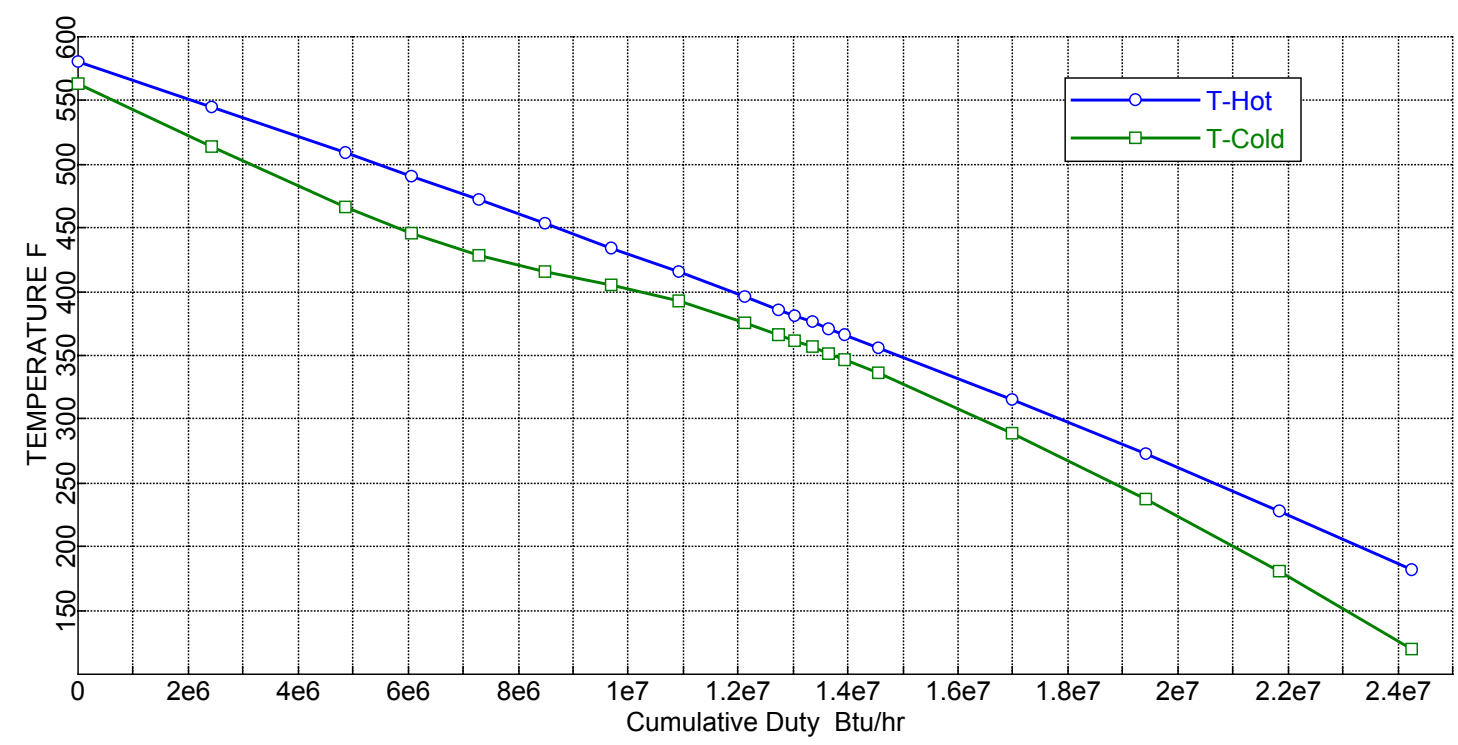

Figure 2. Heating curve for a basic ORC using pure working fluid

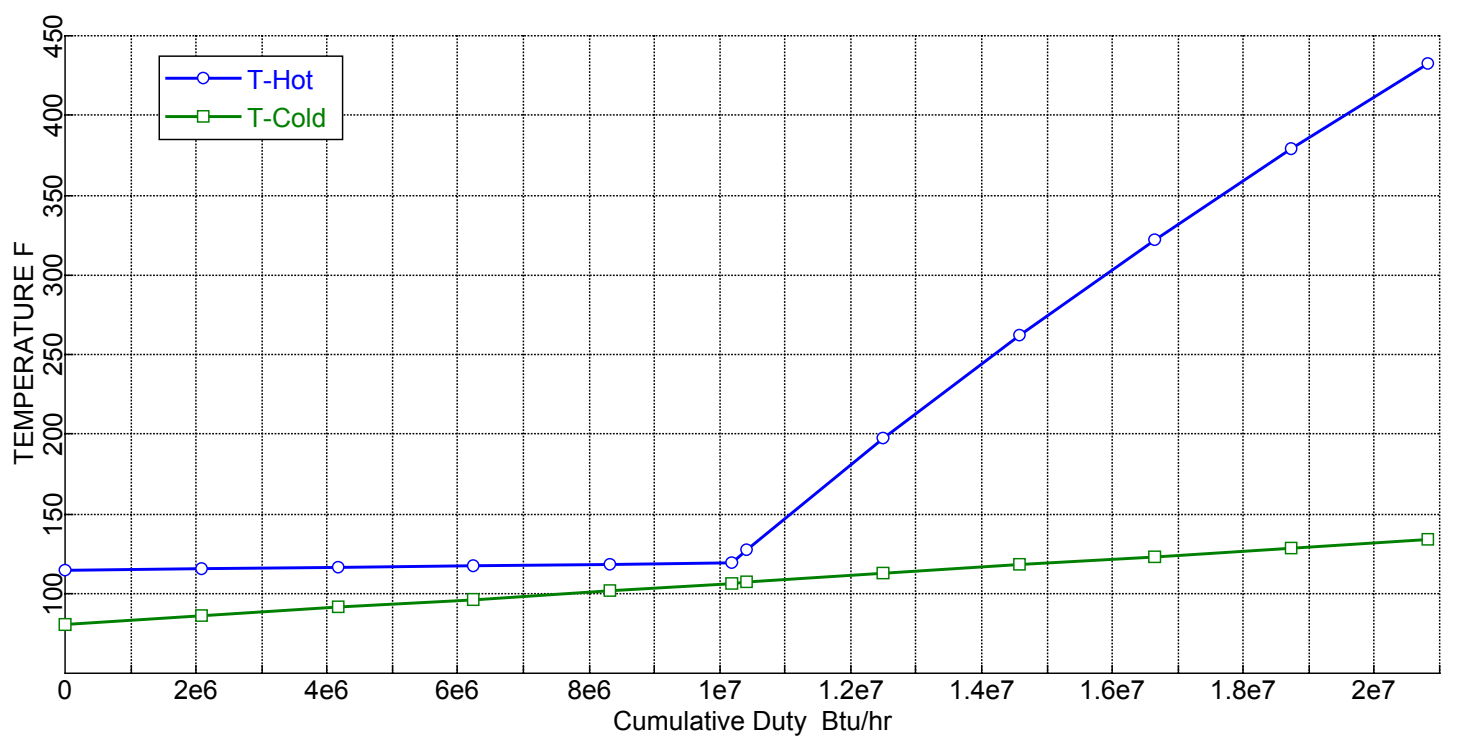

Figure 3. Cooling curve for a basic ORC using pure working fluid 


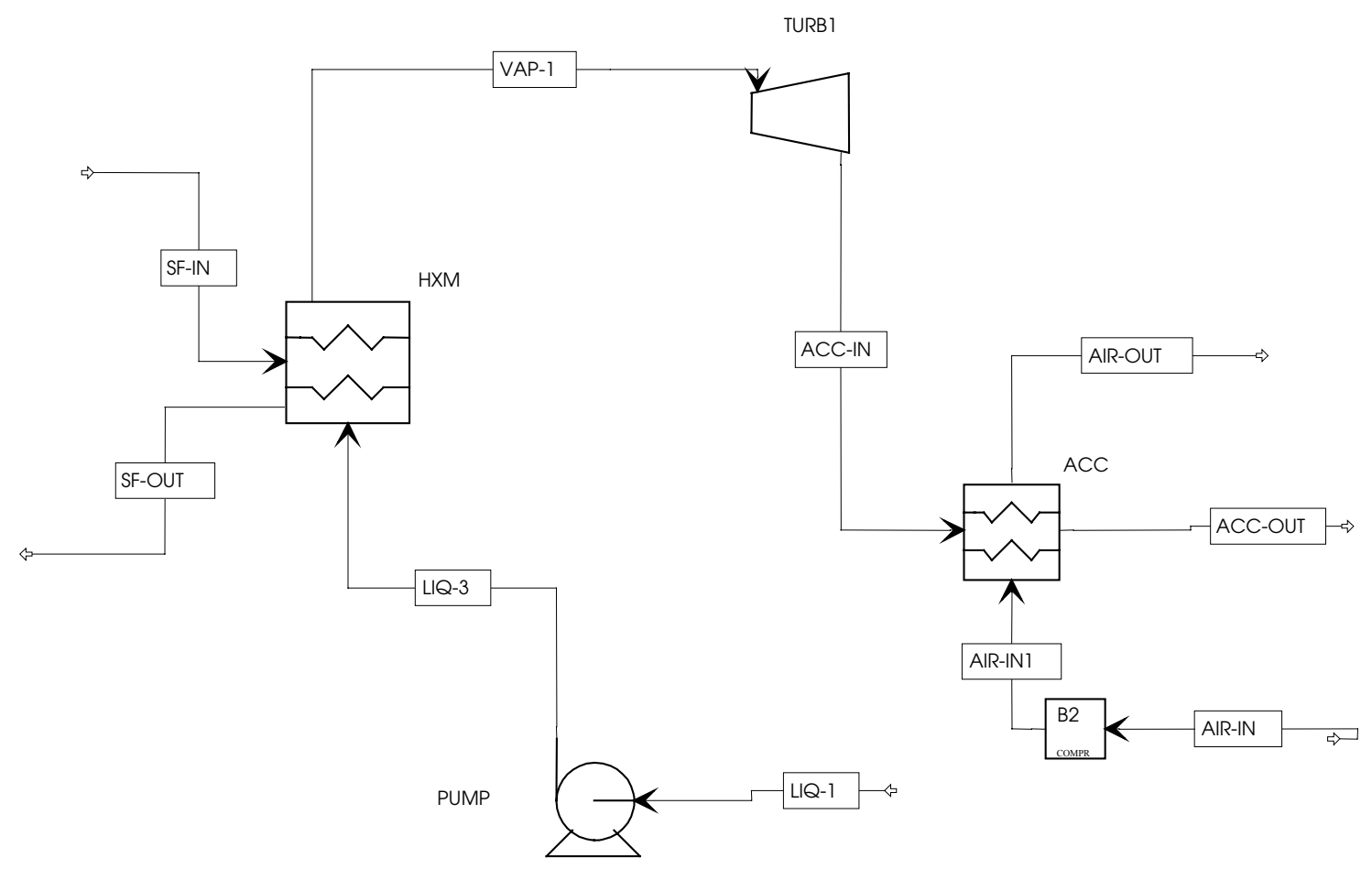

\section{Figure 4. Schematic drawing of the basic ORC (software from Aspen Technology, Inc.)}

\subsubsection{ORC with a Recuperator using Pure Hydrocarbons}

In the analysis of ORC with a recuperator using pure hydrocarbons (Figure 5), the resource entered the heat exchanger at $580^{\circ} \mathrm{F}\left(304^{\circ} \mathrm{C}\right)$, and its exit temperature was $344^{\circ} \mathrm{F}\left(173.3^{\circ} \mathrm{C}\right)$. The working fluid, Pentane, was pumped from a pressure of $20 \mathrm{psia}(0.138 \mathrm{MPa})$ at $114^{\circ} \mathrm{F}\left(45.6^{\circ} \mathrm{C}\right)$ (saturated liquid conditions) to a pressure of $625 \mathrm{psia}(4.31 \mathrm{MPa})$, where it was heated to a temperature of $325^{\circ} \mathrm{F}\left(162.8^{\circ} \mathrm{C}\right)$ inside a recuperator by the stream exiting the turbine. The pressure drop inside the recuperator was assumed to be 15 psia $(103.4 \mathrm{kPa})$ and inside the heater/boiler was $10 \mathrm{psia}(68.9 \mathrm{kPa})$. The working fluid was then passed through the main heat exchanger, where it was heated and boiled by the oil from solar field to a temperature of $563^{\circ} \mathrm{F}$ $\left(295^{\circ} \mathrm{C}\right)$. The vapor exiting the boiler at $600 \mathrm{psia}(4.14 \mathrm{MPa})$ was then passed through a turbine and was allowed to expand to $24 \mathrm{psia}(0.165 \mathrm{MPa})$. The stream exiting the turbine was passed through a recuperator to heat the feed working fluid. The stream exiting the recuperator was sent through an air-cooled condenser where the working fluid was completely condensed. The efficiency of this cycle, including the fan power for the air cooler and the pump power, is $20.1 \%$, which is a significant improvement over the basic ORC case of the previous section. A total pressure drop of 4 psia $(27.6 \mathrm{kPa})$ was assumed for the hot side of the recuperator and the aircooled condenser. The heating and cooling curves for this cycle have been presented in Figures 6 
and 7. Figure 7 shows that by using a recuperator the working fluid temperature entering the condenser was reduced to $172^{\circ} \mathrm{F}\left(78^{\circ} \mathrm{C}\right)$ instead of the $433^{\circ} \mathrm{F}\left(223^{\circ} \mathrm{C}\right)$ observed in the basic ORC case.

The schematic diagram of the cycle (Software from Aspen Technology, Inc.) is shown in Figure 8 and the corresponding state points have been listed in Table 3.

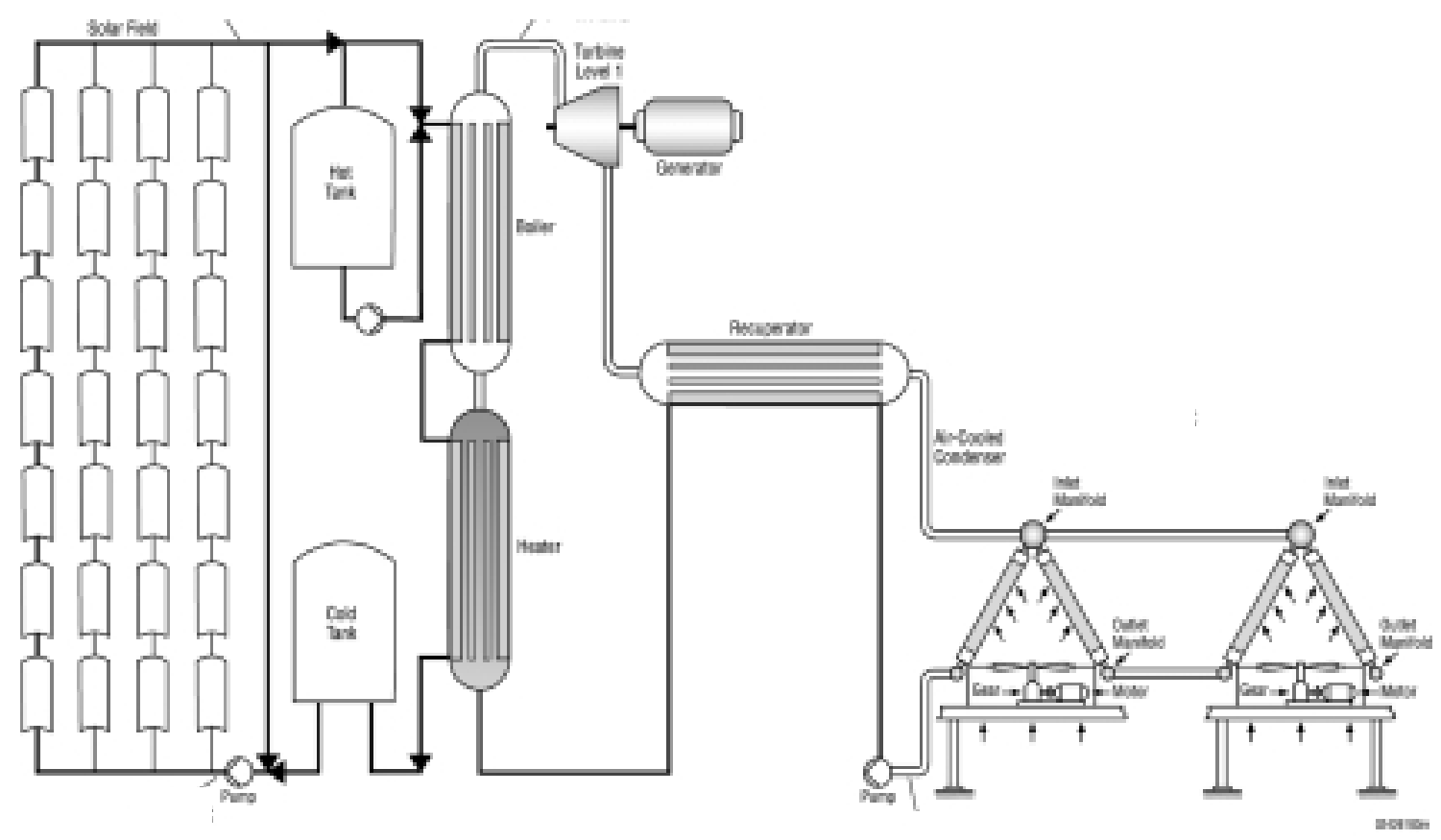

Figure 5. Organic Rankine cycle with recuperation

Figure 6 shows that by choosing a supercritical pressure of 610 psia (4.2 MPa) for the boiler, the heating curve of the working fluid matches the cooling curve of the solar heat transfer fluid very closely, thus reducing the irreversibilities that occur in the boiler. The cooling curve of the working fluid, as shown in Figure 7 , shows that the condensation occurs at a constant temperature (except for the pressure drop effect in the piping). The pinch point of $13^{\circ} \mathrm{F}\left(7.2^{\circ} \mathrm{C}\right.$ ) occurs at the start of condensation.

Note that a conservative condensing pressure of 20 psia $(0.138 \mathrm{MPa})$ was chosen for this analysis. It is possible to condense this working fluid at pressures as low as $15 \mathrm{psia}(0.103 \mathrm{MPa})$; however, an above-atmospheric condensing pressure is very desirable for this cycle. It is also necessary to optimize the condensing pressure with respect to the cycle efficiency. This type of optimization or sensitivity will be discussed later in this report.

It is possible to increase the effective area of the recuperator to enhance the performance of the cycle; however, proper precautions should be taken into account for the pressure drop and the heat transfer coefficient inside the recuperator when the area is increased. Our preliminary analysis showed that doubling the size of the recuperator resulted in a $10 \%$ increase in the overall cycle efficiency. This option will be further analyzed in the optimization section reported later in this report. 


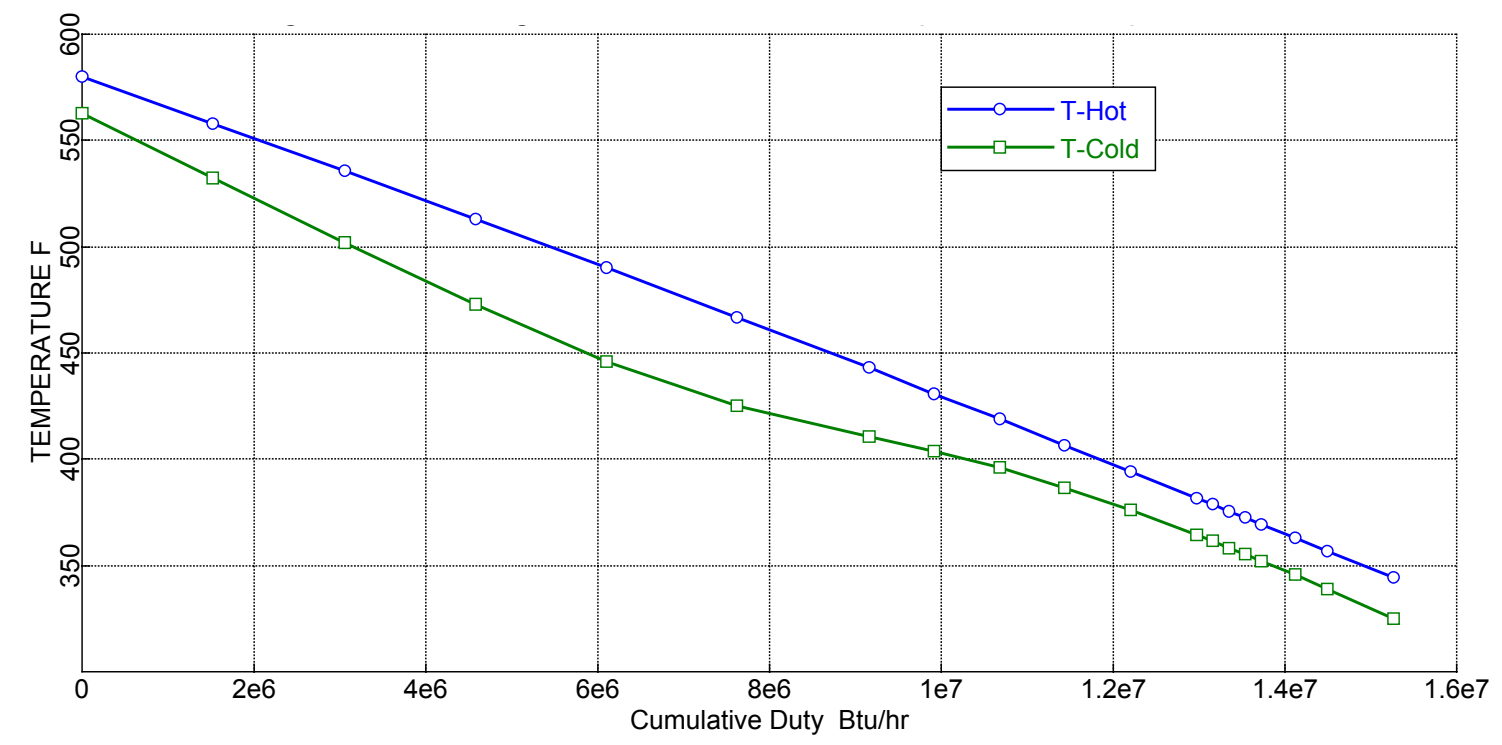

Figure 6. Heating curve for ORC with recuperation with pure fluid

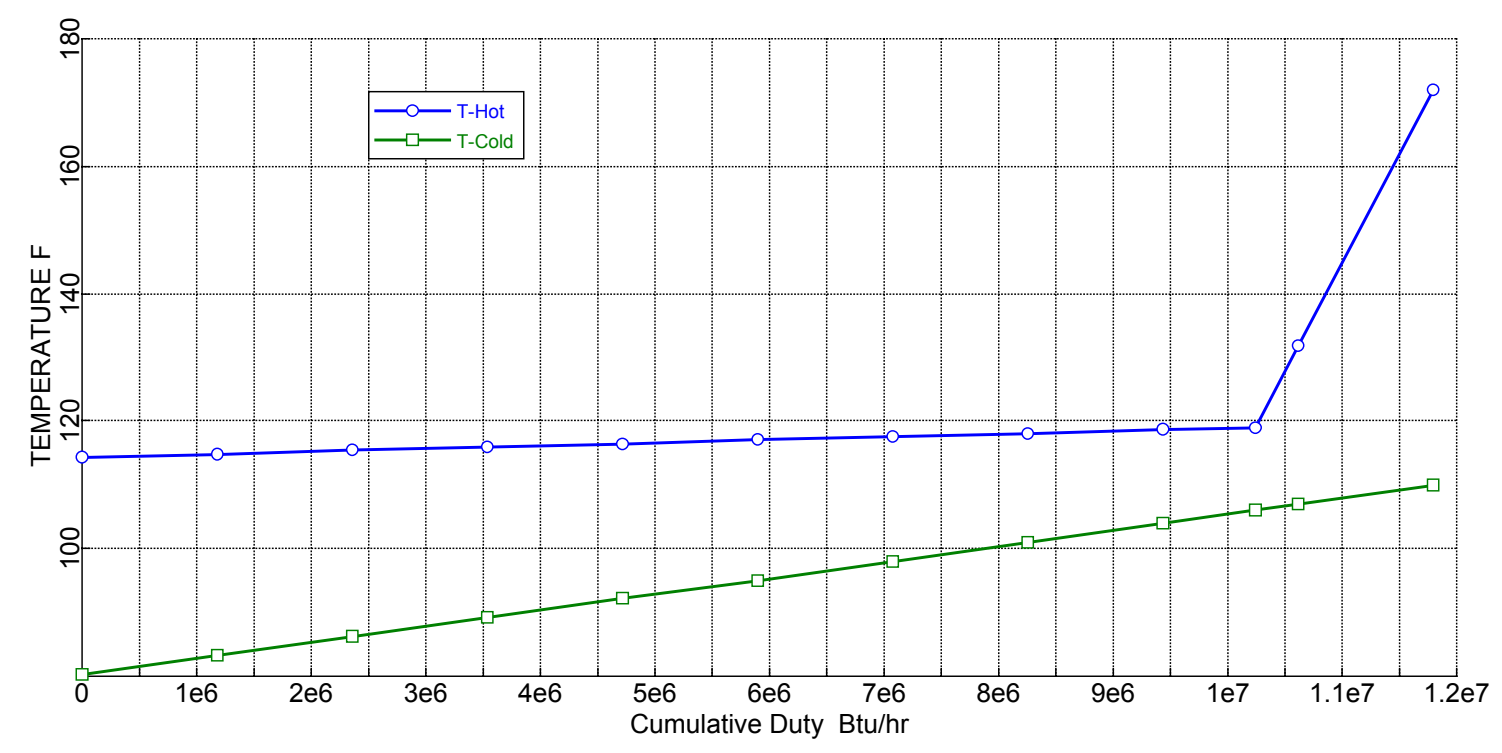

Figure 7. Cooling curve for ORC with recuperation with pure fluid 


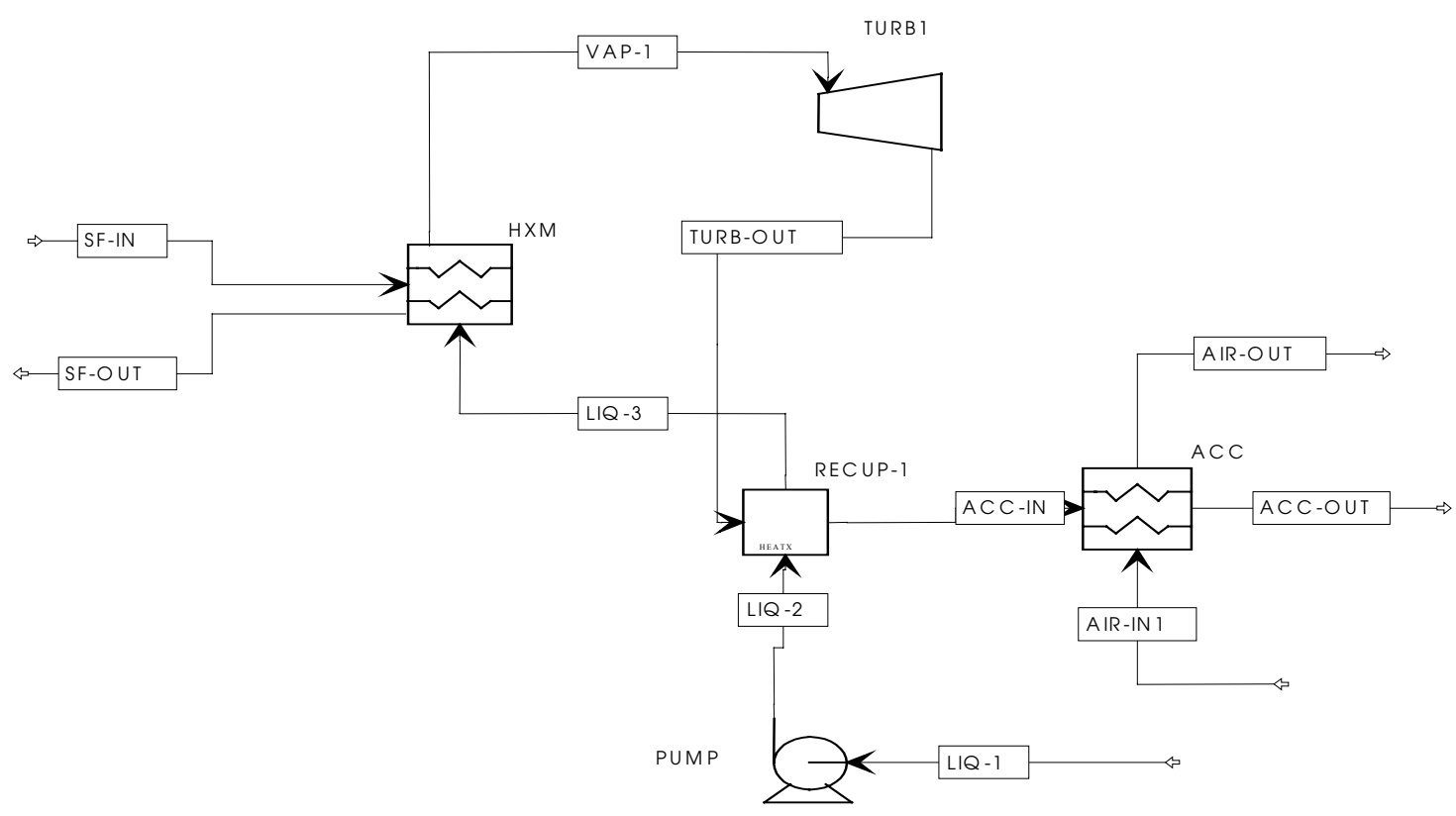

Figure 8. Schematic drawing of the ORC with recuperation

Table 3. State Points for the ORC with Recuperation using Pure Working Fluid

$\begin{array}{lrrrrrrrrrr} & \text { ACC-IN } & \text { ACC-OUT } & \text { AIR-IN } & \text { AIR-IN1 } & \text { AIR-OUT } & \text { LIQ-1 } & \text { LIQ-2 } & \text { LIQ-3 } & \text { SF-IN } & \text { SF-OUT } \\ \text { Temperature F } & & & & & & & & \\ \text { Pressure psi } & 1.72 \mathrm{E}+02 & 1.14 \mathrm{E}+02 & 8.00 \mathrm{E}+01 & 8.03 \mathrm{E}+01 & 1.10 \mathrm{E}+02 & 1.14 \mathrm{E}+02 & 1.20 \mathrm{E}+02 & 3.25 \mathrm{E}+02 & 5.80 \mathrm{E}+02 & 3.44 \mathrm{E}+02 \\ \text { Vapor Frac } & 2.20 \mathrm{E}+01 & 2.00 \mathrm{E}+01 & 1.47 \mathrm{E}+01 & 1.47 \mathrm{E}+01 & 1.47 \mathrm{E}+01 & 2.00 \mathrm{E}+01 & 6.26 \mathrm{E}+02 & 6.10 \mathrm{E}+02 & 5.00 \mathrm{E}+03 & 5.00 \mathrm{E}+03 \\ \text { Mole Flow lbmol/hr } & 1.00 \mathrm{E}+00 & 0.00 \mathrm{E}+00 & 1.00 \mathrm{E}+00 & 1.00 \mathrm{E}+00 & 1.00 \mathrm{E}+00 & 0.00 \mathrm{E}+00 & 0.00 \mathrm{E}+00 & 0.00 \mathrm{E}+00 & 0.00 \mathrm{E}+00 & 0.00 \mathrm{E}+00 \\ \text { Mass Flow lb/hr } & 9.15 \mathrm{E}+02 & 9.15 \mathrm{E}+02 & 5.75 \mathrm{E}+04 & 5.75 \mathrm{E}+04 & 5.75 \mathrm{E}+04 & 9.15 \mathrm{E}+02 & 9.15 \mathrm{E}+02 & 9.15 \mathrm{E}+02 & 7.17 \mathrm{E}+02 & 7.17 \mathrm{E}+02 \\ \text { Volume Flow cuft/hr } & 6.60 \mathrm{E}+04 & 6.60 \mathrm{E}+04 & 1.67 \mathrm{E}+06 & 1.67 \mathrm{E}+06 & 1.67 \mathrm{E}+06 & 6.60 \mathrm{E}+04 & 6.60 \mathrm{E}+04 & 6.60 \mathrm{E}+04 & 9.20 \mathrm{E}+04 & 9.20 \mathrm{E}+04 \\ \text { Enthalpy MMBtu/hr } & 2.71 \mathrm{E}+05 & 1.77 \mathrm{E}+03 & 2.27 \mathrm{E}+07 & 2.27 \mathrm{E}+07 & 2.39 \mathrm{E}+07 & 1.77 \mathrm{E}+03 & 1.78 \mathrm{E}+03 & 2.46 \mathrm{E}+03 & 3.88 \mathrm{E}+03 & 2.54 \mathrm{E}+03 \\ \text { Mass Flow lb/hr } & -5.52 \mathrm{E}+01 & -6.70 \mathrm{E}+01 & 1.20 \mathrm{E}+00 & 1.31 \mathrm{E}+00 & 1.31 \mathrm{E}+01 & -6.70 \mathrm{E}+01 & -6.67 \mathrm{E}+01 & -5.75 \mathrm{E}+01 & -5.37 \mathrm{E}+01 & -6.90 \mathrm{E}+01 \\ \text { AIR } & & & & & & & & \\ \text { OIL } & 0.00 \mathrm{E}+00 & 0.00 \mathrm{E}+00 & 1.67 \mathrm{E}+06 & 1.67 \mathrm{E}+06 & 1.67 \mathrm{E}+06 & 0.00 \mathrm{E}+00 & 0.00 \mathrm{E}+00 & 0.00 \mathrm{E}+00 & 0.00 \mathrm{E}+00 & 0.00 \mathrm{E}+00 \\ \text { N-PEN-01 } & 0.00 \mathrm{E}+00 & 0.00 \mathrm{E}+00 & 0.00 \mathrm{E}+00 & 0.00 \mathrm{E}+00 & 0.00 \mathrm{E}+00 & 0.00 \mathrm{E}+00 & 0.00 \mathrm{E}+00 & 0.00 \mathrm{E}+00 & 9.20 \mathrm{E}+04 & 9.20 \mathrm{E}+04 \\ & 6.60 \mathrm{E}+04 & 6.60 \mathrm{E}+04 & 0.00 \mathrm{E}+00 & 0.00 \mathrm{E}+00 & 0.00 \mathrm{E}+00 & 6.60 \mathrm{E}+04 & 6.60 \mathrm{E}+04 & 6.60 \mathrm{E}+04 & 0.00 \mathrm{E}+00 & 0.00 \mathrm{E}+00\end{array}$

\subsubsection{ORC with a Recuperator using Mixed Hydrocarbons}

The advantage of ORC with a recuperator using mixed hydrocarbons as working fluid (Figure 5) over pure hydrocarbons is that they go through a temperature glide during boiling and condensation, whereas pure components boil and condense at a constant temperature. This phenomenon has significant impact on the cycle efficiency. The heating curve of the working fluid can be forced to follow the cooling curve of the heat source by choosing a proper mixture of fluids. Similarly, the cooling curve of the working fluid can be forced to follow the heating curve 
of the sink. This is very important because this effect will reduce the irreversibilities of the cycle, therefore resulting in higher efficiencies.

To identify the impact of the mixed working fluids on the cycle shown in Figure 5, we used mixed working fluids consisting of pentane/iso-hexane, pentane/iso-butane, and iso-butane/isohexane. Four combinations of the above working fluids were analyzed (Table 4). For the sake of comparison with the pure component working fluid, the results for a mixture of pentane/isobutane (90\% pentane, 10\% iso-butane) are presented here. This working fluid gave the highest efficiency among the cycles analyzed. All the assumptions and working conditions assumed for the pure component case were applied here. The heating and cooling curves for this case are shown in Figures 9 and 10. The state points for this cycle are given in Table 5.

Table 4. Performance of ORC with Recuperation using Mixed Working Fluids

\begin{tabular}{lccccc}
\hline $\begin{array}{c}\text { Working Fluid } \\
\text { Composition }\end{array}$ & Efficiency & $\begin{array}{c}\text { Gross } \\
\text { Electricity } \\
\text { (kWe) }\end{array}$ & $\begin{array}{c}\text { Parasitic } \\
\text { (kWe) }\end{array}$ & $\begin{array}{c}\text { HTF Flow } \\
\text { Ibm/hr }\end{array}$ & $\begin{array}{c}\text { HTF outlet } \\
\text { Temp. } \\
\left.\text { ( }{ }^{\circ} \mathbf{F}\right)\end{array}$ \\
\hline ic4/ic6 (95/5) & 19.2 & 995 & 101 & 91,000 & 351 \\
ic4/c5 (5/95) & 20.3 & 1,118 & 124 & 91,478 & 340 \\
ic4/c5 (10/90) & 20.4 & 1,134 & 130 & 91,065 & 337 \\
c5/ic6 (95/5) & 20.3 & 1,091 & 113 & 92,305 & 346 \\
\hline
\end{tabular}

Table 5. State Points for the ORC with Recuperation using Mixed Working Fluid

\begin{tabular}{|c|c|c|c|c|c|c|c|c|c|c|}
\hline & ACC-IN & ACC-OUT & AIR-IN & AIR-IN1 & AIR-OUT & LIQ-1 & LIQ-2 & LIQ-3 & SF-IN & SF-OUT \\
\hline Temperature $\mathrm{F}$ & $1.55 \mathrm{E}+02$ & $9.47 \mathrm{E}+01$ & $8.00 \mathrm{E}+01$ & $8.03 \mathrm{E}+01$ & $1.03 \mathrm{E}+02$ & $9.47 \mathrm{E}+01$ & $9.99 \mathrm{E}+01$ & $3.18 \mathrm{E}+02$ & $5.80 \mathrm{E}+02$ & $3.37 \mathrm{E}+02$ \\
\hline Pressure psi & $2.20 \mathrm{E}+01$ & $2.00 \mathrm{E}+01$ & $1.47 \mathrm{E}+01$ & $1.47 \mathrm{E}+01$ & $1.47 \mathrm{E}+01$ & $2.00 \mathrm{E}+01$ & $6.25 \mathrm{E}+02$ & $6.10 \mathrm{E}+02$ & $5.00 \mathrm{E}+03$ & $5.00 \mathrm{E}+03$ \\
\hline Vapor Frac & $1.00 \mathrm{E}+00$ & $0.00 \mathrm{E}+00$ & $1.00 \mathrm{E}+00$ & $1.00 \mathrm{E}+00$ & $1.00 \mathrm{E}+00$ & $0.00 \mathrm{E}+00$ & $0.00 \mathrm{E}+00$ & $0.00 \mathrm{E}+00$ & $0.00 \mathrm{E}+00$ & $0.00 \mathrm{E}+00$ \\
\hline Mole Flow $1 \mathrm{bmol} / \mathrm{hr}$ & $9.37 \mathrm{E}+02$ & $9.37 \mathrm{E}+02$ & $7.71 \mathrm{E}+04$ & $7.71 \mathrm{E}+04$ & $7.71 \mathrm{E}+04$ & $9.37 \mathrm{E}+02$ & $9.37 \mathrm{E}+02$ & $9.37 \mathrm{E}+02$ & $7.10 \mathrm{E}+02$ & $7.10 \mathrm{E}+02$ \\
\hline Mass Flow $\mathrm{lb} / \mathrm{hr}$ & $6.60 \mathrm{E}+04$ & $6.60 \mathrm{E}+04$ & $2.23 \mathrm{E}+06$ & $2.23 \mathrm{E}+06$ & $2.23 \mathrm{E}+06$ & $6.60 \mathrm{E}+04$ & $6.60 \mathrm{E}+04$ & $6.60 \mathrm{E}+04$ & $9.11 \mathrm{E}+04$ & $9.11 \mathrm{E}+04$ \\
\hline Volume Flow cuft $/ \mathrm{hr}$ & $2.69 \mathrm{E}+05$ & $1.76 \mathrm{E}+03$ & $3.04 \mathrm{E}+07$ & $3.03 \mathrm{E}+07$ & $3.16 \mathrm{E}+07$ & $1.75 \mathrm{E}+03$ & $1.76 \mathrm{E}+03$ & $2.50 \mathrm{E}+03$ & $3.84 \mathrm{E}+03$ & $2.50 \mathrm{E}+03$ \\
\hline $\begin{array}{l}\text { Enthalpy MMBtu/hr } \\
\text { Mass Flow } \mathrm{lb} / \mathrm{hr}\end{array}$ & $-5.65 \mathrm{E}+01$ & $-6.84 \mathrm{E}+01$ & $1.60 \mathrm{E}+00$ & $1.75 \mathrm{E}+00$ & $1.37 \mathrm{E}+01$ & $-6.84 \mathrm{E}+01$ & $-6.81 E+01$ & $-5.84 \mathrm{E}+01$ & $-5.32 \mathrm{E}+01$ & $-6.87 \mathrm{E}+01$ \\
\hline AIR & $0.00 \mathrm{E}+00$ & $0.00 \mathrm{E}+00$ & $2.23 \mathrm{E}+06$ & $2.23 \mathrm{E}+06$ & $2.23 \mathrm{E}+06$ & $0.00 \mathrm{E}+00$ & $0.00 \mathrm{E}+00$ & $0.00 \mathrm{E}+00$ & $0.00 \mathrm{E}+00$ & $0.00 \mathrm{E}+00$ \\
\hline OIL & $0.00 \mathrm{E}+00$ & $0.00 \mathrm{E}+00$ & $0.00 \mathrm{E}+00$ & $0.00 \mathrm{E}+00$ & $0.00 \mathrm{E}+00$ & $0.00 \mathrm{E}+00$ & $0.00 \mathrm{E}+00$ & $0.00 \mathrm{E}+00$ & $9.11 \mathrm{E}+04$ & $9.11 \mathrm{E}+04$ \\
\hline N-PEN-01 & $5.94 \mathrm{E}+04$ & $5.94 \mathrm{E}+04$ & $0.00 \mathrm{E}+00$ & $0.00 \mathrm{E}+00$ & $0.00 \mathrm{E}+00$ & $5.94 \mathrm{E}+04$ & $5.94 \mathrm{E}+04$ & $5.94 \mathrm{E}+04$ & $0.00 \mathrm{E}+00$ & $0.00 \mathrm{E}+00$ \\
\hline ISO-BUT & $6.60 \mathrm{E}+03$ & $6.60 \mathrm{E}+03$ & $0.00 \mathrm{E}+00$ & $0.00 \mathrm{E}+00$ & $0.00 \mathrm{E}+00$ & $6.60 \mathrm{E}+03$ & $6.60 \mathrm{E}+03$ & $6.60 \mathrm{E}+03$ & $0.00 \mathrm{E}+00$ & $0.00 \mathrm{E}+00$ \\
\hline
\end{tabular}

Figure 9 shows the heating curve of the mixed working fluid. The impact of the mixed working fluid is missed because the boiling is occurring under super-critical conditions. Therefore, the heating curve is not much different than the one experienced for a pure component (compare to Figure 6). However, Figure 10 shows the effect of using mixed working fluid during the cooling process. The cooling curve of the working fluid follows the heating curve of the air much closer, compared to the behavior of the pure fluid as shown in Figure 7. The efficiency of this cycle is $20.4 \%$, which is very comparable to the pure fluid case. Therefore, for cycles operating under supercritical conditions, use of mixed working fluid does not provide any advantages. However, for the off-design or partial-load conditions where the boiler pressure falls below the critical 
conditions (under the dome), use of mixed working fluids will provide significant advantage. Because of the limited scope of this work, we did not carry out partial-load analysis with mixed working fluids. We have left this important topic for future, providing there is enough interest in pursuing it.

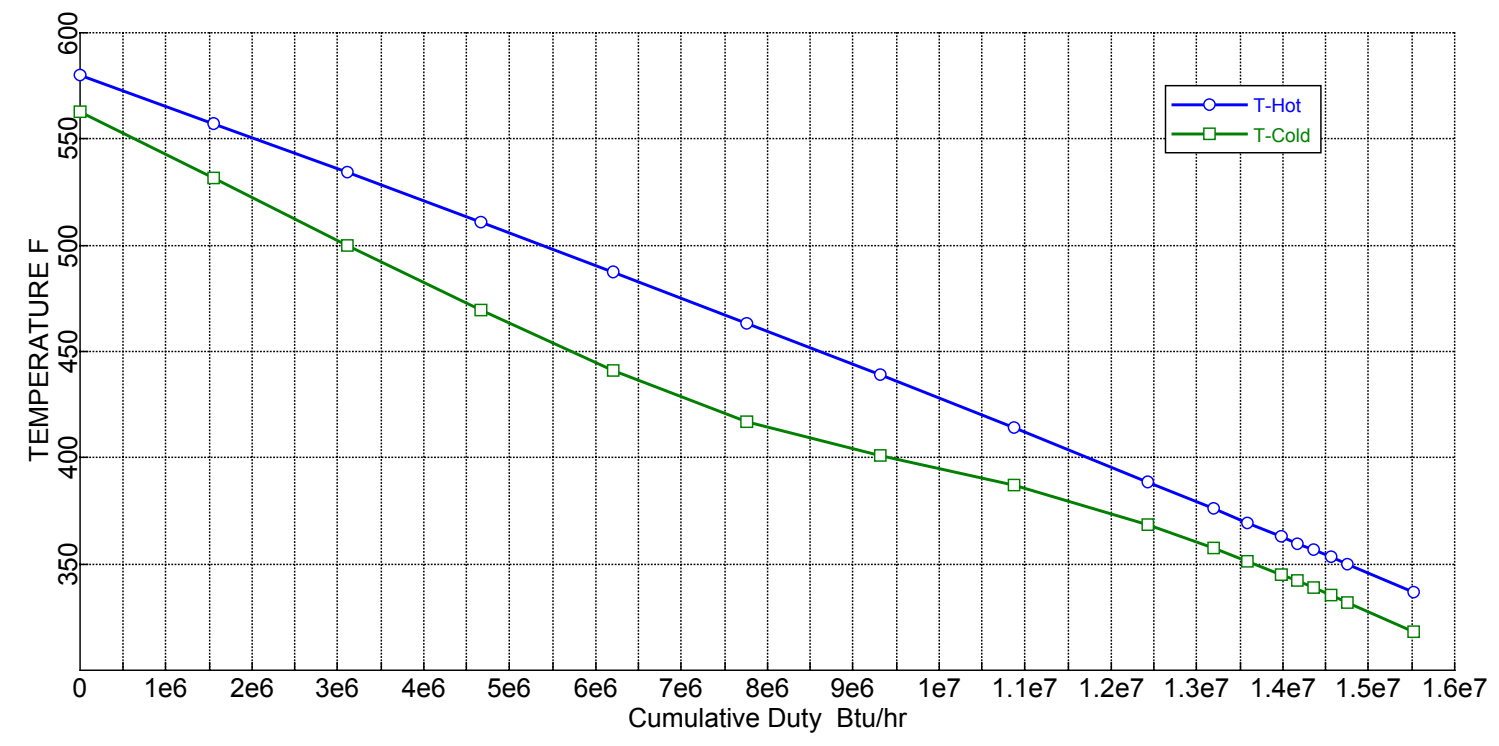

Figure 9. Heating curve for the mixed working fluid (ic4/c5)

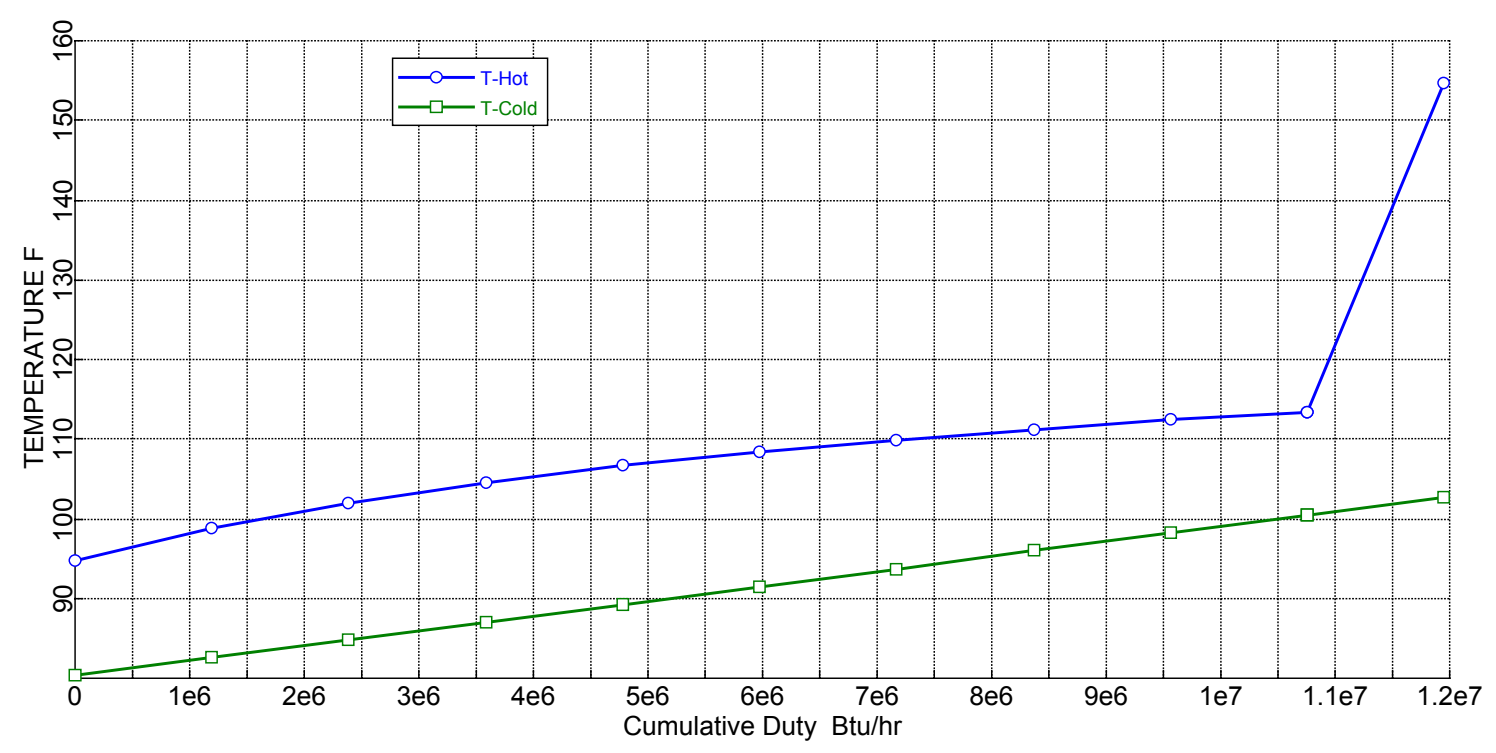

Figure 10. Cooling curve for the mixed working fluid (ic4/c5) 


\subsubsection{ORC with Recuperation and Reheat using Pure Hydrocarbons}

The ORC with recuperation and reheat using pure hydrocarbons is shown in Figure 11. The resource entered the heat exchanger at $580^{\circ} \mathrm{F}\left(304^{\circ} \mathrm{C}\right)$, and its exit temperature was $413^{\circ} \mathrm{F}$ $\left(212^{\circ} \mathrm{C}\right)$. The working fluid, Pentane, was pumped from a pressure of $20 \mathrm{psia}(0.138 \mathrm{MPa})$ at $114^{\circ} \mathrm{F}\left(45.6^{\circ} \mathrm{C}\right)$ (saturated liquid conditions) to a pressure of $625 \mathrm{psia}(4.31 \mathrm{MPa})$, where it was heated to a temperature of $347^{\circ} \mathrm{F}\left(175^{\circ} \mathrm{C}\right)$ inside a recuperator by the stream exiting the lowpressure turbine. Then it was passed through the main heat exchanger, where it was heated and boiled by the oil from solar field to a temperature of $563^{\circ} \mathrm{F}\left(295^{\circ} \mathrm{C}\right)$. The vapor exiting the boiler at $600 \mathrm{psia}(4.14 \mathrm{MPa})$ was then passed through a high-pressure turbine and was allowed to expand to $330 \mathrm{psia}(2.28 \mathrm{MPa})$, where it was superheated to a temperature of $563^{\circ} \mathrm{F}\left(295^{\circ} \mathrm{C}\right)$. This vapor was passed through a low-pressure turbine and was expanded to a pressure of 24 psia. The exhaust of the low-pressure turbine was passed through a recuperator to heat the feed working fluid. The stream exiting the recuperator was sent through an air-cooled condenser where the working fluid was completely condensed. A pressure drop of 10 psia (69 $\mathrm{kPa})$ was assumed for all runs through the boiler/superheater, while the pressure drop for the cold stream through the recuperator was assumed to be 15 psia $(103.4 \mathrm{kPa})$. A total pressure drop of 4 psia $(27.6 \mathrm{kPa})$ was assumed for the recuperator (hot stream) and the air cooled condenser.

The heating and cooling curves for this cycle have been presented in Figures 12 and 13. The state points have been listed in Table 6 . The efficiency of this cycle, including the fan power for the air cooler and the pump power, is $20.6 \%$. This efficiency is only slightly higher than the case analyzed with no-reheat. We anticipate that the cost of this cycle will be high because of the high-pressure and low-pressure turbines. Therefore, it is logical to adhere to the cycle with recuperation only. 
Table 6. State Points for the ORC with Reheat and Recuperation using Pure Working Fluid

\begin{tabular}{|c|c|c|c|c|c|c|c|c|c|c|c|c|c|}
\hline & ACC-IN & ACC-OUT & AIR-IN1 & AIR-OUT & LIQ-1 & LIQ-2 & LIQ-3 & RH-1 & SF-IN & SF-OUT & TURB-OUT & VAP-1 & VAP-2 \\
\hline Temperature $\mathrm{F}$ & $1.79 \mathrm{E}+02$ & $1.14 \mathrm{E}+02$ & $8.03 \mathrm{E}+01$ & $1.10 \mathrm{E}+02$ & $1.14 \mathrm{E}+02$ & $1.20 \mathrm{E}+02$ & $3.47 \mathrm{E}+02$ & $5.29 \mathrm{E}+02$ & $5.80 \mathrm{E}+02$ & 4.13E+02 & $4.68 \mathrm{E}+02$ & $5.63 \mathrm{E}+02$ & $5.63 \mathrm{E}+02$ \\
\hline Pressure psi & $2.20 \mathrm{E}+01$ & $2.00 \mathrm{E}+01$ & $1.47 \mathrm{E}+01$ & $1.47 \mathrm{E}+01$ & $2.00 \mathrm{E}+01$ & $6.25 \mathrm{E}+02$ & $6.10 \mathrm{E}+02$ & $3.30 \mathrm{E}+02$ & $5.00 \mathrm{E}+03$ & $00 \mathrm{E}+03$ & $2.40 \mathrm{E}+01$ & $6.00 \mathrm{E}+02$ & $3.20 \mathrm{E}+02$ \\
\hline Vapor Frac & $1.00 \mathrm{E}+00$ & $.00 \mathrm{E}+00$ & $1.00 \mathrm{E}+00$ & $1.00 \mathrm{E}+00$ & $0.00 \mathrm{E}+00$ & $0.00 \mathrm{E}+00$ & $0.00 \mathrm{E}+00$ & $1.00 \mathrm{E}+00$ & $0.00 \mathrm{E}+00$ & $0.00 \mathrm{E}+00$ & $1.00 \mathrm{E}+00$ & $1.00 \mathrm{E}+00$ & $1.00 \mathrm{E}+00$ \\
\hline Mole Flow $1 \mathrm{bmol} / \mathrm{hr}$ & $9.15 \mathrm{E}+02$ & $9.15 \mathrm{E}+02$ & $5.77 \mathrm{E}+04$ & $5.77 \mathrm{E}+04$ & $9.15 \mathrm{E}+02$ & $9.15 \mathrm{E}+02$ & $9.15 \mathrm{E}+02$ & $9.15 \mathrm{E}+02$ & $1.01 \mathrm{E}+03$ & $01 \mathrm{E}+03$ & $9.15 \mathrm{E}+02$ & $9.15 \mathrm{E}+02$ & $9.15 \mathrm{E}+02$ \\
\hline Mass Flow $\mathrm{lb} / \mathrm{hr}$ & $60 \mathrm{E}+04$ & $6.60 \mathrm{E}+04$ & $1.67 \mathrm{E}+06$ & $1.67 \mathrm{E}+06$ & $6.60 \mathrm{E}+04$ & $6.60 \mathrm{E}+04$ & $6.60 \mathrm{E}+04$ & $6.60 \mathrm{E}+04$ & $1.30 \mathrm{E}+05$ & $1.30 \mathrm{E}+05$ & $6.60 \mathrm{E}+04$ & $6.60 \mathrm{E}+04$ & $6.60 \mathrm{E}+04$ \\
\hline Volume Flow cuft/hr & $2.74 \mathrm{E}+05$ & $1.77 \mathrm{E}+03$ & $2.27 \mathrm{E}+07$ & $2.40 \mathrm{E}+07$ & $1.77 \mathrm{E}+03$ & $1.78 \mathrm{E}+03$ & $2.65 \mathrm{E}+03$ & $2.54 \mathrm{E}+04$ & $5.47 \mathrm{E}+03$ & $3.86 \mathrm{E}+03$ & $3.75 \mathrm{E}+05$ & $1.31 \mathrm{E}+04$ & $2.78 \mathrm{E}+04$ \\
\hline Enthalpy $\mathrm{MMBtu} / \mathrm{hr}$ & $-5.50 \mathrm{E}+01$ & $-6.70 \mathrm{E}+01$ & $1.31 \mathrm{E}+00$ & $1.33 \mathrm{E}+01$ & $-6.70 E+01$ & $-6.67 \mathrm{E}+01$ & $-5.63 \mathrm{E}+01$ & $-4.29 \mathrm{E}+01$ & $-7.58 \mathrm{E}+01$ & $-9.14 \mathrm{E}+01$ & $-4.46 \mathrm{E}+01$ & $-4.22 \mathrm{E}+01$ & $-4.13 \mathrm{E}+01$ \\
\hline Mass Flow $\mathrm{lb} / \mathrm{hr}$ & & & & & & & & & & & & & \\
\hline AIR & $0 \mathrm{E}+00$ & $00 \mathrm{E}+00$ & $7 \mathrm{E}+06$ & $1.67 \mathrm{E}+06$ & $0.00 \mathrm{E}+00$ & $0.00 \mathrm{E}+00$ & $0.00 \mathrm{E}+00$ & $0.00 \mathrm{E}+00$ & $0.00 \mathrm{E}+00$ & $0.00 \mathrm{E}+00$ & $0.00 \mathrm{E}+00$ & $0.00 \mathrm{E}+00$ & $0.00 \mathrm{E}+00$ \\
\hline OIL & $\mathrm{E}+00$ & $0 \mathrm{E}+00$ & $\mathrm{E}+00$ & $0.00 \mathrm{E}+00$ & $0.00 \mathrm{E}+00$ & $0.00 \mathrm{E}+00$ & $0.00 \mathrm{E}+00$ & $\mathrm{E}+00$ & $0 \mathrm{E}+05$ & $30 \mathrm{E}+05$ & $0.00 \mathrm{E}+00$ & $0.00 \mathrm{E}+00$ & $0.00 \mathrm{E}+00$ \\
\hline N-PEN-01 & $6.60 \mathrm{E}+04$ & $6.60 \mathrm{E}+04$ & $0.00 \mathrm{E}+00$ & $0.00 \mathrm{E}+00$ & $6.60 \mathrm{E}+04$ & $6.60 \mathrm{E}+04$ & $6.60 \mathrm{E}+04$ & $6.60 \mathrm{E}+04$ & $0.00 \mathrm{E}+00$ & $0.00 \mathrm{E}+00$ & $6.60 \mathrm{E}+04$ & $6.60 \mathrm{E}+04$ & $6.60 \mathrm{E}+04$ \\
\hline
\end{tabular}

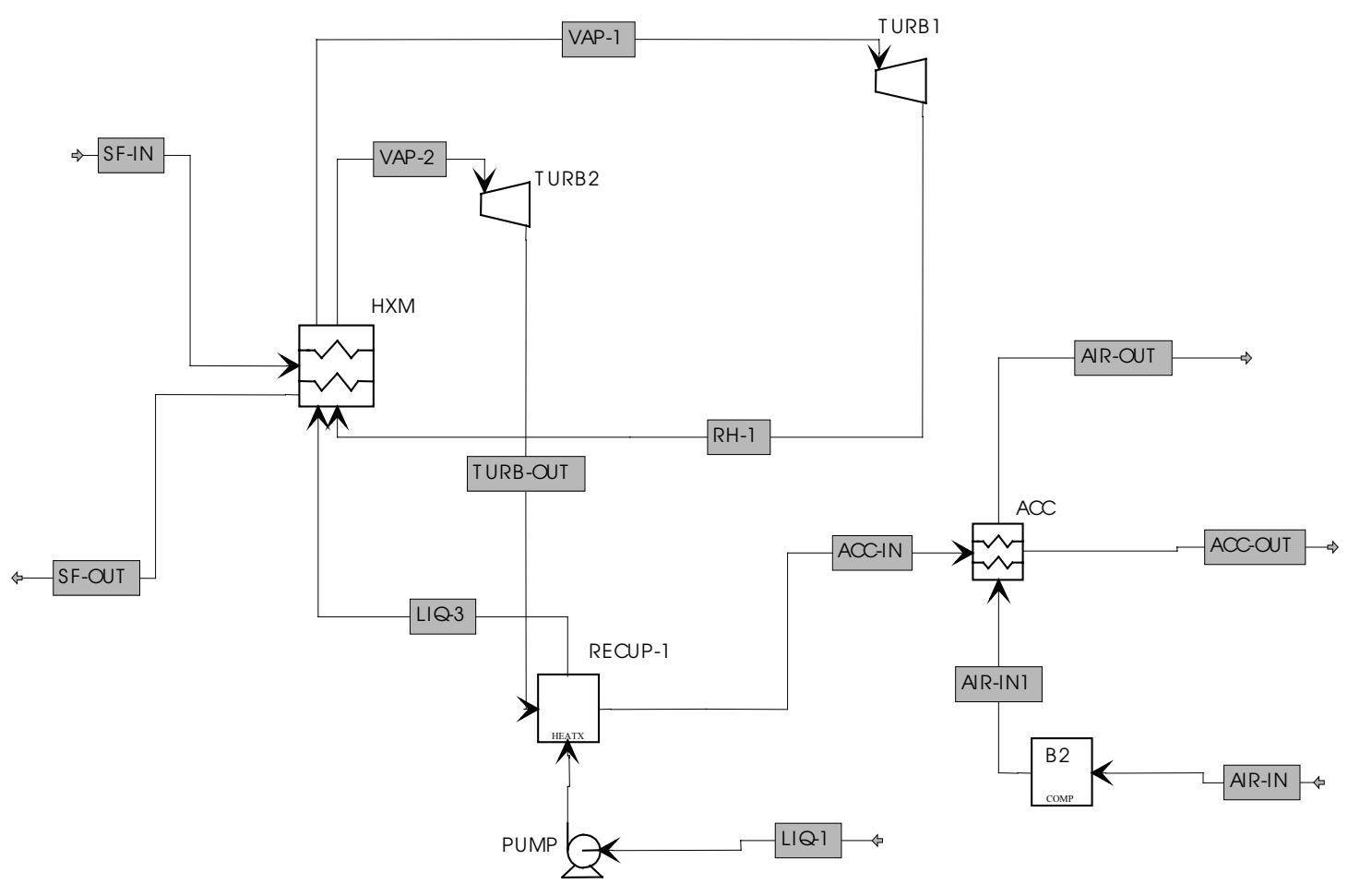

Figure 11. Organic Rankine cycle with reheat and recuperation 


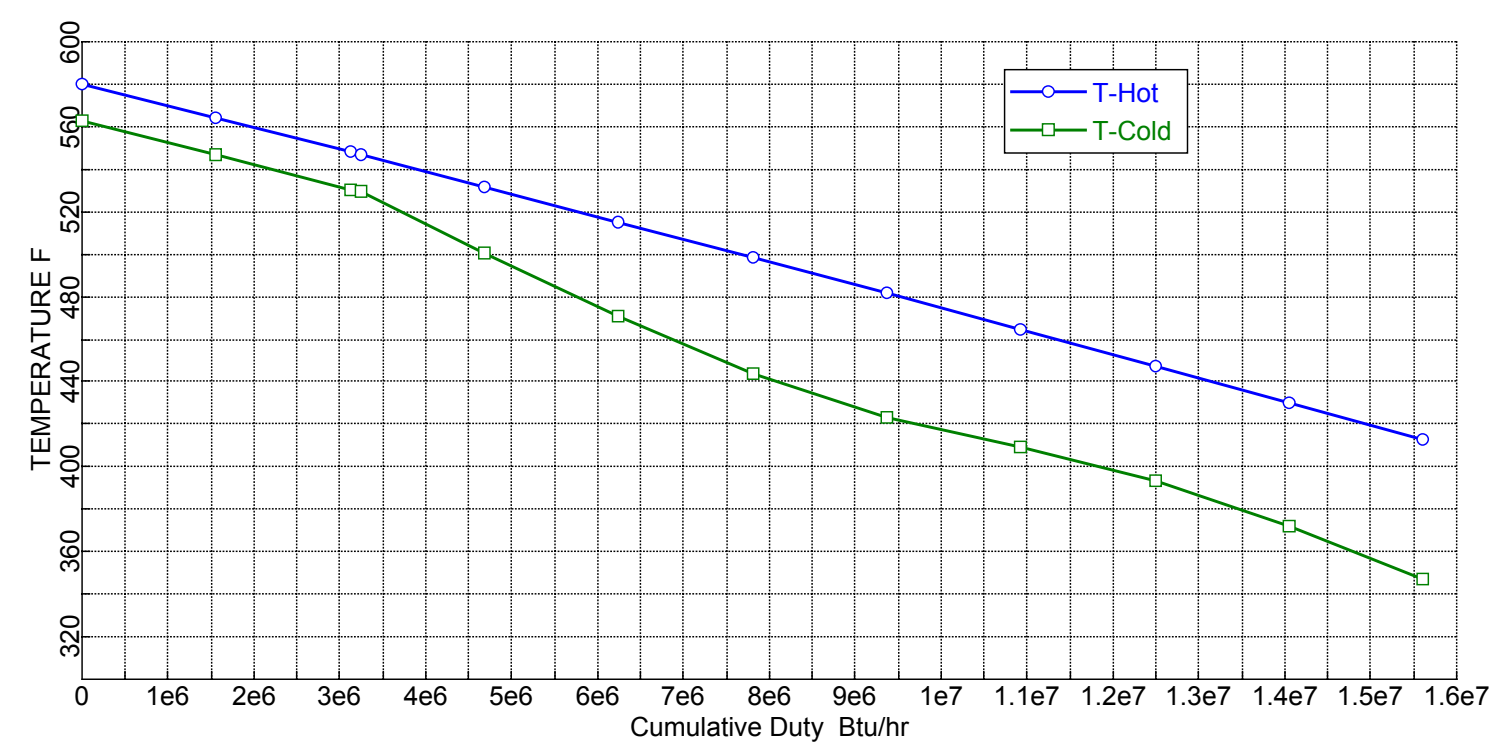

Figure 12. Heating curve for the cycle with reheat and recuperation

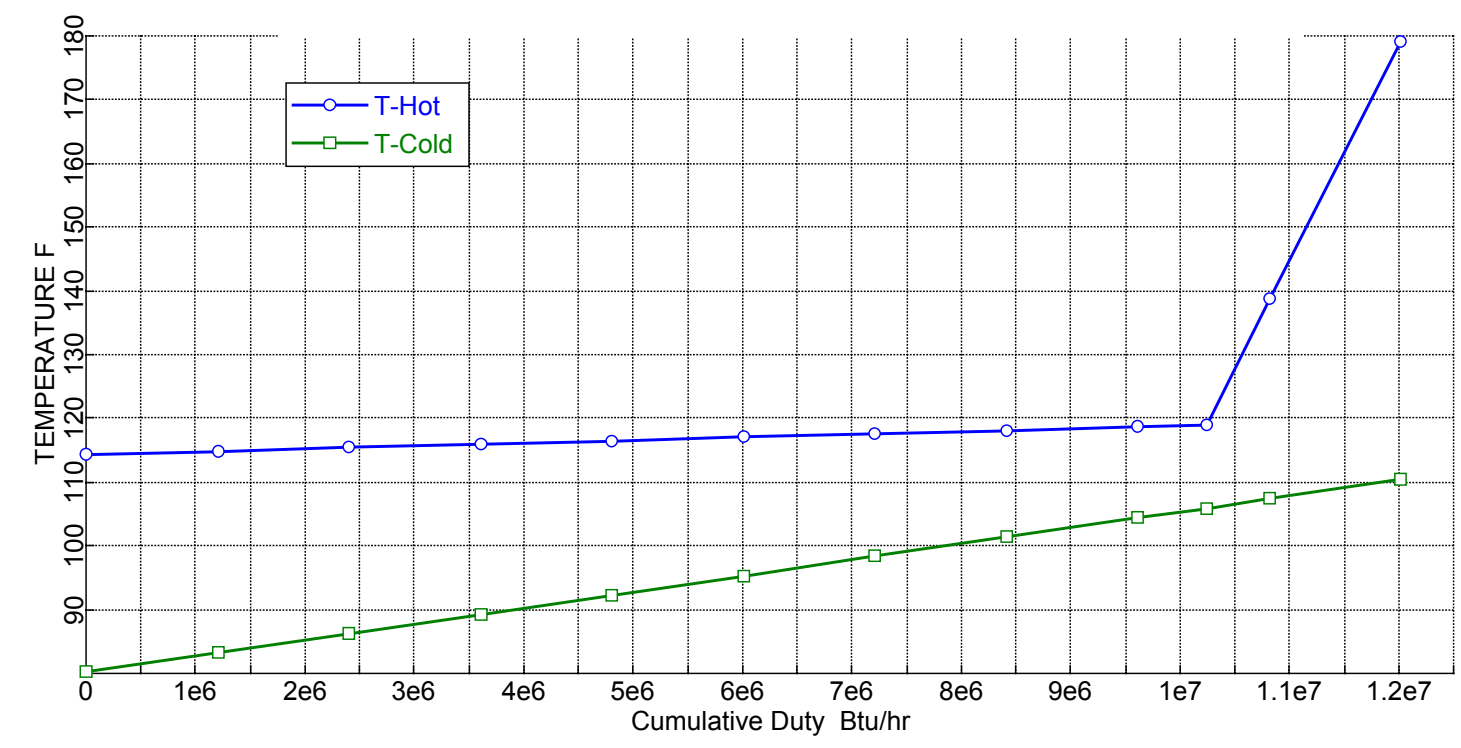

Figure 13. Cooling curve for the cycle with reheat and recuperation

\subsubsection{ORC with Recuperation and Reheat using Mixed Hydrocarbons}

The advantages of ORC with mixed hydrocarbons working fluid was explained earlier. To identify the impact of the mixed working fluids on the cycle shown in Figure 11, we used mixed working fluids consisting of pentane/heptane, pentane/iso-hexane, pentane/iso-butane, and isobutane/iso-hexane. Six combinations of the above working fluids were analyzed (Table 7). For the sake of comparison with the pure component working fluid, the results for a mixture of pentane/iso-butane (95\% pentane, $5 \%$ iso-butane) are presented here. This working fluid gave the highest efficiency $(20.7 \%)$ among the cycles analyzed. All the assumptions and working conditions assumed for the pure component case were applied here. 
Table 7. Performance of ORC with Recuperation and Reheat using Mixed Working Fluids

\begin{tabular}{lccccc}
\hline $\begin{array}{c}\text { Working Fluid } \\
\text { composition }\end{array}$ & Efficiency & $\begin{array}{c}\text { Gross } \\
\text { Electricity(kWe) }\end{array}$ & $\begin{array}{c}\text { Parasitic } \\
(\mathbf{k W e})\end{array}$ & $\begin{array}{c}\text { HTF Flow } \\
(\mathbf{l b m} / \mathbf{h r})\end{array}$ & $\begin{array}{c}\text { HTF outlet } \\
\text { Temp. } \\
\left({ }^{\circ} \mathbf{F}\right)\end{array}$ \\
\hline ic4/ic6 (17/83) & 19.5 & 1,030 & 102 & 138,644 & 430 \\
ic4/ic6 (19/81) & 19.2 & 1,022 & 109 & 142,012 & 434 \\
ic4/ic6 (30/70) & 18.8 & 976 & 98 & 132,076 & 425 \\
ic4/c5 (5/95) & 20.7 & 1,157 & 124 & 129,026 & 410 \\
c5/ic6 (81/19) & 18.7 & 950 & 104 & 138,296 & 438 \\
c5/c7 (50/50) & 18.8 & 976 & 94 & 139,128 & 433 \\
\hline
\end{tabular}

The heating and cooling curves for this case are shown in Figures 14 and 15. The state points have been listed in Table 8. Comparison between the results obtained for pure components versus mixed working fluids indicate that the efficiency of the cycle with mixed working fluid is only slightly higher than that for a pure component. However, as explained earlier, the impact of using mixed working fluids will be more pronounced when using partial load conditions of the solar field.

Table 8. State Points for the ORC with Reheat and Recuperation using Mixed Working Fluid

\begin{tabular}{|c|c|c|c|c|c|c|c|c|c|c|c|c|c|}
\hline & ACC-IN & ACC-OUT & AIR-IN & AIR-OUT & B-IN & B-OUT & LIQ-1 & LIQ-2 & LIQ-3 & RH-1 & TURB-OUT & VAP-1 & VAP-2 \\
\hline mperature $\mathrm{F}$ & $1.70 \mathrm{E}+02$ & $1.04 \mathrm{E}+02$ & $8.00 \mathrm{E}+01$ & $1.07 \mathrm{E}+02$ & $5.80 \mathrm{E}+02$ & $4.10 \mathrm{E}+02$ & $1.04 \mathrm{E}+02$ & $1.09 \mathrm{E}+02$ & $3.43 \mathrm{E}+02$ & $5.30 \mathrm{E}+02$ & $4.67 \mathrm{E}+02$ & $5.63 \mathrm{E}+02$ & $5.63 \mathrm{E}+02$ \\
\hline Pressure $\mathrm{psi}$ & $2.20 \mathrm{E}+01$ & $2.00 \mathrm{E}+01$ & $1.47 \mathrm{E}+01$ & $1.47 \mathrm{E}+01$ & $5.00 \mathrm{E}+03$ & $5.00 \mathrm{E}+03$ & $2.00 \mathrm{E}+01$ & $6.25 \mathrm{E}+02$ & $6.10 \mathrm{E}+02$ & $3.30 \mathrm{E}+02$ & $2.40 \mathrm{E}+01$ & $6.00 \mathrm{E}+02$ & $3.20 \mathrm{E}+02$ \\
\hline Vapor Frac & $1.00 \mathrm{E}+00$ & $0.00 \mathrm{E}+00$ & $1.00 \mathrm{E}+00$ & $1.00 \mathrm{E}+00$ & $0.00 \mathrm{E}+00$ & $0.00 \mathrm{E}+00$ & $0.00 \mathrm{E}+00$ & $0.00 \mathrm{E}+00$ & $0.00 \mathrm{E}+00$ & $1.00 \mathrm{E}+00$ & $1.00 \mathrm{E}+00$ & $1.00 \mathrm{E}+00$ & $1.00 \mathrm{E}+00$ \\
\hline Mole Flow $\mathrm{lbmol} / \mathrm{hr}$ & $9.26 \mathrm{E}+02$ & $9.26 \mathrm{E}+02$ & $6.64 \mathrm{E}+04$ & $6.64 \mathrm{E}+04$ & $1.01 \mathrm{E}+03$ & $1.01 \mathrm{E}+03$ & $9.26 \mathrm{E}+02$ & $9.26 \mathrm{E}+02$ & $9.26 \mathrm{E}+02$ & $9.26 \mathrm{E}+02$ & $9.26 \mathrm{E}+02$ & $9.26 \mathrm{E}+02$ & $9.26 \mathrm{E}+02$ \\
\hline Mass Flow $\mathrm{lb} / \mathrm{hr}$ & $6.60 \mathrm{E}+04$ & $6.60 \mathrm{E}+04$ & $92 \mathrm{E}+06$ & $1.92 \mathrm{E}+06$ & $1.29 \mathrm{E}+05$ & $1.29 \mathrm{E}+05$ & $6.60 \mathrm{E}+04$ & $6.60 \mathrm{E}+04$ & $6.60 \mathrm{E}+04$ & $6.60 \mathrm{E}+04$ & $6.60 \mathrm{E}+04$ & $60 \mathrm{E}+04$ & $6.60 \mathrm{E}+04$ \\
\hline Volume Flow cuft/hr & $2.73 \mathrm{E}+05$ & $1.76 \mathrm{E}+03$ & $2.62 \mathrm{E}+07$ & $2.74 \mathrm{E}+07$ & $5.43 \mathrm{E}+03$ & $3.82 \mathrm{E}+03$ & $1.76 \mathrm{E}+03$ & $1.77 \mathrm{E}+03$ & $2.67 \mathrm{E}+03$ & $2.58 \mathrm{E}+04$ & $3.79 \mathrm{E}+05$ & $1.34 \mathrm{E}+04$ & $2.82 \mathrm{E}+04$ \\
\hline Enthalpy MMBtu/hr & $-5.56 \mathrm{E}+01$ & $-6.77 \mathrm{E}+01$ & $1.38 \mathrm{E}+00$ & $1.36 \mathrm{E}+01$ & $-7.54 \mathrm{E}+01$ & $-9.11 \mathrm{E}+01$ & $-6.77 \mathrm{E}+01$ & $-6.74 \mathrm{E}+01$ & $-5.68 \mathrm{E}+01$ & $-4.33 \mathrm{E}+01$ & $-4.50 \mathrm{E}+01$ & $-4.26 \mathrm{E}+01$ & $-4.17 \mathrm{E}+01$ \\
\hline Mass Flow $\mathrm{lb} / \mathrm{hr}$ & & & & & & & & & & & & & \\
\hline AIR & $0.00 \mathrm{E}+00$ & $0.00 \mathrm{E}+00$ & $92 \mathrm{E}+06$ & $1.92 \mathrm{E}+06$ & $0.00 \mathrm{E}+00$ & $00 \mathrm{E}+00$ & $0.00 \mathrm{E}+00$ & $0.00 \mathrm{E}+00$ & $0.00 \mathrm{E}+00$ & $0.00 \mathrm{E}+00$ & $0.00 \mathrm{E}+00$ & $0.00 \mathrm{E}+00$ & $0.00 \mathrm{E}+00$ \\
\hline OIL & $0.00 \mathrm{E}+00$ & $0.00 \mathrm{E}+00$ & $0.00 \mathrm{E}+00$ & $0.00 \mathrm{E}+00$ & $1.29 \mathrm{E}+05$ & $1.29 \mathrm{E}+05$ & $0.00 \mathrm{E}+00$ & $0.00 \mathrm{E}+00$ & $0.00 \mathrm{E}+00$ & $0.00 \mathrm{E}+00$ & $0.00 \mathrm{E}+00$ & $.00 \mathrm{E}+00$ & $0.00 \mathrm{E}+00$ \\
\hline ISO-BUT & $3.30 \mathrm{E}+03$ & $3.30 \mathrm{E}+03$ & $0.00 \mathrm{E}+00$ & $0.00 \mathrm{E}+00$ & $0.00 \mathrm{E}+00$ & $0.00 \mathrm{E}+00$ & $3.30 \mathrm{E}+03$ & $3.30 \mathrm{E}+03$ & $3.30 \mathrm{E}+03$ & $3.30 \mathrm{E}+03$ & $3.30 \mathrm{E}+03$ & $3.30 \mathrm{E}+03$ & $3.30 \mathrm{E}+03$ \\
\hline N-PEN-01 & $6.27 \mathrm{E}+04$ & $6.27 \mathrm{E}+04$ & $0.00 \mathrm{E}+00$ & $0.00 \mathrm{E}+00$ & $0.00 \mathrm{E}+00$ & $0.00 \mathrm{E}+00$ & $6.27 \mathrm{E}+04$ & $6.27 \mathrm{E}+04$ & $6.27 \mathrm{E}+04$ & $6.27 \mathrm{E}+04$ & $6.27 \mathrm{E}+04$ & $6.27 \mathrm{E}+04$ & $6.27 \mathrm{E}+04$ \\
\hline
\end{tabular}




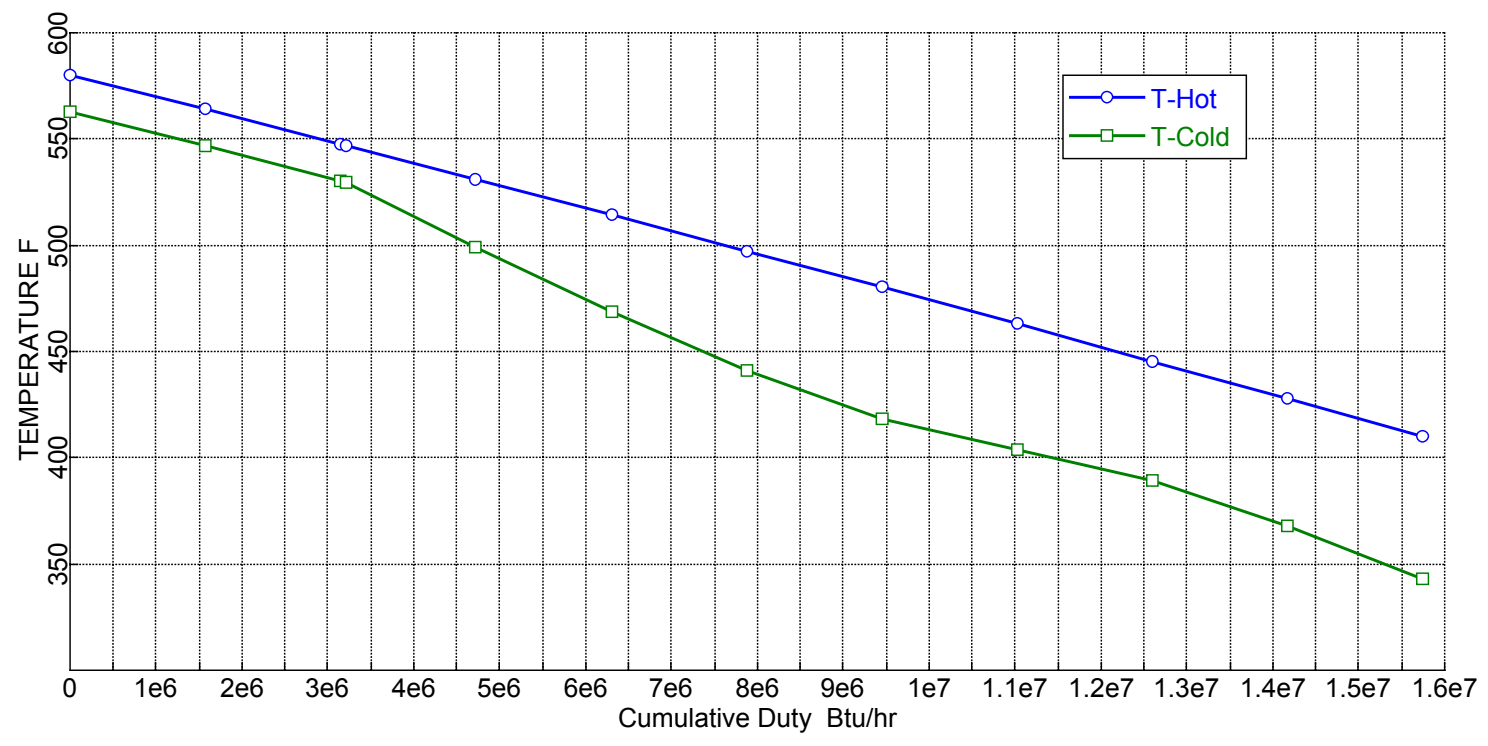

Figure 14. Heating curve for cycle with reheat and recuperation using mixed working fluid

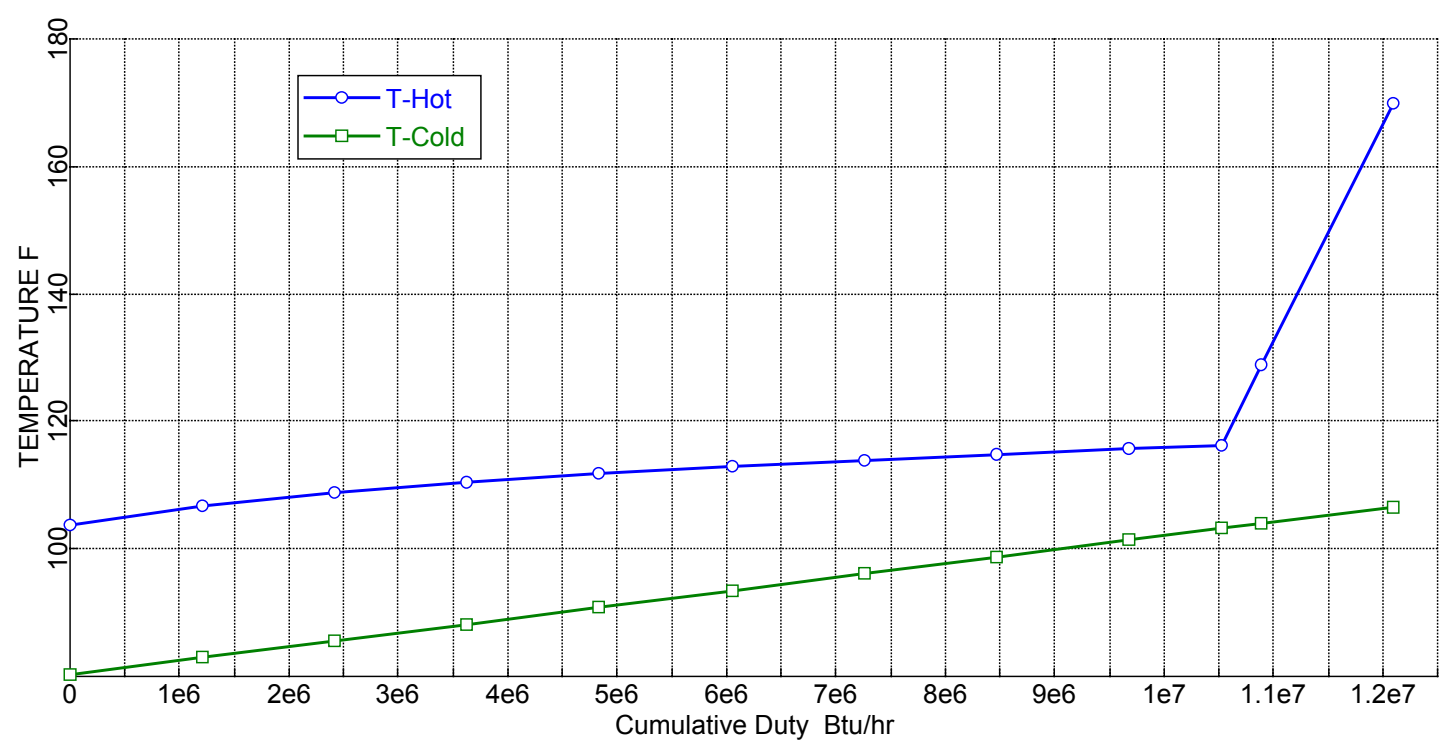

Figure 15. Cooling curve for cycle with reheat and recuperation using mixed working fluid 
A brief review of the results of the cycles analyzed above indicates that neither the use of reheat nor the utilization of the mixed working fluids have significant impact on the performance of the cycle. Therefore, for the sake of achieving lower electricity cost and ease of operation, we will use the cycle with recuperation and pure working fluid (shown in Figure 5) for the optimization and off-design analysis. It should be pointed out that we anticipate a reasonably superior performance for the cycle with mixed working fluid when off-design (partial solar load) conditions are considered. However, in this study, because of limited resources, we did not pursue optimization of any cycle that uses mixed working fluids. Future work will address that interesting topic. The following sections discuss potential options for improving the cycle efficiency and provide a detailed off-design analysis of the cycle.

\subsection{Options for Improving Cycle Efficiency}

The cycle shown in Figure 5 was analyzed for a condensing pressure of 20 psia $(0.138 \mathrm{MPa})$ with a pinch point of $17^{\circ} \mathrm{F}\left(9.4^{\circ} \mathrm{C}\right)$ for the boiler and $13^{\circ} \mathrm{F}\left(7.2^{\circ} \mathrm{C}\right)$ for the condenser. To identify the highest efficiency that one could get for the cycle with recuperator, we decided to lower the condensing pressure to $17.5 \mathrm{psia}(0.121 \mathrm{MPa})$, reduce the pinch point in all the heat exchangers to $5^{\circ} \mathrm{F}\left(2.8^{\circ} \mathrm{C}\right)$, while maintaining the turbine efficiency at 0.75 . In doing so, we obtained a net cycle efficiency of $23.0 \%$. This is a considerable improvement over the $20.1 \%$ efficiency that we were getting earlier. However, the field achievability of the specifications for this cycle need to be further verified and validated. This optimized cycle was then used as base case for our offdesign studies presented in Section 3.4.

\subsection{Off-Design (Partial Load) Operation and Its Impact on Performance}

The cycle shown in Figure 5, ORC with recuperation, was analyzed for off-design conditions. The cycle was first designed and optimized for the following base condition: air-cooled condensing with ambient temperature of $80^{\circ} \mathrm{F}\left(26.7^{\circ} \mathrm{C}\right)$, a solar resource that entered the heat exchanger at $580^{\circ} \mathrm{F}\left(304^{\circ} \mathrm{C}\right)$ and exited at $344^{\circ} \mathrm{F}\left(173.3^{\circ} \mathrm{C}\right)$. The working fluid was Pentane, and it was condensed at a condensing pressure of $17.5 \mathrm{psia}(0.121 \mathrm{MPa})$. The maximum operating pressure in the heater/boiler was set at $610 \mathrm{psia}(4.2 \mathrm{MPa})$, and the pinch point in all the heat exchangers was set to $5^{\circ} \mathrm{F}\left(2.8^{\circ} \mathrm{C}\right)$. The pressure drop on the cold side of the recuperator was assumed to be $10 \mathrm{psia}(69 \mathrm{kPa})$, while it was assumed to be 2 psia $(13.4 \mathrm{kPa})$ on the hot-side. The pressure drop in the condenser was assumed to be also 2 psia $(13.4 \mathrm{kPa})$. The solar-side working fluid flow rate was $112,000 \mathrm{lbm} / \mathrm{hr}(50,909 \mathrm{~kg} / \mathrm{hr})$.

Using the base design operating conditions given above, all the components for the cycle were fixed in size: the turbine, pumps, and heat exchangers. Using the fixed-size components, we carried out off-design tests to study the performance of the cycle. Among many elements that affect the performance of such cycle are the ambient air temperature variations and the flow rate of the solar-side working fluid. The first set of off-design studies was conducted by maintaining the ambient air temperature at $80^{\circ} \mathrm{F}\left(26.7^{\circ} \mathrm{C}\right)$ and varying the solar-side working fluid flow rate from full flow $(100 \%, \mathrm{MH}=1)$ down to $35 \%(\mathrm{MH}=0.35)$ flow rate. Specifically we used $35 \%$, $50 \%$, and $75 \%$ flow rates and obtained cycle performance data. For each flow rate, the turbine inlet pressure was varied until a maximum efficiency point was obtained. Based on the load, the air flow rate was also adjusted to maintain a $5^{\circ} \mathrm{F}$ pinch inside the condensing unit. Figure 16 shows the results for this particular set. This figure shows that a straight line may be drawn through the maximum efficiency points. Table 9 gives the details for the maximum efficiency points for various solar-side fluid flow rates. 
Table 9. Cycle Information for Maximum Efficiency Points

\begin{tabular}{ccccccc}
\hline $\begin{array}{c}\text { HTF Inlet } \\
\text { Temperature } \\
\left.\left({ }^{\circ} \mathbf{F}\left[{ }^{\circ} \mathbf{C}\right]\right)\right)\end{array}$ & $\begin{array}{c}\text { HTF } \\
\text { Mass } \\
(\%)\end{array}$ & $\begin{array}{c}\text { Turbine Inlet } \\
\text { Pressure } \\
(\mathbf{p s i a}[\mathbf{M P a}])\end{array}$ & $\begin{array}{c}\text { Cycle } \\
\text { Efficiency }\end{array}$ & $\begin{array}{c}\text { HTF Outlet } \\
\text { Temperature } \\
\left({ }^{\circ} \mathbf{F}\left[{ }^{\circ} \mathbf{C}\right]\right)\end{array}$ & $\begin{array}{c}\text { Net Power } \\
(\mathbf{k W e})\end{array}$ & $\begin{array}{c}\text { Heat Input } \\
(\mathbf{k W t})\end{array}$ \\
\hline $580^{\circ}\left(304^{\circ}\right)$ & 1.00 & $600(4.14)$ & 23.00 & $381(193.9)$ & 1,137 & 4,653 \\
& 0.75 & $501(3.45)$ & 21.86 & $359(181.7)$ & 839 & 3,841 \\
& 0.50 & $351(2.42)$ & 20.10 & $364(184.4)$ & 505 & 2,510 \\
& 0.35 & $280(1.93)$ & 18.66 & $342(172.2)$ & 358 & 1,923 \\
\hline
\end{tabular}

A similar set of off-design conditions was studied for an ambient temperature of $100^{\circ} \mathrm{F}\left(37.8^{\circ} \mathrm{C}\right)$. Again, the air-flow rate was adjusted according to the load to get a $5^{\circ} \mathrm{F}$ pinch. The cycle efficiencies for this case are consistently lower than the previous case because more air needs to be pumped on the condenser side and also because the condenser pressure is higher. The results for this case are also shown in Figure 16. 


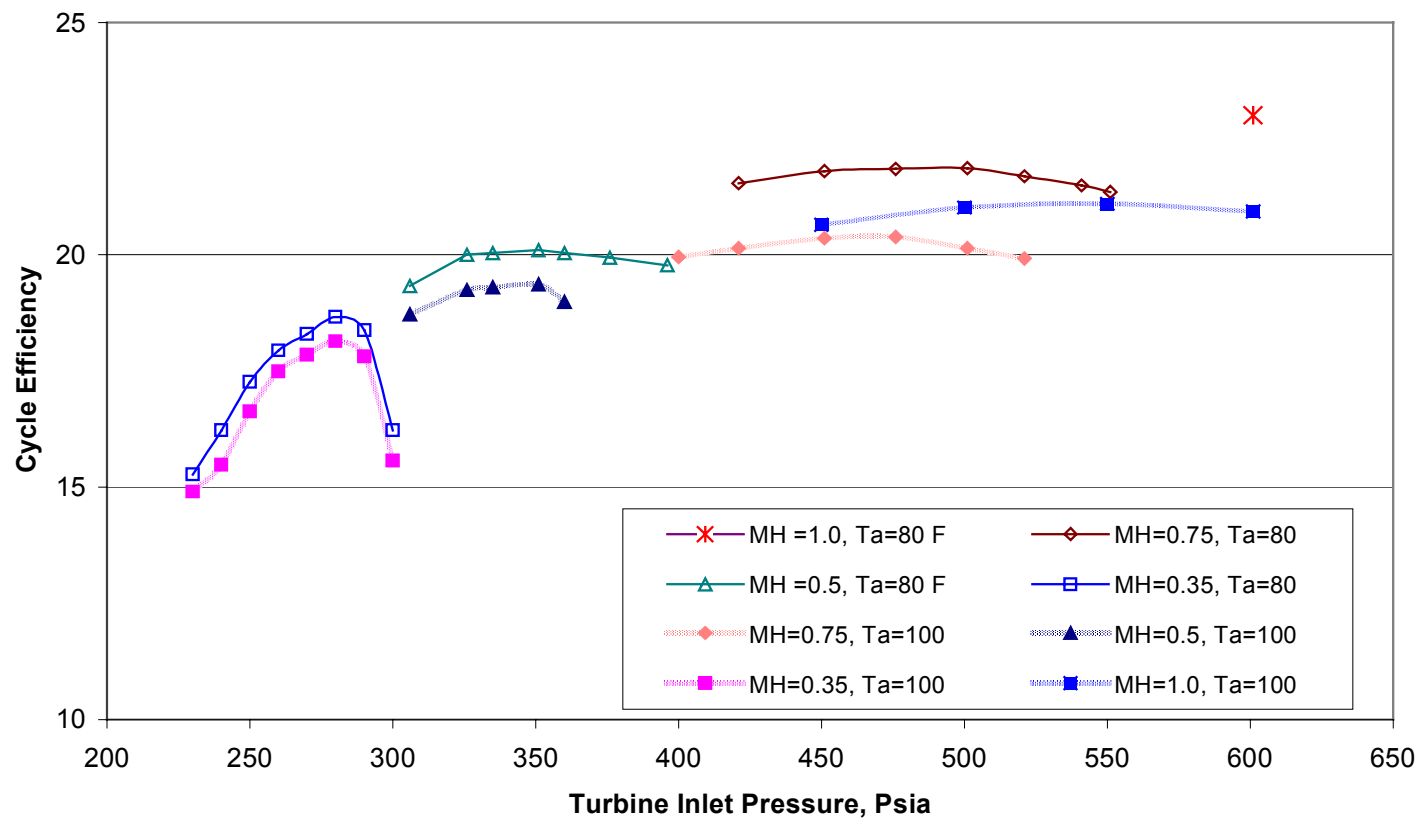

Figure 16. Cycle efficiency versus maximum cycle pressure at ambient temperatures of $80^{\circ} \mathrm{F}\left(26.7^{\circ} \mathrm{C}\right)$ and $100^{\circ} \mathrm{F}\left(37.8^{\circ} \mathrm{C}\right)$ for various turbine inlet pressures

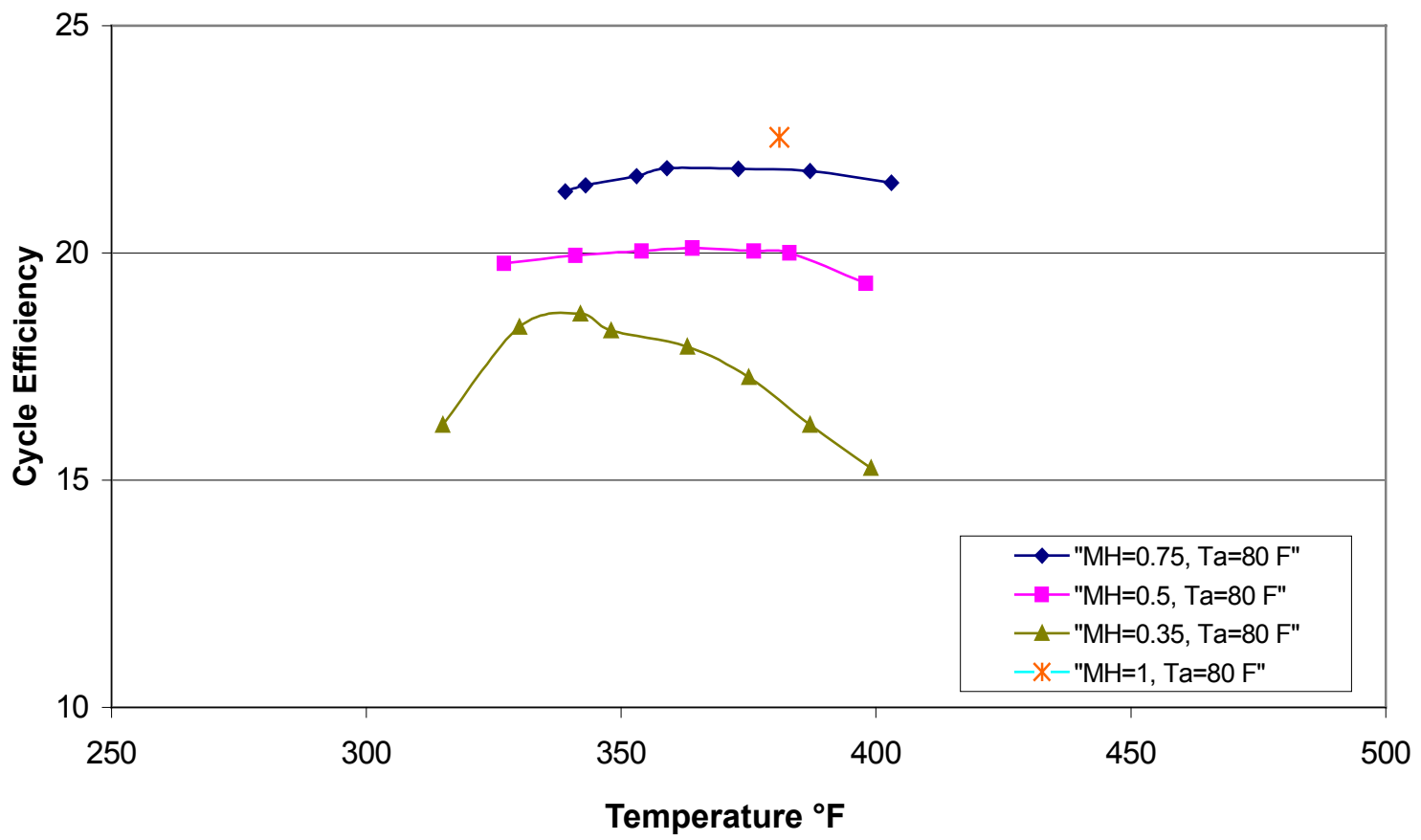

Figure 17. Solar-side fluid outlet temperature versus cycle efficiency 
The effect of the above variations on the solar fluid outlet temperature for the ambient temperature of $80^{\circ} \mathrm{F}\left(26.7^{\circ} \mathrm{C}\right)$ is shown in Figure 17. For the sake of clarity, the outlet temperatures for ambient temperature of $100^{\circ} \mathrm{F}\left(37.8^{\circ} \mathrm{C}\right)$ are not shown in this figure. The outlet temperature for the maximum efficiency point for $\mathrm{MH}=0.35$ is about $342^{\circ} \mathrm{F}\left(172.2^{\circ} \mathrm{C}\right)$, while for the optimum base case it is $381^{\circ} \mathrm{F}\left(193.9^{\circ} \mathrm{C}\right)$. This figure indicates that the above variations have very small effect on the solar-side fluid outlet temperature.

The impact of the above variations on the net power output of the cycle is shown in Figure 18. The optimum base design produces a net power output of 1,137 kWe (not including the pumping power for the solar side). The $\mathrm{MH}=0.35$ case produces a net power output of $358 \mathrm{kWe}$ at its maximum efficiency point.

The simulation software (Aspen Technology, Inc.) that was used for this study did not have special features to maintain a fixed turbine size. However, we maintained the turbine size fixed for all of our cycles by fixing the nozzle size at chocked flow design conditions. To maintain a chocked flow, the turbine flow characteristic was calculated from the following:

$$
\dot{m}=1.093 * \frac{P}{\sqrt{T}}
$$

The flow rate is in $1 \mathrm{bm} / \mathrm{hr}$, and $\mathrm{P}$ and $\mathrm{T}$ are the turbine inlet pressure (psia) and temperature (R).

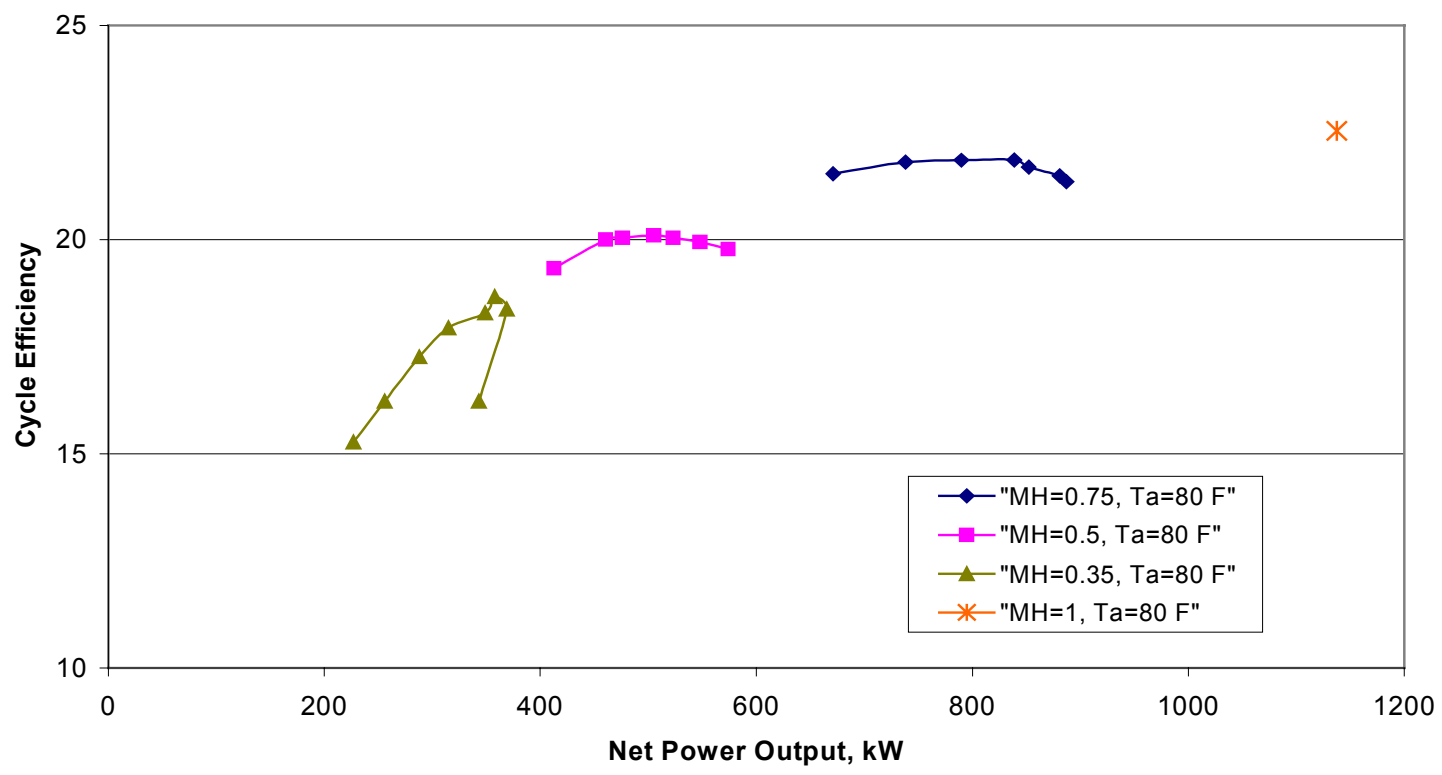

Figure 18. Net cycle power output versus cycle efficiency for $\mathrm{Ta}=80^{\circ} \mathrm{F}$ 


\subsection{ORC Cost for Modular Trough Power Plant (MTPP)}

The installed capital cost for the power cycle side of a MTPP is estimated to be about $\$ 1,700$ per $\mathrm{kWe}$ based on a preliminary analysis carried out by Barber-Nichols for a 1-MWe power plant (Appendix C). The major costs are associated with the turbine and the air-cooled condenser. The air-cooled condenser constitutes about $20 \%$ of the total capital cost, while turbine cost is about $45 \%$ of the total cost. The recuperator, which improves the cycle performance significantly, requires only $6 \%$ of the total cost, whereas the boiler requires about $15 \%$. The remaining $14 \%$ of the capital cost is spent on installation, the pump, and other miscellaneous components. By creating modular designs, the goal is to develop packaged systems with an installed capital cost of less than $\$ 1,000 / \mathrm{kWh}$.

\section{Solar Technology}

Parabolic trough technology has proven to be a very mature solar technology for large-scale power generation. The nine SEGS parabolic trough power plants in the California Mojave Desert consist of 354 MWe of installed electric generating capacity that have been in operation for up to 17 years. The SEGS plants utilize steam Rankine cycle power plants. An overview of parabolic trough technologies can be found in the U.S. Department of Energy / Electric Power Research Institute, Technology Characterizations (U.S. Department of Energy, 1997) and the parabolic trough technology roadmap (Price and Kearney, 1999).

\subsection{Parabolic Trough Collector Technology}

Two parabolic trough solar collector technologies have been considered for integration into the ORC plant. The first is the Luz second-generation collector known as the Luz System Two (LS2). A diagram of the LS-2 collector is shown in Figure 19. The second collector is the Industrial Solar Technology (IST) parabolic trough solar collector. Table 10 highlights the key design parameters of these two collectors. Both collectors have extensive field operational experience and have been tested at the National Solar Thermal Test Facility at Sandia National Laboratories in Albuquerque, New Mexico (Dudley et al., 1994 and 1995). Figure 20 shows the thermal performance of both collectors over a range of operating temperatures. 


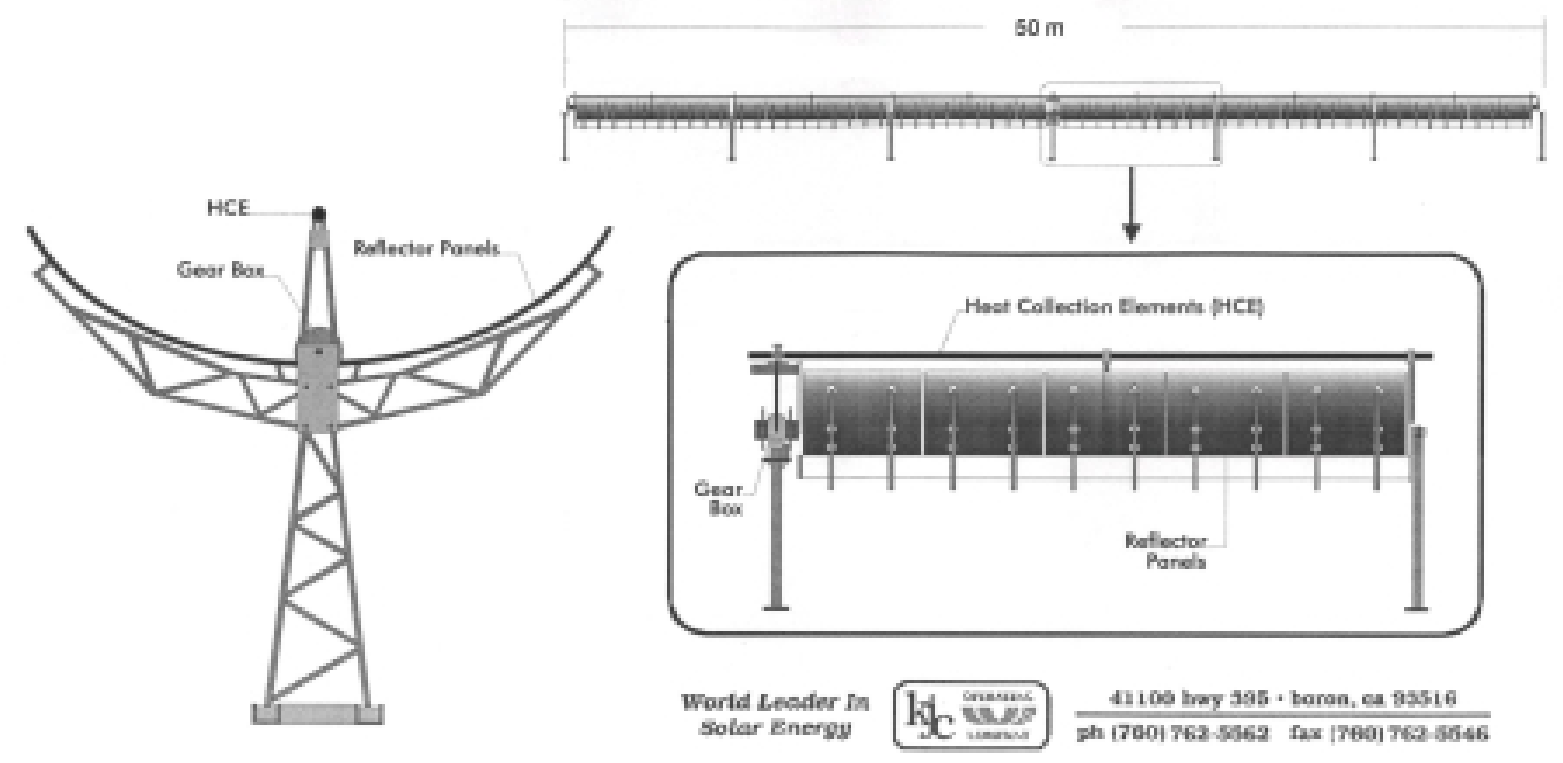

Figure 19. Luz System Two (LS-2) parabolic trough collector

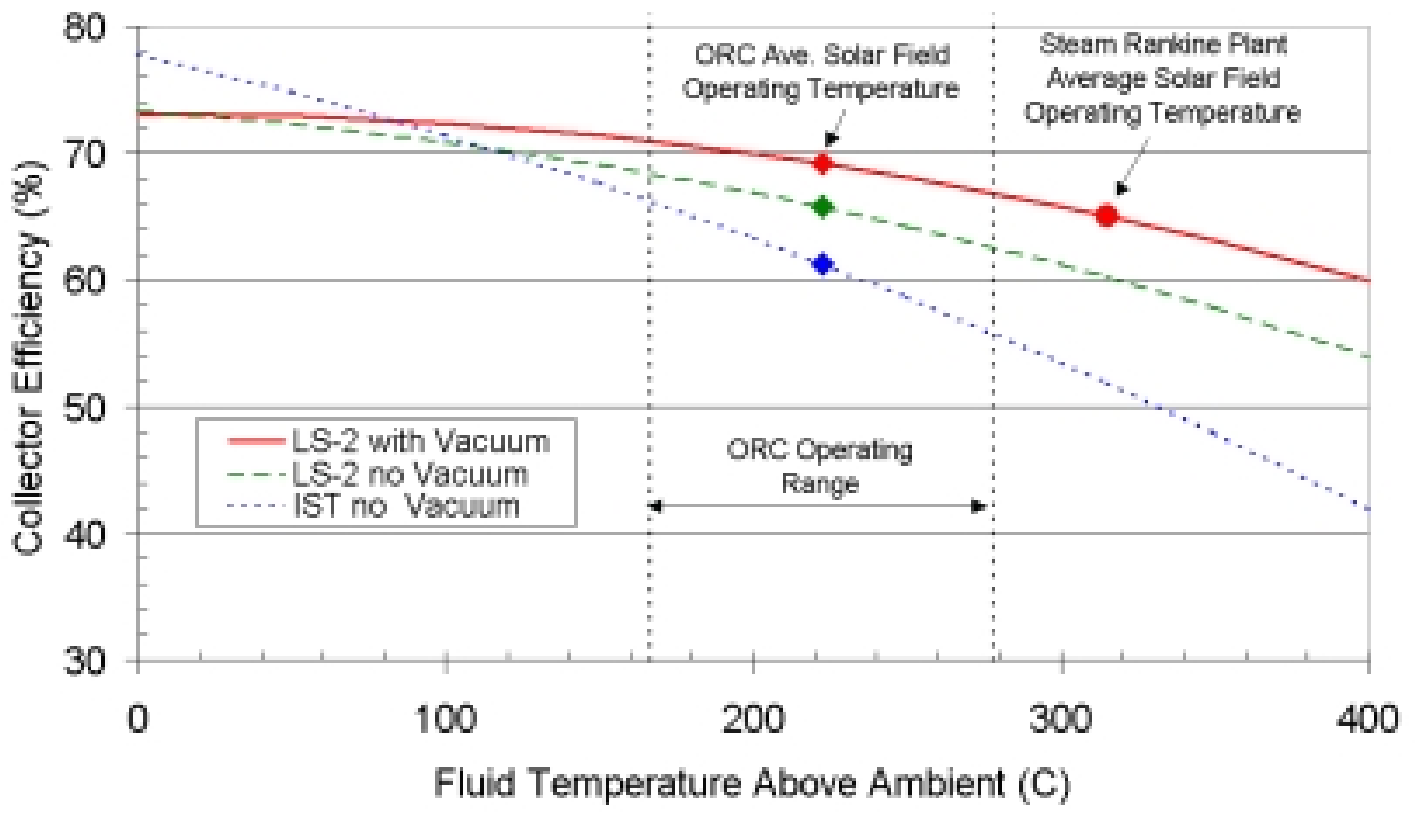

Figure 20. Sandia parabolic trough collector test results 
The LS-2 collector uses a torque-tube, galvanized-steel structure with a silvered glass reflector and an evacuated receiver with a Cermet selective coating. The LS-2 collector has demonstrated excellent performance, high availability, and ease of installation and maintenance. There are several concerns with the LS-2 collector: the capital cost, the lifetime of its evacuated receiver, and the fact that no company currently markets the LS-2 design. Recent cost studies by Flabeg Solar International (Pilkington Solar International, 2000) have estimated collector costs around $\$ 200 / \mathrm{m}^{2}$ for the third-generation Luz parabolic trough collector design (LS-3) for a solar field of 200,000 to $300,000 \mathrm{~m}^{2}$. Given roughly similar components and weight, it is assumed that the LS2 collector is approximately similar in cost. Much effort is currently being focused on resolving the receiver reliability issues, which seems to be related to reliability of a glass-to-metal seal that is necessary for an evacuated receiver. One option under consideration for ORC plants is to use a non-evacuated receiver. Although this will result in reduced solar field performance, it could also reduce cost and improve collector field reliability. Figure 20 indicates a drop of less than $5 \%$ by going to a non-evacuated receiver. Also, note that the solar collector efficiency at ORC temperatures is about the same with a non-evacuated receiver as it is for an evacuated receiver operating at the temperatures required for a steam power plant. Collectors for smaller ORC plants would likely be higher in cost, so some focus is required to find ways to reduce installation and the transaction costs for small systems. The LS-2 collector would be most attractive if it were also being used for large trough projects. This would help drive the cost down for small systems. 
Table 10. Collector Technology

\begin{tabular}{lcc}
\hline Features & Luz LS-2 & IST \\
\hline Concentrator & & \\
Aperture & $5 \mathrm{~m}$ & $2.3 \mathrm{~m}$ \\
Length & $47 \mathrm{~m}$ & $6.1 \mathrm{~m}$ \\
Aperture Area & $235 \mathrm{~m}^{2}$ & \\
Focal Length & $1.84 \mathrm{~m}$ & $0.762 \mathrm{~m}$ \\
Rim Angle & 70 degrees & 72 degrees \\
Concentration Ratio & 71 & 45 \\
$\quad$ Mirror Aperture to Receiver Diameter) & & \\
Mirror Reflectivity & $0.93(\mathrm{est})$. & 0.93 \\
Optical Efficiency & 0.733 & 0.778 \\
Receiver & & \\
Operational Range & $100-400^{\circ} \mathrm{C}$ & $100-300^{\circ} \mathrm{C}$ \\
Tube Diameter (I/O) & $70 \mathrm{~mm}$ & $51 \mathrm{~mm}$ \\
Length & $4 \mathrm{~m}$ & $6.1 \mathrm{~m}$ \\
Glass Envelop Transmittance & 0.96 & 0.96 \\
Selective Coating & Cermet & Black Nickel \\
Absorptance & 0.96 & 0.97 \\
Emittance & $0.14 @ 350^{\circ} \mathrm{C}$ & $0.30 @ 300^{\circ} \mathrm{C}$ \\
Collector Efficiency & & \\
Non-evacuated @ 215 & \\
Evacuated @ $215^{\circ} \mathrm{C}$ & $66.1 \%$ & $61.9 \%$ \\
Evacuated @ $315^{\circ} \mathrm{C}(\mathrm{SEGS}$ Conditions) & $65.0 \%$ & \\
\hline
\end{tabular}

The IST collector uses an aluminum structure and a silvered or aluminumized polymeric reflector bonded to aluminum sheets. The receiver is a non-evacuated design that uses a black nickel selective coating with a solgel anti-reflective coating on the glass envelope. The IST collector has been used primarily for lower temperature process heat applications in field sizes of approximately 2,000 to $5,000 \mathrm{~m}^{2}$. The IST collector has been tested at Sandia National Laboratory at temperatures up to $350^{\circ} \mathrm{C}$ (Dudley et al., 1995). The IST collector field operates unattended and requires minimal on-going maintenance. The primary concerns with the IST collector are the lifetime of the silverized polymeric reflector. The installed cost of the IST collector is about $\$ 200 / \mathrm{m}^{2}$. IST is currently looking at alternative reflectors, conversion of the structure to steel, and increasing the high temperature performance of its receiver. 
The Sandia test data in Figure 20 indicates that the IST collector performs about $6 \%$ below the non-evacuated LS-2 collector at the average temperature needed for the ORC plant. The lower performance is due primarily to the lower concentration ratio of the IST collector and the high emittance of the black nickel selective coating.

\subsection{Thermal Storage System}

The ORC solar resource temperature has been defined by the selection of Caloria as the heat transfer fluid to be used in the analysis. This fluid is a low-cost mineral oil that can be used as a cost-effective form of thermal storage. The upper temperature limit for Caloria is approximately $580^{\circ} \mathrm{F}\left(304^{\circ} \mathrm{C}\right)$. The same fluid was used at the SEGS I project in a two-tank thermal storage system and in a single-tank thermocline system at the Solar One power tower project. The SEGS I storage system had 3 hours of thermal storage capacity and operated on a daily basis for dispatching solar electric generation to the utility's high energy demand period for 13 years. A fire destroyed the storage system in 1999 after an apparent double failure of the ullage system used to maintain a positive pressure in the storage tanks. Given the 13 years of successful operation, it seems likely that a design fix could resolve the concerns with this system. However, special care will be necessary to minimize the potential fire risk.

A thermal-storage-system cost model for parabolic trough power plants has been developed (Nexant, Inc., 2000). The model was developed to evaluate thermal storage systems for large trough plants operating at higher temperatures. For this analysis, the Nexant cost model was modified to calculate the design and cost of two-tank Caloria thermal storage systems operating at the lower temperatures used in a trough-ORC system. Table 11 presents the sizes of thermal storage systems considered in this study and the cost and thermal heat losses from size storage system.

Table 11. Thermal Storage System Cost and Thermal Losses

\begin{tabular}{cccc}
\hline $\begin{array}{c}\text { Hours of } \\
\text { Storage } \\
\text { (hrs) }\end{array}$ & $\begin{array}{c}\text { Storage } \\
\text { Capacity } \\
\text { (MWht) }\end{array}$ & $\begin{array}{c}\text { Storage } \\
\text { Cost } \\
(\mathbf{\$} / \mathbf{k W h})\end{array}$ & $\begin{array}{c}\text { Thermal } \\
\text { Losses } \\
\mathbf{( k W t )}\end{array}$ \\
\hline 1 & 4.7 & 36 & 48 \\
3 & 14.1 & 28 & 54 \\
5 & 23.5 & 24 & 60 \\
8 & 37.5 & 21 & 69 \\
12 & 56.3 & 18 & 80 \\
16 & 75.1 & 15 & 92 \\
20 & 93.8 & 14 & 104 \\
\hline
\end{tabular}




\subsection{Operation and Maintenance}

The O\&M costs for small power systems can be a significant contribution to the total cost of power. The MTPP has been designed to help minimize O\&M costs. The ORC power cycle has been designed to use an above-atmospheric pressure condenser; the heat rejection system uses low maintenance dry cooling towers, and the turbine is a single-stage blade wheel. We assume that these plants will operate unattended with off-site electronic monitoring. This type of operation has been demonstrated for geothermal ORC plants. The plant is assumed to require only weekly on-site inspections.

Based on the experience of IST and the SEGS plants (Cohen et al., 1999), the solar field maintenance requirements are fairly well understood. IST has operated all of its parabolic trough plants remotely. The O\&M cost for the LS-2 and IST collectors averages about $1 \notin / \mathrm{kWh}$. Solar field O\&M includes bi-monthly field inspections and preventive maintenance and a monthly mirror wash. Because the solar field will use non-evacuated receivers, receiver failures are significantly reduced and repairs will be simplified and only require putting a new glass shell on the tube. Because the plant includes thermal storage and only a few loops of collectors, automatic operation and temperature control of the solar field is greatly simplified.

The only water required for the plant will be for mirror wash, fire protection, and on-site potable water for crews. Given the small size of the solar field, the wash crew can bring the water on-site for mirror washing, eliminating the need for an on-site water demineralizer.

\section{Economic Feasibility Analysis}

A detailed analysis has been completed to assess the potential economic feasibility of MTPPs. NREL has developed an hourly performance simulation model capable of modeling the performance of parabolic trough solar power plants. This model has been validated against the actual steam Rankine cycle parabolic trough power plants and found to reproduce annual electric performance within a few percent. Using the ORC power cycle performance for the system developed by Barber-Nichols (Appendix C), NREL has modified the trough power plant model to predict the performance of a parabolic trough-ORC plant.

\subsection{Baseline Trough-ORC System Design}

A nominally 1-MWe net parabolic trough-ORC power plant with thermal storage was modeled for this analysis. Table 12 highlights the key plant design assumptions. The baseline plant was modeled using the NREL Typical Meteorological Year Two data set for Barstow, California. This is the same region where all the SEGS steam Rankine trough power plants are located. The solar field is made up of LS-2 parabolic trough collectors with non-evacuated receivers. The mirror cleanliness is reduced to account for the reduced mirror washing frequency that would be typical of a distributed trough power plant.

The capital cost assumptions include $\$ 200 / \mathrm{m}^{2}$ of collector area, thermal storage cost as shown in Table 11 , and a power system cost of $\$ 1,700 / \mathrm{kWe}$ as estimated by Barber-Nichols. A 10-percent cost factor is added for project development, construction management, and general project contingency. The O\&M cost was assumed to be $2.5 \mathrm{c} / \mathrm{kWh}$. This is a fairly aggressive target; however, the plant has been designed to minimize O\&M cost. Experience from geothermal plants has shown that they can operate unattended. Solar field experience is much the same. The key O\&M costs are replacement receivers, flex hoses, and mirror washing. The non-evacuated 
receivers will significantly reduce receiver replacement costs, the plant will use ball joints instead of flex hoses, and the frequency of mirror washing will be cut in half. This O\&M cost is consistent with small geothermal systems.

\section{Table 12. Design and Cost Assumptions}

Location

Barstow, California

Annual direct normal radiation: $2,800 \mathrm{kWh}_{\mathrm{t}} / \mathrm{m} 2$

Power Cycle

Net electric generation: $1 \mathrm{MWe}$

Recuperated organic Rankine cycle

Air cooling: $80^{\circ} \mathrm{F}\left(27^{\circ} \mathrm{C}\right)$ design point

Thermal-to-net electric efficiency: $22.5 \%$

Capital cost: $\$ 1,700 / \mathrm{kW}_{\mathrm{e}}$ (Barber-Nichols)

Power plant forced outage rate: $5 \%$

Collector Field

Luz LS-2 Collector

Collector field temperature: $380-580^{\circ} \mathrm{F}\left(193-304^{\circ} \mathrm{C}\right)$

Receiver: Cermet selective coating, non-evacuated receiver

Collector optical efficiency: $78 \%$

Collector cleanliness: $90 \%$

Solar field availability: $99 \%$

Collector field cost: $\$ 200 / \mathrm{m}^{2}$

Thermal Storage

Heat transfer fluid: Caloria HT-43

Two-tank thermal storage system

Thermal storage size: 1-20 hours

Cost: \$15-36/kWht (depending on size)

Project Indirect Costs: $10 \%$ engineering design, construction management

Contingency O\&M cost: $2.5 \phi / \mathrm{kWh}$ 
The parabolic trough performance model calculates the solar field thermal delivery on an hourly basis. The solar energy is stored in the thermal storage system. The model has a dispatch strategy to determine when the power plant should be operated. Solar energy can be dispatched for nighttime electric production. The model includes thermal losses from the solar plant and thermal storage and calculates the parasitic electric consumption of the plant for both online and offline.

\subsection{Financial Assumptions}

The trough model also calculates the project economics. For the analysis, we assumed that the project would use conventional independent power project (IPP) financing. The project financing assumptions used in this analysis are shown in Table 13. The project assumes that a power purchase agreement (PPA) has been set up between the project owner and a utility or a large institutional customer. The PPA is structured so that a single energy price is paid for power that escalates each year with inflation. The analysis assumes $2.8 \%$ annual inflation. Annual insurance costs assumed are set at $0.5 \%$ of capital cost. This is consistent with insurance costs from the SEGS plants.

IPP financing relies on the revenue stream from the project as the collateral for the loan or project debt. As such, there are special constraints placed on the project. Typically, there needs to be a long-term power purchase agreement for at least the term of the debt. Because the debt relies on the revenues from the contract, they require that the net project revenues after paying O\&M expenses during any year be larger than the required debt payment that year. The debt service coverage ratio (DSCR) is the ratio of net income after O\&M expenses over the debt payment. Typically, DSCRs of 1.3 to 1.5 are required for IPP projects. Because solar projects are very capital intensive, this constraint becomes very important in the optimization between debt and equity financing. The project economics are based on an assumed 20-year project life and 12year debt terms.

The analysis assumes that the IPP financing takes advantage of the special state and federal financing incentives that are available for trough power plants. These include the $10 \%$ federal solar investment tax credit, the 5-year federal accelerated depreciation for federal income tax, and the California property tax exclusion for solar equipment.

The trough model uses these economic assumptions and the finance constraints to select the optimum mix of debt and equity financing required to minimize the first-year energy price. The first-year energy price is the economic figure of merit used in the remainder of the report to evaluate different plant design configurations. 
Table 13. Economics and Financing Assumptions

\author{
General Financial Assumptions \\ Energy price escalation: $2.8 \%$ \\ Inflation rate: $2.8 \%$ \\ Discount rate: $10 \%$ \\ Annual insurance: $0.5 \%$ of capital cost \\ IPP Ownership Assumptions \\ $14 \%$ IRR, 20-year project lifetime \\ $80 \%$ debt (or less) at $8 \%$ interest, 12 -year term, 1.3 minimum DSCR \\ 10\% Investment Tax Credit \\ Five-year accelerated depreciation \\ No property tax
}

\title{
5.3 Plant Design Optimization
}

Given the design, cost, and economic assumptions listed above, the solar field and thermal storage sizes can be varied, resulting in different annual electric outputs from the plant. The size of the solar field and thermal storage can be varied to optimize the thermal performance, electric output, or project economics. It is interesting to note that the optimum for each of these results in different plant configurations.

Discussing different sizes of thermal storage by the number of hours of equivalent full-load operation is fairly straightforward. However, discussing solar field size can be difficult to correlate between the size of the solar field and the corresponding electric output. To account for this, the terminology of solar multiple is used. A solar multiple of 1.0 means that under some standard design conditions, the solar field will deliver the amount of power required by the power plant to operate at the design-point rated electric output. Thus, the size of the solar field corresponding to a solar multiple of 1.0 will depend on the power cycle size and efficiency and the solar field efficiency. The reference conditions we used to define the solar multiple are as follows: a direct normal solar resource of $1,000 \mathrm{~W} / \mathrm{m}^{2}$, an ambient temperature of $25^{\circ} \mathrm{C}$, a wind speed of $2.5 \mathrm{~m} / \mathrm{s}$, and a solar incidence angle of zero degrees. These standard conditions for referencing a solar multiple mean that a solar field design with a solar multiple of 1.0 will be the same size at any location assuming that the same power plant is used. However, a solar field with the same solar multiple at two different locations will not have the same annual performance. A solar plant with a solar multiple of 2.0 would deliver twice the amount of thermal energy required by the power cycle at the design point conditions. The solar field with a solar multiple of 2.0 is twice the size of the solar field with a solar multiple of 1.0. A solar plant with a large solar multiple would require thermal storage to avoid producing excess energy that the power plant would not be able to use. Table 14 shows the solar multiples analyzed in this study and the corresponding solar field sizes. Note, the SEGS plants do not have thermal storage and have solar multiples of approximately 1.25 , based on our definition. 


\section{Table 14. Solar Field Size for Solar Multiple Cases Evaluated}

\begin{tabular}{cc}
\hline $\begin{array}{c}\text { Solar } \\
\text { Multiple }\end{array}$ & $\begin{array}{c}\text { Collector } \\
\text { Area } \\
\left(\mathbf{m}^{2}\right)\end{array}$ \\
\hline 1.0 & 7,520 \\
1.2 & 9,024 \\
1.5 & 11,280 \\
1.8 & 13,536 \\
2.2 & 16,544 \\
2.6 & 19,552 \\
3.0 & 22,560 \\
\hline
\end{tabular}

Figure 21 shows the annual performance of the baseline plant for a parametric analysis where the solar field size (solar multiple) and thermal storage size (equivalent hours of power cycle operation) are varied. The maximum annual electric performance, shown as the annual plant capacity factor, occurs as expected for the largest solar field with the most thermal storage. Capacity factor is defined as follows:

Capacity Factor $=($ Annual Output $) \div($ hours $/$ year $)($ rated capacity $)$

It is interesting to note that for smaller solar field sizes, there is clearly an optimum amount of thermal storage beyond which the annual performance actually begins to drop off. This is due to increased thermal heat losses from the larger volumes of thermal storage. With larger solar fields, the output significantly increases as thermal storage is added. This is because a significant amount of potential solar field thermal energy is thrown away, or dumped, because the power plant is at capacity, and the thermal storage is full. 


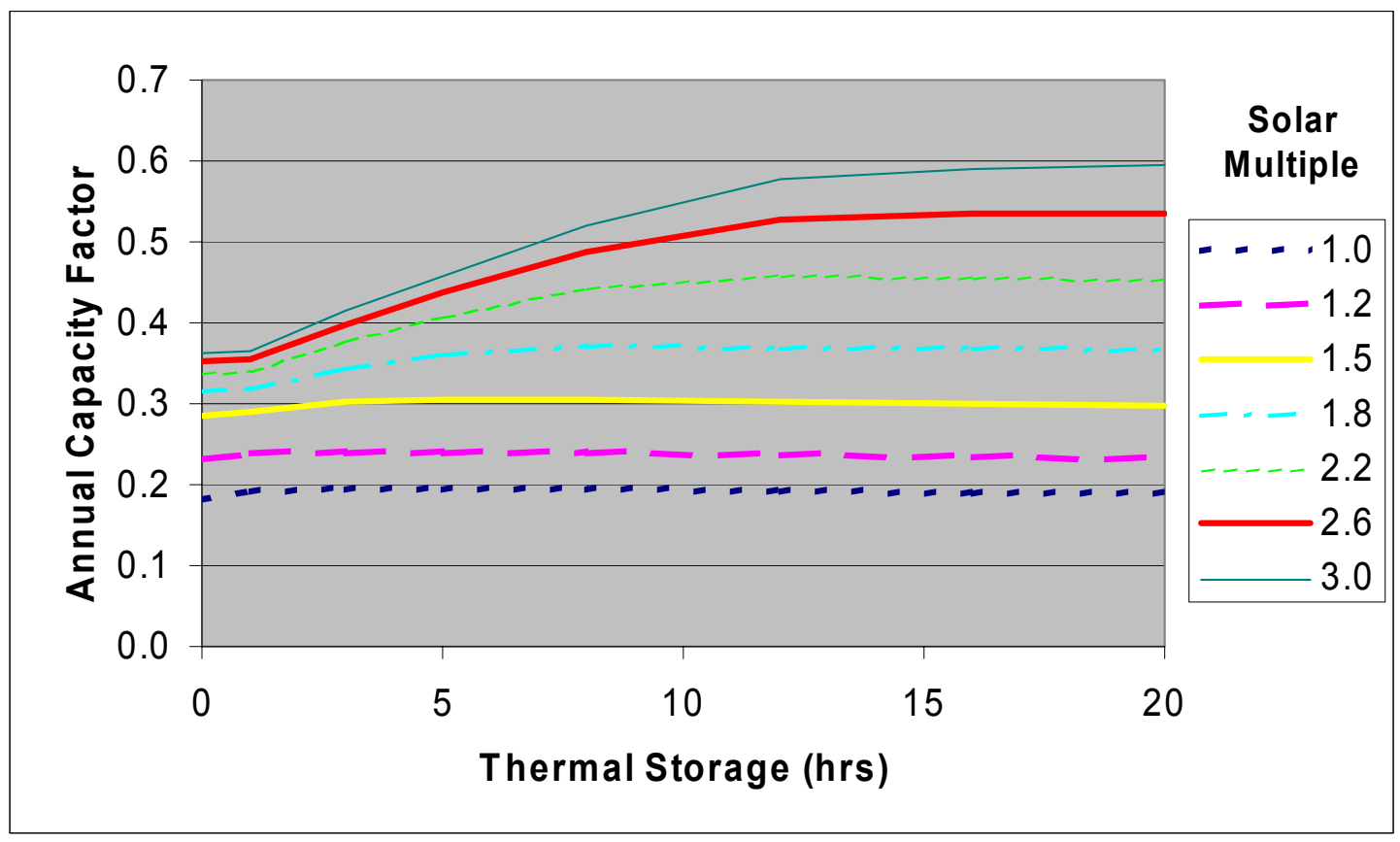

Figure 21. Annual plant capacity factor for 1-MWe trough-ORC plant in Barstow, California

Figure 22 shows the annual solar-to-electric efficiency for the same analysis. The optimum annual efficiency occurs for a plant with a solar multiple of 2.2 and 12 hours of thermal storage. The impact of "dumped energy" is clearly seen for larger solar plants with small amounts of thermal storage. The impact of heat losses from thermal storage can also be seen on the plant with a solar multiple of 1.0. For this plant, the annual efficiency drops off with larger amounts of thermal storage due to the increasing thermal losses from storage. It is also interesting to note that the solar plants with larger solar multiples tend to be more efficient than the solar multiple of 1.0 case. This is due to several factors. First, even with no thermal storage, the power plant can operate at up to about $15 \%$ over design plant output. Since the solar conditions and the solar incidence angle are rarely at the design point where the solar multiple is calculated, the power plant can usually handle the full thermal output from a plant with a solar multiple of 1.2 or even larger. Thus, the efficiency of the plants with a solar multiple of 1.2 are better than the plant with a solar multiple of 1.0, because the turbine is generally operating at a higher average load, and offline parasitic loads are a smaller portion of the total. 


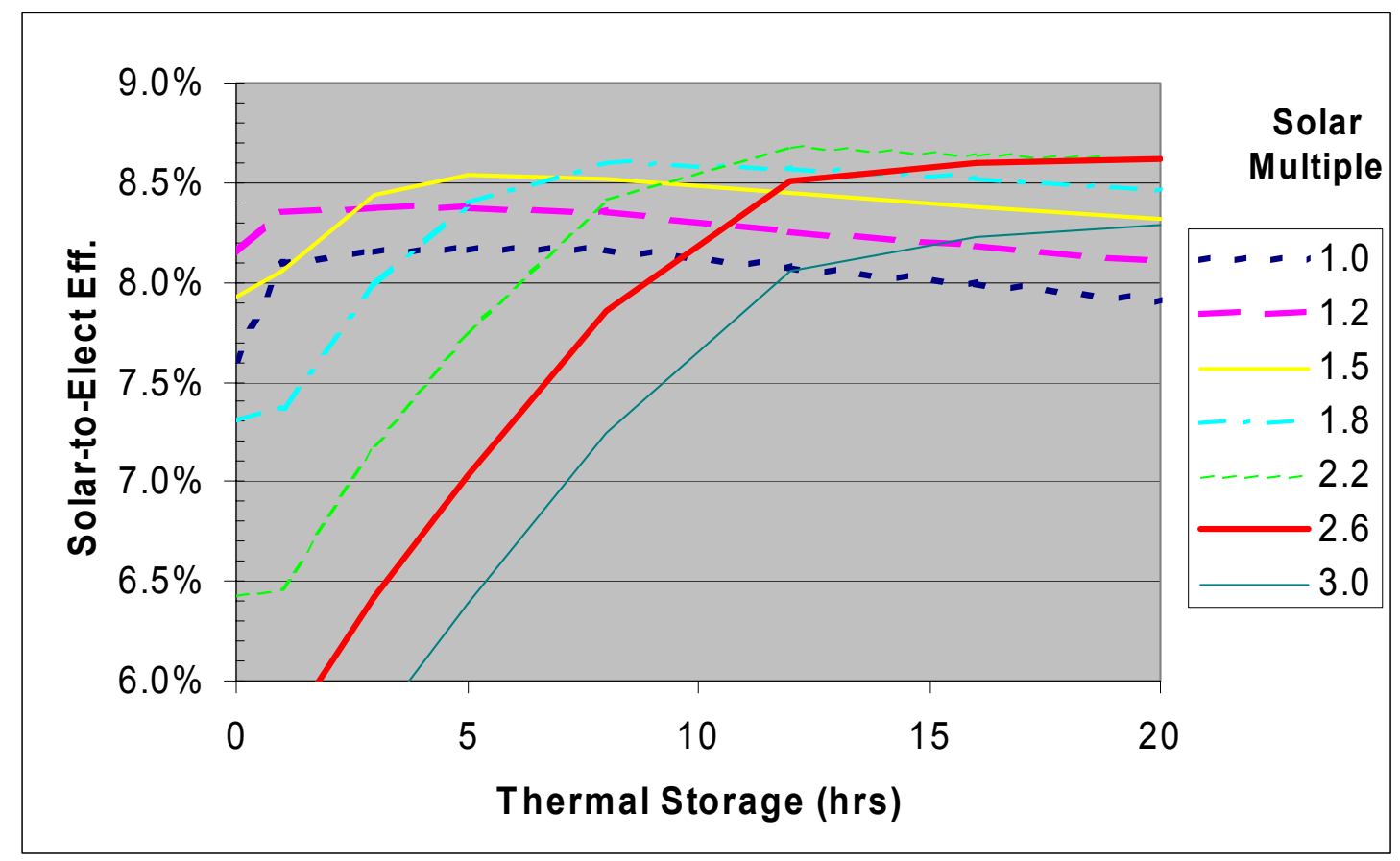

Figure 22. Annual solar to electric efficiency for 1-MWe trough-ORC plant in Barstow, California

For the larger plants, the turbine continues to operate at higher loads, and parasitic losses are relatively smaller. This compensates for thermal energy dumped. The largest solar multiple of 3.0 dumps a significant amount of thermal energy even in the case with 20 hours of thermal storage. Figure 23 shows the fraction of annual solar field thermal energy that is dumped because storage is full and the power cycle is already at full load. Note that virtually no energy is dumped in the plants with the two smallest solar multiples.

Figure 24 shows the minimum first-year energy price for each case that satisfies the financial requirements for equity return on investment and the debt DSCR. Here again the optimum is a different case than either the optimum output case or the optimum efficiency case. The plants with the lowest first-year energy costs are the plants with solar multiples of 2.6 and 3.0 with 12 hours of thermal storage. Although the plant with a solar multiple of 3.0 has a slightly lower first-year energy price requirement, we selected the plant configuration with a 2.6 solar multiple and 12 hours of thermal as the reference case because of its lower initial capital cost. Table 15 gives the reference design, performance, and financial structure for the reference case. 


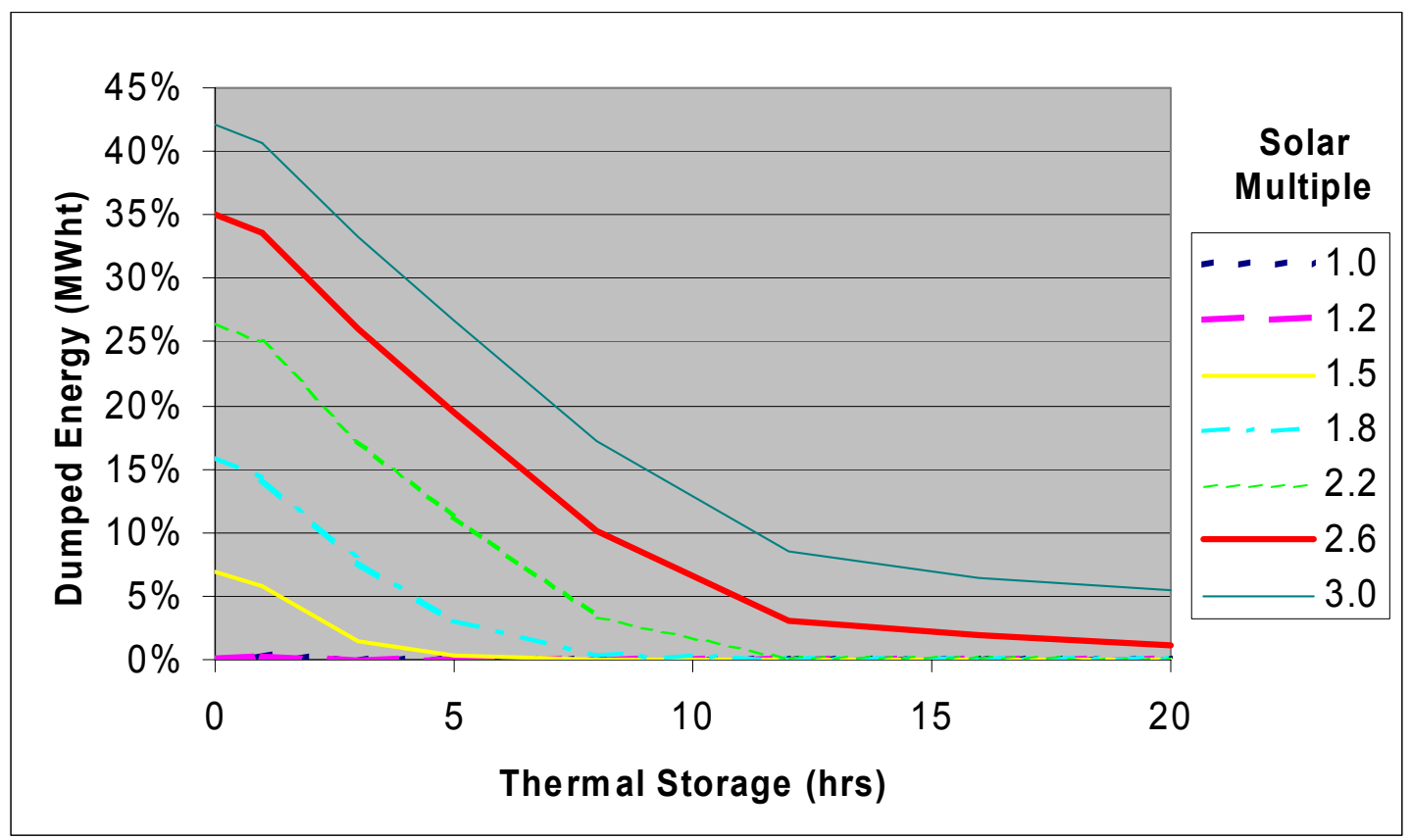

Figure 23. Dumped energy for 1-MWe trough-ORC plant in Barstow, California

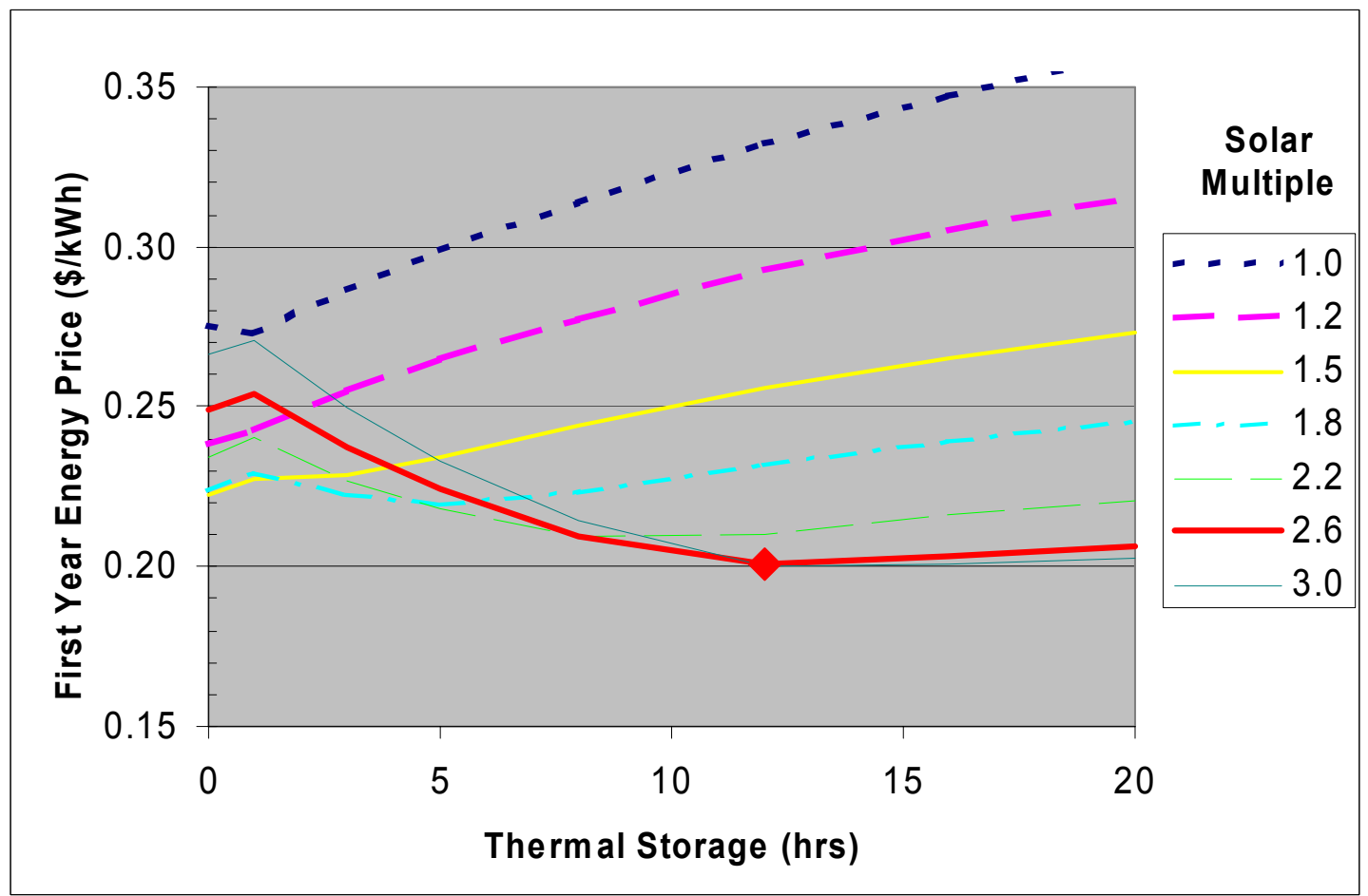

Figure 24. First-year energy price for 1-MWe trough-ORC plant in Barstow, California 
The reference plant in Table 15 has a solar field with $19,552 \mathrm{~m}^{2}$ of LS-2 parabolic trough collectors, 12 hours of thermal storage, and a capital cost of $\$ 7,349 / \mathrm{kWe}$. The plant generates $4,644 \mathrm{MWh}$ of electricity for an annual capacity factor of $54 \%$. The solar field has an annual efficiency of $43.8 \%$ and an annual solar to electric efficiency of $8.1 \%$. The initial energy price is about $20 \notin / \mathrm{kWh}$.

Table 15. Reference Plant Design, Annual Performance, and Economics

\begin{tabular}{lc}
\hline Reference Plant Design & \\
Solar multiple & 2.6 \\
Thermal storage (hrs) & 12 \\
Solar field area $\left(\mathrm{m}^{2}\right)$ & 19,552 \\
Capital cost (k\$) & $\$ 7,349$ \\
Reference Plant Performance & \\
Annual solar field efficiency & $43.8 \%$ \\
Annual heat losses from storage & $2.9 \%$ \\
Dumped energy (storage full) & $3.1 \%$ \\
Annual net electric output (MWh $)$ & 4,644 \\
Capacity factor @ 1 MWe & $53 \%$ \\
Annual solar to electric efficiency & $8.1 \%$ \\
Reference Plant Economics & \\
DSCR (minimum/average) & $1.30 / 1.52$ \\
Debt share & $54 \%$ \\
IRR & $14 \%$ \\
First-year energy price (\$/kWh) & $\$ 0.201$ \\
\hline
\end{tabular}

\subsection{Influence of Ambient Temperature}

Because the ORC power cycle uses dry cooling, ambient air temperature has a significant impact on the power cycle efficiency. The ORC power cycle was evaluated for different ambient air temperatures. Figure 25 below shows how the design point electric output changes for temperatures other than $25^{\circ} \mathrm{C}$. The efficiency improves at lower ambient temperatures and is significantly reduced at high ambient temperatures. 


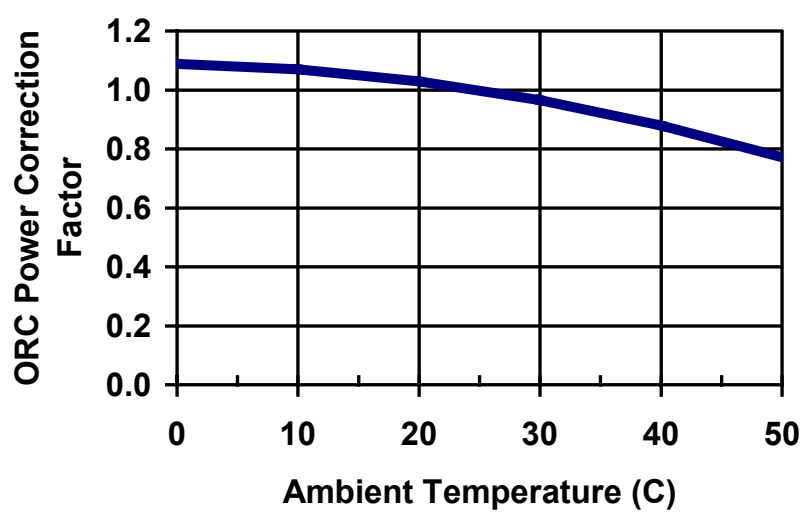

Figure 25. Influence of ambient temperatures on ORC electric output

Because MTPP are likely to be located in hot clear climates where the solar resource is high, it is important to understand the impact of ambient temperature on the annual plant performance. In order to understand this impact, three plant sites were selected for analysis that had similar levels of annual solar resource, but different ambient temperatures. The three sites included Phoenix, Arizona; Prescott, Arizona; and Alamosa, Colorado. Each site has an annual solar resource of approximately $6.9 \mathrm{kWe} / \mathrm{m}^{2}$-yr. The average ambient temperature ranges from $22.5^{\circ} \mathrm{C}$ in Phoenix to $4.9^{\circ} \mathrm{C}$ in Alamosa. The results of the analysis are shown in Table 16 below. Although the ambient temperature is lowest in Alamosa and highest in Phoenix, the annual solar performance is actually best in Phoenix and worst in Alamosa. This, however, is due to the latitude of the locations. The latitude of the plant significantly affects the annual collector optical efficiency. The colder ambient temperatures also increase the thermal losses from the plant, as shown by the collector thermal efficiency. The colder ambient temperatures do improve the power cycle efficiency. When the collector thermal efficiency and power cycle efficiencies are accounted for, the site ambient temperature effect results in a 5\% efficiency improvement at Alamosa over the plant in Phoenix.

\section{Table 16. Influence of Ambient Temperature on Annual Performance}

\begin{tabular}{lccc}
\hline Location & Phoenix, AZ & Prescott, AZ & Alamosa, CO \\
Direct Normal Insolation $\left(\mathrm{kWh} / \mathrm{m}^{2} / \mathrm{yr}\right)$ & 6.90 & 6.95 & 6.93 \\
$\quad$ Average Ambient Temperature $\left({ }^{\circ} \mathrm{C}\right)$ & 22.5 & 12.9 & 4.9 \\
$\quad$ Latitude $\left({ }^{\circ}\right.$ North) & $33.4^{\circ}$ & $34.6^{\circ}$ & $37.4^{\circ}$ \\
Annual Performance & & & \\
$\quad$ Solar to Electric Efficiency (\%) & $\mathbf{8 . 1 \%}$ & $\mathbf{8 . 0 \%}$ & $\mathbf{7 . 8 \%}$ \\
$\quad$ Collector Optical Efficiency (\%) & 56.8 & 54.9 & 52.8 \\
$\quad$ Collector Thermal Efficiency $(\%)$ & 85.0 & 83.7 & 82.5 \\
$\quad$ PB Therm. to Elec. Efficiency $(\%)$ & 20.2 & 21.2 & 21.9 \\
Lower Ambient Temperature Benefit & --- & $\mathbf{3 \%}$ & $\mathbf{5 \%}$ \\
\hline
\end{tabular}




\subsection{Influence of Plant Location}

The annual electric output is directly related to the site environmental conditions. Clearly, the site solar resource impacts performance, but the site latitude also impacts the solar incidence angle, and the site ambient temperature impacts both the power plant and solar field efficiencies. Table 17 looks at the impact on baseline plant-solar-to-electric efficiency and required first-year energy price of plants at different locations. Solar resource has the largest impact on project economics. Site latitude, ambient temperature, and solar resource impact the annual solar-to-electric efficiency and, therefore, have a second-order impact on project economics. From Table 17, it is clear that a significant portion of the United States has solar resources and climates that are reasonable attractive for this type of solar power project. Thus, solar resource alone will not necessarily be the determining factor of where power projects are likely to be attractive.

Table 17. Influence of Plant Location

\begin{tabular}{lccccc}
\hline \multicolumn{1}{c}{ Location } & $\begin{array}{c}\text { Direct } \\
\text { Normal } \\
\text { Insolation } \\
\left(\mathbf{k W h} / \mathbf{m}^{2} / \mathbf{y r}\right)\end{array}$ & $\begin{array}{c}\text { Site } \\
\text { Latitude } \\
\text { (Degrees } \\
\text { North) }\end{array}$ & $\begin{array}{c}\text { Average } \\
\text { Ambient } \\
\text { Temperature } \\
\left({ }^{\circ} \mathbf{C}\right)\end{array}$ & $\begin{array}{c}\text { Solar-to- } \\
\text { Electric } \\
\text { Efficiency } \\
\mathbf{( \% )}\end{array}$ & $\begin{array}{c}\text { First-Year } \\
\text { Electric } \\
\text { Price } \\
(\mathbf{\phi} / \mathbf{k W h})\end{array}$ \\
\hline Daggett, California & 7.650 & 34.9 & 19.8 & 8.1 & 20.1 \\
Las Vegas, Nevada & 7.140 & 36.1 & 19.5 & 7.9 & 22.9 \\
Prescott, Arizona & 6.950 & 34.7 & 12.9 & 8.0 & 23.1 \\
Alamosa, Colorado & 6.930 & 37.5 & 4.9 & 7.8 & 23.7 \\
Phoenix, Arizona & 6.900 & 33.4 & 22.5 & 8.1 & 23.1 \\
El Paso, Texas & 6.820 & 31.8 & 17.8 & 8.3 & 22.7 \\
Reno, Nevada & 6.390 & 39.5 & 10.2 & 7.9 & 24.0 \\
San Francisco, California & 5.159 & 37.6 & 13.1 & 8.1 & 30.0 \\
W. Palm Beach, Florida & 4.110 & 26.7 & 23.6 & 7.5 & 35.0 \\
Raleigh, North Carolina & 4.100 & 35.6 & 14.8 & 7.2 & 41.1 \\
\hline
\end{tabular}




\section{Market Potential for Modular Trough Power Plant Systems}

The price of power from a 1-MWe trough power plant is on the order of $20 \notin / \mathrm{kWh}$. This raises the question: Do any markets exist where this cost is likely to offer an opportunity for a sustained market?

\subsection{Market Assessment}

This section reviews the electric power markets for which the MTPP might be considered.

Wholesale Power: Wholesale power refers to power generated from centralized power stations that market power to utilities or large customers directly. Although there have been substantial fluctuations in prices and relatively short-term supply shortages during 2000 and 2001, demand, supplies, and prices seem to have stabilized. Current gas commodity rates appear to be stabilized at around $\$ 2 /$ million Btu. At this gas price, wholesale power rates are around 2 to $3 \notin$ per $\mathrm{kWh}$. The MTPP with thermal storage can dispatch power to meet utility peak-demand periods when higher prices are paid for energy delivery. If solar power is dispatched to these higher price periods, the average value of wholesale power will be in the range of 4 to $5 \phi$ per $\mathrm{kWh}$. The MTPP is far from competitive in the wholesale power market.

Retail Power Customers: One of the primary advantages of MTPP systems is that they can produce power on the customer side of the meter instead of the utility side. Thus, power generated at a customer site is valued to the customer at their retail rate because it offsets power that would be purchased from the utility at the retail rate. This means that the power generated has an economic value of between about 10 and $15 \phi / \mathrm{kWh}$ instead of the wholesale power rate of 4 to $5 \phi$ per $\mathrm{kWh}$. Customers must be large enough to consume the full power generated from the plant. This means that relatively large commercial or industrial customers are required. These customers would also need a significant amount of land nearby. However, because the power can be dispatched to high rate and high demand periods for the customer, the plant could be used to help reduce peak demand charges. This helps to increase the value of the power. Large federal, state, and local government facilities are likely some of the best opportunities for this type of application. Although the MTPP is not fully competitive in the retail power market, this represents one of the best potential opportunities, especially if costs can be reduced. Also some customer in this market could decide to go with solar power for non-economic reasons.

Remote Power: Remote power applications are typically off-grid applications. There are limited numbers of remote power applications in the United States for which a 1-MWe system would be appropriate. Mining, remote Department of Defense facilities, and agriculture may represent the best opportunities. Internationally, there are a large number of villages that this size of system might be applicable. Typically, small diesel generator sets are the primary source of power for these applications. The price of diesel power can be $25 \notin / \mathrm{kWh}$ or more. Very small remote power systems are even more expensive. If good remote applications can be found this could be a sustainable market for a developer of MTPP systems. It should also be noted that the cost for a small trough system built for a remote power application is likely to be higher than the base case system considered here. This is due to increased transportation and support costs associated with a remote location. In addition, based on the experience of other renewable power technologies, the international market that appears to be attractive will also offer many additional challenges.

Green Power Markets: A number of utilities and retail energy providers offer consumers green energy products. Typically customers can pay a premium of 1 to $2.5 \phi / \mathrm{kWh}$ for green power from 
wind or other renewable power technologies. This market has grown significantly over the last several years, but typically only a few percent of customers switch to green power. In addition, the California power crisis of 2000 and 2001 managed to destroy the green power market that, up to that point, had been developing in the state. Green power markets require a significant overhead to attract customer and cover the administration costs. Based on the small percentage of customers that switch, this market has not represented a significant opportunity for large-scale trough power. However, it could represent an opportunity for MTPPs. If a green power energy provider wanted a few hundred kilowatts to a few megawatts of solar power, the MTPP is likely the most economically competitive.

Renewable Portfolio Standards (RPS): Several states have introduced renewable portfolio standards. These require a specified fraction of an energy provider's electric supply to be made up from renewable power sources. When there is no renewable technology specified, biomass waste, landfill gas, or wind generators are the most economic renewable generators. Solar power typically is not able to compete unless specific set-asides in the RPS are available for solar. Solar RPSs are developed in Nevada and Arizona. Whether or not MTPPs are able to compete in these or other RPSs will depend on how the RPSs are set up. However, the RPSs may offer an excellent opportunity for the RPSs in these two states. Although larger-scale trough projects could significantly lower cost for bulk power, they may offer better incremental capacity increases than larger trough plants. Also, because the plants can be customer sited, they may be able to get both the customer retail price and the RPS.

Based on the market opportunities identified above, only the remote power market appears to be economically attractive for the baseline system: however, this is likely a difficult market to initially penetrate. For the MTPP systems to compete in other markets the cost of power must be reduced. The opportunities for reducing the cost of MTPP systems include the following: improving efficiency, reducing cost, and financial incentives that improve the economic attractiveness to the owner.

\subsection{Improving Efficiency}

Efficiency can be improved in the solar field or the power cycle. The obvious opportunities for improving efficiency in the solar field are by using evacuated receivers in the collector field and by increasing the frequency of mirror wash. Efficiency can be increased in the power plant by using a more complex and efficient power cycle or by going to wet cooling. Although each of these opportunities will result in improved efficiency, they also come with the penalties of either increased capital cost, increased O\&M costs, or both. The potential impact of each is evaluated below.

Evacuated Trough Receivers: The baseline solar plant design in this study assumes that the trough collectors use a non-evacuated receiver design. The evacuated receiver design that is standard at the SEGS plants has significantly lower thermal losses than the non-evacuated receiver, but has a high failure rate and is more expensive. For comparison, we estimate the cost differential between an evacuated and a non-evacuated receiver tube to be $\$ 300$ per receiver tube. Based on this assumption, using evacuated receiver tubes would add $\$ 281,000$ to the cost of the project. This is about a $4 \%$ increase in total capital cost, or about an $8 \%$ increase in the solar field cost on a per square meter basis. Converting to an evacuated receiver significantly reduces thermal losses from the solar field by almost two-thirds. This results in an overall increase in the solar field thermal efficiency by about $15 \%$. However, assuming that the evacuated receivers had a $3 \%$ annual failure rate, the solar field O\&M cost would increase by $0.6 \phi / \mathrm{kWh}$ to account for 
changing out broken receiver tubes. The changes from the baseline systems are highlighted in Table 18. The overall effect is that evacuated receivers appear to reduce the cost of power by about $2.7 \%$. The benefit is relatively small and replacement of broken receivers adds complexity to the plant O\&M. Other factors might dictate whether or not evacuated receivers were to be used.

Increased Mirror Wash: The baseline assumes that the mirror cleanliness is maintained at $90 \%$ of new mirror reflectivity. The SEGS plants claim that they can maintain mirror reflectivity at a $95 \%$ cleanliness factor. The $90 \%$ was selected to reduce the annual O\&M expenses by reducing the frequency of mirror wash. Data from the SEGS plants (Cohen et al., 1999) indicates that the cost of washing mirrors is about $\$ 0.013 / \mathrm{m}^{2}$ of mirror. This works out to $\$ 260$ to wash the baseline system field. Assuming a $90 \%$ cleanliness factor, the solar field is washed approximately once a month for an annual cost of $\$ 3,120$ or $0.07 \notin / \mathrm{kWh}$. Increasing the cleanliness factor to $95 \%$ means the solar field must be washed every 12 days. This increases the annual wash cost to about $0.18 \notin / \mathrm{kWh}$. The output from the plant increases by approximately $7 \%$. From Table 18, we can see that accounting for increased performance and increased mirror washing costs result in a 3\% reduction in cost of power. Note, the analysis is based on the conditions at the SEGS plants. Washing requirements could vary dramatically at different sites. In the case considered, increasing mirror washing frequency appears to make economic sense. However, this will be very sensitive to actual mirror wash costs experienced at individual sites, the rate of mirror soiling, and the effectiveness of cleaning.

Improved Power Cycle Efficiency: The MTPP evaluated has a relatively low thermal-to-electric conversion efficiency compared to the trough steam power plants. The ORC cycle considered here was intentionally very simple to reduce cost and minimize O\&M requirements. More efficient power cycles can be designed that include multiple turbine stages, reheat turbines, or regenerative heating. Wet cooling can also be used to improve power cycle efficiency. All of these variations increase the complexity of the cycle and will result in increased system capital and O\&M costs. Although a detailed design study has not been conducted to evaluate variations, we evaluated the potential benefit of a substantially improved power cycle that would have the same efficiency as the more efficient steam power cycles. To account for the increased complexity, we assume a $20 \%$ increase in capital and O\&M costs. We also assume the solar field must operate at the higher temperatures of the current steam trough plants $\left(293-391{ }^{\circ} \mathrm{C}\right)$. The results of this case are shown in Table 18. Because of the higher operating temperature, the solar field heat losses are increased by $67 \%$, resulting in an $18 \%$ drop in solar field thermal efficiency due to the use of non-evacuated receivers. The power cycle efficiency is increased by $69 \%$, overall resulting in a 33\% increase in thermal-to-electric performance. However, the increased capital and O\&M costs nearly offset the increased thermal-to-electric efficiency. The resulting reduction in cost is minimal from the baseline system, 3.5\%. It doesn't appear that improvements to the power cycle efficiency are warranted if they result in increased capital and O\&M costs.

A second case was considered with the advanced power plant that also included the evacuated receivers in the solar field. In this case, because of the higher average solar field temperatures, the reduction in cost resulting from including the evacuated receivers is greater than for the lower temperature case. Thus, the evacuated receiver will be more attractive if higher solar field temperatures are used. 
Based on the results of these two cases, it is clear that careful assessment of all costs are necessary to correctly evaluate the potential benefit of any design changes. Care must be taken for any design change that affects the system efficiency and the capital and O\&M costs.

Table 18. Improved Solar Field and Power Plant Efficiency

\begin{tabular}{|c|c|c|c|c|c|}
\hline Case & $\begin{array}{l}\text { Base } \\
\text { Case }\end{array}$ & $\begin{array}{l}\text { Evacuated } \\
\text { Receivers }\end{array}$ & $\begin{array}{l}\text { Increased } \\
\text { Mirror } \\
\text { Wash }\end{array}$ & $\begin{array}{c}\text { Improved } \\
\text { Turbine } \\
\text { Efficiency } \\
(\eta)\end{array}$ & $\begin{array}{c}\text { Improved } \\
\text { Turbine \& } \\
\text { Evacuated } \\
\text { Receiver }\end{array}$ \\
\hline Location & Barstow & Barstow & Barstow & Barstow & Barstow \\
\hline Receiver losses $\left(\mathrm{W} / \mathrm{m}^{2}\right)$ & 67 & 23 & 67 & 112 & 39 \\
\hline Solar field size $\left(\mathrm{m}^{2}\right)$ & 19,552 & 18,330 & 18,330 & 12,831 & 11,609 \\
\hline Relative solar field size & $100 \%$ & $94 \%$ & $94 \%$ & $66 \%$ & $59 \%$ \\
\hline \multicolumn{6}{|l|}{ Annual Performance } \\
\hline Solar field $\eta(\%)$ & 43.8 & 50.3 & 46.8 & 36.0 & 45.5 \\
\hline Power plant $\eta(\%)$ & 20.5 & 20.5 & 20.5 & 34.3 & 34.3 \\
\hline Solar-to-electric $\eta(\%)$ & 8.1 & 9.3 & 8.7 & 10.8 & 13.6 \\
\hline Annual Capacity Factor (\%) & 53 & 57 & 53 & 46 & 53 \\
\hline Capital cost (\$/kWe) & 7,713 & 7,757 & 7,431 & 6,262 & 6,186 \\
\hline Solar field $\left(\$ / m^{2}\right)$ & 200 & 215 & 200 & 200 & 215 \\
\hline Power block (\$/kWe) & 1,700 & 1,700 & 1,700 & 2,040 & 2,040 \\
\hline O\&M cost (\$/kWh) & 0.025 & 0.0309 & 0.0261 & 0.030 & 0.036 \\
\hline First-year energy price & 0.2007 & 0.1953 & 0.1944 & 0.1936 & 0.1780 \\
\hline Cost Reduction Benefit & -- & $2.7 \%$ & $3.1 \%$ & $3.5 \%$ & $11.3 \%$ \\
\hline
\end{tabular}

\subsection{Reduced Technology Cost Case}

The system cost analysis above was conducted based on the cost of a first system, not including initial development costs for the turbine, power cycle, and control systems. The cost of additional systems will be lower for the power plant and for the solar field as well. For example, based on standard learning curve used by turbine vendors, the power cycle costs would be reduced from $\$ 1,700 / \mathrm{kWe}$ to about $\$ 1,000 / \mathrm{kWe}$ after a few tens of systems were built. Based on the simplified trough collector concept, the solar field costs are likely to be reduced as well. A parametric analysis was conducted to evaluate a reasonable low-cost scenario after about 10 systems were built, assuming a learning curve of $90 \%$. For this analysis, a $25 \%$ reduction in the collector field cost, thermal storage cost, power cycle cost, and O\&M costs were assumed. Table 19 shows the base case and low-cost assumptions used. Based on these assumptions, the first year cost of power is reduced by $25 \%$ to approximately $15 \notin / \mathrm{kWh}$. 
Table 19. Low-Cost Case

\begin{tabular}{lcc}
\hline Case & Reference & Low Cost \\
\hline Cost Assumptions & & \\
Solar field cost $\left(\$ / \mathrm{m}^{2}\right)$ & 200 & 150 \\
Thermal storage $(\$ / \mathrm{kWht})$ & 17.6 & 13.2 \\
Power cycle cost $(\$ / \mathrm{kWe})$ & 1,700 & 1,275 \\
Total plant capital cost $(\$ / \mathrm{kWe})$ & $\mathbf{7 , 7 1 3}$ & $\mathbf{5 , 7 8 5}$ \\
O\&M cost $(\phi / \mathrm{kWh})$ & 2.5 & 1.9 \\
First-year electricity price $(\phi / \mathbf{k W h})$ & $\mathbf{2 0 . 1}$ & $\mathbf{1 5 . 1}$ \\
\hline
\end{tabular}

\subsection{Financial Incentives}

The analysis of the baseline system assumes current IPP financial assumptions for a plant located in California. Currently, other financial incentives are being considered. IPP plants currently can use a $10 \%$ investment tax credit (ITC). Most renewable technologies are moving away from the ITC to a production tax credit (PTC). We evaluated three tax credit cases in addition to the baseline with the $10 \%$ ITC (Table 19). The first is switching to a 10 -year $1.7 \not /$ per $\mathrm{kWh}$ PTC that inflates with inflation. This gave results very similar to the current $10 \%$ ITC. The second case includes both the current ITC and the proposed PTC. This results in a $9 \%$ cost reduction. The third case increases the ITC from 10 to $50 \%$. This significantly reduces the cost of power by $37 \%$.

California currently offers a capital buydown for small renewable power systems. Systems under $10 \mathrm{kWe}$ are eligible for buydowns of up to $\$ 4,500 / \mathrm{kWe}$, or $50 \%$ of the capital cost. For purpose of this analysis, we looked at a buydown of $\$ 3,500 / \mathrm{kWe}$ (approximately $50 \%$ of the capital cost). This reduced the cost of power by $42 \%$. Currently, a 1-MWe system would not be eligible for this buydown.

California also offers a number of low-interest loans for renewable power technologies. Interest rates of $5 \%$ or lower may be possible. A case was run assuming $5 \%$ interest rate for the capital investment. In this case, $100 \%$ of the capital was purchased with money borrowed at $5 \%$. This case assumes that customer assets provide the collateral on the loan. 
Table 20. Effect of Financial Incentives

\begin{tabular}{lcc}
\hline Incentive & $\begin{array}{c}\text { First-Year } \\
\text { Energy Price } \\
\boldsymbol{\phi} / \mathbf{k W h}\end{array}$ & Benefit \\
\hline Baseline IPP financing in California & 20.1 & \\
1.5 $/$ /kWh PTC in place of 10\% ITC & 20.2 & $-0.5 \%$ \\
1.5 $/$ /kWh PTC and 10\% ITC & 18.3 & $9.0 \%$ \\
ITC increased from 10\% to 50\% & 12.7 & $37 \%$ \\
California buy-down $\$ 3,500 / \mathrm{kWe}$ & 11.7 & $42 \%$ \\
Low-interest financing (5\% Interest) & $\mathbf{1 6 . 0}$ & $\mathbf{2 0 \%}$ \\
\hline
\end{tabular}

Based on these results, it is clear that a combination of technology enhancements, technology cost reductions, and increased financial incentives are likely to be necessary to achieve sustained markets for this technology. However, sufficient niche market opportunities may exist to make this technology attractive to one or more power industry developers. This type of system is likely to provide the lowest cost solar power option in the 100-kWe to 10-MWe system size range.

\section{Discussion and Conclusions}

Industries involved with the organic Ranking cycle and solar power have increasing interest in modular trough power plants. Although trough-ORC integration has been tested before, advances in parabolic trough and organic Rankine cycle technology make this integration worth reconsidering. Based on growing interest, this study was conducted by NREL for an independent assessment of the MTPP concept to gain a better understanding of its potential. Where appropriate, NREL uses technical support from other power industry players to help validate the analysis and results of the evaluation. The study included the following key elements:

- Identification of key assumptions to be used for the study

- Development of detailed organic Rankine power cycle models to evaluate various design options. This work included contracts with the ORC-power industry for validation of NREL's power cycle model, assumptions, and support for optimization of power cycle components. The models were also used to characterize power-cycle off-design performance characteristics

- Development of an hourly simulation model to integrate the solar and power cycle performance and to allow determination of annual system performance

- Assessment of MTPP economics, including: assessment of potential market opportunities, development of detailed capital and O\&M cost models for both the power cycle and solar equipment, and financial cash flow analysis of systems.

The overall goal of the study was to assess the technical and economic merits of the MTPP concept. The type of MTPP system designed would depend primarily on the specific power requirements of the intended application. There is no single solution that is likely to be the best 
approach for all applications. For purpose of this study the following key assumptions were used to guide the analysis:

- The system is be grid connected

- The system is generally in an unattended mode of operation

- The system includes thermal storage to dispatch power to the desired peak electric demand use periods

- The system should minimize water requirements

- The analysis should focus on the smallest possible power system size using off-the-shelf components or standard ORC technologies.

Based on the key assumptions listed above, the study used the following additional guidelines to further focus the analysis:

- A solar field operating temperature of $304^{\circ} \mathrm{C}$ was selected to allow Caloria heat transfer fluid to be used in the solar field so that a low-cost and low-risk thermal storage option would be available

- The power cycle would use dry cooling to minimize water use and simplify operation

- A working fluid with an above-atmospheric condenser pressure would be assumed to minimize safety concerns of potential air in-leakage to a sub-atmospheric condenser with an organic fluid

- Where possible, the design should be simplified to reduce complexity and minimize O\&M requirements.

The detailed ORC power cycle analysis evaluated a number of potential Rankine power cycle configurations, including simple, recuperative, reheat, and reheat/recuperative Rankine cycles. Each of the cycles was optimized for use with different ORC fluids and for mixed organic working fluids. The study selected the recuperated Rankine cycle with pentane as the working fluid for the base system. Although using a reheat cycle and mixed working fluids slightly increased the cycle efficiency, these options were rejected for this study because the increased power cycle complexity and capital cost were expected to outweigh the improvements in system efficiency. A system size nominally of 1 MWe output was selected to use ORC turbine machinery, while keeping turbine speed at acceptable levels. The ORC power cycle technology required for this application is well within the capabilities of existing commercial system technology. One key issue with the system proposed, however, is the long-term stability of the pentane working fluid at the temperatures required in the power cycle.

The power cycle optimization process was inherently different for a solar plant compared to geothermal power plants. For geothermal plants, the focus is typically on minimizing the power cycle capital cost. This is because the geothermal resource is relatively cheap and the resource temperatures are low. Thus, it takes a substantial capital investment to effect much change in cycle efficiency. Solar plants, on the other hand, have relatively expensive solar fuel, so the focus is on increasing power cycle efficiency to minimize solar field size. So the overall optimum plant design will favor a more efficient power cycle and a smaller solar field.

The baseline solar technology evaluated in the study was the Luz System Two (LS-2) parabolic trough collector with a non-evacuated receiver. The LS-2 collector represents a good match for this type of plant, although the Industrial Solar Technology parabolic trough collector could also be used at these temperatures with a small reduction in performance, but potentially at a lower 
cost as well. The non-evacuated receiver appears to be a reasonable trade-off to reduce O\&M requirements and initial capital cost. The analysis assumes a two-tank Caloria thermal storage system, which should be acceptable given appropriate design.

A critical focus of the plant design is to minimize O\&M costs. The plant should be designed to operate without the need of an onsite operator. Ideally, the plant would be able to start-up and shut down automatically. The system should allow remote monitoring and control. Although this type of operation has not been possible at the SEGS plants, it may be feasible for a small ORC system. The solar field may consist of a single or only a few flow paths, which greatly simplifies the flow balance issues that the large SEGS plants face with 50 or 100 parallel flow loops. In addition, the smaller size means that the collectors will all see cloud cover at approximately the same time, whereas the large SEGS plants can experience significant differences in cloud cover from one side of the solar field to the other. Also the two-tank thermal storage will allow better automation and flow control of the solar field. The recuperated ORC power cycle should be much simpler to start-up and shut down than the complex regenerative reheat steam turbines with sub-atmospheric condensers. However, this type of automated operation has not been demonstrated and, thus, remains an issue.

Based on the results of the design analysis and discussion with industry, we believe that the modular trough power plant evaluated in this study is technically feasible. Given the apparent maturity of the two technologies being integrated, we believe that with appropriate care in design, manufacture, and construction, a commercial system could be produced today by the existing ORC and solar industry without too much difficulty.

The economic feasibility is more difficult to assess. The baseline system optimized for solar field size and amount of thermal storage required a $20 \propto / \mathrm{kWh}$ energy payment for economic feasibility. Although some potential exists to reduce this cost, in the near-term it is clear that higher value markets, premiums for green power, or other incentives are likely to be necessary for these systems to make economic sense in a commercial environment. However, some of the incentives currently available for photovoltaic systems would be more than sufficient to make these systems economic in existing markets. In the longer-term, systems could potentially achieve economic competitiveness with other power technologies for distributed retail, high-value green markets, and remote power applications. Expanded tax incentives could greatly help current and future MTPP economics.

Siting issues significantly impact system performance and the resulting cost of electricity. The solar resource is the primary issue, but ambient temperature is also important (lower temperatures are better). However, availability of special market, financial, or taxation incentives could be even more important than solar resource or ambient temperature considerations.

Future development needs include: further analysis of ORC working fluids, additional optimization of ORC power cycles, an improved understanding of O\&M costs, development of automated control systems, design of SF for modular systems, and additional development of thermal storage for this size system. The technology is generally ready for commercial demonstration.

In our judgment, modular trough power plants are likely to be the lowest risk and most cost effective solar technology option in the $100-\mathrm{kWe}$ to 10 -MWe system range for the near-term applications. 


\section{References}

Cohen, G., D. Kearney, and G. Kolb. 1999. Final Report on the Operation and Maintenance Improvement Program for Concentrating Solar Power Plants. SAND99-1290. Albuquerque, New Mexico: Sandia National Laboratories.

Dudley, V., G. Kolb, A. R. Mahoney, T. Mancini, C. Matthews, M. Sloan, and D. Kearney. 1994. Test Results: SEGS LS-2 Solar Collector. SAND94-1884. Albuquerque, New Mexico: Sandia National Laboratories.

Dudley, V., L. Evans, and C. Mathews. 1995. Test Results: Industrial Solar Technology Parabolic Trough Solar Collector. SAND95-1117. Albuquerque, New Mexico: Sandia National Laboratories.

Larson, D. L. 1983. Final Report of the Coolidge Solar Irrigation Project. SAND83-7125. Albuquerque, New Mexico: Sandia National Laboratories.

Nexant, Inc. 2000. Thermal Storage Oil-to-Salt Heat Exchanger Design and Safety Analysis. NREL Subcontract No KAF-9-29765-09. Golden, Colorado: National Renewable Energy Laboratory, November.

Pilkington Solar International. 1999. Solar Steam System Investment Cost. NREL Subcontract No. AAR-9-29442-05. Golden, Colorado: National Renewable Energy Laboratory, December.

Price, H., and Kearney, D. 1999. Parabolic-Trough Technology Roadmap: A Pathway for Sustained Commercial Development and Deployment of Parabolic-Trough Technology. Technical Report TP-550-24748. Golden, Colorado: National Renewable Energy Laboratory.

U.S. Department of Energy, Office of Utility Technologies, and the Electric Power Research Institute, Inc. 1997. "Solar Parabolic Trough." Technology Characterization, TR109496. 


\section{Appendix A}

\section{Analysis Carried Out by Exergy, Inc.}

Exergy, Inc., under a subcontract to NREL, carried out a comprehensive analysis of KCS-33 (Kalina Cycle \#33) for application to a solar resource temperature of $580^{\circ} \mathrm{F}$ and $735^{\circ} \mathrm{F}$. A summary report prepared by Exergy, Inc., is presented here. For this resource temperature, Exergy used a cascade cycle where steam is used at the high temperature cycle and a mixture of ammonia/water is used at the lower temperature cycle. The cycle analysis of KCS-33 indicated a gross electrical efficiency (i.e., shaft power less the turbine mechanical and electrical generator losses) of $31.2 \%$. The schematic of the cycle and the state points have been shown and listed here. Note that KCS-33 uses air for heat rejection. It is important to note that Exergy uses a pinch point of about $5^{\circ} \mathrm{F}$ to $6^{\circ} \mathrm{F}$ for recuperators. Before any comparison is made between KCS-33 and any other cycle in this report, the reader should make sure that the pinch points and the component efficiencies used in both cycles are the same. 


\title{
Final Report
}

\section{Overview of Kalina Cycle System 33}

\author{
Exergy, Inc.
}

Mark Mirolli and Alex Dvoiris

Exergy, Inc.

22320 Foothill Blvd., Suite 540

Hayward, CA 94541

(510) 537-5881 


\section{Overview of Kalina Cycle System 33}

This system comprises two sub-cycles, one steam, one water-ammonia. They are connected by two heat exchangers, in each of which steam is condensed by giving up heat to a water-ammonia mixture.

In the steam sub-cycle, subcooled water is pumped from point \#47 to point \#50 and enters an HRSG where it acquires heat from some of the hot oil. Superheated, it is expanded in a turbine, and expanded to an intermediate pressure. All of the liquid contained in the turbine extraction, and some of the vapor, is sent into heat exchanger HE-6 via a separator, where it is condensed while bringing a water-ammonia mixture to its dew point.

The remaining saturated vapor steam is sent into the low-pressure turbine, expanded, and then the exhaust is condensed while being used to partially boil the water-ammonia mixture in heat exchanger HE-7.

The two streams of condensed steam are mixed after the lower-pressure stream is pumped to the higher pressure, producing a subcooled liquid stream at point \#47, closing the steam sub-cycle.

Note that the steam sub-cycle acquires only external heat, and is condensed recuperatively by the water-ammonia sub-cycle.

The water-ammonia is condensed by a cooling medium (typically air or water) in final condenser HE-1, at whatever pressure is required for condensation of the chosen composition at the temperature dictated by the cooling medium.

The water-ammonia mixture is then pumped to high pressure, and preheated to its boiling point recuperatively in heat exchanger HE-2. There is additional heat available in the turbine exhaust, and it is used in heat exchanger HE-3 to partially boil the water-ammonia mixture.

The water-ammonia mixture is partially boiled in the first steam condenser, and brought to its dew point at the exit of the second steam condenser. The saturated vapor is then superheated by some of the hot oil in the superheater, and admitted to the water-ammonia turbine where it is expanded. It is still superheated vapor at the turbine exit.

The turbine exhaust is partially condensed in heat exchangers HE-3 and HE-2, preheating and partially boiling the upcoming high-pressure water-ammonia stream. It enters the final condenser HE-1 and is condensed.

In heat exchanger HE-3, there is a pinch point, a minimum in the temperature difference between the hot and cold streams. It is point \#37 the dew point of the turbine exhaust. Above that we have superheated vapor; below that we have a condensing stream. The composition of the waterammonia mixture is chosen to meet a specified temperature at the pinch point.

Note that although approximately $75 \%$ of the external heat acquisition occurs in the steam boiler, approximately $65 \%$ of the power is generated in the water-ammonia turbine. The primary purpose of the steam sub-cycle is to transfer heat to the water-ammonia; the primary purpose of the water-ammonia sub-cycle is to generate power. 


\section{KCS 33 Applied to the (Cold) Solar Pond}

We assume that $54 \mathrm{MW}$ of heat is available from hot oil, at temperatures from $580^{\circ} \mathrm{F}$ to $460^{\circ} \mathrm{F}$. We use $43 \mathrm{MW}$ to produce steam, and $11 \mathrm{MW}$ to superheat the water-ammonia mixture.

The high pressure steam turbine generates about $5 \mathrm{MW}$ of shaft power, expanding $162,500 \mathrm{lb} / \mathrm{hr}$ from a pressure of $800 \mathrm{psia}$ down to $163 \mathrm{psia}$. The $100,000 \mathrm{lb} / \mathrm{hr}$ of the exhaust is condensed at 163 psia $\left(365^{\circ} \mathrm{F}\right)$.

The remaining $63,000 \mathrm{lb} / \mathrm{hr}$ is further expanded, to a pressure of $82 \mathrm{psia}\left(314^{\circ} \mathrm{F}\right)$, and condensed. The low-pressure steam turbine generates about $1 \mathrm{MW}$ of shaft power.

The two steam condensers, meanwhile, deliver $37 \mathrm{MW}$ thermal to the water-ammonia mixture in heat exchangers HE-6 and HE-7. The disposition of the $43 \mathrm{MW}$ thermal acquired in the boiler is $6 \mathrm{MW}$ shaft power and $37 \mathrm{MW}$ thermal transferred to the water-ammonia sub-cycle.

The water-ammonia mixture acquires $11 \mathrm{MW}$ of heat from the hot oil in the fired superheater. It generates 11.5 MW shaft power, for a total of about 17.5 MW.

The low-pressure water-ammonia stream delivers another $37 \mathrm{MW}$ of heat to the upcoming highpressure water-ammonia stream, before rejecting $37 \mathrm{MW}$ in the final condenser.

Total recuperation in the system is almost $75 \mathrm{MW}$ thermal, in heat exchangers HE-2, HE-3, HE6, and HE-7.

\section{KCS 33 Applied to the (Hot) Solar Pond}

For the hot case, with hot oil temperatures ranging from $735^{\circ}$ down to about $560^{\circ} \mathrm{F}$, we add two heat exchangers to the water-ammonia sub-cycle. Both of them use the turbine exhaust.

In HE-5, we use the much hotter turbine exhaust to superheat the water-ammonia mixture before we acquire external heat. In HE-4, we use the turbine exhaust in parallel with the two steam condensers to finish the boiling.

We acquire $66 \mathrm{MW}$ thermal in the HRSG, generate $12 \mathrm{MW}$ shaft power in two steam turbines, and transfer $54 \mathrm{MW}$ thermal to the water-ammonia sub-cycle through the two steam condensers.

We acquire about $27 \mathrm{MW}$ thermal of external heat in the water-ammonia sub-cycle, and the 54 MW thermal received from the steam, for a total of $81.5 \mathrm{MW}$ thermal. We generate $21 \mathrm{MW}$ of shaft power, and reject almost $61 \mathrm{MW}$ thermal in the final condenser. The purely recuperative heat transferred in the water-ammonia sub-cycle is about $66.5 \mathrm{MW}$.

\section{Cold Solar Pond Performance}

The cold solar pond has a heat source ranging from an inlet of $580^{\circ} \mathrm{F}$ down to an outlet of $460^{\circ} \mathrm{F}$; for the Kalina Cycle, the cooling water temperature ranges from an inlet of $78^{\circ} \mathrm{F}$ to an outlet of $114.75^{\circ} \mathrm{F}$. We assumed that the mass flow of oil was the same as in the hot case, but since the specific heat is a little less, and the temperature span is reduced by a third, we computed a total heat input to the system of $54,272 \mathrm{~kW}$ thermal. 
The Kalina Cycle System 33 produces $17,746.8 \mathrm{~kW}$ of turbine expansion work. This is a first law efficiency of only $32.7 \%$. To properly assess that number, let us consider what a Carnot Cycle would produce operating between a source temperature of $580^{\circ} \mathrm{F}$ and a sink of $78^{\circ} \mathrm{F}$.

Next, let's correct the Carnot Cycle for the temperature changes in the source and sink, to obtain a more accurate number for a perfectly reversible cycle; we call that the Second Law Maximum. Finally, let's express the first law efficiency as a percent of the second law maximum.

\section{Percent Efficiency}

\begin{tabular}{|l|l|}
\hline & Cold \\
\hline Carnot Cycle & 48.28 \\
\hline Second Law Maximum & 43.25 \\
\hline First Law Efficiency & 32.70 \\
\hline Second Law Efficiency & 75.61 \\
\hline
\end{tabular}

It is Exergy's opinion that a Second Law Efficiency in the mid-seventies is extremely good.

We have used the turbine expansion work as our measure of first law efficiency. The Carnot Cycle, after all, answers the question: What is the maximum mechanical work that can be extracted from thermal energy?

We might consider that the gross electrical power at the generator terminals is, however, the appropriate first law efficiency for other purposes. It reflects additional losses, such as electric generator losses and turbine mechanical losses. The gross electrical (first law) efficiency is somewhat lower, of course, being $31.2 \%$ in this case.

\section{Hot Solar Pond Performance}

As before, we list the first law efficiency based on turbine expansion work; the efficiency of a Carnot Cycle operating between fixed temperatures (of source $735^{\circ} \mathrm{F}$ and of sink $78^{\circ} \mathrm{F}$ ); the Second Law Maximum taking into account the temperature variations of the source and sink; and the ratio of First Law Efficiency to Second Law Maximum.

\section{Percent Efficiency}

\begin{tabular}{|l|l|}
\hline & Hot \\
\hline Carnot Cycle & 54.99 \\
\hline Second Law Maximum & 49.72 \\
\hline First Law Efficiency & 35.53 \\
\hline Second Law Efficiency & 71.46 \\
\hline
\end{tabular}

The (first law) gross electrical efficiency (i.e., shaft power less the turbine mechanical and electrical generator losses) is about $33.9 \%$. 


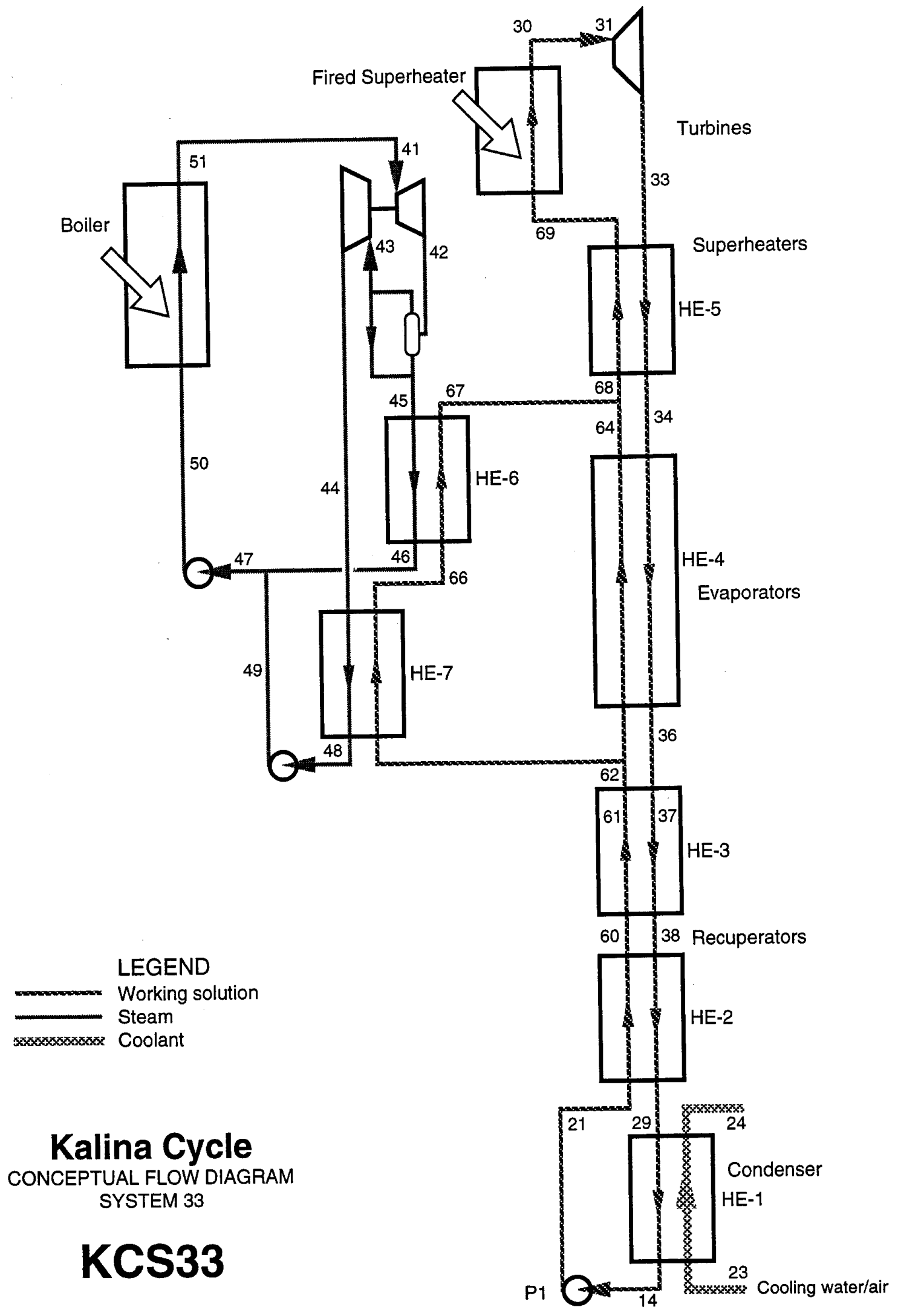




$==$

SYSTEM 33 CONIROL DATA

2000 Apr 13 17:35:34

$\begin{array}{lrlc}\text { K A I N A } & \text { CYCLE } & \text { C ON T ROL } & \text { D A T A } \\ \text { P41 } & 1450 & \Delta \text { TrC } & 5.4 \\ \text { P30 } & 550 & \Delta T 3 & 9 \\ \text { T30 } & 700 & \Delta T a & 15 \\ \text { T23 } & 80 & \Delta \text { Tw } & 12 \\ \Delta T 68 & 0 & \text { Stages } & 2 \\ \text { HE } / 5 ? & 9 & \text { MW in } & 93.157\end{array}$

Assumed Turbine Efficiencies

$\begin{array}{llll}\text { ATE Wat-Arm } & .87 & \text { TME } & .9541 \\ \text { ATE Steam 1 } & .87 & \text { ATE pumps } & .8 \\ \text { ATE Steam 2 } & .87 & \text { ATE Aux 8 } & 0\end{array}$

Heat Exchanger Pressure Drops

$\begin{array}{lccc}\Delta P \text { coolant } & .05 & \Delta P 30-31 & 25 \\ \Delta P 29-14 & .3 & \Delta P 33-34 & 2 \\ \Delta P 21-60 & 20 & \Delta P 34-36 & 2 \\ \Delta P 60-62 & 10 & \Delta P 36-38 & .7 \\ \Delta P 62-66 & 5 & \Delta P 38-29 & .3 \\ \Delta P 66-68 & 5 & \Delta P 50-51 & 35 \\ \Delta P 68-69 & 5 & \Delta P 51-41 & 25 \\ \Delta P 69-30 & 25 & & \end{array}$

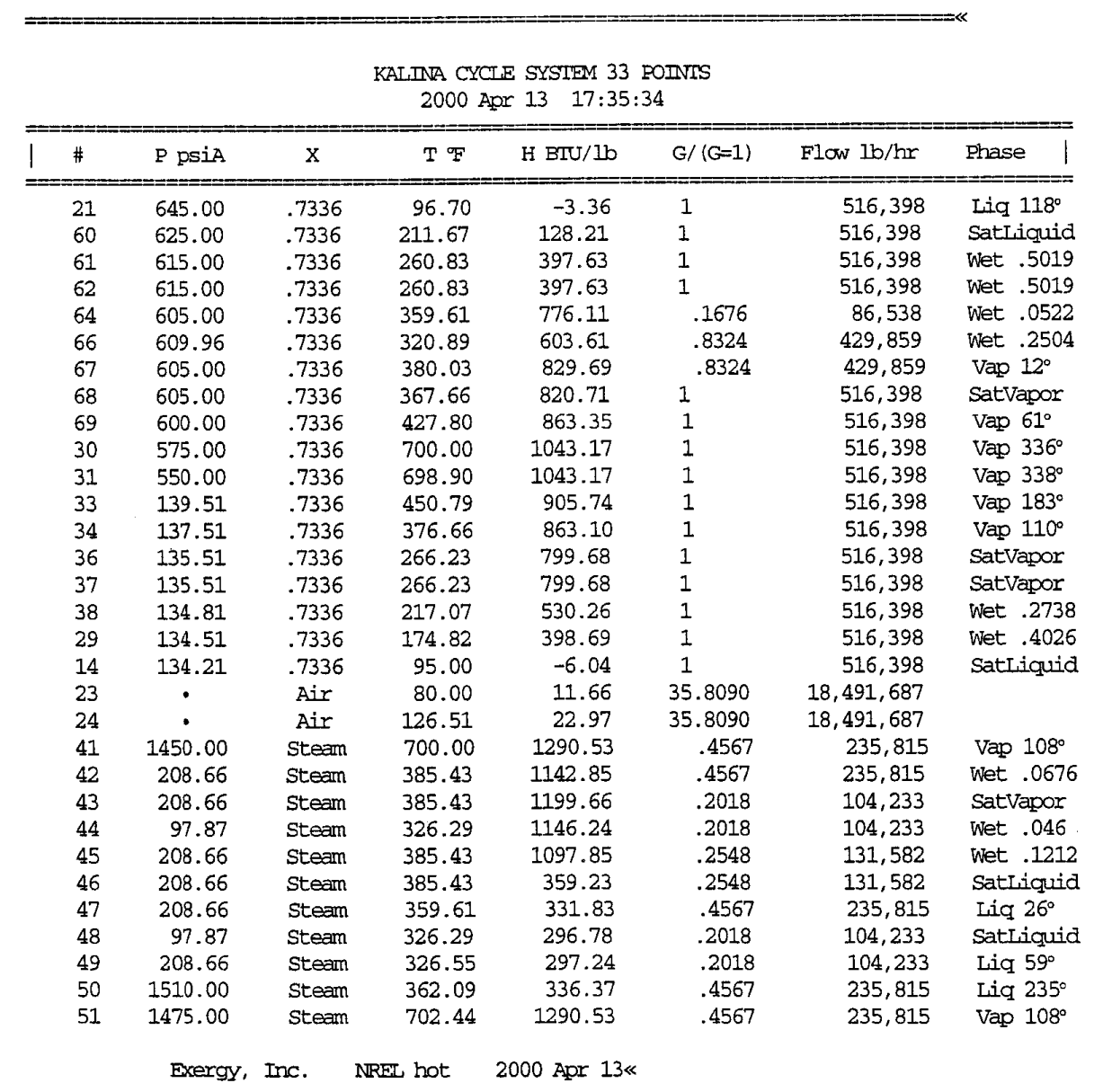




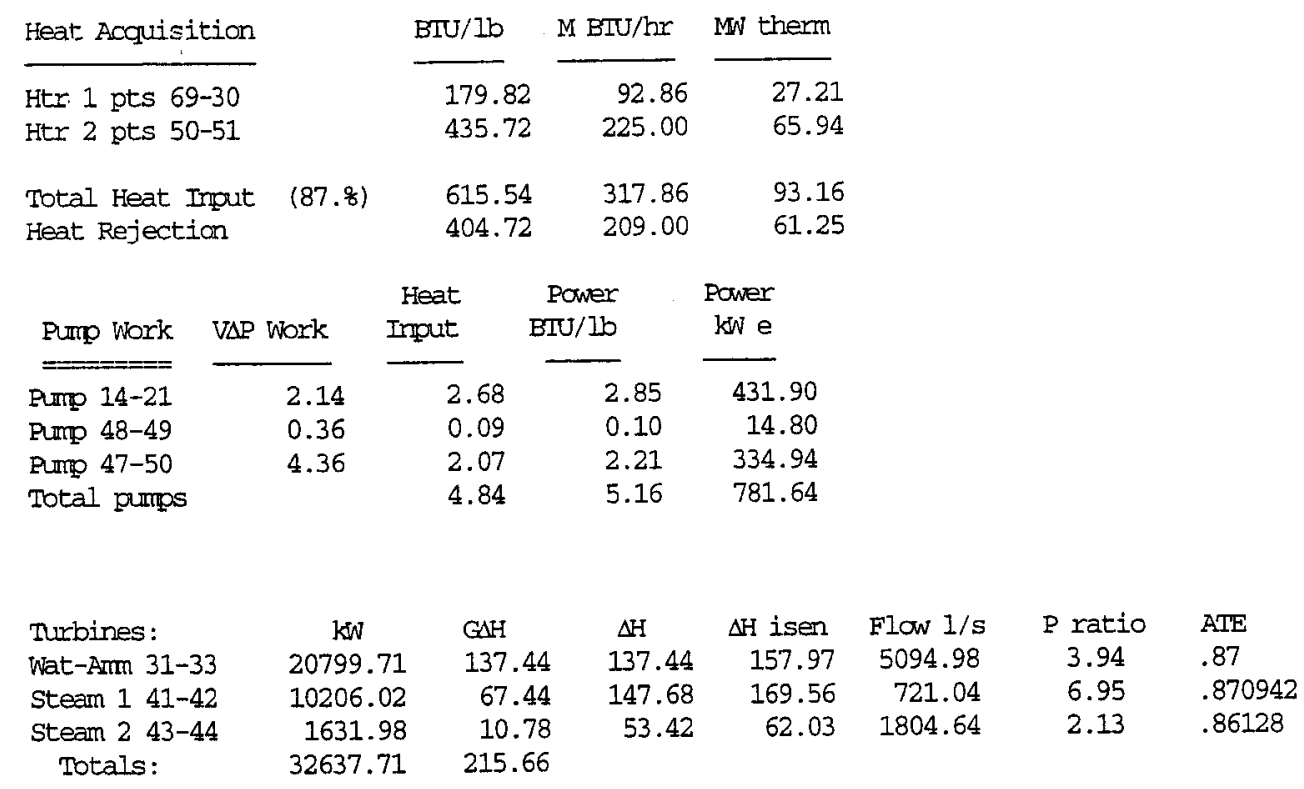

Performance Summary S33

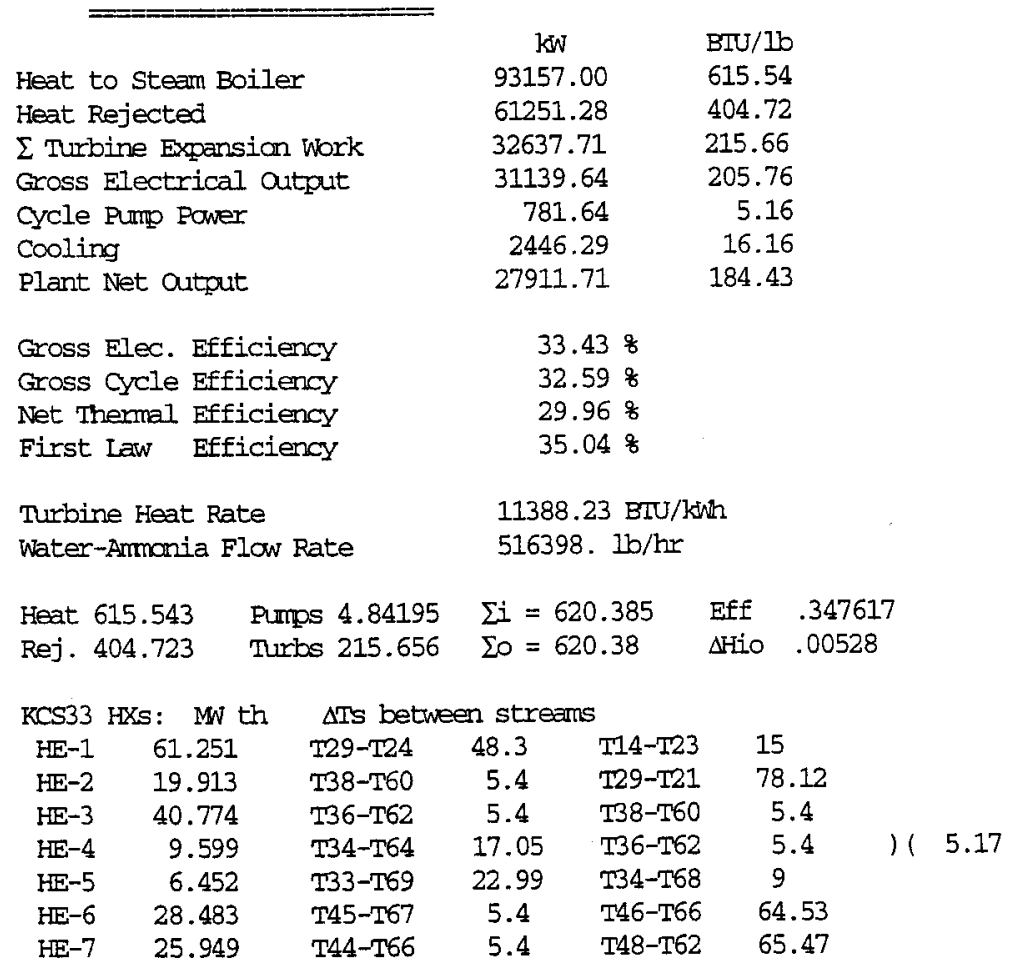




$==$

SYSTEM 33 CONIROL DATA

2000 Apr $11 \quad 12: 19: 48$

$\begin{array}{lccc}\text { K A I I A } & \text { C Y CLE } & \text { C ON T R O } & \text { D A T A } \\ \text { P41 } & 1450 & \Delta \operatorname{TrC} & 5.4 \\ \text { P30 } & 550 & \Delta \mathrm{TH} & 9 \\ \text { T30 } & 700 & \Delta \mathrm{Ta} & 7 \\ \text { T23 } & 78 & \Delta \mathrm{TW} & 6 \\ \Delta \mathrm{T} 68 & 0 & \text { Stages } & 2 \\ \text { HEA } / 5 ? & 9 & \text { MN in } & 93.157\end{array}$

Assumed Turbine Efficiencies

$\begin{array}{llll}\text { ATE Wat-Amm } & .87 & \text { TME } & .9541 \\ \text { ATE Steam 1 } & .87 & \text { ATE pumps } & .8 \\ \text { ATE Steam 2 } & .87 & \text { ATE Aux \& } & 0\end{array}$

Heat Exchanger Pressure Drops

$\begin{array}{lccc}\Delta P \text { coolant } & 35 & \Delta P 30-31 & 25 \\ \Delta P 29-14 & .3 & \Delta P 33-34 & 2 \\ \Delta P 21-60 & 20 & \Delta P 34-36 & 2 \\ \Delta P 60-62 & 10 & \Delta P 36-38 & .7 \\ \Delta P 62-66 & 5 & \Delta P 38-29 & .3 \\ \Delta P 66-68 & 5 & \Delta P 50-51 & 35 \\ \Delta P 68-69 & 5 & \Delta P 51-41 & 25 \\ \Delta P 69-30 & 25 & & \end{array}$

\begin{tabular}{|c|c|c|c|c|c|c|c|}
\hline \multicolumn{8}{|c|}{$\begin{array}{l}\text { KALINA CYCLE SYSTEM } 33 \text { POINIS } \\
2000 \text { Apr } 11 \\
12: 19: 48\end{array}$} \\
\hline$\#$ & P psiA & $\mathrm{x}$ & $\mathrm{T} F$ & $\mathrm{H} \mathrm{BIU} / \mathrm{lb}$ & $\mathrm{G} /(\mathrm{G}=1)$ & Flow lb/hr & Phase \\
\hline 21 & 645.00 & .7362 & 86.70 & -13.77 & 1 & 478,198 & Liq $128^{\circ}$ \\
\hline 60 & 625.00 & .7362 & 211.22 & 128.30 & 1 & 478,198 & SatIiquid \\
\hline 61 & 615.00 & .7362 & 250.85 & 363.96 & 1 & 478,198 & Wet .5492 \\
\hline 62 & 615.00 & .7362 & 250.85 & 363.96 & 1 & 478,198 & Wet .5492 \\
\hline 64 & 605.00 & .7362 & 359.26 & 776.98 & .1646 & 78,689 & Wet .0492 \\
\hline 66 & 610.12 & .7362 & 313.08 & 578.86 & .8354 & 399,509 & Wet .2762 \\
\hline 67 & 605.00 & .7362 & 378.29 & 827.34 & .8354 & 399,509 & Vap $11^{\circ}$ \\
\hline 68 & 605.00 & .7362 & 366.89 & 819.05 & 1 & 478,198 & SatVapor \\
\hline 69 & 600.00 & .7362 & 406.91 & 847.90 & 1 & 478,198 & Vap $41^{\circ}$ \\
\hline 30 & 575.00 & .7362 & 700.00 & 1042.09 & 1 & 478,198 & $\operatorname{Vap} 337^{\circ}$ \\
\hline 31 & 550.00 & .7362 & 698.90 & 1042.09 & 1 & 478,198 & $\operatorname{Vap} 339^{\circ}$ \\
\hline 33 & 119.93 & .7362 & 426.57 & 891.64 & 1 & 478,198 & $\operatorname{Vap} 168^{\circ}$ \\
\hline 34 & 117.93 & .7362 & 375.89 & 862.79 & 1 & 478,198 & Vap $119^{\circ}$ \\
\hline 36 & 115.93 & .7362 & 256.25 & 794.83 & 1 & 478,198 & SatVapor \\
\hline 37 & 115.93 & .7362 & 256.25 & 794.83 & 1 & 478,198 & SatVapor \\
\hline 38 & 115.23 & .7362 & 216.62 & 559.17 & 1 & 478,198 & Wet .239 \\
\hline 29 & 114.93 & .7362 & 173.21 & 417.10 & 1 & 478,198 & Wet .3758 \\
\hline 14 & 114.63 & .7362 & 85.00 & -16.52 & 1 & 478,198 & SatLiquid \\
\hline 23 & - & Water & 78.00 & 46.00 & 11.1768 & $5,344,706$ & \\
\hline 24 & - & Water & 116.80 & 84.80 & 11.1768 & $5,344,706$ & \\
\hline 41 & 1450.00 & Steam & 700.00 & 1290.53 & .4912 & 234,894 & $\operatorname{Vap} 108^{\circ}$ \\
\hline 42 & 204.41 & Steam & 383.69 & 1141.48 & .4912 & 234,894 & Wet .0688 \\
\hline 43 & 204,41 & Steam & 383.69 & 1199.39 & .2109 & 100,840 & SatVapor \\
\hline 44 & 87.70 & Steam & 318.48 & 1140.04 & .2109 & 100,840 & wet .0503 \\
\hline 45 & 204.41 & Steam & 383.69 & 1097.92 & .2803 & 134,054 & wet .1205 \\
\hline 46 & 204.41 & Steam & 383.69 & 357.37 & .2803 & 134,054 & Satiiquid \\
\hline 47 & 204.41 & Steam & 356.05 & 328.07 & .4912 & 234,894 & Lig $28^{\circ}$ \\
\hline 48 & 87.70 & Steam & 318.48 & 288.65 & .2109 & 100,840 & SatLiquid \\
\hline 49 & 204.41 & Steam & 318.74 & 289.13 & .2109 & 100,840 & Iiq $65^{\circ}$ \\
\hline 50 & 1510.00 & Steam & 358.51 & 332.63 & .4912 & 234,894 & Liq $239^{\circ}$ \\
\hline 51 & 1475.00 & Steam & 702.44 & 1290.53 & .4912 & 234,894 & Vap $108^{\circ}$ \\
\hline
\end{tabular}




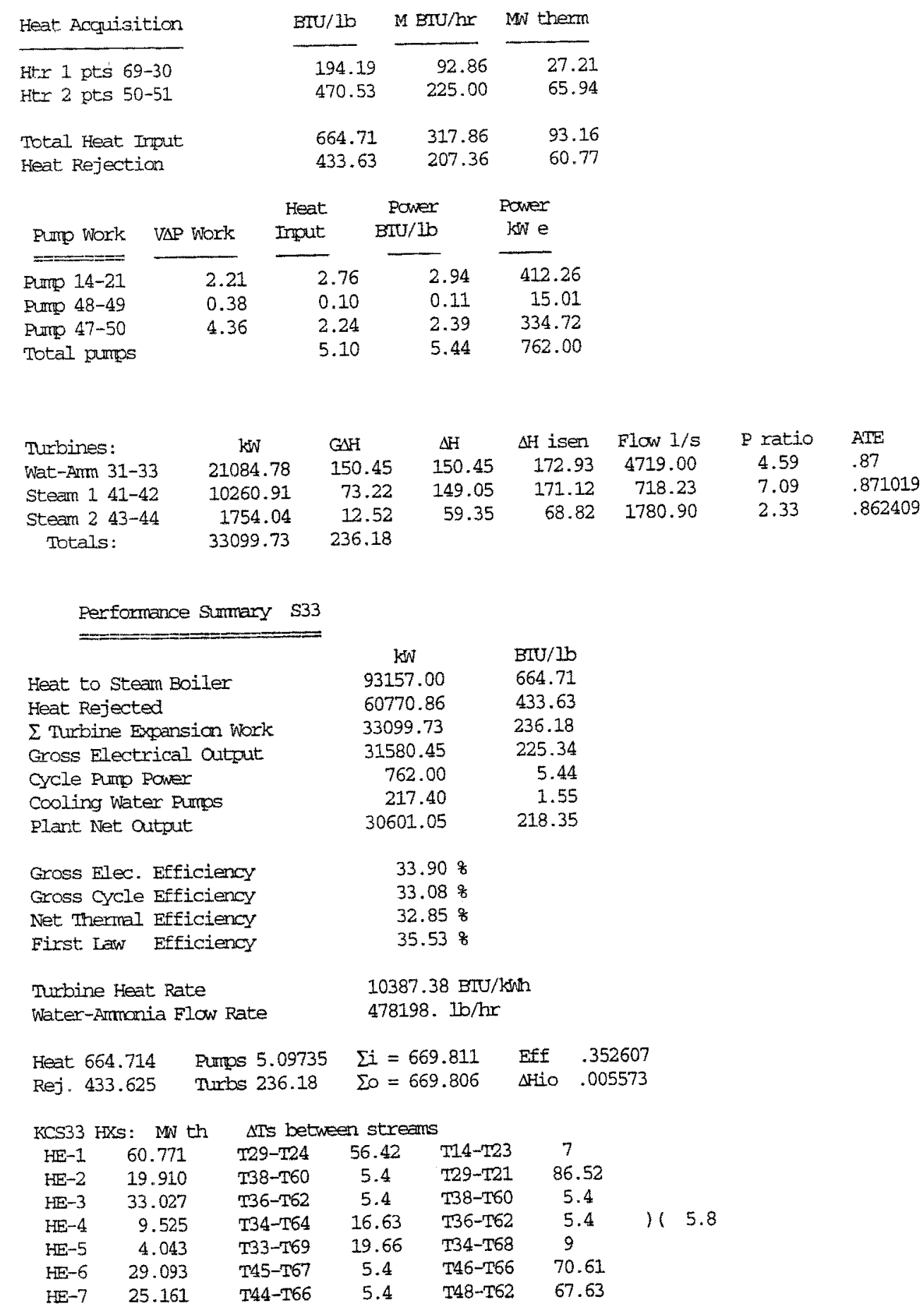




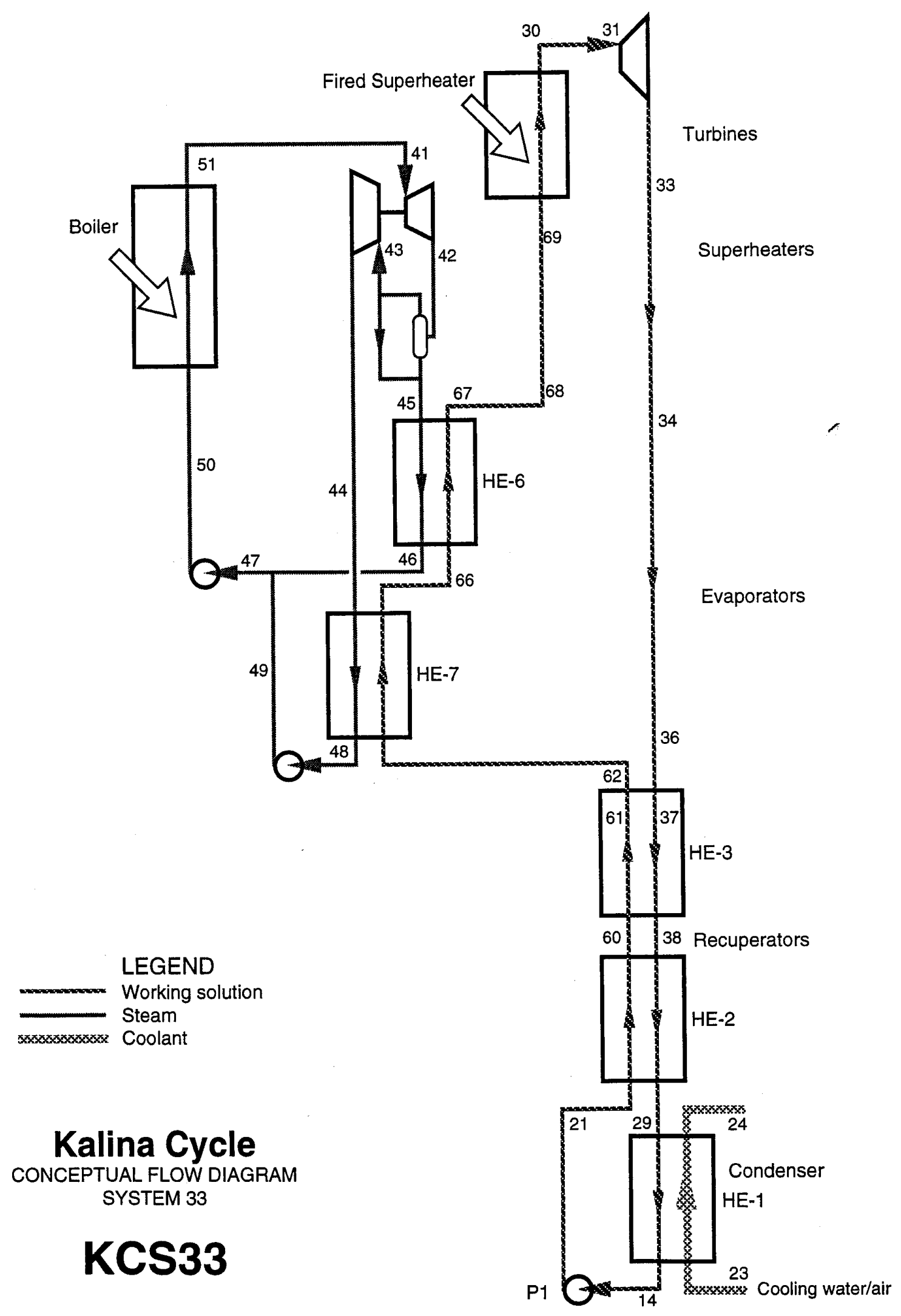




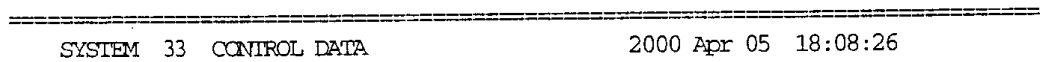

SYSTEM 33 CONIROL DATA

2000 Apr 05 18:08:26

$\begin{array}{lccc}\text { K A I N A } & \text { CYCLE } & \text { C ON T ROL } & \text { D A T A } \\ \text { P41 } & 800 & \Delta \mathrm{TrC} & 5.4 \\ \text { P30 } & 500 & \Delta \mathrm{TB} & 9 \\ \text { T30 } & 545 & \Delta \mathrm{T} \text { a } & 7 \\ \text { T23 } & 78 & \Delta \mathrm{TW} & 6 \\ \Delta \mathrm{T} 68 & 0 & \text { Stages } & 2 \\ \text { HE } / 5 ? & 0 & \text { MN in } & 54.272\end{array}$

Assumed Turbine Efficiencies

$\begin{array}{llll}\text { ATE Wat-Arm } & .9 & \text { ATE TME } & .9541 \\ \text { ATE Steam 1 } & .87 & \text { ATE pumps } & .8 \\ \text { ATE Steam 2 } & .89 & \text { ATE Alx 8 } & 0\end{array}$

Heat Exchanger Pressure Drops

$\begin{array}{lrcc}\Delta \mathrm{P} \text { coolant } & 35 & \Delta \mathrm{P} 30-31 & 25 \\ \Delta \mathrm{P} 29-14 & .3 & \Delta \mathrm{P} 33-34 & 2 \\ \Delta \mathrm{P} 21-60 & 20 & \Delta \mathrm{P} 34-36 & 2 \\ \Delta \mathrm{P} 60-62 & 10 & \Delta \mathrm{P} 36-38 & .7 \\ \Delta \mathrm{P} 62-66 & 5 & \Delta \mathrm{P} 38-29 & .3 \\ \Delta \mathrm{P} 66-68 & 5 & \Delta \mathrm{P} 50-51 & 35 \\ \Delta \mathrm{P} 68-69 & 5 & \Delta \mathrm{P} 51-41 & 25 \\ \Delta \mathrm{P} 69-30 & 25 & & \end{array}$

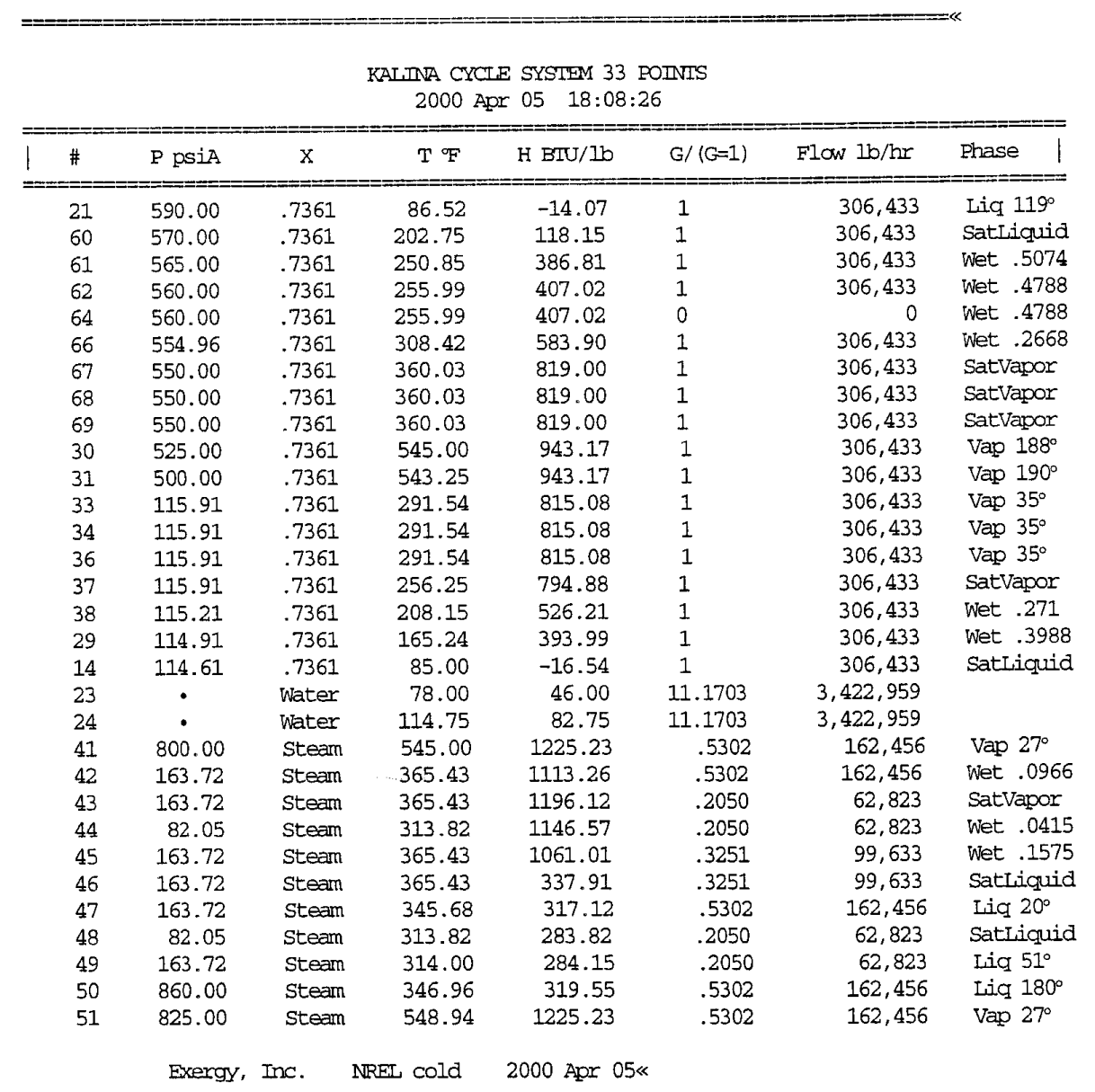




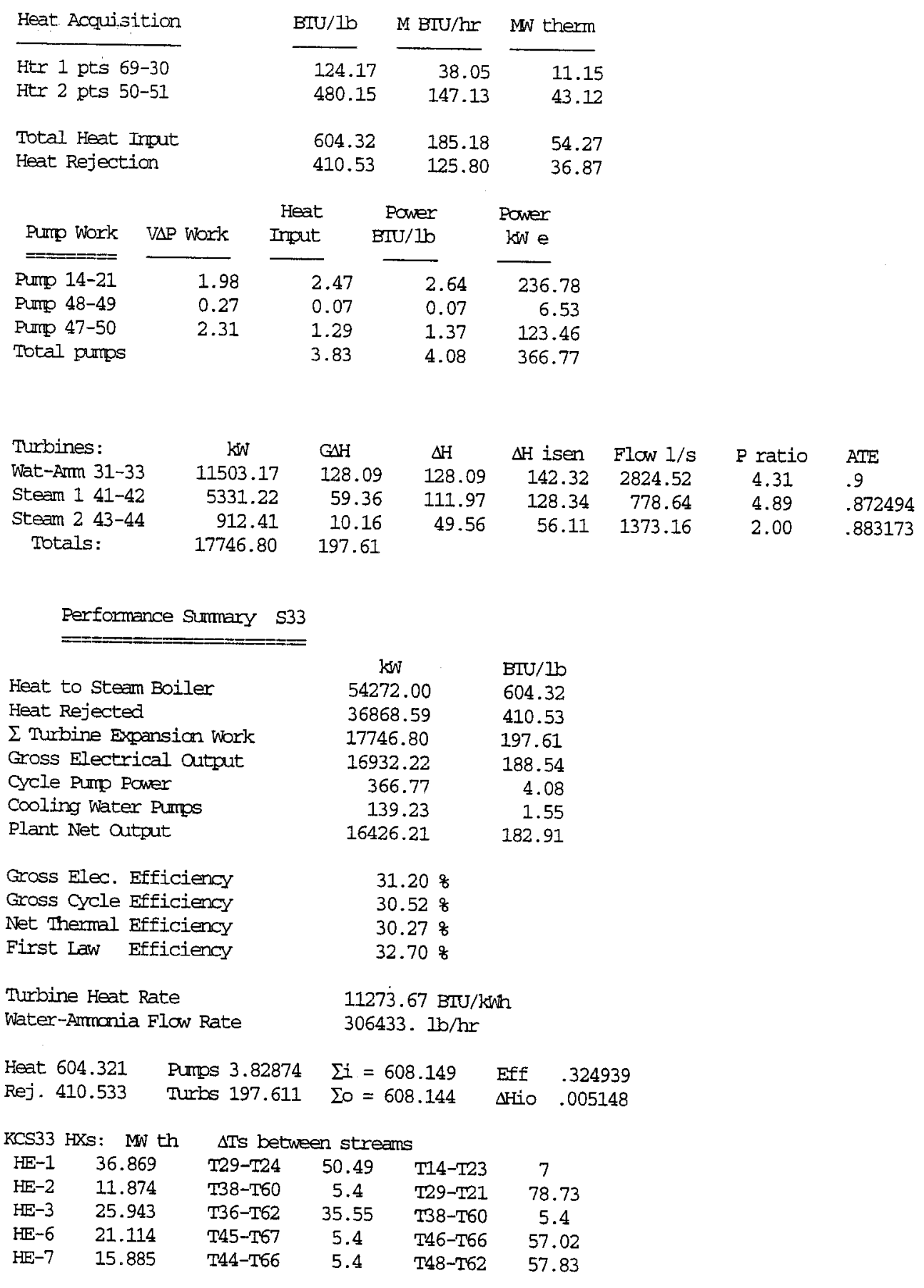




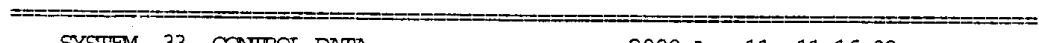

SYSTHM 33 CONIROL DATA

2000 Apor $11 \quad 11: 16: 08$

$\begin{array}{lccc}\text { K A I I A } & \text { CYCLE } & \text { CON T R O } & \text { D A T A } \\ \text { P41 } & 800 & \Delta \text { TrC } & 5.4 \\ \text { P30 } & 500 & \Delta \mathrm{TT} & 9 \\ \text { T30 } & 545 & \Delta \mathrm{Ta} & 15 \\ \text { T23 } & 80 & \Delta \mathrm{TW} & 12 \\ \Delta \mathrm{T} 68 & 0 & \text { Stages } & 2 \\ \text { HE4/5? } & 0 & \text { MN in } & 54.272\end{array}$

Assumed Turbine Efficiencies

$\begin{array}{llll}\text { ATE Wat-Arm } & .9 & \text { TME } & .9541 \\ \text { ATE Steam 1 } & .87 & \text { ATE purms } & .8 \\ \text { ATE Steam 2 } & .89 & \text { ATE Aux 8 } & 0\end{array}$

Heat Exchanger Pressure Drops

$\begin{array}{lccc}\Delta \mathrm{P} \text { coolant } & .05 & \Delta \mathrm{P} 30-31 & 25 \\ \Delta \mathrm{P} 29-14 & .3 & \Delta \mathrm{P} 33-34 & 2 \\ \Delta \mathrm{P} 21-60 & 20 & \Delta \mathrm{P} 34-36 & 2 \\ \Delta \mathrm{P} 60-62 & 10 & \Delta \mathrm{P} 36-38 & .7 \\ \Delta \mathrm{P} 62-66 & 5 & \Delta \mathrm{P} 38-29 & .3 \\ \Delta \mathrm{P} 66-68 & 5 & \Delta \mathrm{P} 50-51 & 35 \\ \Delta \mathrm{P} 68-69 & 5 & \Delta \mathrm{P} 51-41 & 25 \\ \Delta \mathrm{P} 69-30 & 25 & & \end{array}$

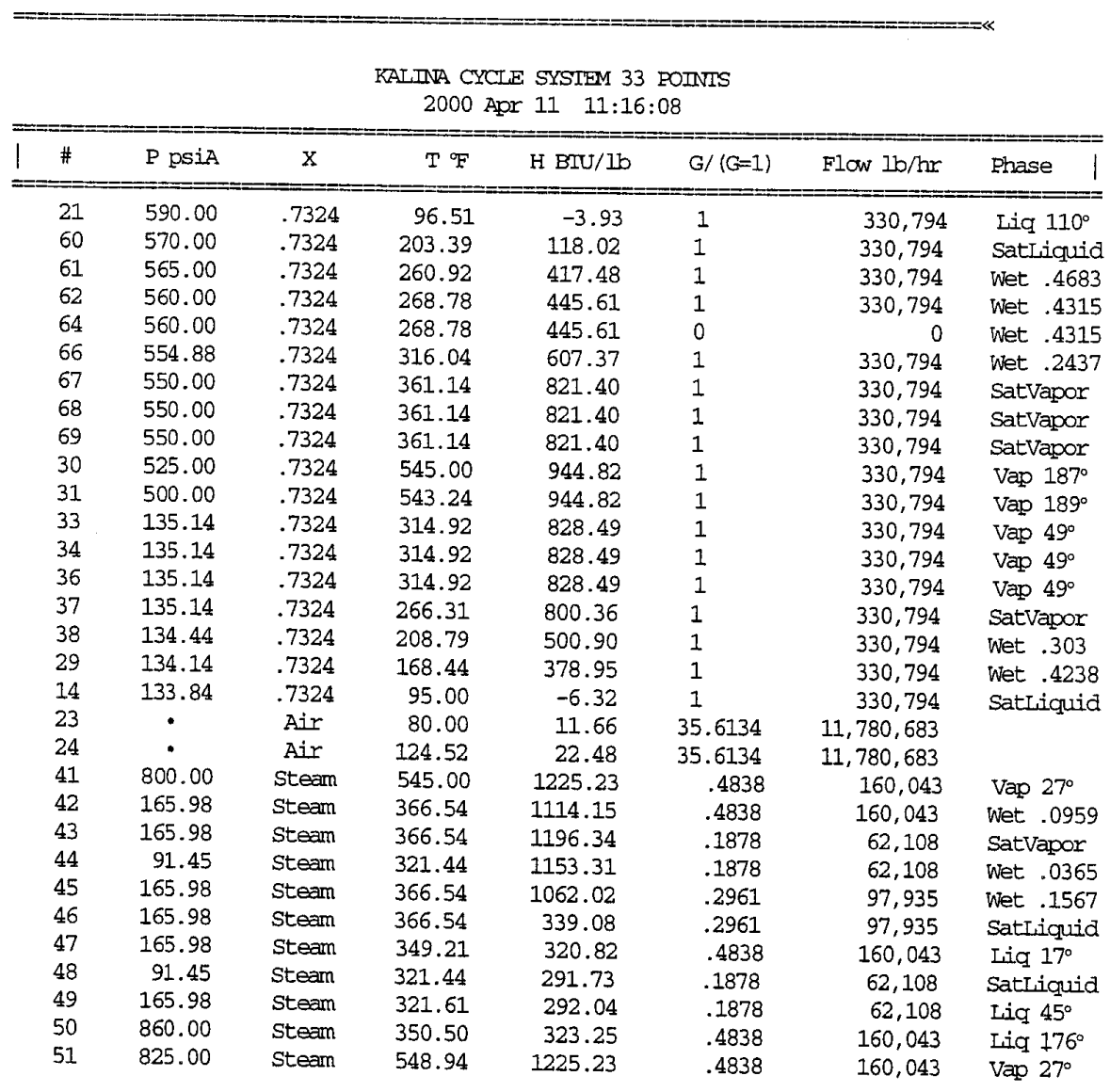

Exergy, Inc. NREI cold 2000 Apr $11 \ll$ 


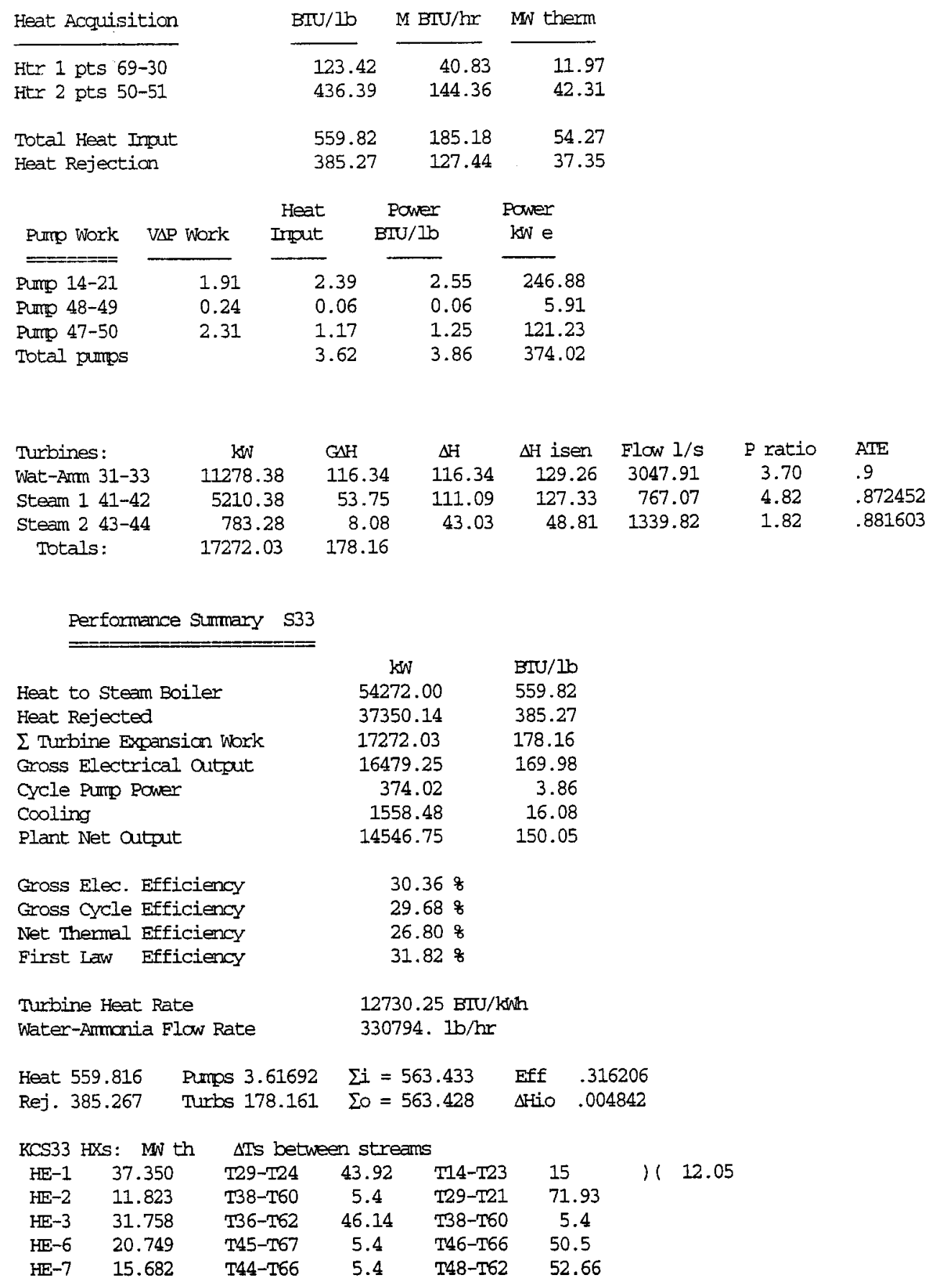



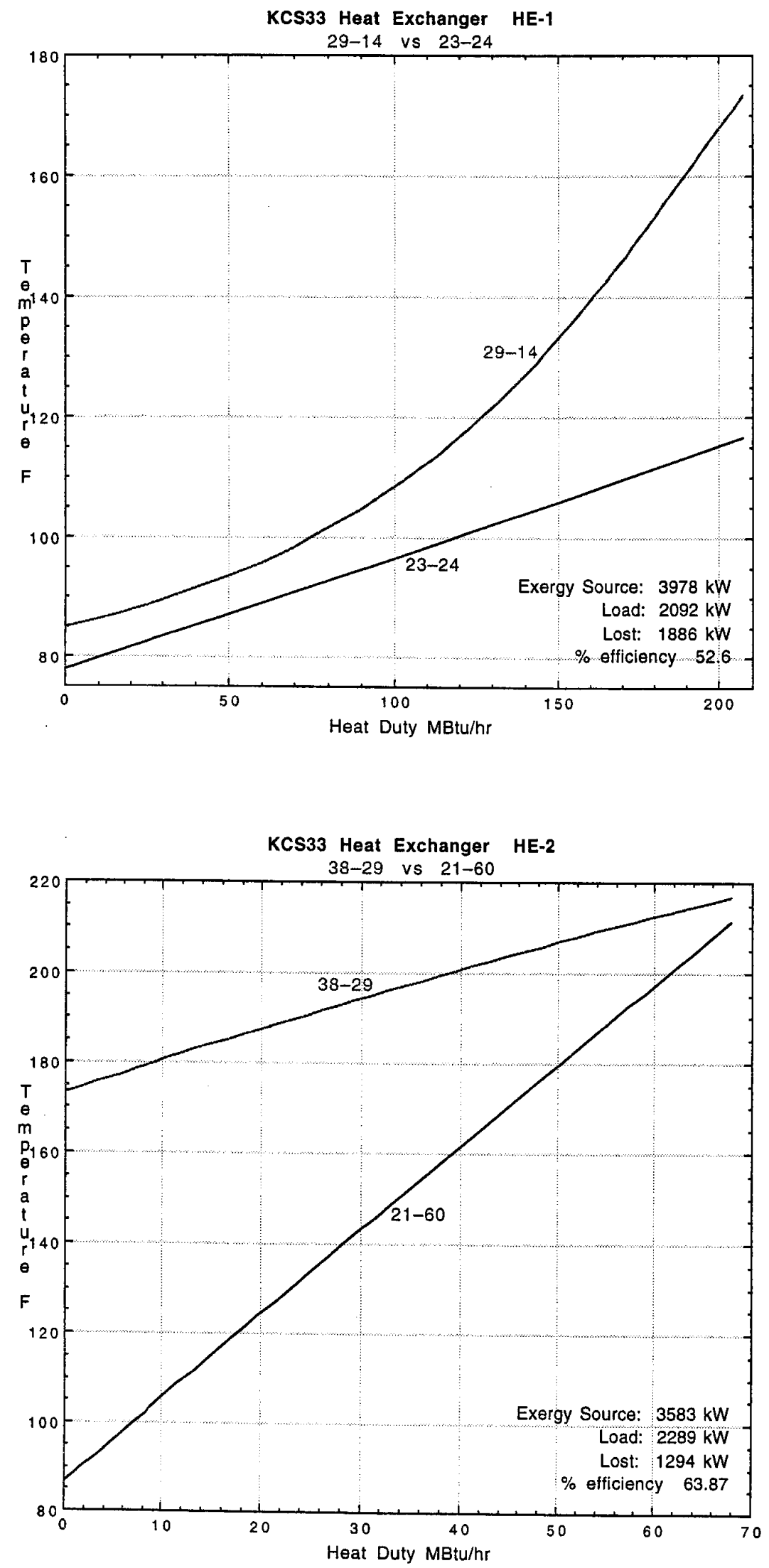

A-16 

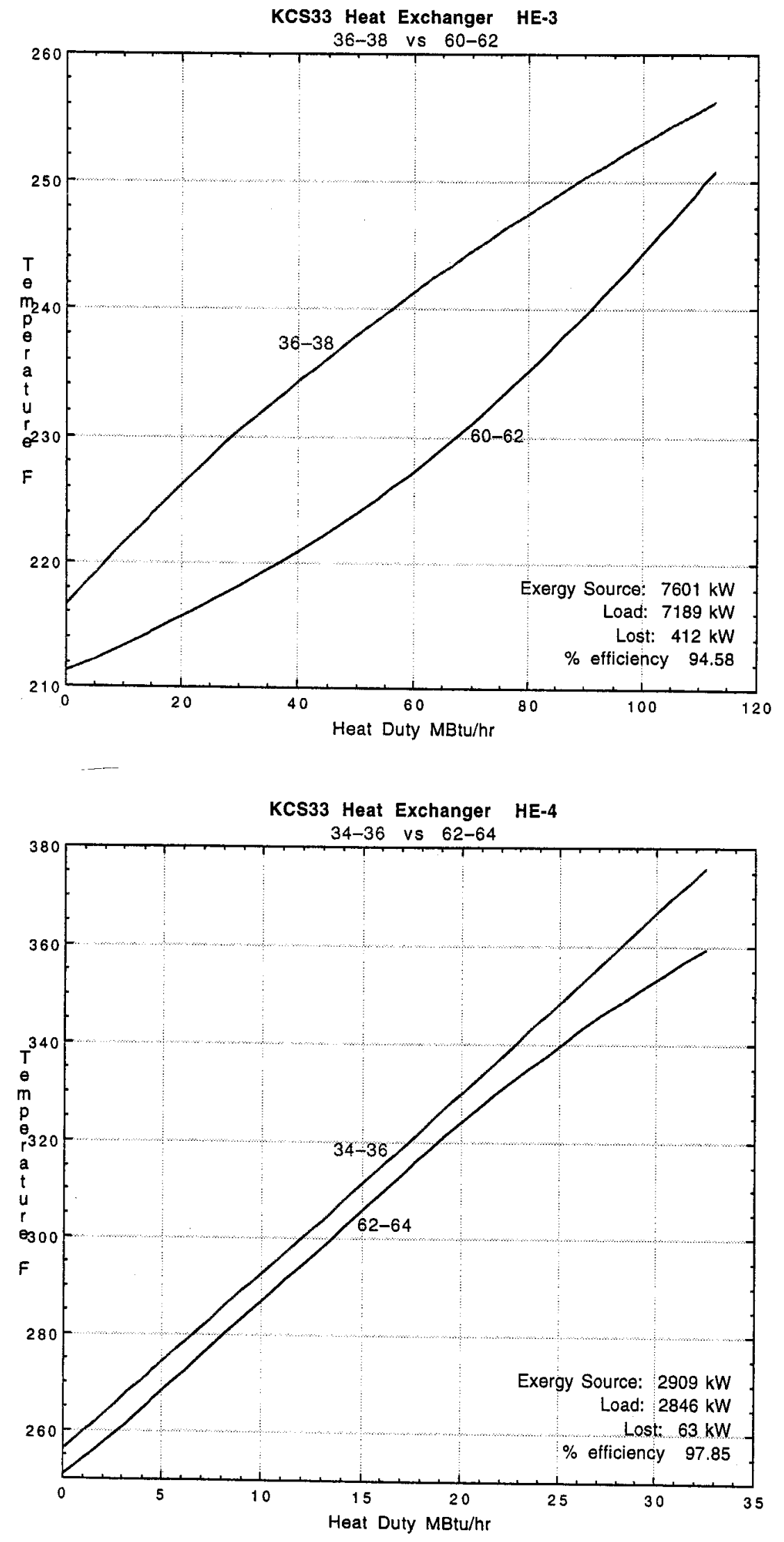

A-17 

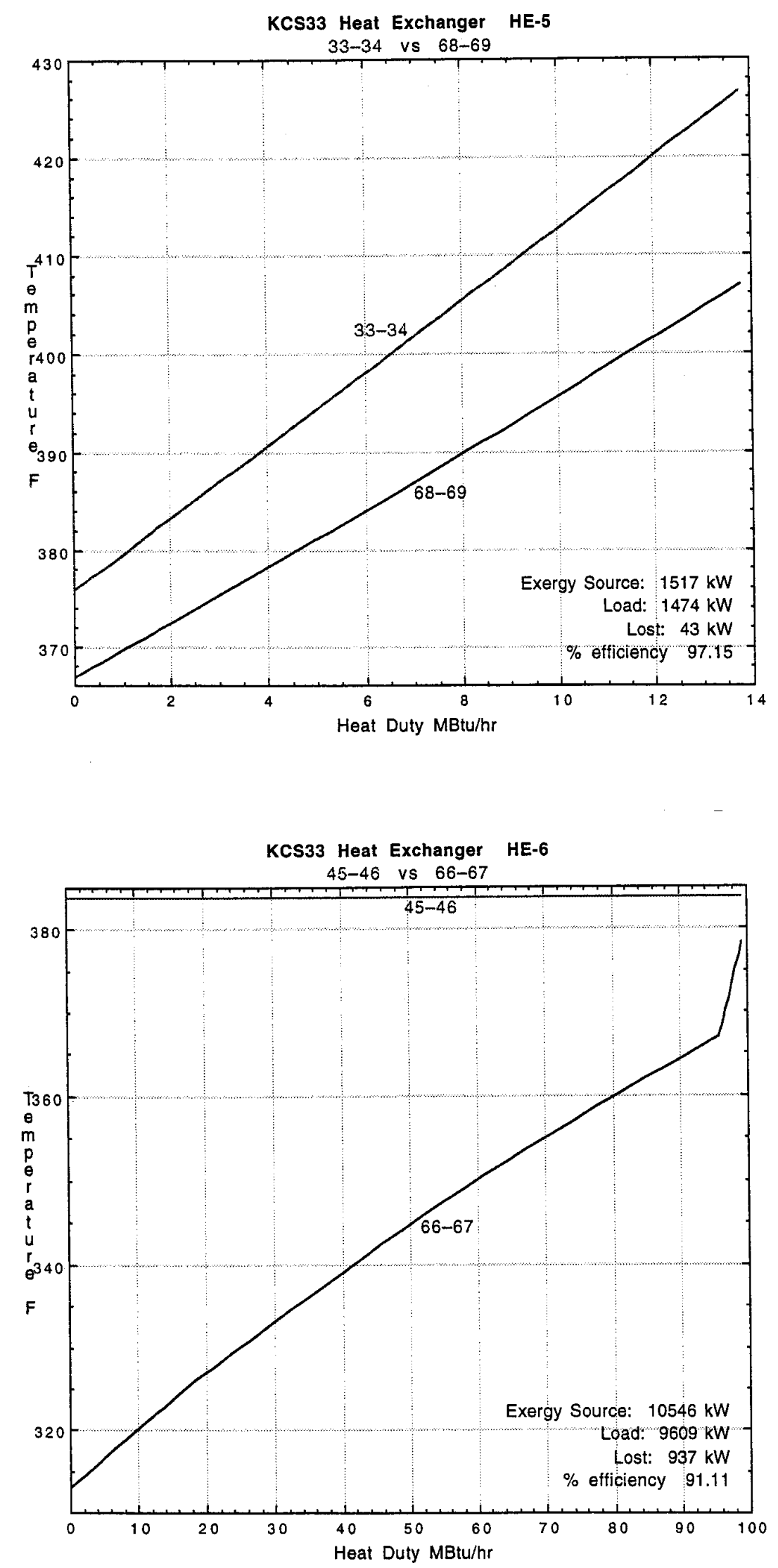

A-18 


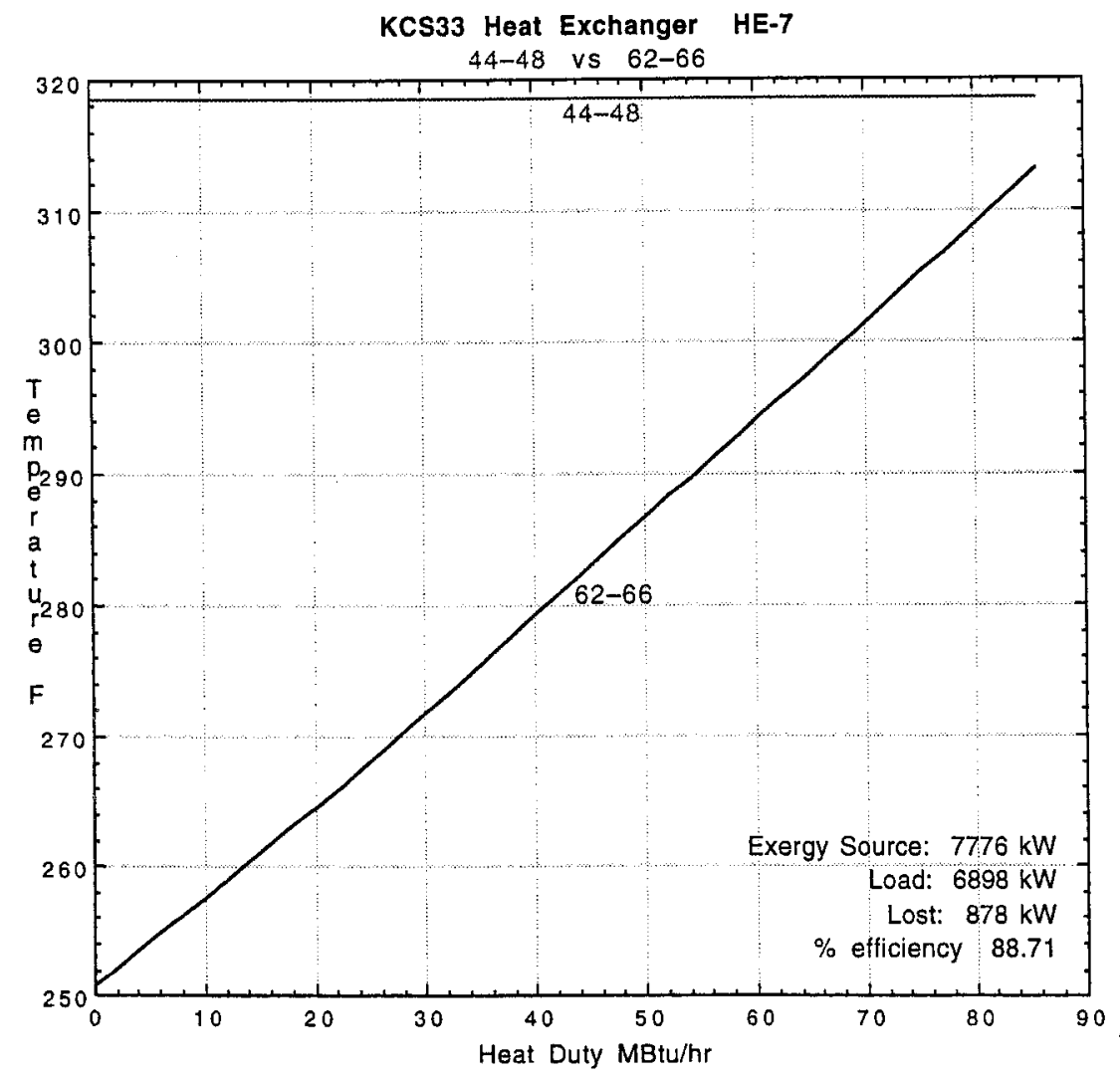

A-19 


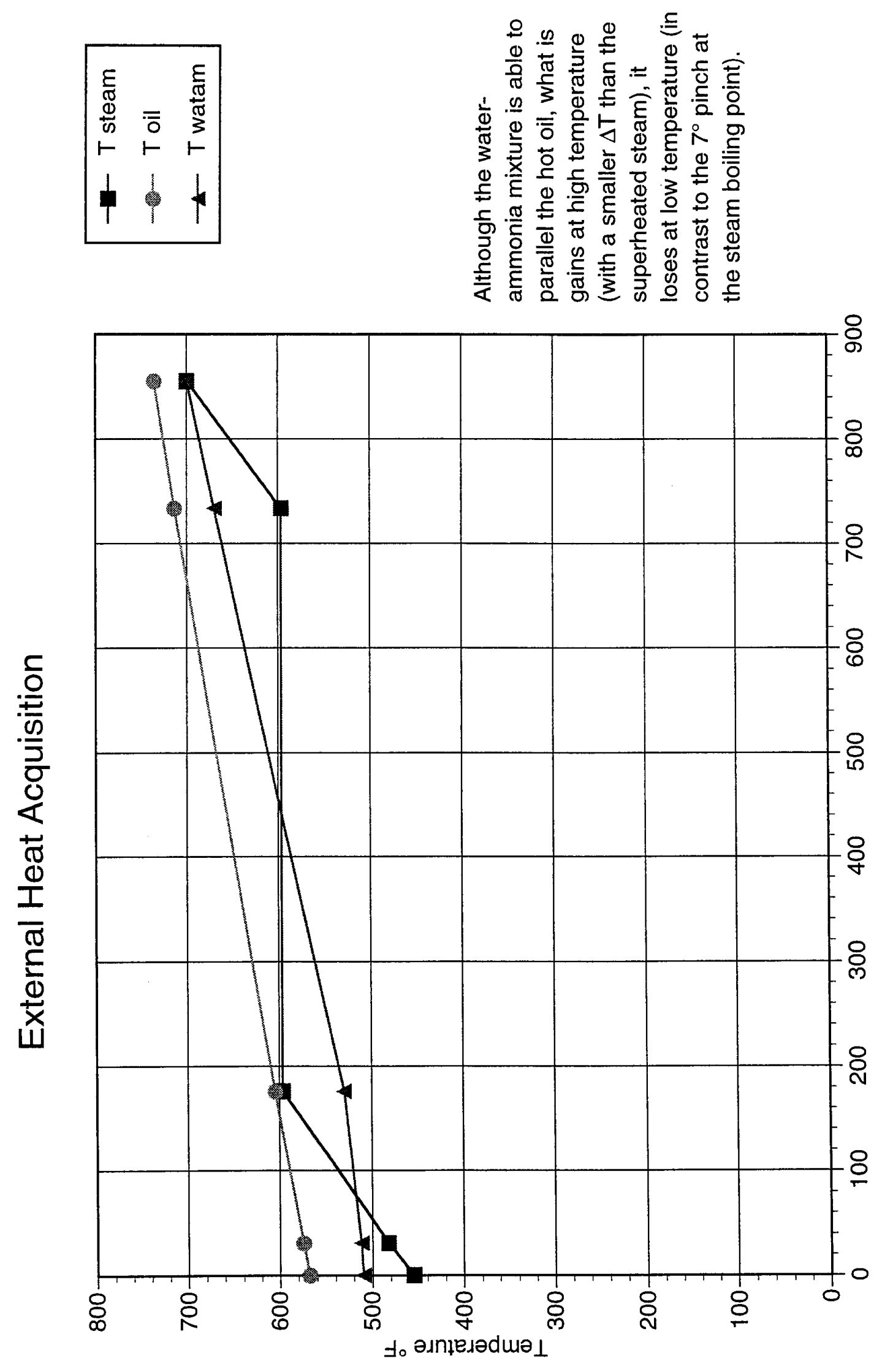




\section{Appendix B}

\section{Analysis Carried Out by Reflective Energies}

Reflective Energies (RE) investigated the feasibility of using an ORC coupled with commercial solar troughs. Three different cycles were analyzed: a simple ORC, an ORC using mixed working fluid, and a Cascade cycle. The basis for the conceptual design carried out by RE was a pure solar plant designed for a net output power of $10 \mathrm{MWe}$. The ambient temperature used in their design was $89^{\circ} \mathrm{F}$. The report provided by RE is presented here.

The simple ORC analyzed by RE using butane as working fluid shows an overall efficiency of about $13.2 \%$ (not including the solar field heat transfer fluid pumping power). This cycle shows a very low efficiency because the maximum temperature reached in the $\mathrm{ORC}$ is $360^{\circ} \mathrm{F}$ (note that the resource temperature used in RE's analysis is $550^{\circ} \mathrm{F}$ ). The maximum pressure of this cycle is 545 psia.

The other cycle analyzed by RE uses a mixture of butane and hexane as working fluid. The composition of the working fluid expressed as mole fraction was $90 \%$ butane and $10 \%$ hexane. For this case, the overall efficiency of the cycle was 13.6\%. Again the maximum temperature in the boiler was very low, $375^{\circ} \mathrm{F}$, compared to the resource temperature of $550^{\circ} \mathrm{F}$. The maximum cycle pressure was 540 psia.

The last cycle analyzed by RE was a cascade cycle where cyclohexane was used in a topping cycle and butane was used in a bottoming cycle. Cyclohexane was heated by the hot oil from solar field to a temperature of $550^{\circ} \mathrm{F}$ at $425 \mathrm{psia}$. After expanding through the turbine it was passed through a recuperator to heat the working fluid of the bottoming cycle. Before entering the recuperator, the working fluid of the bottoming cycle was pre-heated by the oil from solar field. The return temperature of the oil from solar field was $200^{\circ} \mathrm{F}$. The maximum temperature and pressure of the bottoming cycle were $330^{\circ} \mathrm{F}$ and 595 psia. The efficiency of this cycle is $15.9 \%$ (not including the pumping power required for the circulation of the solar field oil). 


\section{The Solar Trough Organic Rankine Electricity System (STORES)}

Final Report

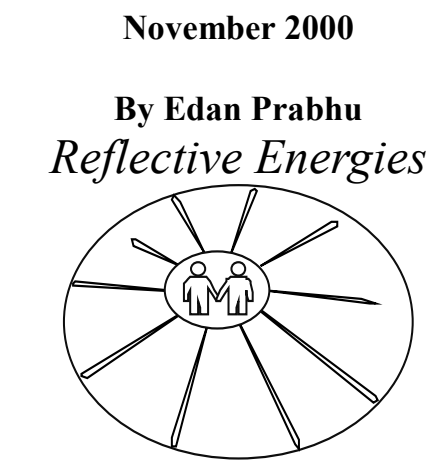

Clean Energy for the Planet

With Support from

John Brugman and Laurie Hardy

Bibb \& Company

And

Robert Cable

KJC Operating Company

22922 Tiagua, Mission Viejo, CA 92692 USA Tel: 949/380-4899 FAX: 949/380-8407 email: edanprabhu@home.com 


\section{The Solar Trough Organic Rankine Cycle Electricity System (STORES)}

\section{Summary}

The nine California Solar Trough power plants, totaling 354 megawatts of power, were once the shining success of the solar program, and even today, produce more electricity than all other solar thermal and PV plants combined; yet no new plants have been built in over a decade. With rising oil and gas prices and energy shortages, there is now the opportunity to resurrect this highly successful technology.

This study seeks to open a new path toward cost-effective electricity from troughs. Proven solar trough plants can be coupled with proven Organic Rankine plants and proven storage systems in creative new ways to produce electricity that will be competitive in hundreds of applications beyond the grid. Small and modular, STORES plants can deliver electricity day and night. Trough technology will, for the first time, become Distributed Generation. The new power plants are intended for off-grid applications where electricity is commonly generated using diesel engines, and commands much higher prices. STORES power output increases as ambient temperature decreases. By generating electricity during cooler evenings and nights, storage therefore actually enhances output. Winter output (for the same input) is higher than summer output, partially compensating for the lower insolation and collection in the winter.

Such plants may be located in remote areas in the Southwest U.S., such as Indian Reservations that are distant from the grid and are considering electricity using diesel engines today. STORES plants will also be the preferred source of generation in the thousands of remote communities all across the Sahara and other deserts, much too remote to be connected to the grid. Rather than compete in the bulk power market, STORES offers the opportunity to establish itself in the specialty power off-grid market where prices are significantly higher.

The STORES power plant considered for the study is 10 megawatts peak; it includes four hours of storage at peak output; in effect, it would be able to deliver power at any time necessary. No other fuel would be necessary. As configured, the plant would use no water except that needed for washing the mirrors. The estimated "commercial" capital cost of the first plant will be around $\$ 4,000-\$ 4,500$ per $\mathrm{kWe}$, comprising $\$ 1,700-2,000$ per $\mathrm{kWe}$ for the solar field, $\$ 2,000$ per $\mathrm{kWe}$ for the power plant and $\$ 300-600$ per $\mathrm{kWe}$ for storage. This includes some allowances for the challenges that will be faced in resurrecting the trough Solar Collector Assembly manufacturing and supply industry. The learning-cost reduction curve will be rapid, and the tenth such plant is estimated to have a capital cost of about $\$ 3,000$ per $\mathrm{kWe}$, far lower than the lowest cost Photovoltaics (PV). Plants may be built in modular increments, in multiples of one megawatt or five megawatts, depending on the need. Unlike the ISCCS plants, the STORES plants could be installed quickly, within a few months. Once the community and site are selected and funds available, the plant does not have to wait upon transmission access, fossil fuel links, major environmental studies and the attendant bureaucratic decision-making delays. Any existing generators could be retained as back up.

A small off-grid STORES plant that includes storage will compete with today's remote diesel power plants, not with large combined cycle or coal plants. It will be a major advancement over large PV systems, with a much higher capacity factor and built-in storage. As with PV, when fuel is free, the cost of electricity from a STORES plant is largely dependent on the cost of capital 
and the cost of labor. With market-priced commercial credit and U.S. labor rates, the cost of electricity from the first plant will be about $\$ 0.26$ per $\mathrm{kWh}$. With a five-percent capital carrying charge and U.S. labor rates, the cost of electricity from the first plant will be in about $\$ 0.18$ per $\mathrm{kWh}$. With developing country labor rates (in the range of $\$ 1$ to $\$ 5$ an hour), electricity costs will drop to between $\$ 0.18$ an hour for $10 \%$ capital carrying charge and $\$ 0.12$ for a $5 \%$ capital carrying charge. If a capital subsidy of only $\$ 2$ per watt is computed, which is much smaller than subsidies provided to $\mathrm{PV}$, the cost of electricity will drop to about $\$ 0.06$ per $\mathrm{kWh}$. For comparison, a diesel engine using reasonably priced fuel of $\$ 2.00$ to $\$ 3.00$ a gallon, by comparison, would produce power in the range of $\$ 0.15$ to $\$ 0.25$ per $\mathrm{kWh}$, or even higher. In brief, STORES power plants have the opportunity to become the lowest cost of generating electricity in certain selected areas of the globe, creating the likelihood of growth and costreductions.

STORES promises to deliver in three ways: it creates a far better power plant using today's proven technologies; it incorporates storage that takes advantage of cooler evenings and winters to produce more electricity; and it can deliver dependable power to off-grid markets desperate for power where the price and value of electricity are significantly higher.

It is recommended that additional study be performed to explore some of the findings of this study more fully, with a view to building the first commercial power plant in the U.S., with public policy funds to support the unusual costs associated with the first-of-a-kind development. Subsequent plants should follow in high insolation developing countries, supported to the extent needed by GEF, World Bank, and similar multilateral institution funding available for clean energy.

The National Labs have a pivotal role to play in fostering this concept. NREL and Sandia should provide definitive data on Direct Normal Radiation, provide introductions to interested parties such as Native American interests in solar power and liaison with foreign governmental inquiries. NREL and Sandia should also provide their modeling expertise to assist in the development of STORES power plants. 


\section{Introduction}

This study investigated the feasibility of a STORES system as a potential pathway toward continuing the growth and commercialization of Solar Troughs.

Trough technology was immensely successful in the 1980s, with over 350 megawatts of power plants built in the southern California desert. Even though the plants are all fully operational and performing better than when they were installed, no new plants have been built since then. This is a tragedy, because this group of solar plants produces more electricity than all PV and solar thermal plants combined. Efforts to build Integrated Solar Combined Cycle Systems (ISCCS) have not yet been successful; the solar fraction of such plants is necessarily small, and the overall logistics of developing such large power plants have resulted in long delays.

Organic Rankine Cycles have also been commercially used for geothermal power plants with almost one hundred megawatts of commercial units running for the last ten years. Whereas Organic Rankine Cycles have been used with low temperature geothermal applications, there is only one known instance of a small solar Organic Rankine system tested. Nevertheless, the Organic Rankine Cycle is a strong candidate for low temperature energy conversion to electricity.

Storage of solar energy was proven in the first large Trough plant, SEGS I, but other than the experimental Solar Two project that used molten salt and Solar One before it, storage of solar energy has not been considered. One reason for this is that the SEGS plants were connected to the robust Southern California Edison grid, and the SEGS contracts were "Standard Offers" that paid premium prices, especially for summer peaks. While almost all the SEGS plants can run on solar only, they are all hybrids, and use 25 percent natural gas.

Despite several attempts, no new Trough-based power plants have been built in the last ten years. The strategy has been that the best path to commercialization and cost reduction is to integrate trough plants with modern combined cycle fossil fired plants to create the Integrated Solar Combined Cycle System (ISCCS). The fraction of solar power delivered by such plants was less than ten percent of the total power generated. This pathway has proven difficult, because the location, logistics and costs had to satisfy both the needs of a large solar plant and a large fossil fueled plant, each a major challenge in its own right. A second problem that proved difficult was that the power plant had to be designed for the solar peak, resulting in unused capacity during the evenings and at night. If the capacity is recovered by fossil fuel supplemental firing, then the fossil fuel consumption goes up to the point where it approaches the quantity of fossil fuel that would be used to deliver full capacity for a fossil-only plant without any solar.

This study looked for a new pathway that would avoid the problems of the ISCCS. It was based on the following premises:

- Only proven technologies would be considered

- The Organic Rankine Cycle would be considered because of its success with the lower temperature geothermal fluids. The STORES power plant would be optimized to maximize output consistent with low-cost electricity

- Storage would be an integral part of the power plant

- The power plant would be built for remote, off-grid communities where the value and cost of alternative power production would be much higher than grid power supply

- No fossil fuel would be used 
- To the extent possible, water use would be minimized because water is scarce in remote desert areas

- Power would be delivered as needed, day or night

- The power plant would be $10 \mathrm{MWe}$ peak, with the solar field also capable of $10 \mathrm{MWe}$ peak, thus simplifying the comparison with plants that have no storage. While it is known that storage allows the field and power plant to be sized to suit the demand of the consumer, that consideration was not used in the optimizations of this study

- Labor rates were considered both for the U.S. market and for remote areas in the developing world

- The sensitivity of market based and low-cost capital and subsidies was also considered.

\section{Technical Considerations}

The technical evaluation focused mostly on the development of an Organic Rankine Cycle and a storage system. The solar field selected was based upon proven LS2 Trough designs. A storage system similar to the Caloria thermal storage system from SEGS1 was selected, having proven successful for over 10 years. The impact of various HTF temperature differentials on power output was examined. These systems are described in the paragraphs to follow.

\section{The Organic Rankine Cycle (ORC)}

The ORC is not new. It was initially developed by Ben Holt Company (whose successor is Bibb $\&$ Co, a participant in this study) and others for low-temperature geothermal applications where the geothermal fluid temperature was too low for flashing into steam or for a traditional Rankine Steam Cycle. Almost one hundred megawatts of such ORC plants were installed and are currently in service, performing relatively trouble-free.

There are several advantages of the ORC for low and moderate temperature applications:

- A wide range of fluids may be chosen with characteristics that suit the temperature needs

- The system can be maintained above atmospheric pressure at all times, eliminating the complicated vacuum system, and practically eliminating the need for make-up fluid

- Power output can be increased during periods when the ambient temperature drops, unlike a steam cycle that is limited by condenser vacuum and does not increase output below about $90^{\circ} \mathrm{F}$

- Small turbines are commercially available for these systems for refrigeration and cryogenic needs, for energy recovery at pressure-reducing stations in natural gas pipelines and similar applications.

The ORC also has several disadvantages that must be considered:

- The fluids are hydrocarbons, far less stable than water

- Cracking could result in carbon deposition

- A single fluid will not cover the wide temperature range that steam/water systems can handle

- Simple cycle efficiencies are low. 
Many strategies were considered to overcome the low efficiency of the ORC. These strategies were addressed in the Task 1 and Task 2 reports. The result of those efforts is presented here.

- A carefully selected two-tier cascade cycle will produce efficiencies approaching the efficiency of a steam system at high ambient temperatures. A two-tier cascade cycle was chosen as a result of this study.

- The efficiency of the lower cycle significantly improves as the ambient temperature drops. This efficiency gain for this lower cycle is about 2 percent for every $10^{\circ} \mathrm{F}$ drop in ambient temperature. This means that for the same input, output during cold winter months will be significantly higher than an equivalent steam cycle, partially compensating for the lower insolation and cosine losses during the winter months.

- Storage during the hottest part of the day for power production during the cooler evenings and nights will result in an increase in efficiency and output.

- The system efficiency for a cascade cycle increases when the HTF hot temperature $\left(\mathrm{T}_{\text {hot }}\right)$ increases, and also increases when the HTF low temperature $\left(\mathrm{T}_{\text {cold }}\right.$ increases. This gain does not occur for the simple cycle. For the two-tier cascade cycle with $\mathrm{T}_{\text {hot }}$ at $560^{\circ} \mathrm{F}$, the efficiency gain was from an efficiency of $13.9 \%$ for a $\mathrm{T}_{\text {hot }}-\mathrm{T}_{\text {cold }}$ temperature difference of $400^{\circ} \mathrm{F}$, to $19.1 \%$ for a $\mathrm{T}_{\text {hot }}-\mathrm{T}_{\text {cold }}$ temperature difference of $100^{\circ} \mathrm{F}$, a gain of $37 \%$. For the two-tier cascade cycle with no recuperation, there was no further increase in efficiency as the $T_{\text {hot }}-T_{\text {cold }}$ temperature difference was narrowed further. With recuperators and/or addition of a third tier, additional gains will be achieved. Obviously, the reduction in field temperature differences must be examined for the solar field as well. The impact upon the field of raising $\mathrm{T}_{\text {cold }}$ to achieve these efficiency gains is addressed in Section 2.2 .

- O\&M costs for the ORC are significantly lower than for a steam plant. An ORC plant may be operated automatically or remotely, whereas a steam plant usually needs operator attention.

- Water requirements for the ORC are virtually zero, a further O\&M savings, particularly if water is scarce and expensive.

- Further improvements in efficiency and costs are possible.

- The simple ORC is shown in Figure 2.1a, and the Mixed ORC is shown as Figure 2.1b. Figure 2.1c is the first cascade cycle that was considered. The selected ORC is shown in Figure 2.1d. The major difference between the two cascade cycles is that for cycle shown in Figure 2.1c the HTF undergoes a higher temperature differential and heats both the upper and lower cycles, whereas for Figure 2.1d the HTF has a lower temperature differential and heats only the upper cycle; the condenser for the upper cycle is the evaporator for the lower cycle. 


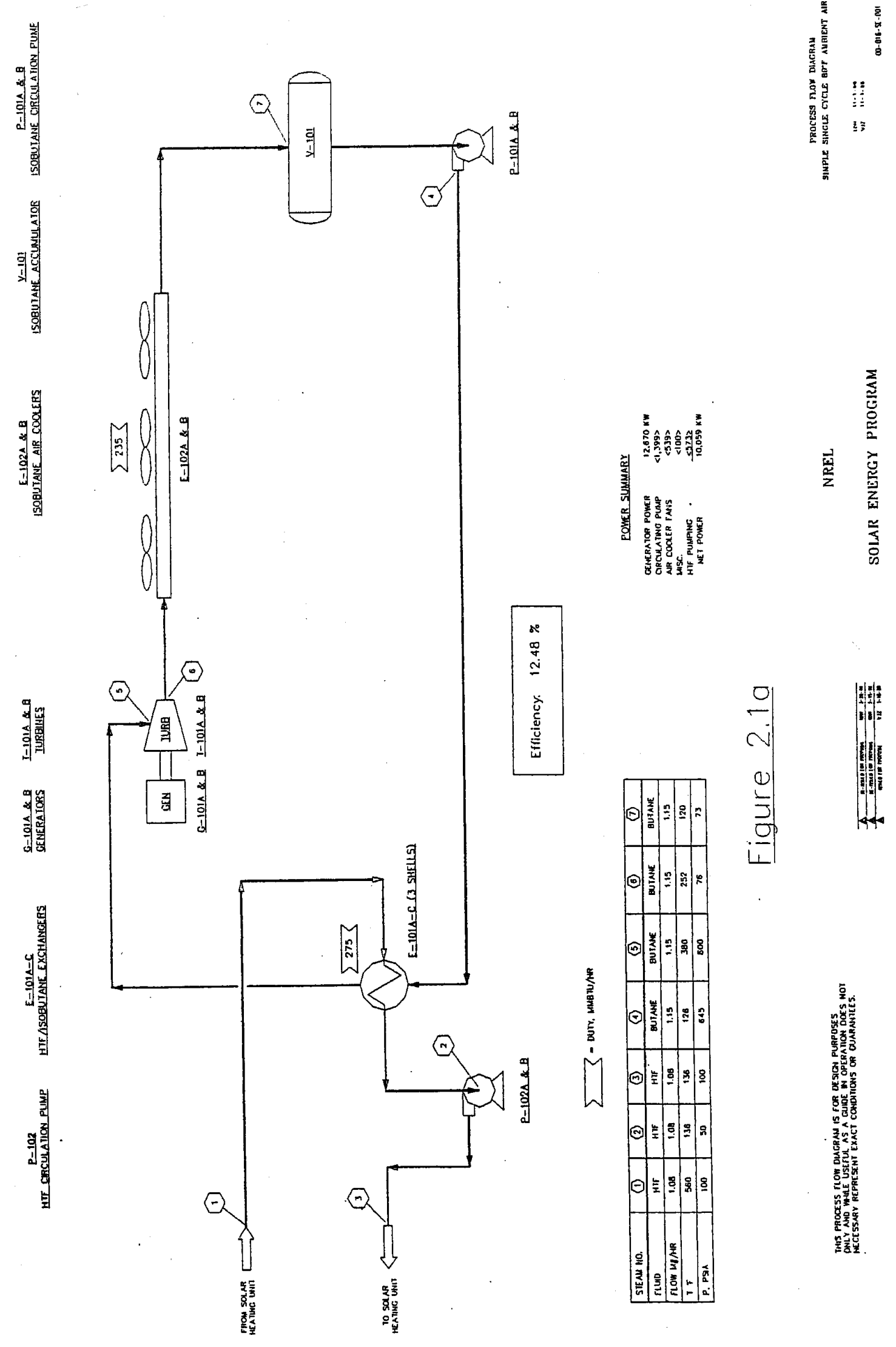




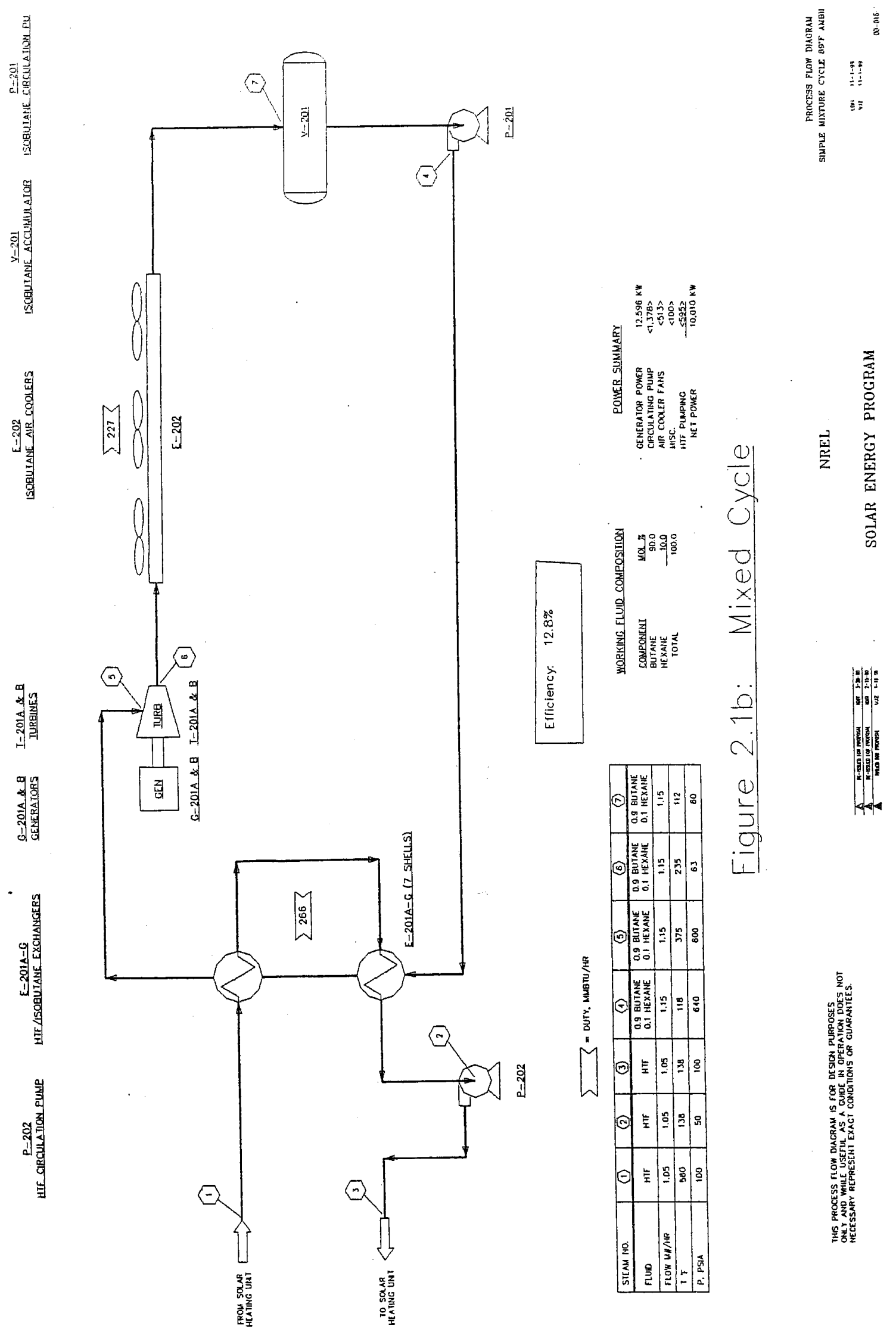




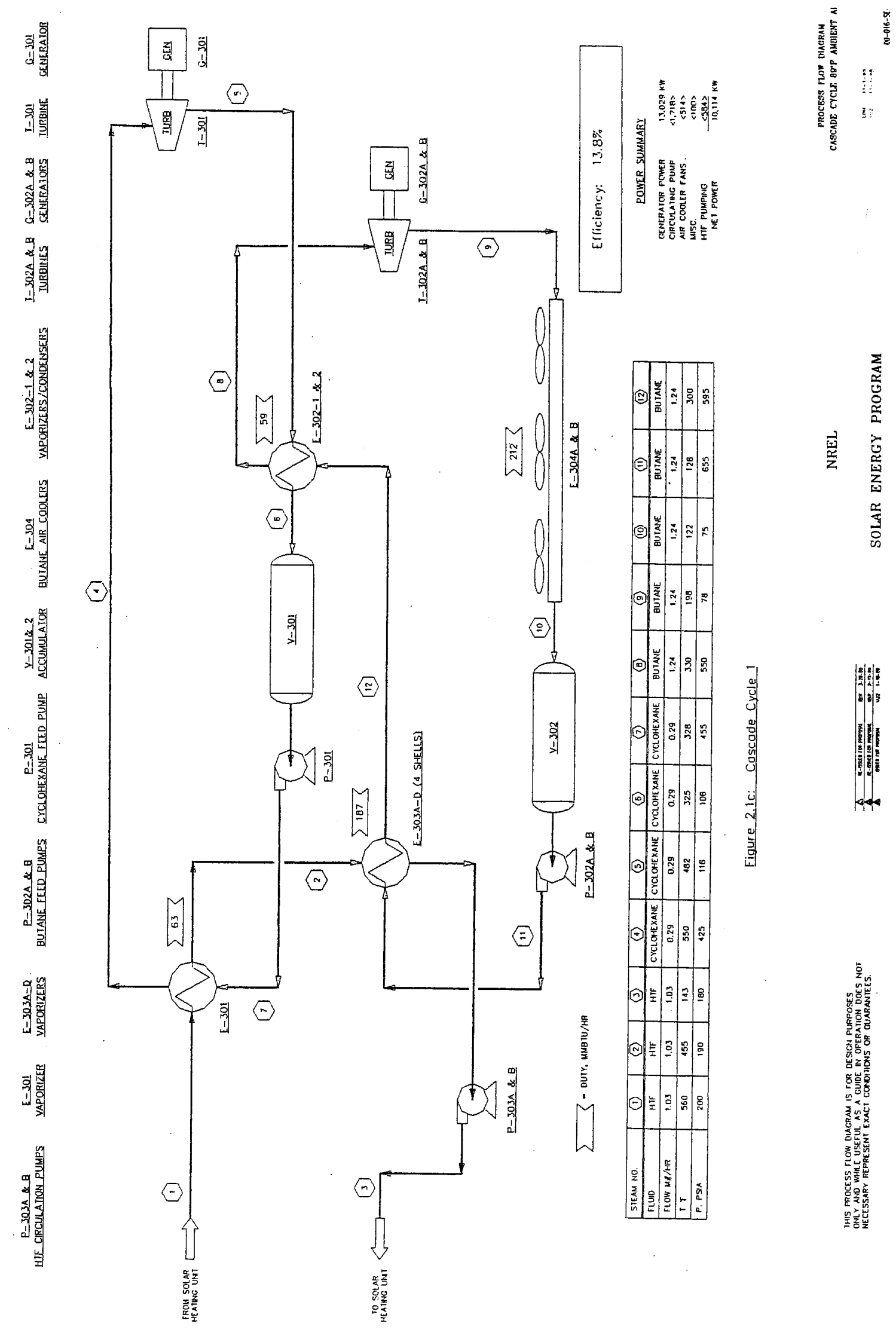

B-10 


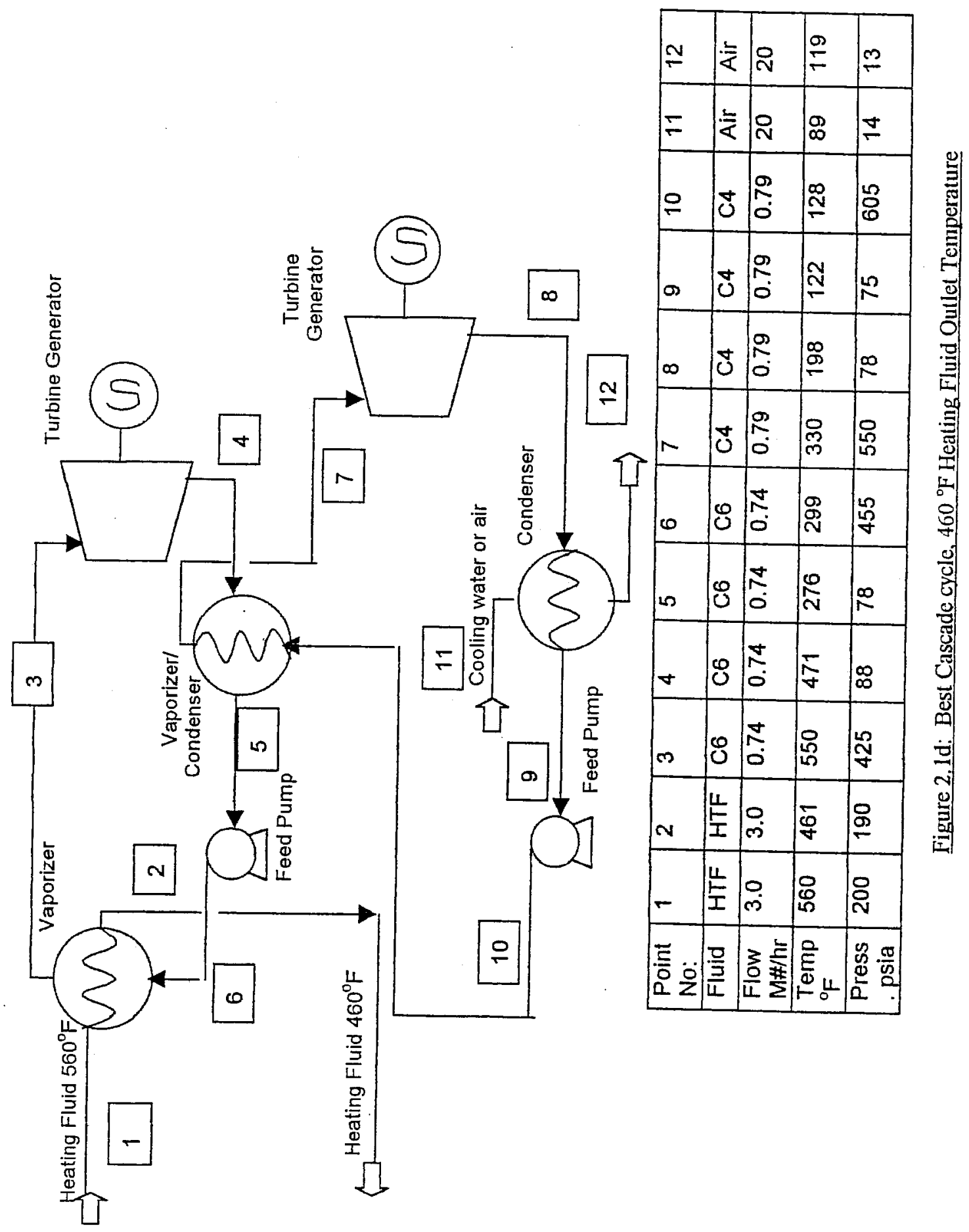




\section{Choice of ORC Technology Suppliers}

The field of ORC suppliers is fortunately rather wide. They include the following companies with excerpts from the literature of the company provided in quotes when available.

- Rotoflow Division of Atlas-Copco Industries. "Rotoflow Inc., a pioneer of turboexpanders in natural gas applications, has designed and manufactured over 2,300 turboexpander units for natural gas, dew point control, geothermal, pressure let down, energy recovery, air separation and other applications where pressure and temperature are dropped."

- Mafi-Trench Corporation. "Mafi-Trench Corporation is the leading manufacturer of radial expansion turbines, or turbo-expanders. Mafi-Trench turboexpanders, for process and power recovery applications, are in service worldwide in industries such as cryogenic natural gas processing, petrochemicals, including ethylene, ammonia, MTBE and methanol; low temperature refrigeration, hydrogen purification; and dew point control. Unlike other manufacturers, Mafi-Trench Corporation concentrates its entire resources on the design and manufacture of turboexpanders. That focus enables MafiTrench to single-mindedly pursue product perfection."

- Barber-Nichols. Barber-Nichols (Appendix C) designs and manufactures custom steam, gas and hydraulic turbines for almost any service. We have an extensive background in design and manufacture of highly efficient Rankine Cycle engines for unique applications. We have designed and manufactured turbines that operate at speeds from 2,000 to 130,000 RPM and power levels up to 6 MWe.

- Ormat. "Since 1965, ORMAT power solutions have combined ecology with economy to produce environmentally sound energy systems that make business sense. The revolutionary ORMAT ${ }^{\circledR}$ Energy Converter is today the basis for dozens of geothermal power plants ranging from $300 \mathrm{kWe}$ to over $130 \mathrm{MWe}$. Other innovative ORMAT applications include the production of power from industrial waste heat, solar energy, and low-grade fuels, and powering unattended telecommunication repeaters and cathodic protection systems."

- Exergy. Exergy is a company dedicated to the development of the Kalina Cycle that combines and separates steam and ammonia in a manner that allows recovery of energy at low-temperatures. The Kalina cycle does not have a proven track record to the extent of the other suppliers; nevertheless, it does address the issue of recovering energy at low temperatures and is included here.

This study focused on the process design, to find a means to maximize output and keep power costs to a minimum. The study was not intended to perform a rigorous selection between the potential suppliers. Bibb and Co., the engineering subcontractor on this project, has worked with all the above manufacturers or developers and is well positioned to evaluate the strengths of each relative to the STORES power plant. Each of the above suppliers is a potential candidate for part or all of the turbines needed for the selected cycles, and will be considered.

\section{The Solar Field}

For this study, it was decided to use a solar field with elements similar to those used at SEGS 3 through 6. The basic building block is the LS2 heat Solar Collector Assembly (SCA). For an overall efficiency of $25 \%$, and an output of 10 megawatts net, the total mirror surface required is 63,000 square meters. The capacity factor used was the same as the capacity factor for the "nostorage" case, approximately $27 \%$. Each SCA has a length of 47.1 meters and a width of 5 meters 
(projected area), which means an aperture of 235 square meters, thus requiring a total of 268 SCAs for the entire field.

Rather than examine ways to improve or modify each SCA, it was decided to investigate the relationships of receivers to the power production requirements. SEGS VI has sixteen SCAs in series, each adding almost $10^{\circ} \mathrm{F}$ for a total temperature increase of $155^{\circ} \mathrm{F}$ with a total of $26 \mathrm{such}$ loops. SEGS VI operates between $559^{\circ} \mathrm{F}$ and $735^{\circ} \mathrm{F}$. It has a total of $800 \mathrm{SCAs}$; with 16 loops per SCA, there are 50 loops in total.

In order to achieve the efficiency gains that derive from a lower solar field temperature differential, it becomes necessary to change the series/parallel connections of the collectors. For a temperature difference of $100^{\circ} \mathrm{F}$, ten SCA in series will comprise one loop. This change is feasible and practical. The pumping energy through each SCA is relatively constant, with a constant pressure drop of 10 psi per SCA and a total pumping energy of about $1.5 \mathrm{kWe}$ per SCA plus header losses. Header losses can be controlled by changing header pipe size. The pumping energy is therefore essentially the same no matter what the field arrangement. In practical terms, the cost of pumps themselves will be lower as each SCA loop is reduced in size because the lowhead high flow pumps are simpler and less expensive than high head pumps of the same energy output.

Figure 2.2a shows, for illustration, a simplified comparison of two fields, each with 16 SCAs. They collect the same amount of solar energy, and use the same pumping power. However, the field representing a SEGS VI loop has a temperature differential of approximately $160^{\circ} \mathrm{F}$ whereas the other field has a temperature differential of only $40^{\circ} \mathrm{F}$. The fluid flow through the second field is four times that in the first.

\section{Storage}

Storage is a vital part of the power plant in this study. Most solar and wind power plants operate only when the sun shines or when the wind blows. These plants are constrained to deliver power to the grid, or to be part of hybrids. Low-cost storage for PV and wind is not available; the only choice today is batteries that are expensive to buy and to maintain.

SEGS I included two tanks that stored the HTF (Caloria) at atmospheric pressure. The tank operated successfully for over 10 years until an unfortunate fire in 1998. It proved that commercial storage was feasible. The hot tank was maintained at $580^{\circ} \mathrm{F}$ and the cold tank was maintained at $470^{\circ} \mathrm{F}$, a temperature differential of $110^{\circ} \mathrm{F}$. This study considered $\mathrm{T}_{\text {hot }}$ storage temperature of $560^{\circ} \mathrm{F}$ and a $\mathrm{T}_{\text {cold }}$ temperature of $460^{\circ} \mathrm{F}$ to $510^{\circ} \mathrm{F}$.

One factor to be considered is that as the $T_{\text {hot }}-T_{\text {cold }}$ temperature differentials are reduced, the volume of stored fluid goes up. For example, a temperature differential of $50^{\circ} \mathrm{F}$ stores only half the energy as a temperature differential of $100^{\circ} \mathrm{F}$, and therefore requires twice the storage of a temperature differential of $100^{\circ} \mathrm{F}$. On the other hand, when smaller temperature differentials are considered, a thermocline tank without internal barriers may be adequate, reducing storage by fifty percent, whereas higher temperature differentials may suggest two separate tanks.

Assuming a $50^{\circ} \mathrm{F}$ temperature differential and four hours of storage (545 million Btu), the total storage capacity required is about 2.2 million gallons for a thermocline tank, and twice that if two tanks are to be used. Storage tanks for HTF are available commercially, as from CB\&I. 


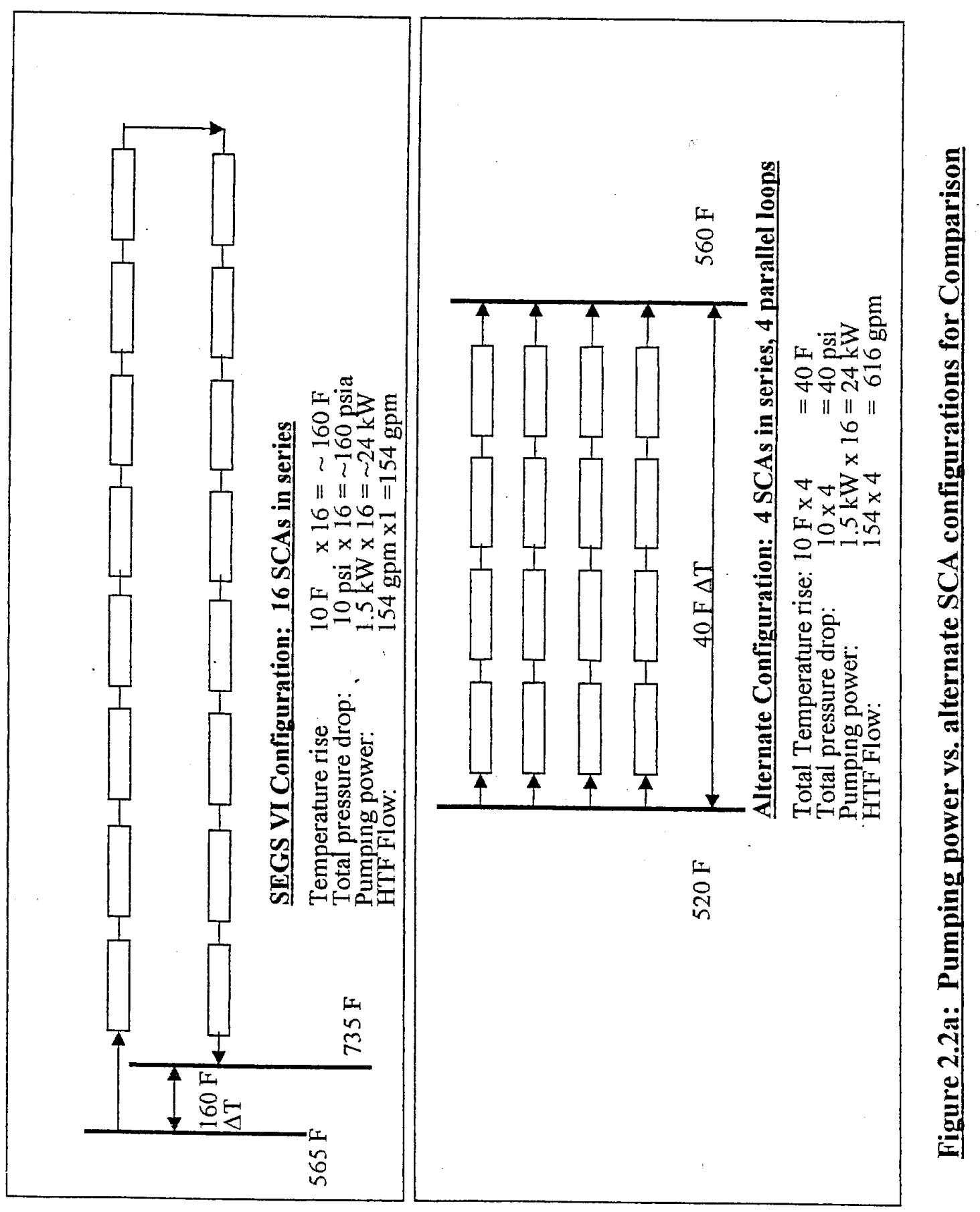


A STORES plant must optimize the cost of increased storage against the efficiency gained when $\mathrm{T}_{\text {cold }}$ is increased. The price of heat transfer fluids has been climbing as the price of oil has risen, shifting the economic choice toward a higher temperature differential and lower storage. Should the cost of HTF continue to rise, there may be room for creating heat capacity using rocks as was done in Solar One.

\section{Integration Between Solar and Power Plants}

Unlike power plants without storage, the addition of storage allows a de-coupling of solar energy collection from power production. Solar power is collected whenever it is available. The passing of a cloud does temporarily reduce the energy collected, but it does not immediately reduce the production of power. Heat is drawn from the storage tank to make electricity. The heat is drawn whenever there is a demand for electricity, as long as there is energy left in the storage tank. The segregation caused by storage means that there is no longer a need to integrate closely the designs of the two systems.

\section{Land Requirements}

The land requirements for SEGS VI are 162 acres for 188,000 square meters of HCA aperture. These requirements would be in approximately the same relationship for similar insolation levels. The land required by the STORES plant would be about 55 acres.

\section{Potential For Efficiency Gains}

The study showed that by careful selection of the field and cycle arrangements, significant gains in efficiency are possible. However, the Carnot Cycle efficiency (1-T2/T1) for a working fluid between a high temperature of $550^{\circ} \mathrm{F}$ and $120^{\circ} \mathrm{F}$ is over $42 \%$. An examination of the Temperature-Enthalpy Diagram for the Cascade Cycle shows several potential areas for improvement. Each tier could be improved by using a recuperator. A third tier may be feasible. While this study considered only dry cooling, should the price of water allow, combination wetdry cooling towers may be able to reduce the temperature differential to the heat sink during summer months; a hyperbolic induced-draft cooling tower could eliminate the excessive pumping costs. While these enhancements were beyond the scope of this study, they should be considered in the design of a STORES Power Plant.

Another potential efficiency gain would result if the HTF high temperature is raised to $580^{\circ} \mathrm{F}$ rather than $560^{\circ} \mathrm{F}$. SEGS I operated its HTF tank at $580^{\circ} \mathrm{F}$ and even higher. The Carnot ideal efficiency goes from $42.5 \%$ to $43.6 \%$ when the working fluid temperature correspondingly goes from $550^{\circ} \mathrm{F}$ to $570^{\circ} \mathrm{F}$. Furthermore, by taking advantage of lower ambient temperatures in the evening and in winter, efficiency gains may be achieved. 
Figure 2.6a: Cascade Cycle Opportunities for Recuperation

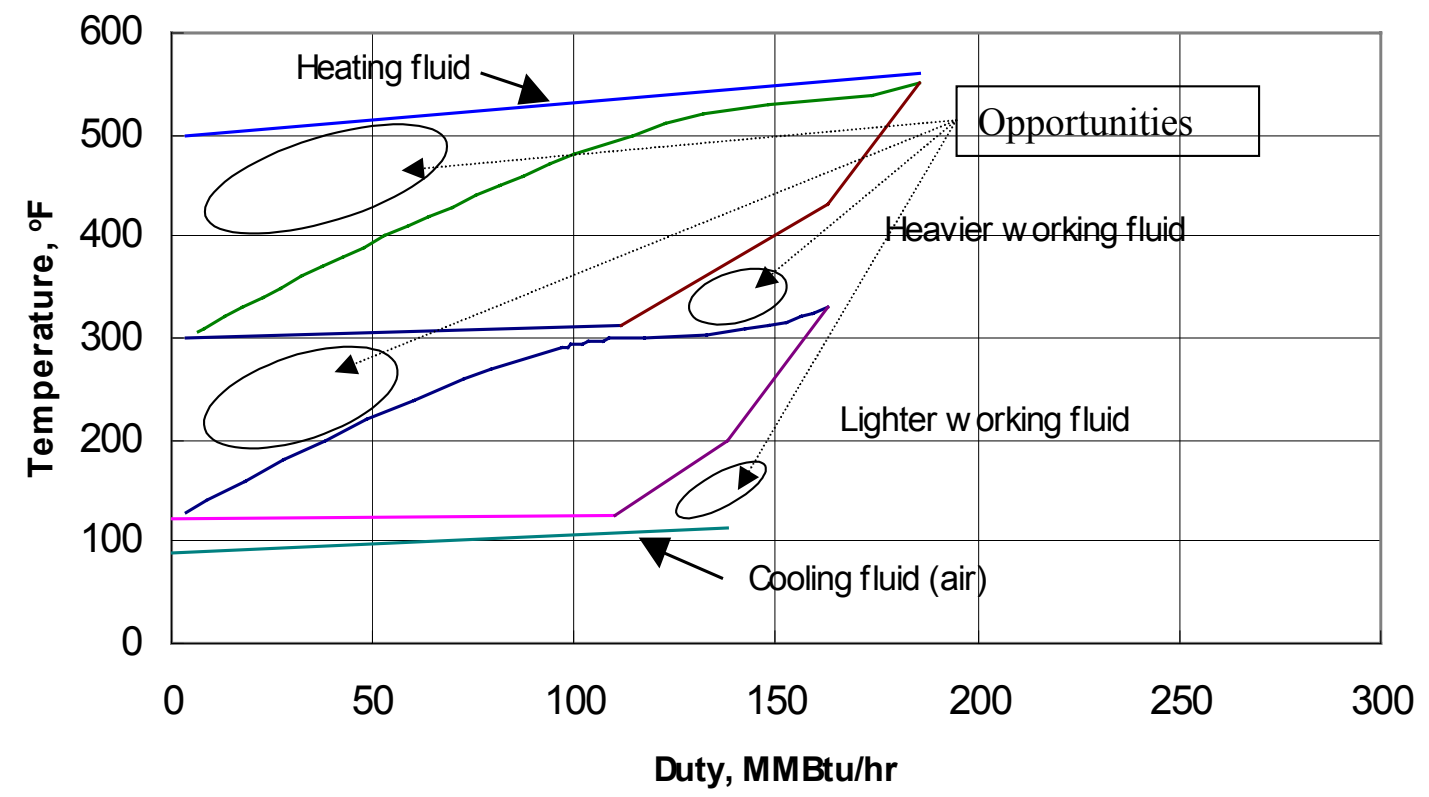

A third potential gain was the one identified by Dr. Vahab Hassani of NREL. He added recuperators to a Simple Cycle and was able to boost efficiency for that cycle from $12.2 \%$ to $14.3 \%$, an increase of 17\%. Figure 2.6a shows the opportunities for recuperation of the selected cascade cycle.

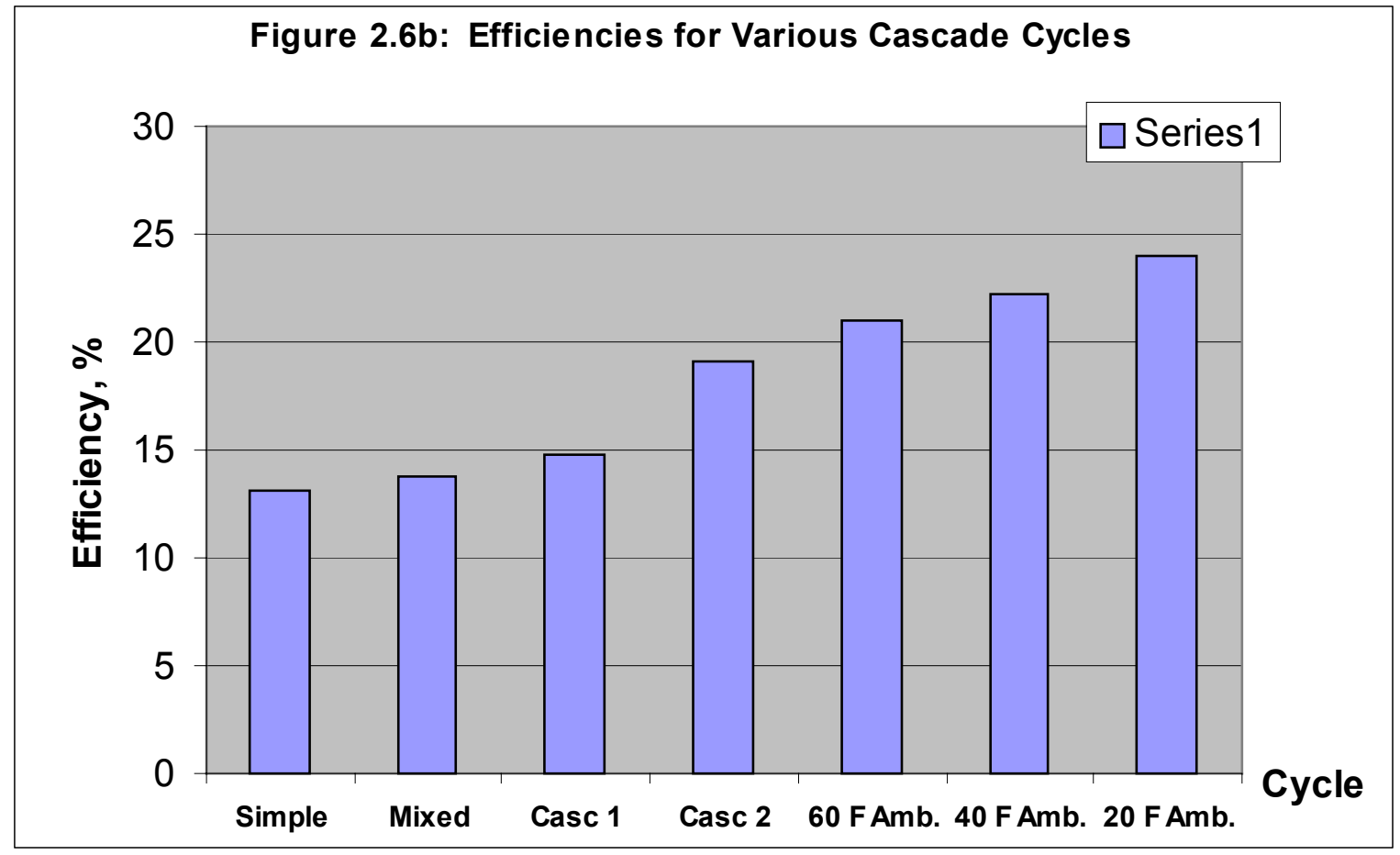


A fourth potential gain may be obtained by raising the pressure of the working fluid. This was analyzed in the Bibb Task 3 report which stated that further efficiency gains may be achieved by raising the fluid working pressure, and thereby its maximum operating temperature.

While each of the above improvements will make a gain, the incremental gain as each improvement is sequenced on to previous gains is smaller. It is felt that the ORC efficiency at an ambient temperature of $89^{\circ} \mathrm{F}$ will reach $25 \%$, with additional gains in efficiency as the ambient temperature drops. Figure 2.6b shows the overall efficiency gains with lower temperatures. Figure 2.6b does not show the potential for gains in efficiency that may be achieved by raising the high temperature, recuperation, pressure increases and improved heat rejection.

\section{Costs and Economics}

The capital and operating costs of major components of the STORES plant are considered in this section, followed by an economic evaluation that examines the sensitivity of the costs for a U.S.based installation and a Developing Country installation.

\section{Capital Costs}

The total cost of the first STORES plant of 10 megawatts is estimated to be $\$ 4,000-4,500$ per $\mathrm{kWe}$, or $\$ 40,000,000$ to $\$ 45,000$, of which $\$ 1,700-2,000$ per $\mathrm{W}$ is the field, $\$ 2000$ is the power plant, and \$300-600 is storage. In addition, the first plant is estimated to have an additional "firstof-a-kind" cost of $\$ 500$ per $\mathrm{kWe}$. This additional cost includes the cost of resurrecting the production and supply of the SCAs. The capital costs for the solar field, the power plant, and storage are examined in more detail below. Just as there is a potential for increased efficiency, there is also room for cost reductions. At this stage it was decided not to pursue aggressive costreduction strategies.

The purpose of the study was to evaluate Organic Rankine Cycles. Another approach would be to consider a small steam plant for power generation. Such small steam power plants are difficult to obtain at the present, and their costs are therefore uncertain, but are expected to be in the same range as the ORC plants that were evaluated. Future work in this area should follow-up on steam plant cost and availability prior to selection of the power cycle.

\section{Solar Field}

The size of the field is 63,000 square meters based upon an assumed power plant efficiency of $25 \%$. KJC Operating Company was requested to estimate the cost of the field for a new field. Their best estimate at this time is $\$ 270$ a square meter, including piping, pumps, and other accessories, resulting in a total field cost of $\$ 17,000,000$, or about $\$ 1,700$ per kWe. Because of the uncertainty related to efficiency gains and other factors, a range of $\$ 1,700-2,000$ per $\mathrm{kWe}$ is used here. Assuming a reduction of three percent for each subsequent field for the first ten plants, the cost of the tenth plant will be about $\$ 200$ per square meter or about $\$ 1,260$ per $\mathrm{kWe}$. By this time, there will be a total of 630,000 square meters of total SCAs, about one quarter of the SCA's currently installed at the SEGS plants. If the first plant is successful, the time-frame for the tenth plant may be no more than 4 or 5 years, each plant more cost-effective than the one before it. In addition to the costs above, it is anticipated that there will also be a cost to resurrect the production lines for SCA and other costs associated with starting up an industry that has long 
been dormant; such costs are estimated to be roughly about $\$ 5,000,000$ or a once-only charge of about $\$ 500$ per $\mathrm{kWe}$.

Should the ultimate power plant selected have a lower efficiency than $25 \%$, the size of the solar field would increase proportionately to the reduced efficiency, and with it the costs on a linear basis.

In discussions with NREL, it is a continuing concern that the resurrection of the SCA supply production line will be difficult. It is in this arena that significant support will be needed from NREL as the project moves forward. It may be necessary to consider an alternate SCA supplier should it become impossible to resurrect the LS2 supply system. SCA supply was not a part of this study, and these comments are intended to be cautionary rather than authoritative. Duke Solar has expressed an interest in supplying SCAs, as have IST and Solel. It is hoped that the prospect of real opportunities will help stimulate the supply.

\section{Power Plant}

The estimated constructed cost of the ORC two-tier Cascade Cycle power plant is $\$ 1,940$ per $\mathrm{kWe}$, compared to a Simple Cycle of $\$ 1,650$ per $\mathrm{kWe}$. The respective equipment costs for the cascade cycle are $\$ 800$ per $\mathrm{kWe}$. Of these, the largest costs are the turbine-generators $(58 \%)$ and the condenser air coolers (22\%). For the Simple cycle, the equipment cost is $\$ 686$ per $\mathrm{kWe}$, with the turbine generator cost $56 \%$ and the condenser air coolers at $28 \%$. The higher efficiency of the cascade cycle means a higher turbine-generator cost, but more energy will be converted into electricity, resulting in less heat rejection, meaning a lower cost for air coolers. Thus the increased cost of higher efficiency is somewhat offset by the lower cost of heat rejection. Figure 3.1.2a is an equipment list showing the costs of the various equipment components. The estimates are considered conceptual, with a margin of error of $25 \%$. Further efficiency improvements such as recuperators, an improved cooling system, and perhaps a third tier will increase certain costs and decrease others because as more energy is converted into electricity, there will be less energy and lower costs for heat exchangers for the lower tiers. For this study, the cost of the Power Plant is assumed to be $\$ 2,000$ per $\mathrm{kWe}$. The cost of subsequent power plants will also decline as more power plants are built. The decline will not be as steep as for the solar side, because the supply side is already active. However, orders for multiple units will result in a lower per-unit cost for each subsequent unit. A cost-decline rate of $2 \%$ per plant for the first few plants is assumed.

There is some risk that at the higher temperatures the long-term stability of the upper-tier cycle fluids may be in question. This issue is considered manageable, by selecting an appropriate fluid for the upper cycle. The temperature ranges certainly do not push the envelope of available fluids.

\section{Storage}

The HTF to be used is Caloria. The reason for selecting Caloria is that it is inexpensive, has a very low vapor pressure at $560^{\circ} \mathrm{F}$, and can be stored in an ordinary, unpressurized tank. There are obviously significant efficiency penalties to be suffered by using Caloria, but the benefits are considered to outweigh the penalties. This study did not consider molten salts, phase change fluids or other means for storage; it simply looked for a feasible, proven low-cost option. Four hours of storage of peak power mean storing a total of 546 million Btu of energy. This requires about 2.2 million gallons of fluid. SunRay Industries has found that the price of HTF roughly 


\begin{tabular}{|c|c|c|c|c|c|c|c|c|c|c|}
\hline \multicolumn{11}{|c|}{$\begin{array}{r}\text { Figure 3.1.2a } \\
\end{array}$} \\
\hline \multicolumn{11}{|c|}{ Ten Megawatt STORES Power Plant Study } \\
\hline \multicolumn{11}{|c|}{ Equipment List: Various Cycles } \\
\hline \multicolumn{2}{|c|}{ Simple Single Cycle } & & & & \multicolumn{2}{|c|}{ Design } & \multirow{2}{*}{$\begin{array}{l}\text { Head } \\
\text { psi }\end{array}$} & \multirow[b]{2}{*}{ HHP } & \multirow[b]{2}{*}{$\mathrm{T},{ }^{\circ} \mathrm{F}$} & \multirow[b]{2}{*}{ Price } \\
\hline No. & Tag \# & QTY. & Cap. Ea & Description & Flow & Units & & & & \\
\hline & Butane & & & & & & & & & \\
\hline & E-101A-C & 3 & $100 \%$ & Preheater $\mathrm{HX}$ & 275 & \multicolumn{2}{|c|}{ MMBtu/hr total } & & & 477,000 \\
\hline & $E-102$ & 1. & $100 \%$ & Air Coolers - 63 fans & 235 & \multicolumn{2}{|c|}{ MMBtu/hr total } & & & $1,916,000$ \\
\hline & $P-101 A-B$ & 2 & $50 \%$ & Circulating Pumps & 2300 & gpm & 572 & 1031 & 120 & 326,000 \\
\hline & $P-102 A-B$ & 2 & $50 \%$ & HTF Pumps & 1981 & gpm & 274 & 423 & 136 & 191,000 \\
\hline & TG-101A-B & 2 & $50 \%$ & Turbine Generator Package & & & & & & $3,896,000$ \\
\hline & $V-101$ & 1 & $100 \%$ & Accumulator & & & & & & 60,000 \\
\hline & \multicolumn{3}{|c|}{ Total Equipment Cost } & & & & & & & $6,866,000$ \\
\hline & & & & & & & & & & \\
\hline \multicolumn{11}{|c|}{\begin{tabular}{|l|l|l|} 
Simple Mixture Cycle & & \\
\end{tabular}} \\
\hline No. & Tag \# & QTY. & Cap. Ea & Description & & & & & & \\
\hline 3 & E-201A-F & 5 & $100 \%$ & Preheater HX & 146 & \multicolumn{2}{|c|}{ MMBtu/hr total } & & & 566,000 \\
\hline 4 & $E-201 G$ & 1. & $100 \%$ & Vaporizer HX & 120 & \multicolumn{2}{|c|}{ MMBtu/hr total } & & & 140,000 \\
\hline 2 & $E-202$ & 1 & $100 \%$ & Air Coolers -60 fans & 227 & \multicolumn{2}{|c|}{ MMBtu/hr total } & & & $1,750,000$ \\
\hline 5 & P-201A-B & 2 & $50 \%$ & Circulating Pumps & 2260 & $\mathrm{gpm}$ & 587 & 1020 & 112 & 324,000 \\
\hline 6 & $P-202 A-B$ & 2 & $50 \%$ & HTF Pumps & 1926 & gpm & 293 & 439 & 138 & 195,000 \\
\hline 1 & TG-201A-B & 2 & $50 \%$ & Turbine Generator Package & & & & & & $3,869,000$ \\
\hline & $V-201$ & 1 & $100 \%$ & Accumulator & & & & & & 67,000 \\
\hline & \multicolumn{3}{|c|}{ Total Equipment Cost } & & & & & & & $6,911,000$ \\
\hline & & & & & & & & & & \\
\hline \multicolumn{11}{|c|}{ Cascade Cycle } \\
\hline No. & Tag \# & QTY. & Cap. Ea & Description & & & & & & \\
\hline 8 & $E-301$ & 1 & $100 \%$ & Cyclohexane HX & 63 & \multicolumn{2}{|c|}{ MMBtu/hr total } & & & 177,000 \\
\hline 5 & E-302-1 & 1 & $100 \%$ & Cyclohexane Butane HX1 & 36 & \multicolumn{2}{|c|}{ MMBtu/hr total } & & & 126,000 \\
\hline 6 & $E-302-2$ & 1. & $100 \%$ & Cyclohexane Butane $\mathrm{HX} 2$ & 23 & \multicolumn{2}{|c|}{ MMBtu/hr total } & & & 98,000 \\
\hline 4 & $E-303 A-D$ & 4 & $100 \%$ & Butane Preheater $\mathrm{HX}$ & 187 & \multicolumn{2}{|c|}{ MMBtu/hr total } & & & 451,000 \\
\hline 3 & $E-304$ & $1)$ & $100 \%$ & Air Coolers - 60 fans & 212 & \multicolumn{2}{|c|}{ MMBtu/hr total } & & & $1,781,000$ \\
\hline 9 & $P-301$ & 1 & $100 \%$ & Cyclohexane Circ. Pumps & 997 & gpm & 349 & 271 & 325 & 73,000 \\
\hline 7 & P-302 & 2 & $50 \%$ & Butane Clrculating Pumps & 2481 & gpm & 580 & 1120 & 104 & 343,000 \\
\hline 10 & P-303 & 2 & $50 \%$ & HTF Pumps & 1889 & gpm & 293 & 431 & 143 & 193,000 \\
\hline 2 & TG-301 & 1 & $100 \%$ & Cyclohexane T-G Package & & & & & & $1,150,000$ \\
\hline 1 & TG-302 & 2 & $50 \%$ & Butane T-G Package & & & & & & $3,563,000$ \\
\hline & V-301 & 1 & $100 \%$ & Accumulator & & & & & & 48,000 \\
\hline & $V-302$ & 1 & $\therefore 100 \%$ & Accumulator & & & & & & 69,000 \\
\hline & \multicolumn{3}{|c|}{ Total Equipment Cost } & & & & & & & $8,072,000$ \\
\hline
\end{tabular}


tracks the price of retail gasoline. A bulk price of $\$ 1.50$ a gallon was assumed. This price has been rising as a result of the recent increase in oil prices, and any increases in price will directly be reflected in increased costs of oil inventory. Should the price of HTF continue to climb, it may be practical to use a heat capacitor such as rocks as was used in Solar One. Several suppliers are available for Heat transfer Fluids in the temperature ranges considered.

Tanks in the 2-million gallon range cost about $\$ 0.40$ a gallon, installed and insulated. Figure 3.1.3 shows the cost-curve for such storage tanks. Smaller tanks are more expensive on a unit basis. The technology is proven and CB\&I, the supplier of the SEGS I tank, the world's foremost tank constructor, is ready to provide tanks for future projects. The total cost of the storage system, HTF included, will be about $\$ 5,000,000$ or about $\$ 500$ per kWe. The anticipated heat loss from the tanks is anticipated to be small, less than $1 \%$ per day. This loss reduces the overall efficiency, partially offsetting the $2 \%$ gain in efficiency resulting from storing the fluid in the day and producing power in the evenings and at night. The benefit of storage is the ability to allow power on demand, and total off-grid operation where the value of electricity and the cost of alternate generation is much greater.

Should the temperature differential of the HTF be increased to $100^{\circ} \mathrm{F}$, the cost of storage will be reduced by nearly one-half. However, there will be a price to pay in efficiency. This becomes a significant issue should the cost of HTF continue to rise. On the positive side, the increases in HTF price are symptomatic of higher energy prices that spur the growth of renewable energy and are therefore welcome. The trade-off between storage costs and temperature differentials should be more fully analyzed before the first STORES plant is built.

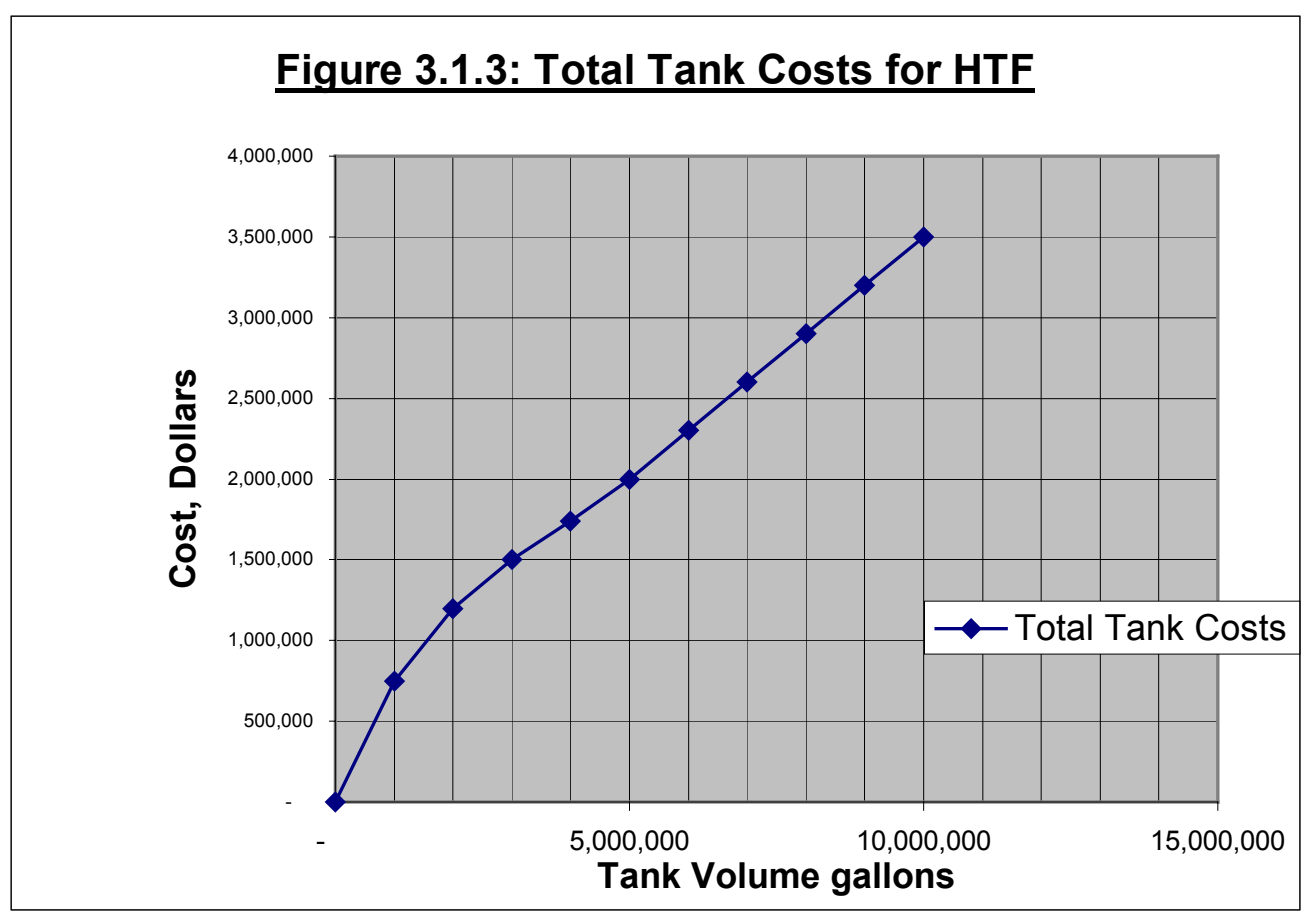




\section{Operating and Maintenance Costs (O\&M)}

As with capital costs, the O\&M costs are broken out separately for the Field and for the Power Plant. The O\&M costs of storage are rolled into Field O\&M costs. Labor costs are separated from non-labor costs because the huge difference in labor costs in the U.S. and in developing countries have a significant impact on the economics and the cost of power.

\section{Field O\&M Costs}

\section{The Solar Field}

KJC estimates, based on its experience, that the field and power plant together will require a total of 33 people to operate. This includes the common managerial and administrative functions necessary. Of these, the field may be allocated a total of 17 people including all those assigned to general management and administration. The steam power plant would require a staff of 16 people to operate. Figure 3.2.1a shows the total number of operators and the breakdown for the power plant and the solar field. As is seen below, an ORC power plant would require far fewer operators.

\section{The ORC Power Plant}

Bibb \& Co., based on its experience, estimates that the ORC power plant will require a staff of 7 people, including 4 operators (one per shift for two shifts a day plus coverage for time off and special assignments), one electrician, one mechanic, and one manager. During the night shift, the plant would be unmanned. This is significantly lower than the staffing estimated by KJC for the steam power plant. Figure 3.2.1a shows the staffing requirements for the power plant and solar field. Much of the difference can be attributed to the increased complexity of a steam plant, especially during startup and shutdown. It is recommended that a closer look be taken at staffing requirements before the ORC is constructed.

The major cost in operating the field are labor, the cost of pumping, and damage replacement. The cost of demineralized water for mirror cleaning is not very large. In the U.S., far and away the largest cost is labor. Field O\&M cost estimates were obtained from KJC Operating Company. The total annual non-labor maintenance costs for the plant are estimated to be $\$ 500,000$ of which water costs are $\$ 6,000$. Whereas water costs are not a major part of the costs at Kramer Junction, they may be a much bigger factor in other desert locations where water is scarce.

\section{Economic Considerations}

The basic economic consideration is whether the electricity that is generated by the STORES system will be cost-effective relative to the alternate systems that may be available. The initial considerations did not include any benefits or subsidies for renewable energy. Once the basic evaluations are performed, the sensitivity of the costs to supports was considered as the sole environmental adder. No value was ascribed to externalities, global warming, carbon tax credits, or other such credits.

The other major Trough concept being considered today is the ISCCS power plant. The economic considerations for STORES and for ISCCS are very different. ISCSC plants must find sites that are first optimized for a combined cycle power plant, including a robust power grid, a 


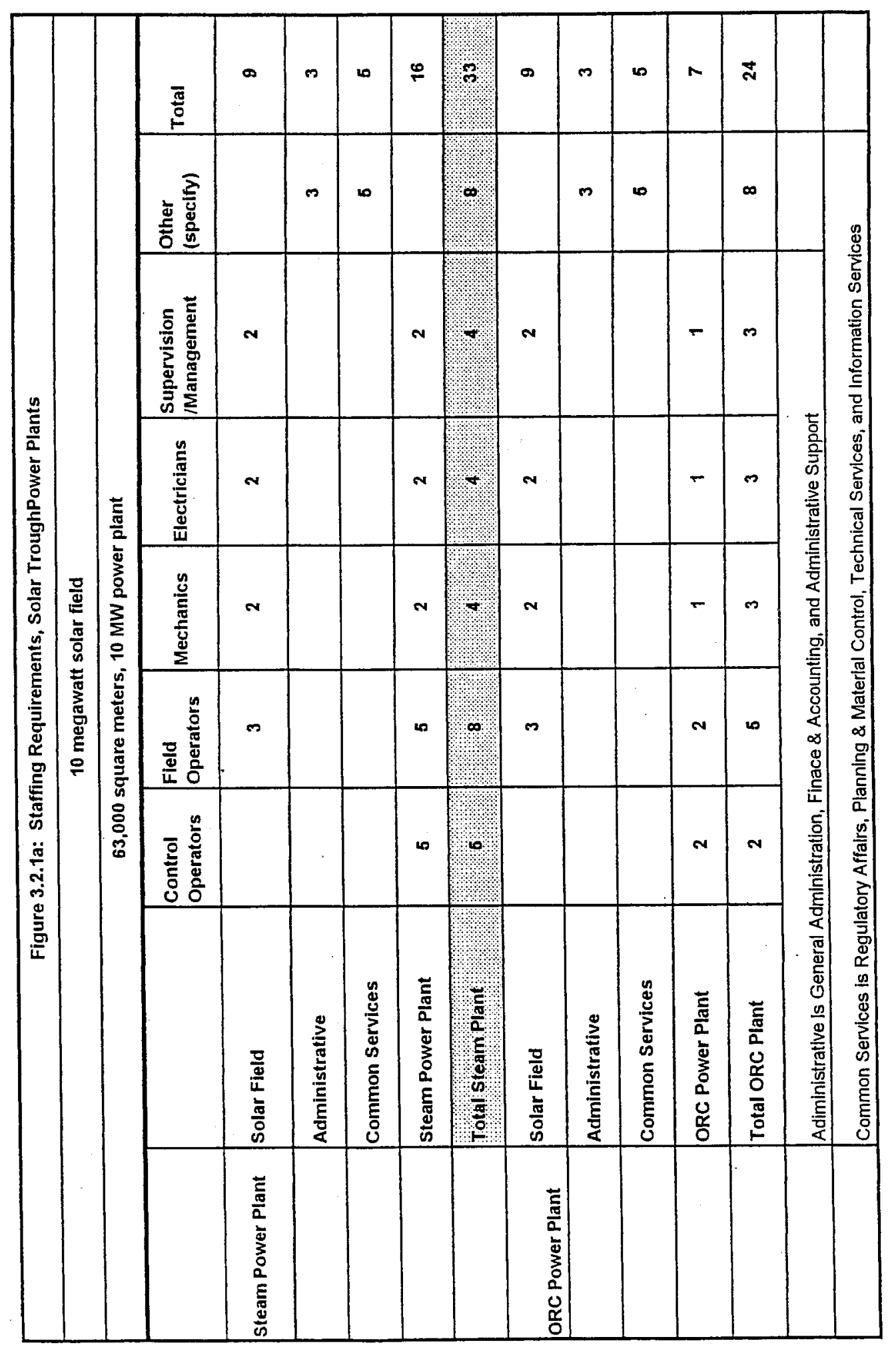


major supply link for fuel, and a demand for large quantities of electricity. In addition, the site must have high insolation. ISCCS requires much greater logistics and approvals, resulting in much deliberation and delay. The process of obtaining approvals from renewable energy funding agencies is also much more difficult, because the solar fraction is less than $10 \%$. The robust grid generally also means that the average cost of electricity is low, generally below $\$ 0.10 \mathrm{a} \mathrm{kWh}$. STORES power plants, by contrast can be built quickly, and funds can be obtained quickly, because the power plant is $100 \%$ solar. Approvals will also be rapid. STORES will displace diesel electricity that is already very expensive. The economic incentive for STORES power plants is thus radically different from the ISCCS.

\section{Cost of Capital}

Solar power plants are capital intensive and have free fuel. The cost of electricity generated is therefore significantly impacted by the cost of capital. The initial evaluation considered a carrying charge for capital of $10 \%$ per year. Then subsequent sensitivity calculations examined the impact of lower capital carrying costs or capital buydowns as is prevalent in several areas for PV. Whereas the early Trough Projects found financing to be difficult because of the unknowns associated with such plants, there is now a solid track record of almost 15 years during which the SEGS plants have consistently performed at or above capacity, and the plants today are generally in better shape than when they were constructed. Financial institutions should find comfort in the success and offer very attractive lending rates to such projects. The same solid track record should also bring confidence to the World Bank, the GEF, and other institutions that are looking to create sustainable renewable energy development to developing countries. The simplicity of the STORES power plant, and the established, proven technologies that will be employed, will provide further assurance.

The cost of capital will be one of the biggest factors in determining the pace of sustained growth of this important technology.

\section{Labor Rates}

Another large factor in arriving at a cost of electricity is the cost of labor, which depends on the location, the length of plant operation, and alternative employment available. The average fully loaded labor rate at $\mathrm{KJC}$ is somewhat above $\$ 40$ an hour. Bibb estimates that the labor rate for new operators in a new plant would be around $\$ 35$ an hour. For this study, it was decided to use a labor rate of $\$ 40$ an hour.

In many countries where such plants may be located, labor rates can be as low as $\$ 1$ an hour, or even lower. Here, too, the approach used was to start with U.S. labor rates and then consider the changes when the power plant is operated in other countries.

The strategy for design of STORES plants in the U.S. and in developing countries should consider the implications of labor cost. In general, high capital cost to reduce labor is justified in the U.S., while highly labor-intensive work that keeps capital low is preferred in developing countries.

Table 3.3.2 shows the cost and performance indicators in tabular form, similar to those used by SunLab in developing its roadmap for Trough Technology. At first glance, the STORES system does not appear to compare favorably with ISCCS systems. However, when considering that STORES power plants will displace far more expensive electricity and can be built in a small 


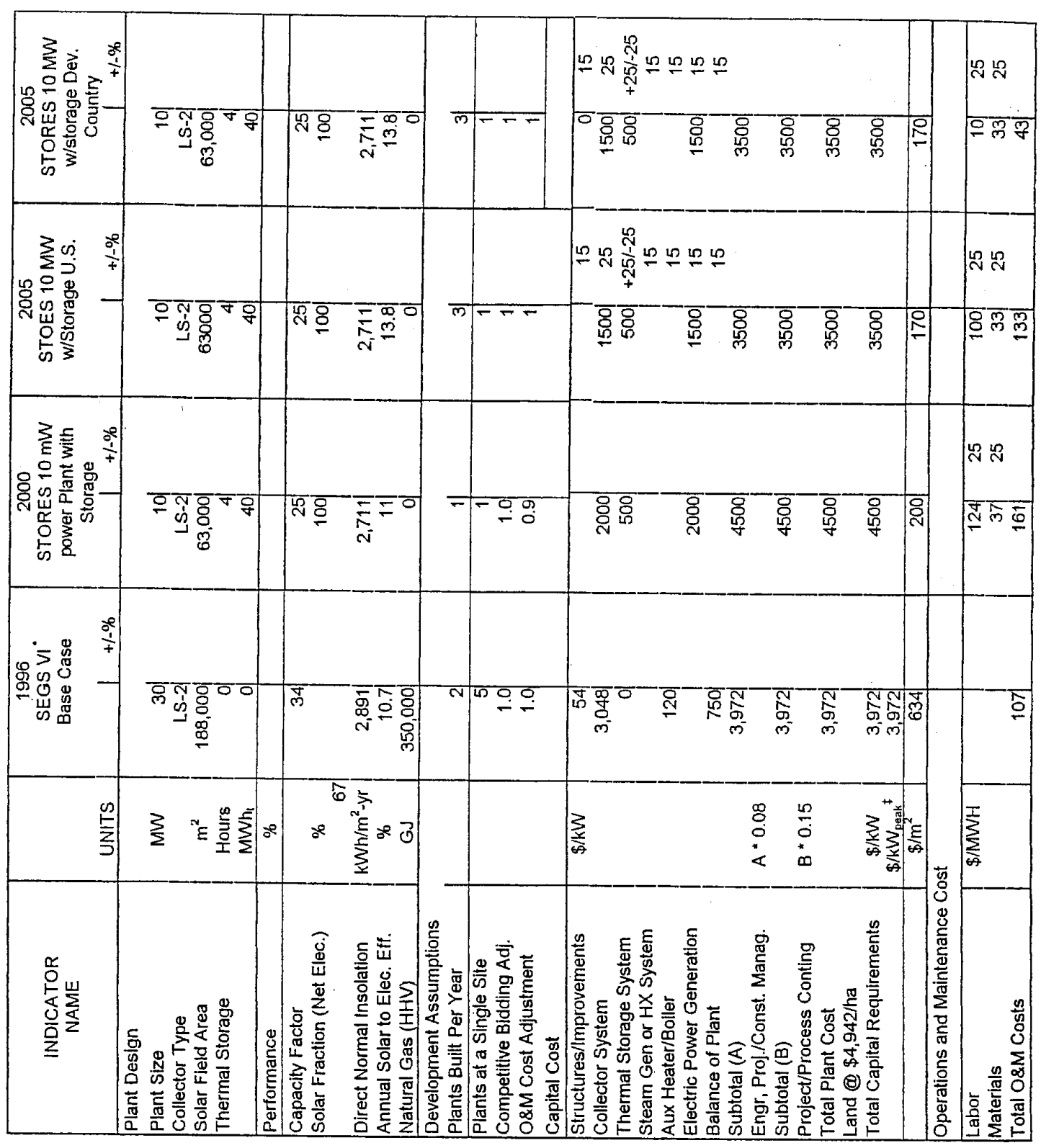

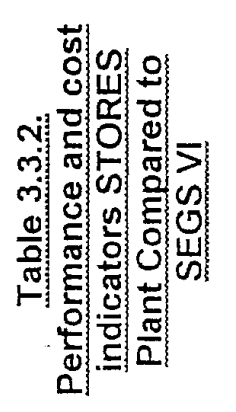


fraction of the time it takes to license, build, and operate an ISCCS plant, the economic rationale shifts significantly in favor or STORES.

\section{Cost of Electricity: U.S. Power Plant}

Using a $10 \%$ capital carrying charge and a labor rate of $\$ 40$ an hour, the first STORES plant will generate electricity in the range of $\$ 0.22$ to $\$ 0.31$ per $\mathrm{kWh}$. If the carrying charge is reduced to $7.5 \%$, the cost of electricity is reduced to $\$ 0.19$ to $\$ 0.25$ per $\mathrm{kWh}$. A carrying charge of $5 \%$ obtains an electricity cost of $\$ 0.16$ to $\$ 0.20$ per $\mathrm{kWh}$. The electricity costs with a $\$ 2$ per watt subsidy, such as is available for several PV installations, results in a cost of electricity of $\$ 0.10$ to $\$ 0.15$ per $\mathrm{kWh}$.

While these numbers are high, they are dramatically below the cost of electricity from PV, and furthermore include the most important value of electricity on demand. The corresponding cost of generation from diesel engines at such remote sites is also expensive. At a modest $\$ 2$ a gallon, the cost of electricity from diesel is $\$ 0.16 \mathrm{a} \mathrm{kWh}$, and at $\$ 2.50$ a gallon is $\$ 0.22 \mathrm{a} \mathrm{kWh}$. The gap to be bridged for cost-effective STORES is only a few cents per kWh. Thus the crossover point between STORES and alternate generation for STORES is far closer than for any other solar technology or even trough plants delivering power to the grid.

Perhaps the biggest advantage of STORES is that it moves the trough technology from an on-grid technology to an off-grid Distributed Generation technology, where the alternative cost of electricity is directly tied to the cost of diesel fuel. Diesel fuel in remote locations is expensive.

\section{Cost of Electricity: Developing Countries}

It is in developing countries where the cost-effectiveness will be achieved the quickest. The twin factors of low-cost labor and expensive diesel fuel dramatically swing the economics in favor of STORES. With a $10 \%$ capital carrying charge and labor rates of $\$ 5$ an hour, the cost of power will be $\$ 0.15$ to $\$ 0.20$ per $\mathrm{kWh}$, already lower than diesel generation. With labor of $\$ 1$ per hour, the cost of power is $\$ 0.14$ to $\$ 0.18$ per $\mathrm{kWh}$ and lower. When carrying charges are reduced to $5 \%$, the cost of electricity drops to the range of $\$ 0.09$ and $\$ 0.15$ per $\mathrm{kWh}$. With a $\$ 2$ a watt subsidy, the costs of electricity drops below $\$ 0.05$ to $\$ 0.07$ per $\mathrm{kWh}$.

There are other reasons for developing countries to consider such plants: they create jobs, and they displace expensive imported diesel fuel. Potential buydowns from the GEF, the WORLD Bank and other multilateral institutions make the prospect of such plants even more attractive to developing countries.

Figure 3.3.4a shows a comparison of costs of STORES plants with the capital, labor, and buy down scenarios described above.

For many developing countries, these power plants will be a small fraction of the cost of extending the grid to the remote area. Once again, the Distributed Generation benefit becomes the key to cost-effectiveness. 


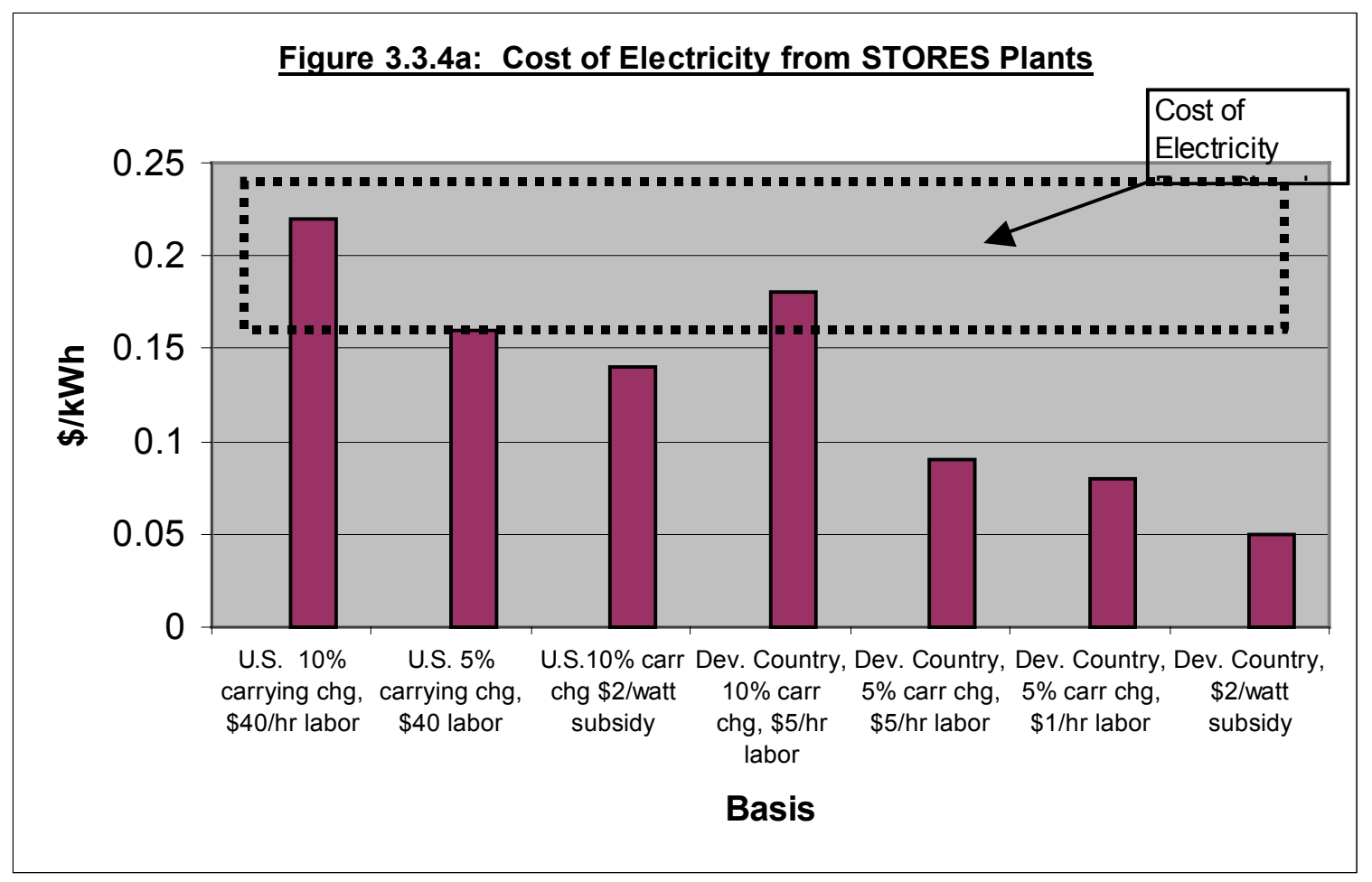

\section{Room For Further Reductions}

As STORES power plants proliferate, it is anticipated that the capital costs will drop. It will also be possible to achieve efficiency gains. Additional labor savings for U.S.-based plants may also be realized. In Developing Nations, the impact of reducing staffing is not as important. While an initial cost of $\$ 270$ per square meter of trough aperture was assumed for this study, the cost should drop to $\$ 200$ a square meter and even less, as more plants are constructed. The cost of electricity shown in Figure 3.3.4a will continue to decline, offering an excellent hedge against increasing oil prices.

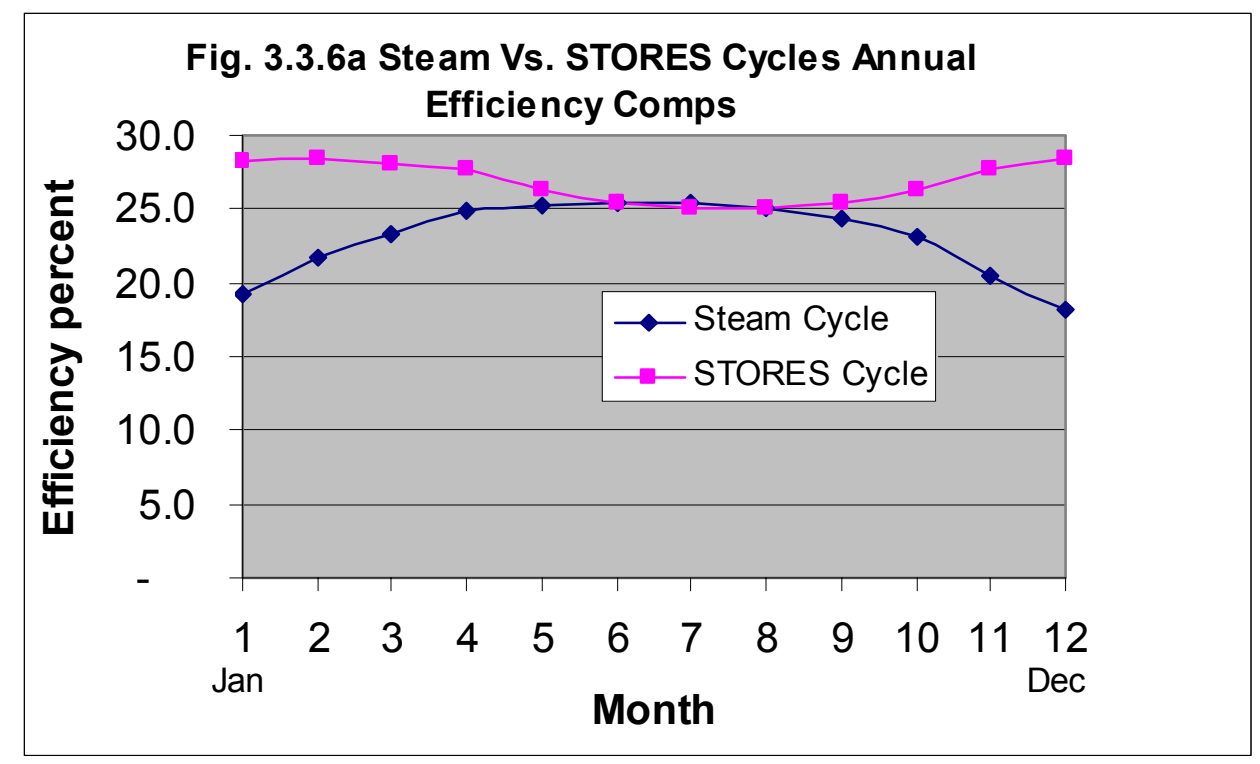

B-26 


\section{Comparison with the Rankine Steam Cycle}

A comparison with the Rankine Steam Cycle is considered important because all existing Trough power plants use this cycle. The steam cycle cannot increase output appreciably as ambient temperature drops, limited by condenser pressures close to absolute zero, thereby limiting performance. This is one of the reasons why steam plants have attempted to raise the HTF high temperature as much as possible. The supply of small steam turbines has also declined as the market declined, and small steam power plants are expected to be much more expensive than ORC power plants, where the turbines continue to be manufactured for the pipeline, cryogenic, and other markets. Figure 3.3.6a shows the efficiency comparison between the optimized STORES and steam systems during each of the twelve months of the year for the Kramer Junction area. Figure 3.3.6b shows the increase in output between the STORES plant and the Steam plant for Kramer Junction through the year. It is seen that the output of a STORES plant is significantly higher as the ambient temperature declines. These differences will be considered very important for remote areas where electricity is scarce.

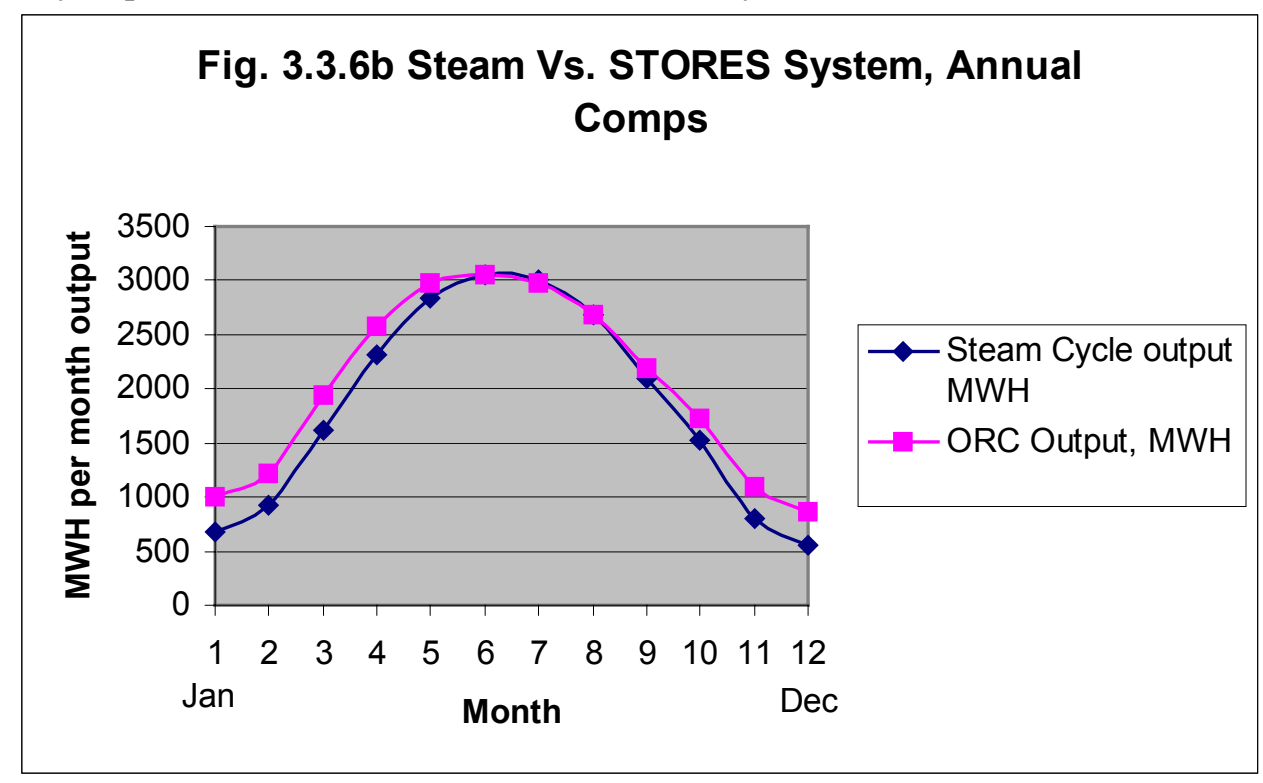

Another major difference with the Steam Cycle is that whereas the ORC can operate virtually operator-free, a steam plant needs constant attention. KJC's estimate for staffing for the steam plant alone is 16 people. Bibb's estimate for the ORC plant is 7 people. This difference is magnified for U.S. plants where labor costs are high. Steam plants also have a high make-up water requirement, further increasing O\&M costs in areas where water is scarce.

In summary, the ORC has lower cost, lower O\&M, lower labor requirements than a steam plant and is the system of choice for a stand-alone Trough-based power plant.

\section{Plant Size}

The plant size selected for this project is a nominal 10 megawatts. This is considered a good starting size. However, most of the components are modular and can be arranged to create much smaller power plants. It is quite likely that even the 10-megawatt plant, when fully optimized, will comprise two 5-megawatt power plants, as was the case for the ORC system at Mammoth. Plants as small as one megawatt will not suffer a significant unit cost increase. 
However, in order to jump-start the trough technology, a minimum volume of SCAs will be necessary to justify the resumption of their production. A 10-megawatt plant will require 63,000 square meters and 268 SCAs. This should be sufficient to stimulate the restart of the industry, especially when there is the potential for more plants to come.

Further study will be necessary to evaluate the scaling up and down of STORES plants and to come up with a flexible, modular design.

\section{Conclusions and Recommendations}

\section{Conclusions}

The STORES power plant provides an option to the ISCCS for restoring Trough solar power plants to their rightful place in renewable energy. The following are advantages of STORES power plants:

- They will be able to deliver power around the clock to remote areas, at a cost already close to the cost of alternative generation

- STORES will lead more rapidly toward cost-effectiveness than the ISCCS option

- The simpler operation of STORES plants will result in O\&M Costs that are significantly lower than comparable steam power plants

- Storage is feasible and can be provided at a reasonable cost, allowing for power to be delivered on-demand, an important value for remote areas not connected to the grid

- The output of well-chosen ORC plants, given the same input, will increase output during cooler evenings and during colder winter months

- The cost of electricity in the U.S. will be close to competitive with the potential other means of generation for remote areas using diesel generators

- In Developing Countries with low labor rates, the cost of electricity will be lower than that from diesel engines, perhaps even for the first such plant

- If a low capital can be obtained for renewable energy and global warming reduction benefits, it will significantly reduce the cost of electricity produced

- A subsidy of $\$ 2$ a watt will make the cost of electricity generated in developing countries very attractive

- Even though STORES plants are not in common use, the building blocks of a STORES plant are proven and successful; this will enhance the likelihood of attracting developers and financiers

- Subsequent STORES plants can be built quickly, responding to short-term needs

- STORES plants will need much simpler environmental review than ISCCS plants

- STORES plants will need very little infrastructure development compared to ISCCS plants

- STORES are pure solar plants, with no fossil fuel requirements, avoiding contentious debates on "solar fraction." The solar fraction is one hundred percent.

The initial STORES plants should preferably be installed only in places remote from the grid, where the electricity will displace existing or proposed diesel engines. 


\section{Recommendations}

This study identifies an alternate pathway for the revival and growth of Solar Trough Power Plants: the use of STORES power plants for remote electricity needs.

While the study identified several promising options for STORES plants, some of the options uncovered were beyond the scope of the study; these options, such as improvement of the cascade cycle, a more thorough comparison with steam options, and optimizing the cooling system, should be pursued more thoroughly.

Should the STORES concept continue to prove promising after further study, the next step may be to build and operate a pre-commercial STORES plant project, with public policy funds provided to offset the high cost of the first-of-a-kind pre-commercial system. This would involve selection of a high-value site, conceptual design, and formation of a team to undertake the project. Such a project could be completed in two or three years.

Upon successful completion of the pre-commercial project, a series of subsequent projects should follow, in the U.S., Saharan countries, and the Middle East, where hundreds of remote communities are without access to dependable electricity. Such projects should be supported by funds from the GEF, the World Bank, and perhaps USAID, the Winrock foundation, the UN Foundation and other multilateral funding sources dedicated to clean energy.

\section{SUNLAB Participation}

SUNLAB would have an important role in developing STORES power plants. A partnership with SUNLAB would be very helpful in moving the STORES technology forward. SUNLAB should consider providing the following support services:

- Provide detailed year-round Direct Normal Insolation and temperature information for each potential site

- Use its modeling capabilities to provide dependable solar heat collection data in support of the STORES power plant design

- Provide its expertise on storage technologies to help make the right choices relative to storage methods, sizes, and needs

- Provide links to potential high-value sites for the power plant, such as to satisfy Native American demands for power

- Provide introductions to other nations interested in developing solar trough power plants, especially those that have large segments of their populations in remote areas far from the grid

- Act as a facilitator between the World Bank, the GEF, the UN Foundation, and other multilateral institutions that are promoting renewable energy globally. 


\section{Appendix C}

\section{Analysis carried out by Barber-Nichols}

Under a subcontract to NREL, Barber-Nichols carried out a comprehensive analysis of an ORC with recuperator using pentane as working fluid. This study was carried out with the specific objective of validating the cycles analyzed by NREL by an independent industry partner. NREL and Barber-Nichols engineers met regularly during this work and compared notes to make sure that NREL engineers were employing the correct assumptions and component sizing for design of the cycles. The report provided by Barber-Nichols is provided here and their results is in close agreement with NREL's results. 
Final Report

\section{NREL n-Pentane Solar Rankine Cycle Analysis and Review}

\section{Barber \\ Denver, Colorado USA

Date: August 31, 2000

To: Vahab Hassani and Henry Price

NREL, National Renewable Energy Laboratory 1617 Cole Blvd.

Golden, CO 80401-3393

From: Bill Batton and Kevin Hotton

Barber-Nichols Inc.

6325 W. $55^{\text {th }}$ Ave.

Arvada, CO 80002 


\section{Introduction}

Barber Nichols Inc. (BNI) has completed a preliminary power-generation Rankine cycle review for NREL. The review included: validation of the NREL cycle thermodynamic data, consultation on system issues, the economic feasibility of the proposed cycle, and estimated power output.

The NREL cycle is a solar-heated power-generation Rankine cycle. Solar energy heats Caloria HT-43 (a heat-transfer fluid marketed by Exxon Corp.). The Caloria HT-43 then flow through a heat-exchanger where its thermal energy is transferred to normal-pentane (the working fluid used within the Rankine cycle). The Rankine cycle is super-critical and the cycle contains a recuperator and air-cooled condensers. The initial NREL cycle contained a two-stage turbine with reheat between stages. Subsequent analysis by BNI and discussion with NREL led to the adoption of a single-stage turbine with the corresponding elimination of reheat. The modified cycle also had a 3 -fold increase in the n-pentane mass flow rate. Two distinct super-critical cycles were reviewed (600psia and 800psia max. turbine inlet pressure cycles). Feasibility study results led to the selection of the 600 psia cycle as the preferred one.

\section{Cycle Thermodynamic Data}

NREL modeled the power-generation cycle with the ASPEN software package. BNI simulated the cycle using its proprietary software. The fluid property equation-of-state used in the BNI software is outlined in Kenneth E. Starlings book, "Fluid Thermodynamic Properties for Light Hydrocarbon Systems." This equation-of-state is an enhancement of the Benedict-Webb-Rubin (BWR) equation (adding 3 additional equation parameters - bringing the total to 11 parameters). BNI calculated Caloria HT-43 specific heat using linear curve-fits to Exxon data sheets. The thermodynamic property equations used in the ASPEN software is unknown to BNI. Results generated by the ASPEN and BNI's software compared favorably with temperature, pressure, and enthalpy deviations less than 2\%. Some uncertainty remained in how recuperator effectiveness and overall cycle efficiency were modeled and calculated with ASPEN.

\section{System Issues and Cycle Modifications}

Upon review of the original NREL cycles, BNI suggested several cycle modifications that would result in a more practical cycle. A brief summary of these cycle modifications follows:

- Eliminate the two-stage turbine with reheat and use a simpler single-stage turbine (reheat N/A). This change reduces cycle power output slightly (approximately $3 \%$ reduction).

- High-rotational speed (particularly in the $1^{\text {st }}$ turbine stage) also favored a single-stage turbine cycle. The resulting singe-stage turbine speed is $25 \%$ slower than the rotational speed of the $1^{\text {st }}$ stage turbine in the original NREL 2-stage turbine cycle. The single-stage turbine speed was still unacceptably high at $(26,000 \mathrm{rpm})$. Increasing the n-pentane mass flow rate to $66,000 \mathrm{lbm} / \mathrm{hr}$ reduced the turbine speed to $15,000 \mathrm{rpm}(600 \mathrm{psia}$ turbine inlet pressure cycle). This speed will still require a 2 -stage gear reduction (to 1800rpm) and fall into the category of a "high-speed" gearbox and a corresponding cost premium for it and the high-speed shaft coupling. If turbine speed could be reduced below 13,600rpm, a singlestage "high-speed" gear reduction is possible - which would lower the gearbox cost. Reducing turbine speed would lower turbine efficiency slightly. However, lower rotational speed typically improves system life. 
- The high shaft speed also makes the shaft seal difficult from a longevity standpoint. Therefore, a lower shaft speed would be desirable to reduce maintenance.

- To operate the Rankine cycle in a controllable / sustainable fashion requires the inclusion of additional components and their resultant pressure drops. Added components: Feed pump flow control valve, check-valve and filter (15psid, 20psid max. - at filter replacement) Turbine inlet control valve (1psid), high-pressure leg of recuperator (5psid), low-pressure leg of recuperator (2psid), super-critical HX (20psid), air-cooled condenser (n-pentane side) (2psid). Note: pressure drop estimates include the small minor piping pressure losses between components.

- Increase condensing temperature. Though not done in the cycles analyzed, the following cycle feasibility section indicates a high cost and large parasitic load for an air-cooled condenser sized for an $80^{\circ} \mathrm{F}$ ambient and $102^{\circ} \mathrm{F}$ condensing temperature. BNI recommends a design condensing temperature of $115^{\circ} \mathrm{F}$, but this may not be optimal.

- The 600psi turbine inlet temperature cycle is favored. The 800psi-cycle operates at a pressure in excess of the maximum allowable housing pressure for common vertical centrifugal pumps. Also, the additional pressure probably would require two pumps in series due to the large number of stages (28-stages). The $800 \mathrm{psi}$ cycle will generate only an additional $2 \%$ power over the 600 psi cycle - due mainly to the large $34 \%$ increase in feed pump power.

- Maximum temperature of n-pentane $\left(563^{\circ} \mathrm{F}\right)$ may cause thermal decomposition. BNI advises NREL to research this important point before further cycle optimizations are conducted.

\section{Cycle Feasibility and Cost}

For the feasibility / cost analysis, one "design-point" cycle was chosen. This cycle had $600 \mathrm{psia}, 563^{\circ} \mathrm{F}$ turbine inlet conditions, a recuperator with $75 \%$ effectiveness, and a condensing temperature of $102^{\circ} \mathrm{F}$.

BNI gathered preliminary ROM estimates of major cycle components. BNI scope was restricted to the Rankine cycle only and includes none of the solar energy collection circuit except for the super-critical HX where the solar-collected heat energy is transferred to the n-pentane.

The super-critical HX is likely to be a shell-and-tube design. A welded plate design is a remote possibility. The high pressure difference between the heat-transfer fluid and the n-pentane $(+550 \mathrm{psi}-\mathrm{I}$ assume a high-pressure solar loop with thermal storage is not practical) do not work well with the flat "sheet-like" geometry of a plate HX. Also, plate collectors does not work well with large increases in volumetric flow through the HX (shell-and-tube HX address this point by requiring multiple units in series with different baffle spacing and/or tube numbers).

The BNI cycle simulation software predicts an air-cooled condenser fan parasitic loss of $125 \mathrm{hp}$. The normal BNI approach is to run condenser fans slower than standard commercial practice. This lowers fan power, but has the impact of increasing condenser size and cost. Hudson Products returned a budgetary quote of $\$ 260,000$ for an induced draft design using six 13-ft diameter fans fitted with $30 \mathrm{hp}$ motors. The actual fan parasitic power is estimated at $150 \mathrm{hp}$. The 
condensers would occupy an area of $42 \times 40$ feet. BNI does feel the condensing temperature of $102^{\circ} \mathrm{F}$ is too low for an $80^{\circ} \mathrm{F}$ ambient temperature. Raising the condensing temperature from $102^{\circ} \mathrm{F}$ to $115^{\circ} \mathrm{F}$ is projected to lower air-cooled condenser area, parasitic power (from $125 \mathrm{hp}$ to 75hp). The cost would also be lower.

A cost estimate summary is presented in Table 1. This Table contains only the major components and prices listed are unburdened. Also site preparation, foundation, structures, motor controls, piping, electrical switchgear, electrical or mechanical assembly, and general system integration costs are not shown.

\section{Closing Remarks}

After reviewing the "design-point" cycle and its cost, BNI suggest the following modifications. 1) Increase recuperator effectiveness to $85 \%, 2$ ) Raise the condensing temperature to at least $115^{\circ} \mathrm{F}$. and 3) Lower turbine design speed to $13,500 \mathrm{rpm}$ (this will lower turbine efficiency from 0.77 to 0.75 , but single-stage gearbox efficiency is 0.99 - up from 0.98 for two-stage gearbox). The cycle that results from these changes is one of greater efficiency and lower cost $(20.0 \% \mathrm{vs}$ $19.0 \%$ efficiency with BNI estimated condenser parasitic power included). BNI cycle-simulation printouts for both the "design-point" cycle and the modified cycle are includes with this report. BNI feels that the n-pentane Rankine cycle (with the above mentioned changes) to be a reasonable cycle of good efficiency. The major reservation that remains is the thermal stability of the n-pentane at the high turbine inlet temperature. BNI's task was to comment on the Rankine cycle portion of the entire system. BNI does not know enough about the intended use for this solar-heated power generating system to judge the overall practicality of the total system. 
Table 1. NREL cycle: major component cost estimates for original "design-point"

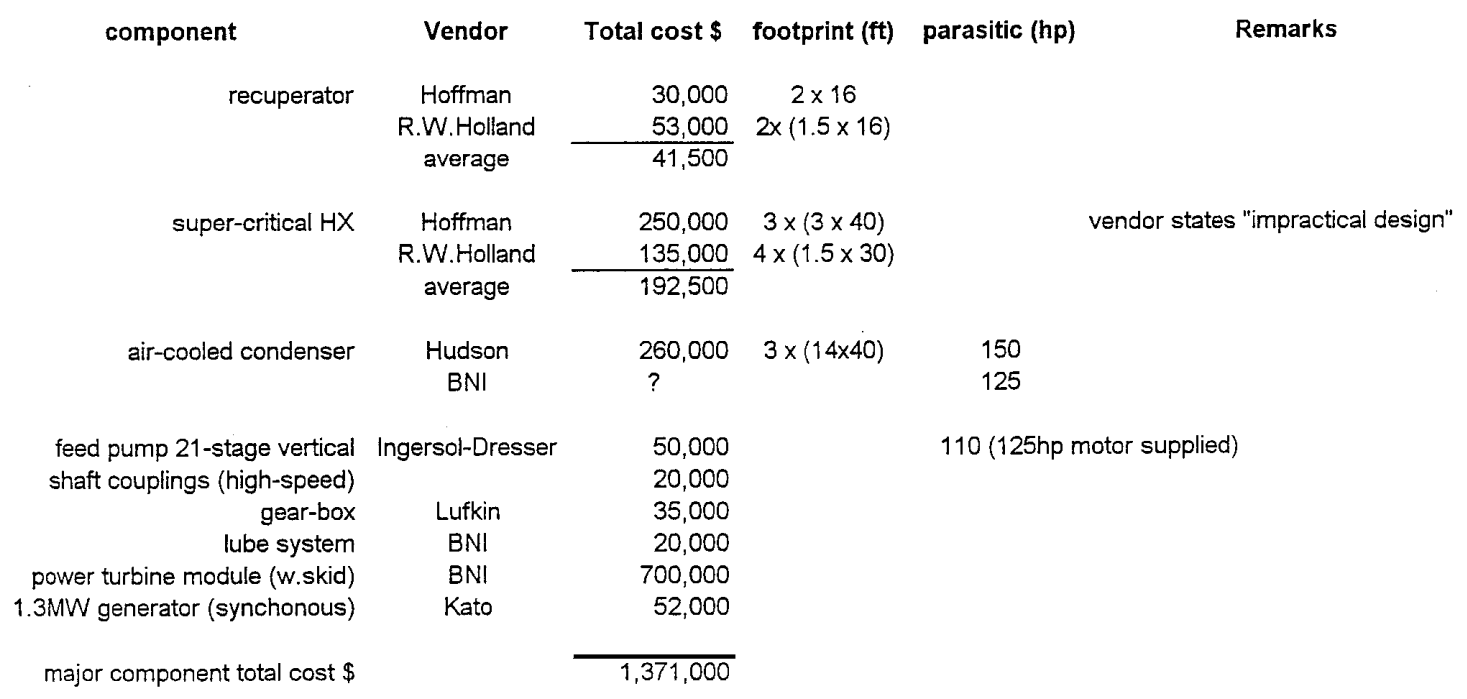




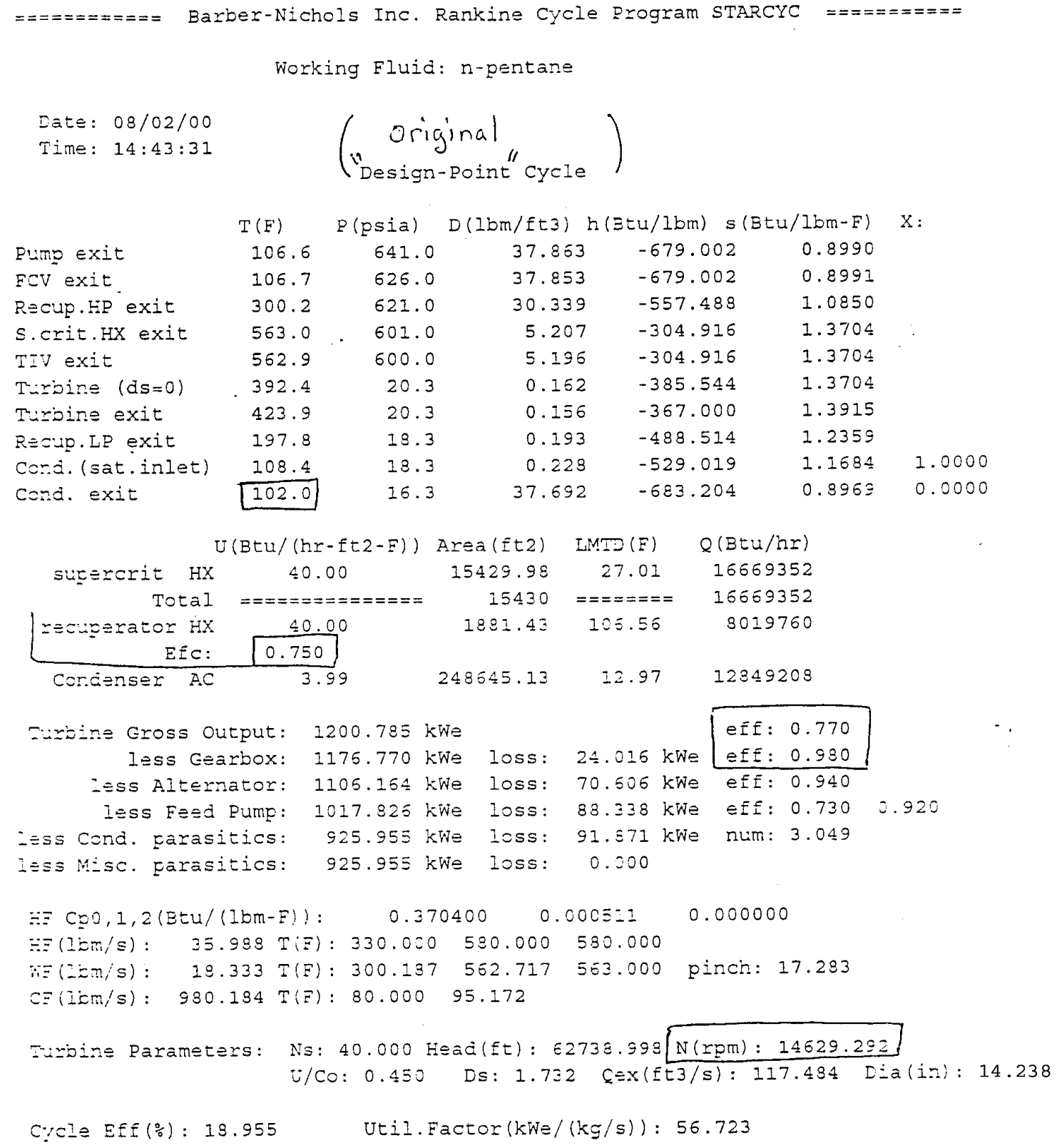




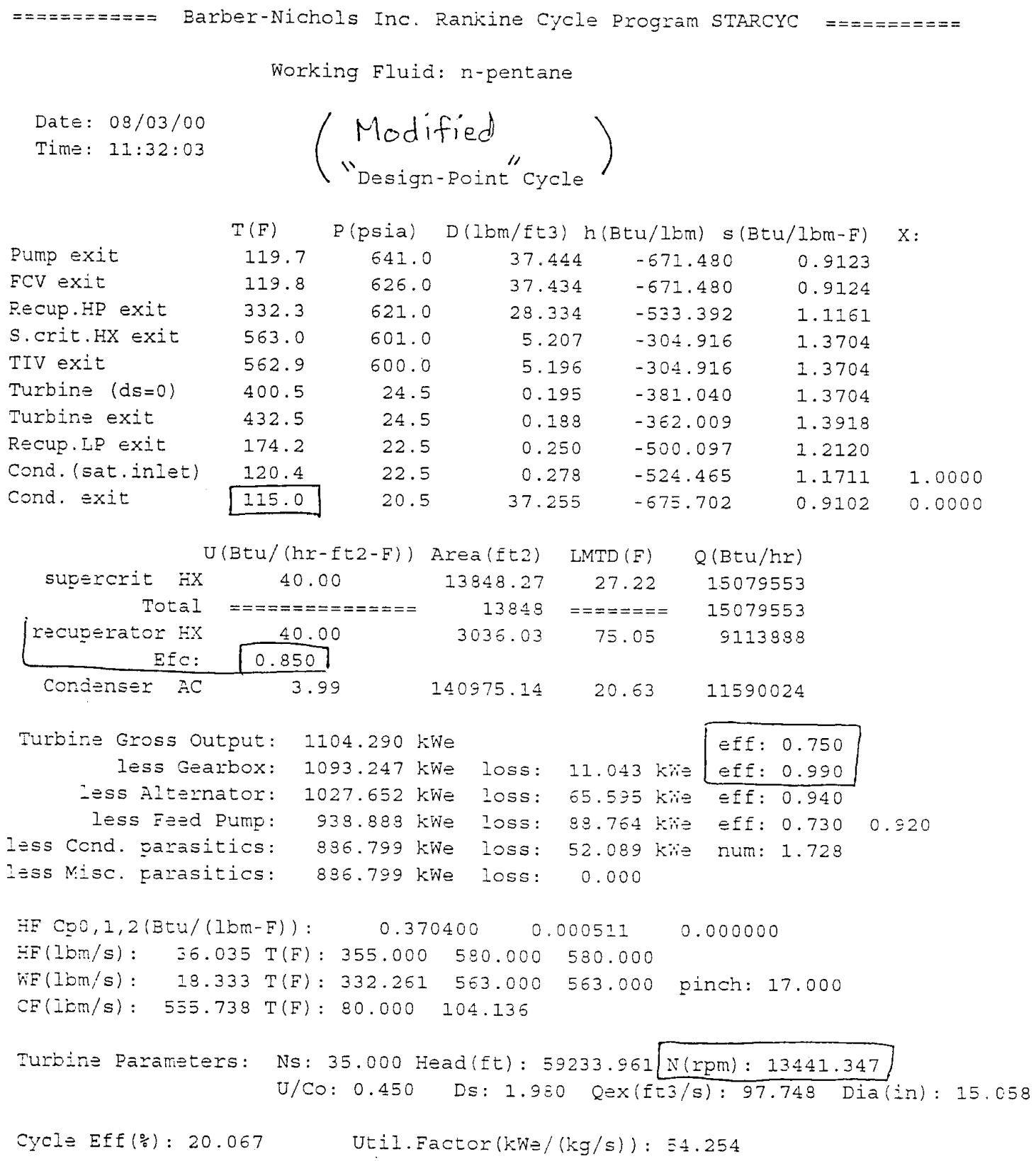




\section{Appendix}

NREL n-Pentane Cycle (misc. topics):

\section{Heat-Exchanger Effectiveness:}

In the cycle review completed by Barber-Nichols, a minor difference in the application of heatexchanger effectiveness was encountered. The difference hinges on the particular definition chosen. BNI selected the fundamental (but prior to computer analysis, the less practical) definition that effectiveness is the ratio of the actual heat transfer rate accomplished in the heatexchanger to the maximum heat transfer rate possible. In essence, this definition is a ratio of enthalpy differences. The effectiveness definition chosen by NREL is the one then derived from the basic definition if a constant specific heat value is defined for each of the separate "hot" and "cold" streams in the heat-exchanger. This is a simplifying assumption and results in the common equation of effectiveness given in most engineering textbooks. In this common equation, the 'minimum' specific heat is not the measure of the minimum value for a given stream (as the assumption is that the specific heat is constant for the given stream) but rather that that specific heat is less than the 'constant' specific heat of the other stream (the maximum specific heat).

\section{Turbine Efficiency:}

Turbine adiabatic efficiency is strongly a function of specific speed and specific diameter (reference Figure 1.). Predicting turbine efficiency is a complex subject and simple correlations should be used with caution. More sophisticated methods must be used if confidence in the efficiency estimate is required. The first requirement in predicting turbine efficiency is a well-defined cycle (with design-point and off-design points). Too many loosely defined cycle parameters will not allow a unique and optimal efficiency turbine to be designed. The current cycle is near the region where a partial admission turbine design may be used to advantage. Further cycle refinement and definition are necessary before the optimal turbine design can be selected. BNI is providing NREL with a curve-fit for turbine total-to-static adiabatic efficiency as a function of specific speed (Figure 2.).

\section{Application of Figure 2:}

Figure 2. is a plot of total-to-static turbine adiabatic efficiency as a function of specific speed. The efficiency values shown represent a well-designed turbine sized at the optimal specific diameter. Formally, specific speed should be a non-dimensional parameter. However, common practice (as is done at Barber-Nichols) is to use a dimensional form of the parameter:

$$
N s=\frac{N \cdot \sqrt{Q e}}{H_{a d}^{3 / 4}}
$$

Ns: $\quad$ Specific Speed

$N: \quad$ Rotational Speed (rpm)

Qe: Turbine (actual) exit volumetric flow $(\mathrm{ft} 3 / \mathrm{s})$

$H_{a d}$ : Isentropic head across turbine stage $(\mathrm{ft} \cdot \mathrm{lbf} / \mathrm{lbm})$ 


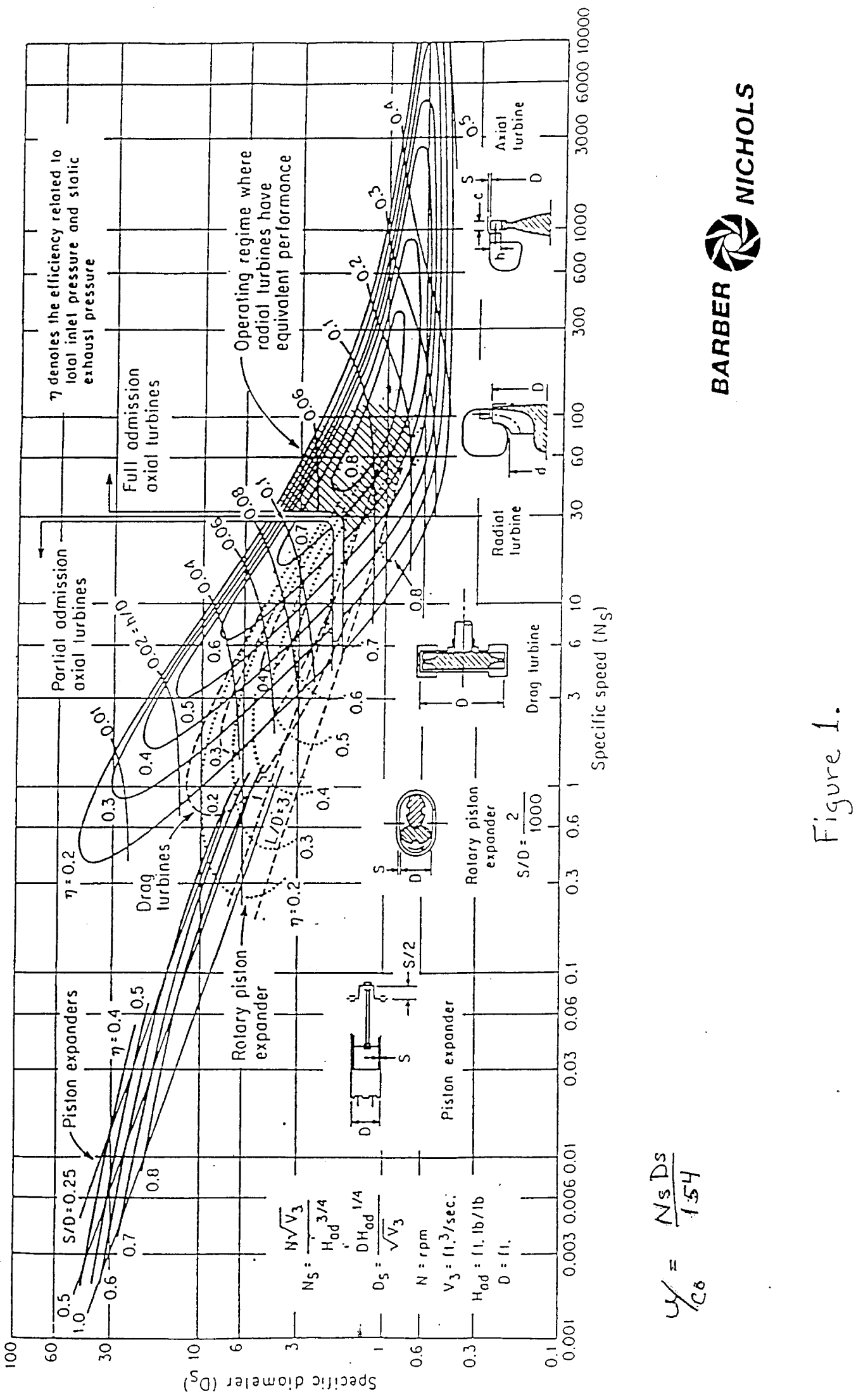


Axial Turbine Efficiency vs Specific Speed (at optimal specific diameter)

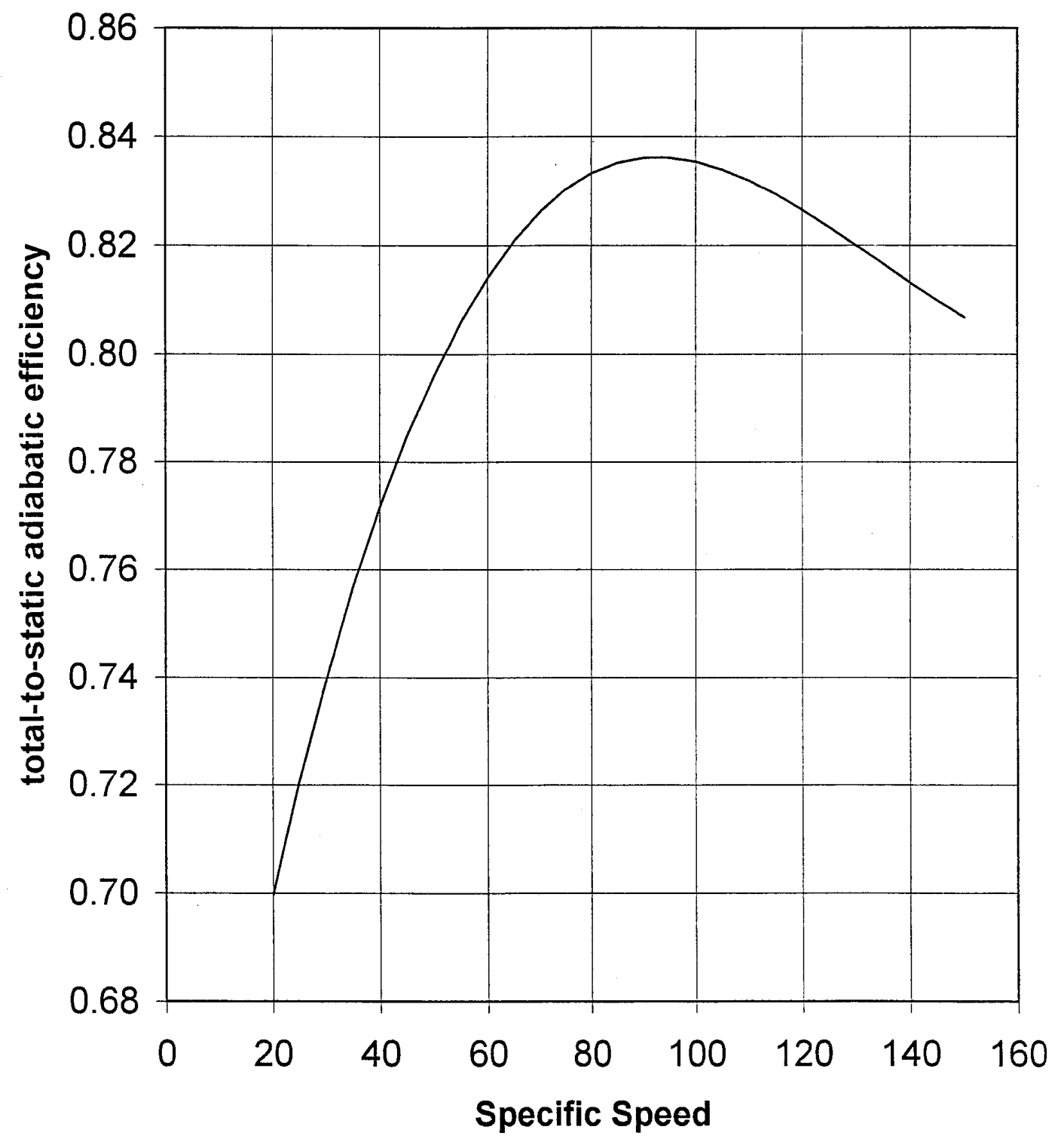

curve-fit: $y=1.296 e-7 x^{3}-5.244 e-5 x^{2}+6.381 e-3 x+5.920 e-1$

Figure 2

Barber-Nichols Inc.

$7: 31$ AM 8/15/00 
It is clear from Figure 2. that maximum turbine efficiency occurs at a specific speed near 90. However, important design considerations and constraints often will not allow a turbine for a given application to be designed at a specific speed of 90. For example, the NREL proposed $900 \mathrm{~kW}$ normal-pentane system would need to rotate at a clearly impractical speed near $30,000 \mathrm{rpm}$.

The definition of specific speed masks a subtlty that complicates its calculation. The desire is to calculate a specific speed and then use Figure 1. to read off a turbine efficiency. However, to properly calculate specific speed requires knowledge of the actual turbine exit volumetric flow rate-which in turn is effected by turbine efficiency. So the calculation becomes iterative: ideal (isentropic) volume flow rate is used to calculate a specific speed estimate which is then used to estimate turbine efficiency. This estimate of turbine efficiency then allows an estimate of the actual turbine exit volume flow rate to be made - and the specific speed calculated to be refined. The refined specific speed value then allows an improved estimate of turbine efficiency followed by an improved value for the exit volume flow rate. This iterative calculation rapidly converges. In many instances the improved accuracy of the iterated specific speed will not be necessary-i.e. using isentropic exit volume flow rate is sufficiently accurate. The isentropic head is simply the isentropic enthalpy change expressed in units of work (i.e. multiply enthalpy change in Btu/lbm by $778 \mathrm{ft}-\mathrm{lbf} / \mathrm{Btu})$.

The above process provdes the design-point turbine efficiency. The process for estimating the off-design turibne efficiency is rather complex and requires significant iterative calculations. Therefore, it is not included here. 


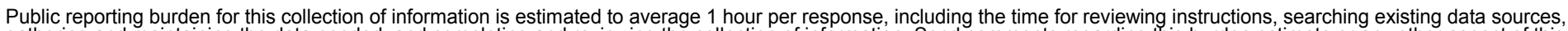

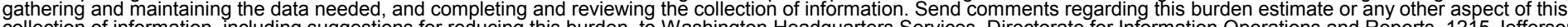

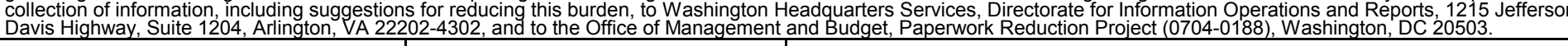
1. AGENCY USE ONLY (Leave blank)
2. REPORT DATE January 2002

\section{REPORT TYPE AND DATES COVERED}
Technical Report

\section{TITLE AND SUBTITLE \\ Modular Trough Power Plant Cycle and System Analysis}

6. $\operatorname{AUTHOR}(\mathrm{S})$

7. PERFORMING ORGANIZATION NAME(S) AND ADDRESS(ES)

8. PERFORMING ORGANIZATION REPORT NUMBER

TA: CP11.2000

9. SPONSORING/MONITORING AGENCY NAME(S) AND ADDRESS(ES)
National Renewable Energy Laboratory
1617 Cole Blvd.
Golden, CO 80401-3393

11. SUPPLEMENTARY NOTES

12a. DISTRIBUTION/AVAILABILITY STATEMENT National Technical Information Service

12b. DISTRIBUTION CODE

U.S. Department of Commerce

5285 Port Royal Road

Springfield, VA 22161

13. ABSTRACT (Maximum 200 words)

This report summarizes an analysis to reduce the cost of power production from modular concentrating solar power plants through a relatively new and exciting concept that merges two mature technologies to produce distributed modular electric power in the range of 500 to $1,500 \mathrm{kWe}$. These are the organic Rankine cycle (ORC) power plant and the concentrating solar parabolic (CSP) trough technologies that have been developed independent of each other over many years.

14. SUBJECT TERMS

Modular Trough power plant, organic Rankine cycle, ORC, concentrating solar parabolic trough, CSP

17. SECURITY CLASSIFICATION OF REPORT Unclassified
18. SECURITY CLASSIFICATION OF THIS PAGE Unclassified
19. SECURITY CLASSIFICATION OF ABSTRACT Unclassified
15. NUMBER OF PAGES

16. PRICE CODE

20. LIMITATION OF ABSTRACT

UL 